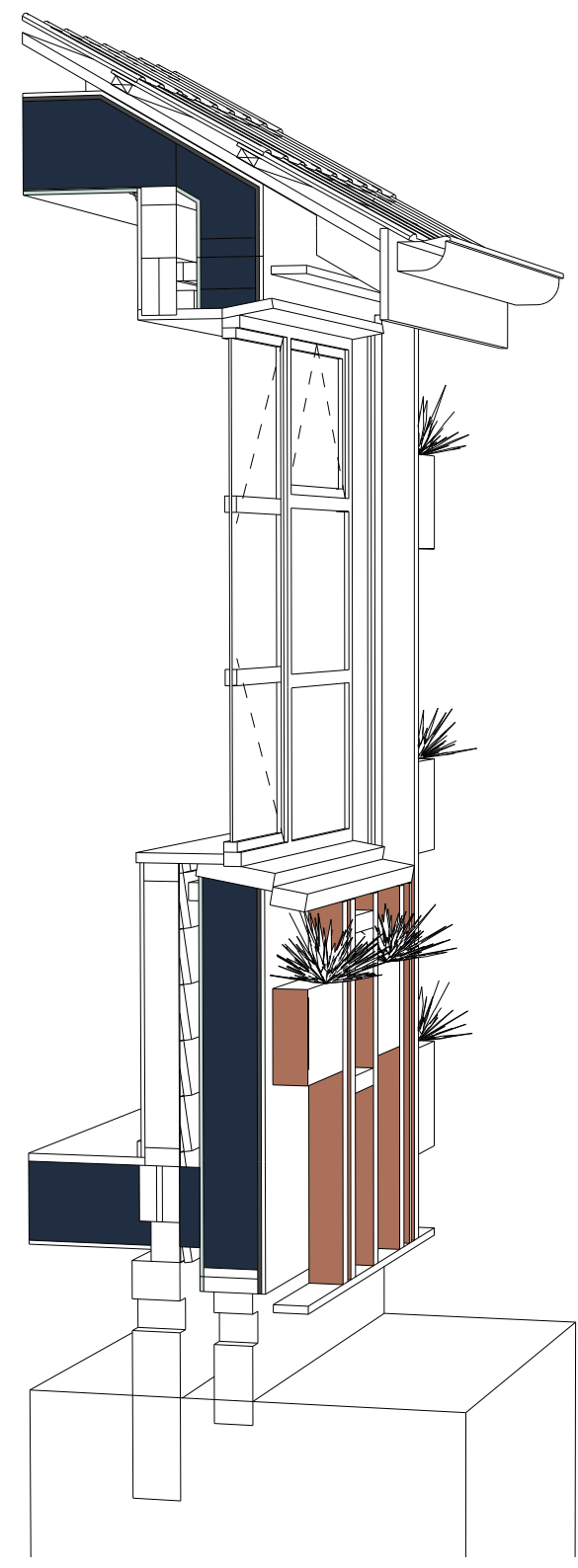

Enriching the Envelope Experience

A design strategy to enrich the external envelope of existing homes 



\title{
Enriching the Envelope Experience
}

\author{
Emily Martin \\ A 120 point thesis submitted in partial fulfilment \\ of the requirements for the Masters of Architecture \\ [Professional]
}

Victoria University of Wellington

School of Architecture

2021 



\section{Thank you...}

Antony Pelosi, for your supervision and guidance.

BRANZ, for your support and funding.

Wright \& Gray Architects, for your support and understanding.

Family, friends, flat family, archi crew, dance family, church family, lifefroup, and God, for your love, laughter, support, kindness, running adventures, roadies, swims, prayers, food, fun, smiles and encouragement. 


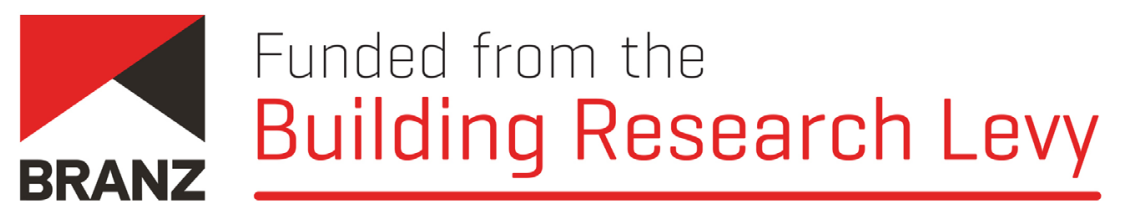




\section{onpol}

The following thesis is part of the Advanced Manufacturing and Prototyping for Design Research Lab. AMPD aims to investigate and define innovative techniques and methods of modern construction applicable to the architecture and construction sector through the use of advanced tools of design, fabrication, and manufacturing. The fourth industrial revolution is core to our research exploring methods of improving information flow from design to fabrication-across the digital continuum-to design architecture that builds wellbeing for people and the planet. We can't keep doing what we have always done-our research questions the status quo by designing and constructing prototypes. You should consider the thesis within the larger body of research that AMPD Research Lab undertakes. Each thesis has focused on an aspect of AMPD's aim. 


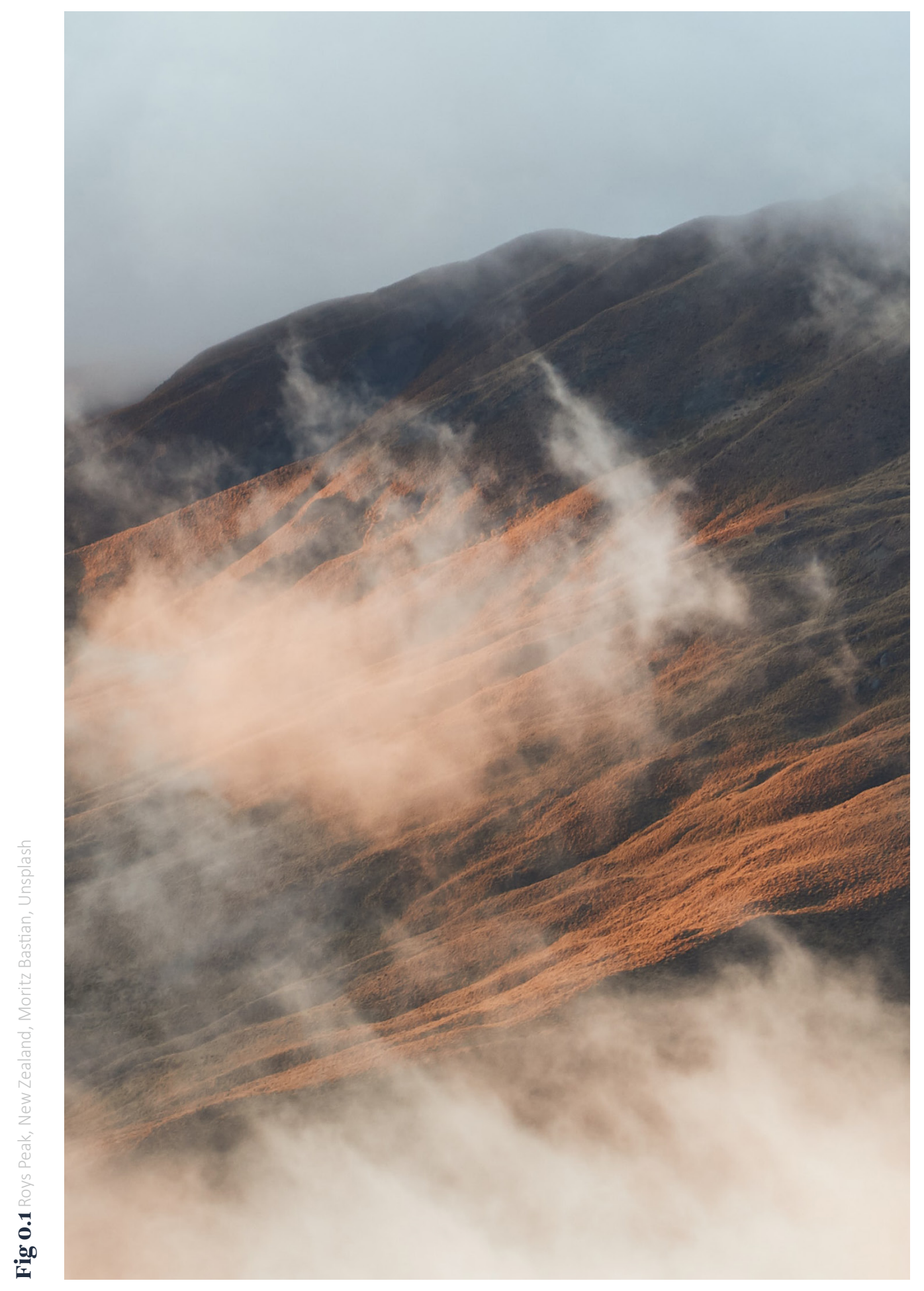


Enriching the Envelope Experience is a design strategy for an external retrofit to revitalise existing housing. The aim is to create warmer, drier, healthier homes without having to displace the occupants.

For many New Zealander's, inefficient housing is negatively affecting occupant health and wellbeing. Preventable health issues place pressure on healthcare systems, costing valuable resources. The climate, housing, and healthcare crisis desperately require improvements to existing housing for warmer, healthier, and happier homes. Currently, the design of New Zealand housing is inefficient for climate resulting in uncomfortable living conditions. There is a global dependence on finite resources, and the ongoing resource use will reach capacity. Desperate attention to the environmental and economic impact is needed to sustain the precious resources. New Zealand is obligated to reach the 2050 climate goals. The design of buildings needs attention to mitigate the $39 \%$ carbon emissions by the construction industry and achieve net-zero carbon housing goals. Lengthy rebuilds require displacing people from their homes and communities and increase the demand for housing and resources. The demolition and rebuild further adds to the significant waste issue. Therefore, there is an opportunity to improve the existing housing stock as a readily available resource. The 1940s-1960s State House is a standardized housing typology mass-produced in New Zealand, and often of poor condition, it was an appropriate site to investigate for a retrofit design strategy. A design framework informed by sustainable design standards, case studies and understanding of the 1940s-1960s house typology directed the design process. The research outcome resulted in an external wall design strategy to improve the occupants' home experience. 


\title{
Contents
}

\author{
Acknowledgements \\ AMPD Context \\ Abstract \\ Contents \\ 1.0 INTRODUCTION \\ Aims \& Objectives $\quad 04$ \\ Scope $\quad 05$ \\ Overview $\quad 07$ \\ Methodology $\quad 08$ \\ 2.0 BACKGROUND " \\ Construction Industry \& Climate Change 13 \\ Home Impact $\quad 14$ \\ Energy Efficiency $\quad 16$ \\ Passive Design $\quad 17$ \\ Design Standards $\quad 18$ \\ Economic Benefit $\quad 19$ \\ Changes Ahead 20 \\ Environmental Experience $\quad 23$ \\ Parametric Digitalisation $\quad 24$
}

3.0 RELATED WORK

Research Drivers $\quad 31$

Passivhaus Database $\quad 32$

EnerPHit State House Retrofit 34

State House Retrofit 35

Energiesprong $\quad 36$

NZ Retrofit 37

Critical Reflections \& Findings $\quad 39$

4 SITE 41

1940s-1960s State House $\quad 43$

Critical Assessment 44

Existing Issues $\quad 45$

Thermal Imaging $\quad 50$

Digital Model $\quad 52$

Findings $\quad 55$

\begin{tabular}{lr}
\hline FAMEWRY & 57 \\
& 59 \\
Establishing a Design Strategy & 62 \\
Framework & 63 \\
The Design Strategy & 71 \\
Supportive Findings &
\end{tabular} 


\subsection{INTIALDSIGN}

Base Exploration $\quad 85$

Responsive Exploration $\quad 101$

Integrated Exploration $\quad 113$

Critical Reflections \& Findings $\quad 127$

7.0 BASE COMPONENT

Concept Design Exploration $\quad 137$

Opening Sequence Exploration $\quad 147$

The Base Component 159

Critical Reflections \& Findings $\quad 167$

8.0 PROGRAM COMPONENT

Wall Program Development $\quad 175$

Physical Model Exploration $\quad 183$

Digital Development $\quad 189$

Program Brief Series $\quad 199$

Critical Reflections $\mathcal{E}$ Findings 217

9.0 ADAPTION COMPONENT

Digitalisation: Parametric Variation 225

Critical Reflections \& Findings 233

Program Application Visualisation 235

10.0 CRTTCAL REFLECTIONS

Base Component 252

Program Component 253

Adaption Component $\quad 254$

Scope \& Limitiations 255

11.0 CONCLUSION

Key Contributions $\quad 259$

Future Research $\quad 260$

12.0 REERENCES

$\begin{array}{ll}\text { Figures } & 269\end{array}$ 


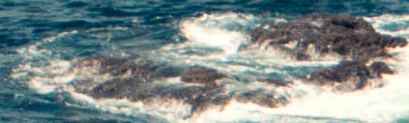

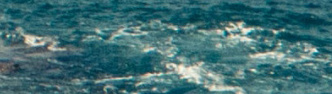
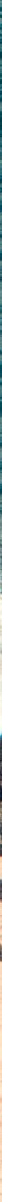

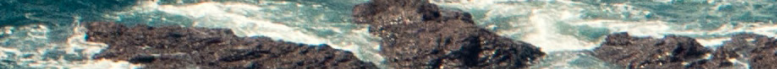

\section{Introduction}

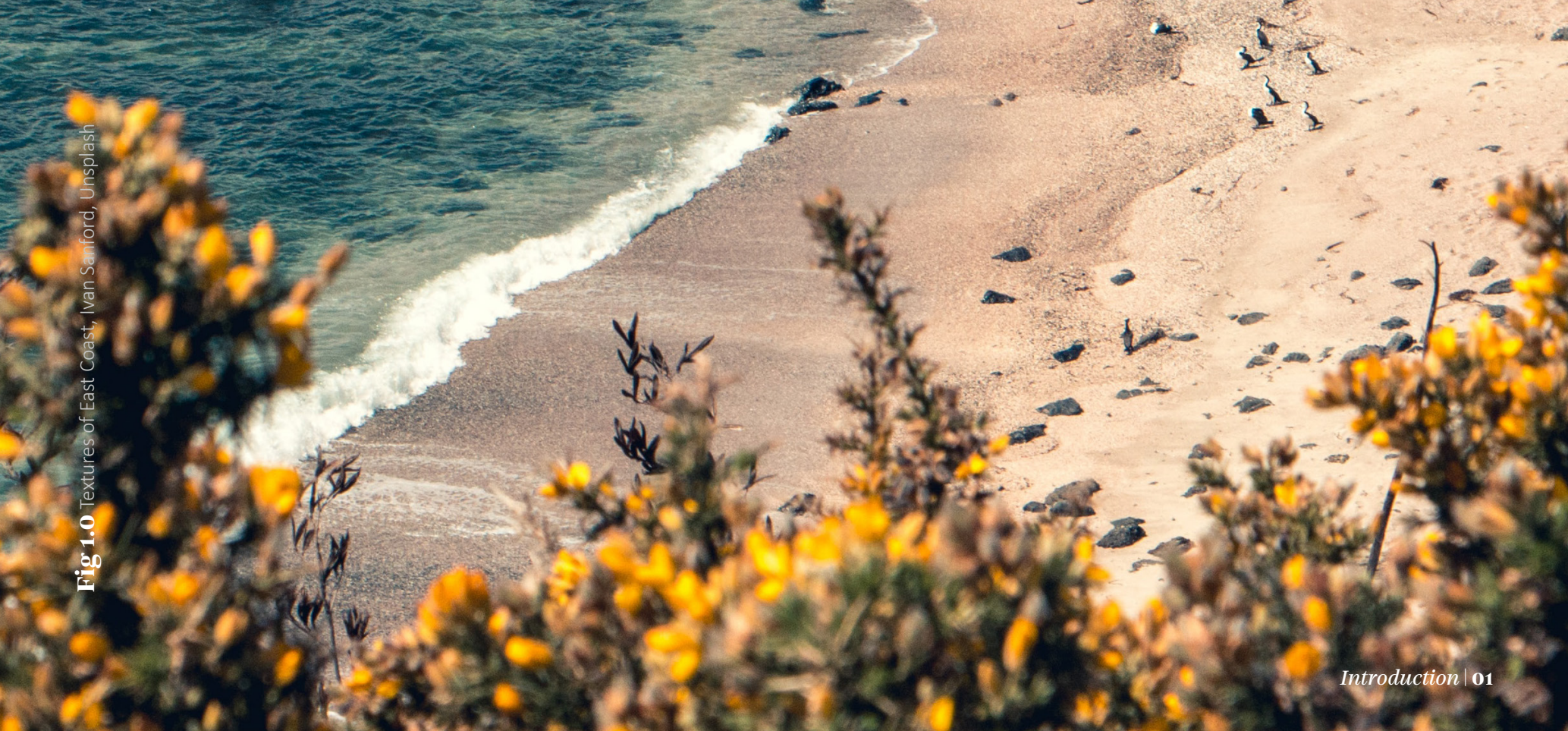


A design strategy to enrich the external envelope of existing homes by thermal performance of the lived experience for occupant health $\mathcal{F}$ wellbeing.

${ }^{6}$ We will never be truly healthy, satisfied, or fulfilled if we live apart and alienated from the environment from which we evolved"

(Kellert, 2012, P. x). 


\section{Introduction}

Enriching the Envelope Experience is a design strategy for an external retrofit of existing housing. The aim is to create warmer and healthier homes and enrich the home environmental experience for occupant health and well-being.

Both the natural and the built environment have a direct impact on occupant health and wellbeing. Designers hold the privilege of designing space for people but, unfortunately, New Zealand homes have often neglected occupant health and well-being. This is primarily because houses have been constructed according to minimum design standards for the climate. The houses tend to lack climate responding design techniques and often underperform for thermal comfort. Therefore, they require high energy demands to provide some occupant comfort, but the home performance can still be insufficient, negatively affecting occupant health. Underperforming houses are widespread around New Zealand, with $40 \%$ of homes damp and mouldy, and 53\% of New Zealand homes would benefit from insulation (BRANZ, 2015). These poor condition houses are expensive to maintain but replacing the houses is a lengthy, costly and wasteful process, further burdening the environment and finite resources. The available housing resource proposes a design innovation opportunity to improve thermal performance and enrich occupants' home experience. Fortunately, retrofit applications to existing housing have proven effective for occupant and environmental benefits. However, the majority require displacing occupants from their homes and communities during the retrofit. The emerging international external retrofit methods highlight an approach to retrofit the homes for net-zero energy without displacing the people from their homes.

Additionally, the occupant experience within space affects health and well-being beyond the home's thermal performance. The natural environment directly affects people's health and well-being due to an innate connection with nature (Wilson, 1984, in Ulrich, 1993, p. 73). Designing to encourage the human-nature relationship presents an opportunity to further enrich health and well-being for people. The design research investigates externally retrofitting the available housing resource, specifically the 1940s-1960s state house, for thermal performance and enriching home experience for people. The innovation challenge is how best to reuse the existing housing to propose a strategy to address the research gap for people and the environment.

Therefore, the question to drive the design research is:

How can the thermal performance of existing New Zealand houses be radically improved to enrich peoples home experience? 


\section{Aims $\mathscr{G}$ Objectives}

\section{Aims:}

- Use the design process to explore a strategy to improve home thermal performance without displacing the occupants.

- Explore how design could enrich the home experience through an integrated program within the strategy.

- Test the possibility of the design strategy to be parametrically adaptable.

\section{Objectives:}

- Investigate the impact of the current housing condition on occupant health and well-being and identify a research gap to support occupant health and well-being.

- Investigate the existing 1940s-1960s housing typology to inform design decisions.

- Identify fundamental case studies from precedents to inspire design decisions and implement global approaches to a New Zealand context.

- Propose a design strategy for inefficient 1940s-1960s housing in New Zealand to increase the home's thermal performance without occupant displacement.

- Propose an architectural response to enrich the environmental experience.

- Explore the use of parametric digital tools for adaptability of the design strategy.

- Critically analyse the design strategy and identify how future development could further evolve the strategy beyond the thesis's scope. 


\section{Scope}

\section{Focus:}

The research focused on designing the external wall envelope to enrich the existing home experience using program and improving the home's thermal performance. The investigation focused on enhancing housing-dependent health and well-being through an environmentally conscious approach without occupant displacement.

\section{Areas addressed in research:}

- The problem, people and environment

- An exploration of the 1940s-1960s house typology to inform the design

- The use of precedent research to inspire design decisions

- The design of a conceptual base strategy to improve home performance

- The design of a program application to complement the base strategy

- The design of a parametric script for design adaptability

- The design of an overall strategy proposing how designers could apply the strategy at scale to existing housing

\section{Limitations for research scope:}

- One housing typology explored to inform research

- The material specifications not identified to limit design exploration

- The breadth of possible design outcomes limited for scope

- $\quad$ The response to occupant limited to a program brief

- The response to site and environment limited to focus on the design strategy concept

- The climate response not specific to a local climate but used overarching performance design techniques

Use:

Designers can use the design strategy to apply an external envelope to existing housing in New Zealand. 


\section{Design of a STRATEGY}

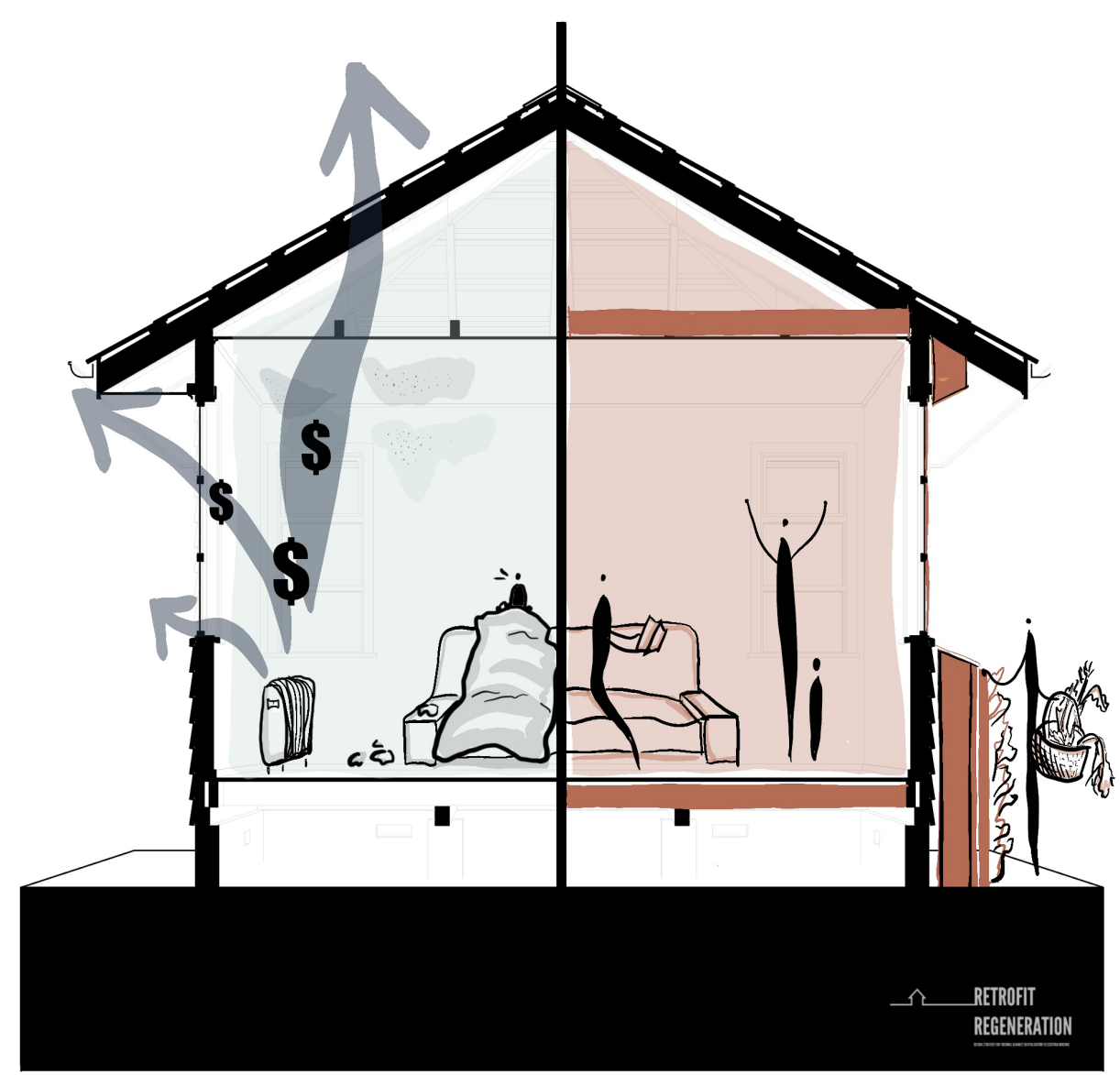

Fig 1.1 


\section{Overview}

\section{What:}

- Design the overall design strategy

- Enrich the envelope experience

- Improve home thermal performance

Why:

- To improve occupant health and well-being

- To mitigate occupant displacement from home and community

\section{Where:}

- Existing 1940s-60s state housing in New Zealand as an available resource

Who:

- For home occupant

How:

- External retrofit of prefabricated wall units with integrated program

- Parametrically adaptable to each home

- Program adaptability as appropriate to occupant and site

\section{Problem:}

- Poor occupant health and wellbeing directly related to substandard housing conditions

- Occupant displacement

- Environmental impact of construction industry

\section{Opportunity:}

- Inspired from global industry to improve homes for occupant health and well-being and environmental benefit

- Explore architectural program variation to enrich occupant home experience

- $\quad$ Explore adaptability of strategy using advanced digital design tools to highlight the future possibility

\section{Existing Research Gap:}

- Internationally, design has achieved external retrofit to row houses for net-zero energy

- International approaches function as a base performance level; however, parametric adaptability and program inclusion for occupant use are currently not included.

- $\quad$ Current New Zealand retrofit methods displaces occupants 


\section{Methodology}

\begin{abstract}
The research method followed a design-led research feedback process to develop a design strategy for existing homes, with a program for thermal performance. The design-led research driven by a framework (Chapter 5.0) was informed by background research, case studies and the site. The framework informed the design process and revealed three focus components for the strategy's design. Simultaneous design of the components drove the research development.
\end{abstract}

The first area was the design of the base component, which focused on increasing thermal performance. The existing construction of the selected 1940s-1960s New Zealand state house established a base of understanding and typical issues informed the design framework. The base component required a design exploration of envelope continuity to reduce heat loss, increase airtightness and insulation, and reduce thermal bridging. The base component design resulted in a high performing prefabricated base unit for the architectural program to be applied to.

The second area was the design of the architectural program component, focused on enriching the occupant experience. A program brief restricted the research scope and identified three program function types to inform the program design. The outcome was a series of program units exploring variations of the program functions. The program units are a tool where occupants can select their desired home experience and the selections collectively inform an outcome for each home.

The third area was the design of the adaption component, which used the parametric design software, Grasshopper, to explore the adaptability of the design. As a result the outcome was a digital model adaptable to the input parameters of size, composition, materials, and program design. The digital adaption proposes the design strategy's potential to be efficiently adapted as appropriate and applied at mass-scale to New Zealand housing.

The thesis's design research was developed to investigate an overall design strategy's components to improve existing housing typologies for thermal performance and occupant experience. The research designed an adaptable strategy approach to address the problem rather than produce a singular design. 


\begin{tabular}{|c|c|c|c|c|c|c|c|c|}
\hline $\begin{array}{l}\text { Construction } \\
\text { Industry }\end{array}$ & $\begin{array}{c}\text { Home } \\
\text { Impact }\end{array}$ & $\begin{array}{c}\text { Energy } \\
\text { Efficiency }\end{array}$ & $\begin{array}{l}\text { Passive } \\
\text { Design }\end{array}$ & $\begin{array}{l}\text { Design } \\
\text { Standards }\end{array}$ & $\begin{array}{c}\text { Economic } \\
\text { Benefit }\end{array}$ & $\begin{array}{c}\text { Changes } \\
\text { Ahead }\end{array}$ & $\begin{array}{l}\text { Environmental } \\
\text { Experience }\end{array}$ & $\begin{array}{c}\text { Parametric } \\
\text { Digitalisation }\end{array}$ \\
\hline 0 & • & ○ & ○ & • & ○ & ○ & • & • \\
\hline
\end{tabular}

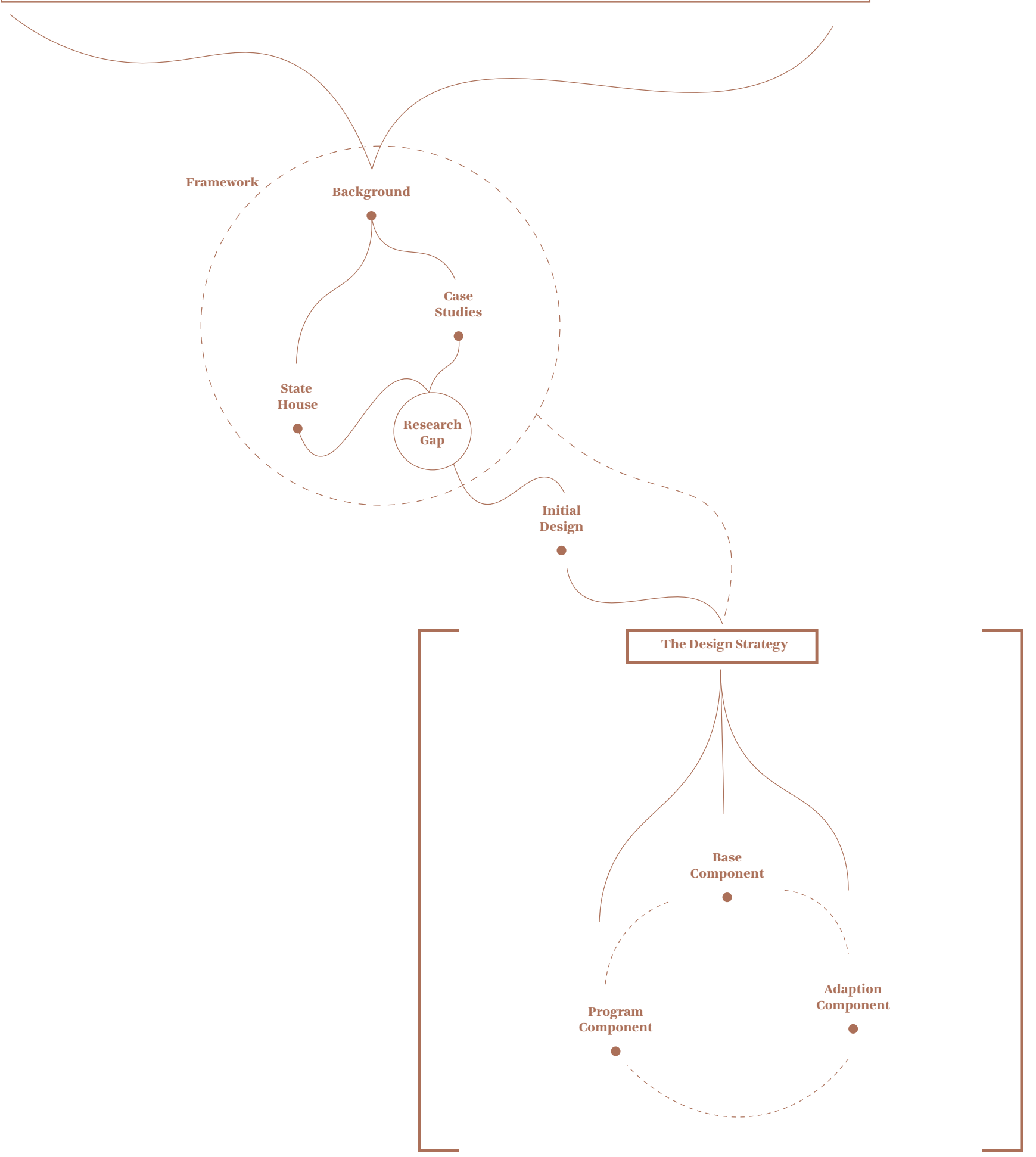

Fig 1.2 Methodo logy Diagram 


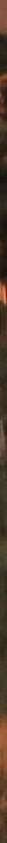


"...look at buildings and see both the physicality and the process by which they are created - an opportunity to not only save energy, water and carbon emissions

but to educate, create jobs, strengthen

communities, improve health and wellbeing..."

(Czerwinska, 2016).

The following Chapter fulfils the research objective: Investigate the impact of the currenthousing condition on occupant health and well-being and identify a research gap to support occupant health and wellbeing. The objective was to understand the existing context, occupant and environmental impacts of existing low condition housing and understand the local and international standards and design guidelines to identify the research gap. Further, to investigate how the environmental experience could enrich the human-nature connection and how the use of digital tools streamline the design. The background investigation informs the design framework (Chapter 5.0) to influence design decisions and propose an overall design strategy to meet the research gap. The principle, Kaitiakitanga (guardianship), drove the research. The protection of the environment and people using efficient design, available resources and advanced technologies to enrich the envelope experience. 
Research highlights the need to reduce the construction industry's high environmental impact to address climate change targets. The construction industry is responsible for approximately 39\% of carbon emissions (IEA, 2019). The Paris Agreement outlines the global 2050 net-zero carbon targets to slow the effects of climate change (Paris Agreement, 2015). New Zealand is obligated to play its part in meeting its Nationally Determined Contribution (NDC) along the way. By 2030, New Zealand is committed to a 30 percent reduction in greenhouse gas emission below 2005 levels (New Zealand Government, 2018). Changes have to be made within the construction industry and to occupant behaviour to achieve this milestone. The changes need to achieve net-zero carbon housing, reduce emissions and sustain precious finite environmental resources. The environmental implications of design are, more than ever, crucial to integrate and drive design innovation toward a reduction in construction environmental impacts. Building design and education to ensure New Zealand reduces it's collective carbon emissions. 


\section{Home Impact}

Unfortunately, New Zealand housing can underperform within the climate and this often results in cold, damp and unhealthy homes which negatively affects occupant health and well-being. New Zealand has a beautiful landscape, but the effect of the landscape results in a varying climate. Research has found that countries with milder climates, such as New Zealand, have worse housing conditions than those with more intense winter conditions with poorer housing-related illness and mortality resulting from hard to heat, poorly insulated homes (Keatinge et al., 1997, p. 1341; World Health Organisation, 2018, p. 32). A New Zealand study by Shorter et al. (2017) found that exposure to mould in homes directly relates to respiratory illness (Shorter et al., 2014, p. 1; Shorter et al., 2017, p. 14). The study found up to 14 times increase in respiratory illness as a result (Shorter et al., 2014, p. 1; Shorter et al., 2017, p. 14). Additionally, New Zealanders' spend up to $72-73 \%$ in the indoor home environment, with a higher percentage for those with illness, disability, the elderly and children (Baker et al., 2007, p. 2). Therefore, the condition of the home lived environment needs attention to support positive health and well-being outcomes for occupants. Preventable respiratory illness is a direct result of low housing standards. However, further research has found the effects can be mitigated by adding insulation, ventilation and heating (Keatinge et al., 1997, p. 1341; World Health Organisation, 2018 , p. 32). A relationship of adding insulation to homes reduced mental and physical health effects and improved occupants' health and well-being. (World Health Organisation, 2018, p. 37). Further, a New Zealand study by Howden-Chapman et al. (2007) looked at the impact of insulating existing houses to increase indoor air temperatures for improved occupant health and well-being. HowdenChapman et al. (2007) found that the indoor environments improvement to be warmer and drier, resulting in fewer colds or flu, reduced days off work, school, doctors visits or hospital admissions, and general improvement in mental and physical health (p.1). Howden-Chapman et al. (2007) further found a reduction in social and health inequality (p.8). The outcome highlights the direct influence the housing standard has on occupants. Therefore, the design must increase the house's thermal performance significantly. The design challenge is how to improve the home condition to mitigate housing-related illness and improve overall health and well-being. 


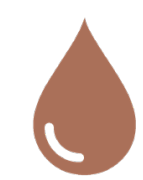

$40 \%$

DAMP \& MOULDY

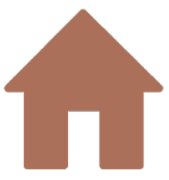

$53 \%$

BENEFIT FROM

INSULATION

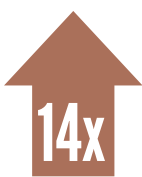

INCREASE

RESPIRATORY

ISSUES WITH

MOULD EXPOSURE

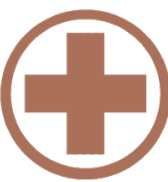

PREVENTABLE

HEALTHCARE

DEMAND

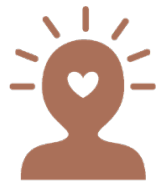

NEGATIVE

WELLBENGG

IMPACTS 


\section{Energy Efficiency}

An increase in energy efficiency in New Zealand housing is needed to reduce the environmental impact of housing. The operational energy used in homes results in high energy demand and affects the environment. New Zealand housing uses about a third of the energy generated (Overton, 2019, p. 62). A study by Chandrakumar et al. (2020) found that existing detached houses are projected to contribute to $66 \%$ of climate impacts in New Zealand. Of the amount, three-quarters are due to operational energy, and therefore, the study emphasises the high focus to retrofit and refurbish existing housing to reduce the impacts (p. 8). An increase in thermal performance increases energy efficiency and would significantly reduce the environmental impact. A net-zero energy building where energy use and regeneration is balanced, reduces environmental impact through decreasing energy and resource demand. While the homes energy efficiency depends on thermal performance, occupant behaviour and energy use also impact the home's operational energy. Energiesprong (2019) saw a reduction in operational energy by assessing and educating occupant energy use habits and upgrading to more efficient household appliances. The result more efficient use of energy resources and a reduction in energy generation necessary for the home (p. 1-2). Combined with the retrofit methods discussed in Chapter 4, the houses made sufficient energy to achieve net-zero energy and reduce long term energy cost through a retrofit approach (Energiesprong, 2019, pp. 1-2). Therefore to improve existing housing in New Zealand, both the home performance and occupant behaviour must be addressed for the result to help people and the environment.

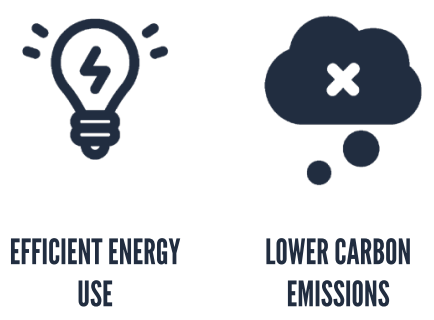




\section{Passive Design}

Passive design strategies use the benefits of existing resources and maximise energy efficiency. As described by Randy Croxton, a pioneer of contemporary ecological design in Kibert (2016), passive design is to consider nature as the default for the building to be as responsive to nature as possible, limiting the need for active energy (p.277). A holistic approach which uses available resources of sunlight, wind, vegetation, and site features to meet the building's heating, cooling, ventilation, and lighting requirements (Kibert, 2016, p. 277; Kopec, 2009, p. 165). The building's site and design are the two areas of passive design approaches, where the location, climate and environmental conditions impact building performance and efficiency. The building is designed with methods such as orientation, form, ratio, massing, materials, and intended use to optimise the available resources to reduce the building's energy demand (Kibert, 2016, p. 277278). However, designing with existing buildings has less control around the existing structure. Site-specific design strategies may be impacted by limited control over site orientation, building form, ratio and materials. The design challenge is to apply passive design strategies to the existing building and site conditions for performance efficiency. Refer to Chapter 5.0 for passive design findings informing the design framework. 


\section{Design standards}

A design standard well beyond the low New Zealand standards is crucial to create an energy-efficient home of high thermal performance for the occupant comfort. A more significant reduction in energy use can be achieved if designed well beyond New Zealand minimum standards to achieve efficient performance results. The World Health Organisation (2018) recommends a minimum of $18^{\circ} \mathrm{C}$ temperature for any occupied areas to improve the home conditions and recommends installing thermal insulation to new and existing housing to improve the conditions (p. 34). However, recommendations need to be viewed as a minimum to improve housing conditions dramatically. A study by Grimes et al. (2016) assessed the household energy use impacts and savings as a result of the Warm Up New Zealand: Heat Smart Scheme, where home insulation and clean heating methods were installed. The scheme aimed to increase indoor temperature, lower humidity, and increase energy efficiency to reduce the energy demand per household and improve occupants' health (p. 165). Grimes et al. (2016) found a more significant overall energy efficiency increase with co-benefits, particularly on occupant health improvements (p. 184). However, there was only a slight reduction in energy use ( $p$. 183). The scheme insulated homes to the current low New Zealand standards. The outcome showed that improvement to the houses has a positive result for occupants. However, the scheme to a higher standard would significantly benefit the occupants and the environment. Higher standards such as Passive House standards (refer to Chapter 4.0) result in up to $90 \%$ energy savings and provide far greater comfort year-round for occupants (Passive House Institute, 2015a). The standards require higher insulation and airtightness to increase thermal comfort and energy efficiency, therefore reducing the home's environmental impact and supporting occupant health and well-being by providing a healthy environment. The expectation must shift beyond the minimum to much greater standards to efficiently retrofit the existing housing stock to benefit occupant and environmental health. Refer to Chapter 5.0 for relevant high performing design standards and findings diagram informing the design framework.

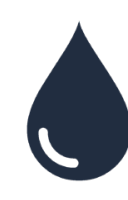

MITIGATE MOULD \& DAMP

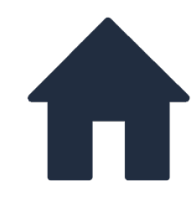

INSULATE
VENITLATE, AIRTIGHT 


\section{Economic Benefit}

Research has found the improvement of existing homes to have economic benefits. The approach to improve thermal performance and the energy efficiency of homes has led to economic savings on health services due to the people's improved health and well-being. In the United Kingdom, the approach to improve homes' energy efficiency through retrofitting insulation has been estimated to save £1.4 billion in health services (Nicol et al., 2011, p. 9). While locally, a New Zealand study by Chapman et al. (2009) found the benefits of retrofitting insulation were one and a half to two times the amount of the retrofit cost. With concern for energy, health, days off school and work, reduced doctor visits and hospitalisations and reduced carbon emissions perspectives, this results in a positive argument for value for money (p. 271). The study found 61\% were saved in the health sector (p. 274). The impact of housing on occupant health and well-being has economic healthcare savings and reduces demand for system resources. Additionally, the New Zealand Green Building Council (2020) has recently found a potential \$1.5-\$3.1 billion-dollar net benefit to boost the economy, provide jobs and resolve housing issues from the adverse effects of Covid-19 through the improvement of 120000 homes. The improvement of homes uses existing available resources, reduces the preventable healthcare burden and can benefit the economy while benefiting occupant health.

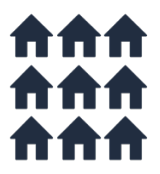

UTILISE EXISTING SUPPLY

$\$ 1.5$ $\$ 3.1 \mathrm{BIL}$

$\begin{array}{cc}\$ 1.5-\$ 3.1 \text { BIL } & 1300 \text { JOBS } \\ \text { NET BENEFIT } & \text { CREATED (120 000 } \\ \text { (120 000 IMPROVED } & \text { HOMES, } 4 \text { YEARS) }\end{array}$

HOMES)

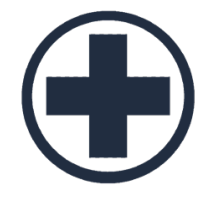

PREVENT \& MITIGATE

HOUSING RELATED

HEALTHCARE

DEMAND

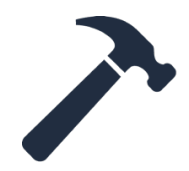

(NZGBC, 2020) 


\section{Changes Ahead}

New Zealand guides and changes to the construction industry recently released (Figure 2.1) highlight the design research gap and standard for New Zealand homes and possible opportunities to mitigate the issues. Recent documentation includes the following:
- Building for Climate Change, Ministry of Business, Innovation and Employment (MBIE), New Zealand Government, 2020(b). MBIE are currently upgrading construction sector standards for climate and reducing emissions.

- A Green Recovery, New Zealand Green Building Council, 2020. The document outlines the opportunity to improve the economy and provide healthier homes for occupants responding to effects of Covid-19.

- Boost to Upgrade State Housing to be Warmer, Drier, Healthier Homes, The New Zealand Government, 2020(a). A recent investment of $\$ 500$ million for a Retrofit Program to improve existing state housing. (Refer to Chapter 4.0).

- A Zero Carbon Roadmap for Aotearoa's Buildings, New Zealand Green Building Council, 2019. Outlines the required steps needed for New Zealand's buildings to be net-zero carbon by 2050 for existing and 2030 for new buildings.

- The Sustainable Development Goals, United Nations, 2015. 17 core economic, social and environmental goals for the crucial sustainable development for humanity and the planet before 2030 .

- The World Green Building Council (2017) identifies 9 of the goals the green building industry has responsibility and opportunities for change. Refer to Chapter 5.0 for the design response to the goals. 
NZ

Global 2015

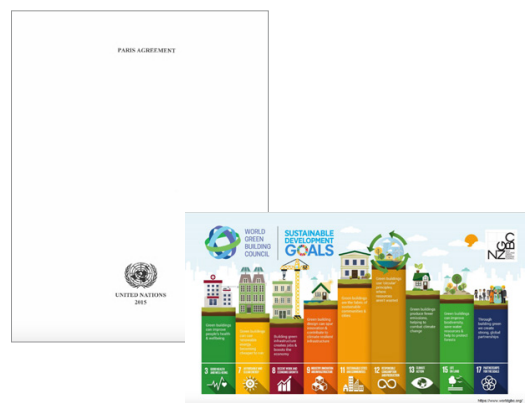

\section{A GREEN
RECOVERT}

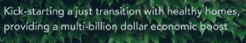

AZero Carbo
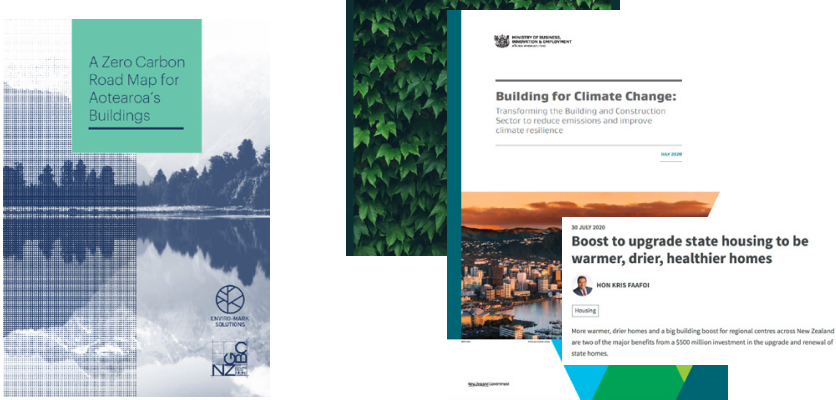

2019

2020

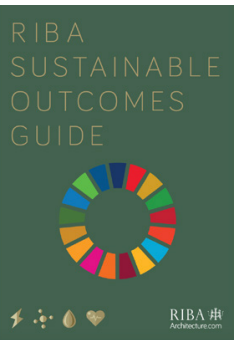

Fig 2.1 Timeline highlights relevence of design research with recent increased focus for environment building standards to New Zealand infrastructure influenced by international standards. 


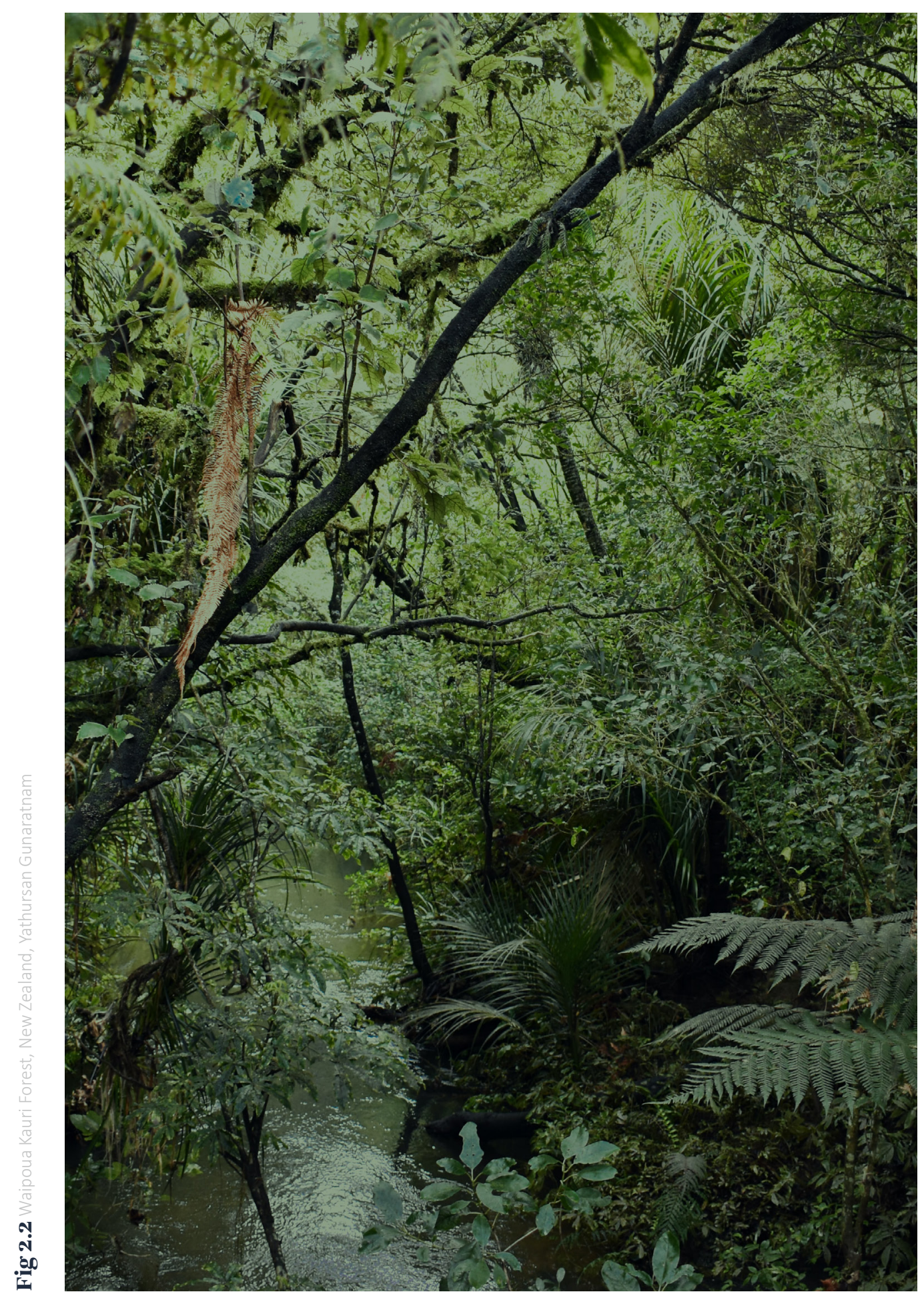




\section{Environment Experience}

The natural environment has an innate positive relationship with people, and both can mutually benefit the other for human and environmental health. Wilson (1984) described in Ulrich (1993), a relationship between the environment and people as fundamental for a positive human response due to an intrinsic human connection to nature, termed Biophilia (p. 73). The restoration of health and well-being is encouraged by an environment rich in sensations to stimulate the subconscious without demanding and increasing stress (Grahn \& Stigsdotter, 2010, p. 265). Tactile interactive play is an opportunity to stimulate the senses and support human development. As described by Ayres (2005) play and tactile interaction encourage the development of cognitive and sensory-motor skills due to sensory integration to develop effective adaptive responses (p. 7). Research highlights that connecting with nature provides mental relief and reduces stress (Grahn and Stigsdotter, 2003, p. 44; Ulrich, 2006, p. S39; Grahn and Stigsdotter, 2010, p. 264). Biophilia has proven to be beneficial for human health and well-being, with findings of improved mental health and encouraging play and physical activity (Rogers, 2019). Grahn and Stigsdotter (2010) investigated the impact of rest restoration and urban green spaces. They found the most successful combination of factors to restore the effect of stress to be refuge and nature (p. 273). The refuge dimension comprises a space where one feels safe, sheltered and protected while generally having a view out and able to experience the power and vitality of nature on its terms (pp. 267268). Together, the refuge and nature dimensions positively impacted lowering stress and were the most preferred options by the tested highly stressed individuals (Grahn and Stigsdotter, 2010, p. 272). The findings indicate the need to design for Biophilia within the built environment for beneficial health and well-being. The concept of Biophilia has been interpreted into fourteen Biophilic principles to inform the design of the built environment to mitigate stress, improve cognitive performance and affect emotion and mood with enhanced humannature connection (Browning et al., 2014, p. 12). The integration of Biophilia with design could enrich the environmental experience for occupant health and well-being, drawing from the design techniques. Refer to Chapter 5.0, Figure $X$, for findings from the principles to inform the design framework.

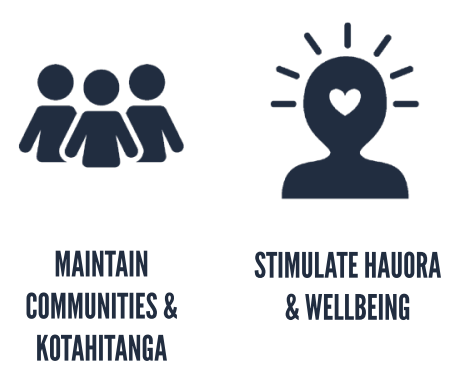




\section{Parametric Digitalisation}

Digitalisation can increase design, construction and resource efficiency. The use of complex digital modelling of parametric design has a powerful capacity to improve designs' adaptivity with precision and correlation between design elements (Schumacher, 2009, p. 15; Schumacher, 2011, p. 345). Schumacher (2009) describes parametrism as an open and incomplete system. A combination of relationships continually modifiable and increasing complexity as components and systems integrate (p. 23). The benefit allows the designer to adapt developed designs for future decisions that are to be made later in the process and therefore increases the design output efficiency (Schumacher, 2011, p. 346). Compared to static 2D or 3D analogue or digital design techniques, design changes late in the design process may require a significant time investment to make the design modifications (Schumacher, 2011, p. 345). Although Schumacher (2011) critiques that to benefit from the productivity gain, the designer has to anticipate future design variations effectively and, therefore, may require a higher preparation modelling time (p. 346). Schumacher (2009) describes the responsive ability to respond kinetically to environmental parameters. The ability to optimise the design in response to result in a far more resolved design output. For example, to adapt the design appropriately to site conditions. A high level of detail parameters integrated into the parametric design script anticipating future adaption. The precise control of materials can be included in the malleable design to optimise resource use. The design output directs digital prefabrication methods, such as CNC (Computer numerical control), and is responsive to dynamic design input. The digital tool's highly detailed ability is beneficial for a strategic design applied to a large scale of different housing typologies and serves varying functions. Therefore, the parametric design tool was appropriate to design with, even though the initial design process costs more time due to apprehending future complexities.

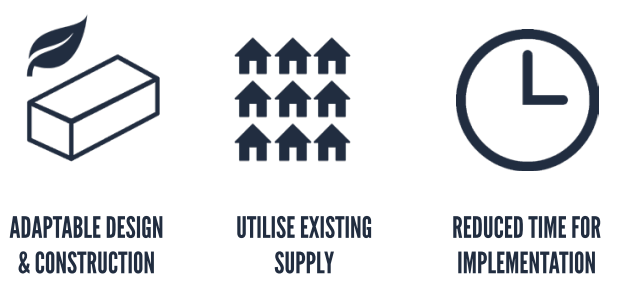




\section{Problem}

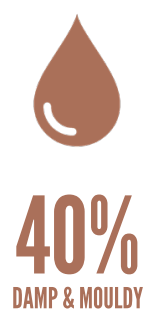

(BRANZ, 2015)

กni

ntr

กнi

EXISTING SUPPLY

NOT USED

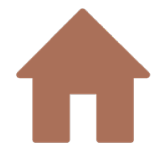

$53 \%$

BENEFIT FROM

INSULATION

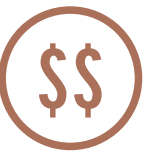

NEW BUILD,

HIGH COST
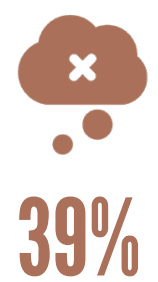

CONSTRUCTION

CARBON EMISSIONS

(IEA, 2019)

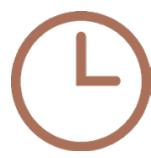

NEW BUILD,

LONG TIME

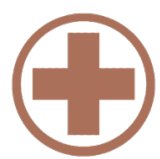

PREVENTABLE

hEALTHCARE

DEMAND

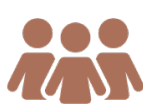

DISPLACED

COMMUNITIES

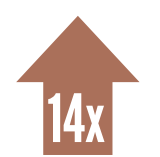

INCREASE

RESPIRATORY

ISSUES WITH

MOULD EXPOSURE
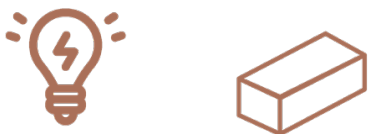

INEFFICIENT

ENERGY USE

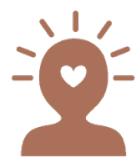

NEGATIVE

WELLBENE

IMPACTS

RIGID

CONSTRUCTION

PROCESS

\section{opportunity}

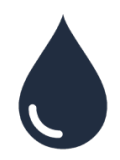

MITIGATE MOULD \& DAMP

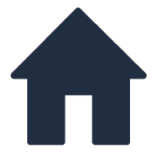

INSULATE, VENITLATE, AIRTIGHT

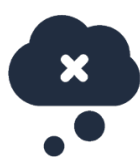

LOWER CARBON EMISSIONS

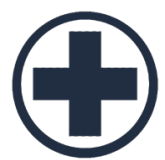

PREVENT \& MITIGATE HOUSING RELATED HEALTHCARE DEMAND

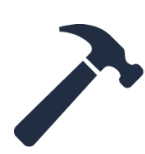

1300 JOBS CREATED (20000 HOMES, Y YEARS)

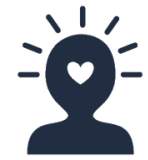

STIMULATE HAUORA \& WELLBEING

\section{An \\ กnก กnt}
UTILISE EXISTING SUPPLY

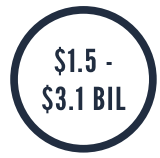
$\$ 1.5-\$ 3.1$ BIL NET BENEFIT (120 O0O IMPROVED HOMES)
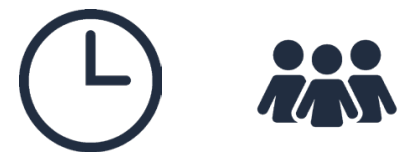

REDUCED TIME FOR IMPLEMENTATION
MAINTAIN

COMMUNIIIES \& KOTAHITANGA

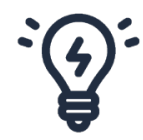

EFFICIENT ENERGY USE

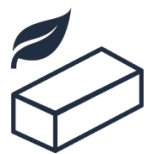

ADAPTABLE DESIGN \& CONSTRUCTION

Fig 2.3 Diagram highlighting problems and 


\section{Findings}

The background research chapter identifies problems with and the opportunities to utilise the existing housing in New Zealand. However, it can be inefficient and have a poor thermal performance to the detriment of occupant health and wellbeing, often resulting from low New Zealand design standards. Further, the construction industry has a harsh environmental impact due to construction methods, home energy inefficiency, excess resource use and wastage. However, the research identified that higher home performance as proven internationally using passive design and thermal envelope techniques achieves net-zero energyefficient homes for occupant and environmental benefits. The research found potential economic benefits of improving the homes and highlighted the recent shift in the construction industry to improve the environmental impact. A further advantage to occupant health and well-being results from the occupant relationship with nature to reduce stress, affect mood, emotion and cognitive performance. Therefore, an integration of the biophilia design techniques would support enriching the environmental experience for the occupants. The design and construction industry could innovate to mitigate harsh environmental effects and adapt to existing housing through digitalisation. Parametricism for design and construction is a digital tool to anticipate and adapt the design as needed and for malleable outcomes. The research findings suggest using innovative design techniques to improve existing homes' performance for high thermal performance and encourage the humannature relationship beneficial to occupant health and well-being. The outcome suggests developing a fluid design solution adaptable as appropriate for efficient design and construction outcomes. Further research results to inform a framework and strategy outlined in Chapter 5.0 to address the research gap. 


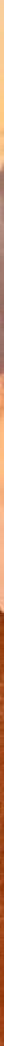

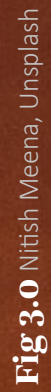


The Chapter fulfils the research objective: Identify fundamental case studies from precedents to inspire design decisions and implement global approaches to a New Zealand context. The objective was to identify the existing national and international approaches to retrofit existing housing, particularly to identify an approach to achieve high home performance without displacing the occupants. The case study research explored but was not limited to location, retrofitting externally and internally, climate, passive design techniques, control layer techniques, thermal performance, environmental performance, and design. The search identified fundamental case studies to inform the design and highlighted a current research gap to retrofit New Zealand housing externally to inform the design process.

NEW ZEALAND

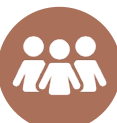

NO DISPLACEMENT IXXTERNAL RETROFIT
U1 STATEHOUSE

介 


\section{Research Drivers}

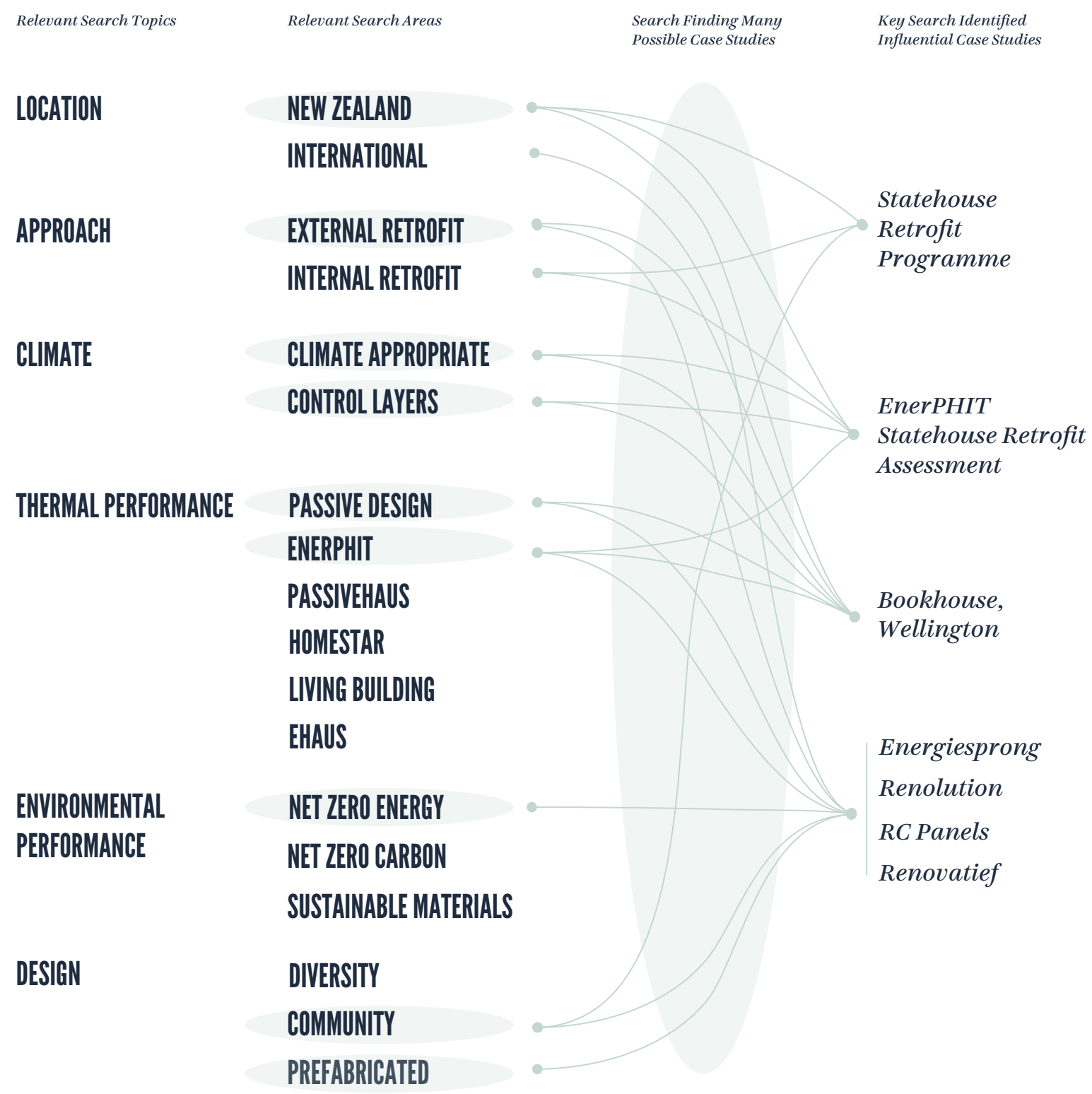

Fig 3.1 Diagram of research drivers used to investigate case 


\section{Passivhaus Database}

The research process used Passive House Database (2020) to identify high-performance buildings in New Zealand within an international context to position the research. The investigation compared the homes which applied for and achieved certification, limiting the research. However, additional homes may also perform to the standard but without certification.

The growing quantity of international successful Passivhaus case studies contrasted the very few in New Zealand. The search identified a total of 5028 buildings to the Passivhaus standard internationally, and only a total of 41 in New Zealand, and they are predominantly new builds (Passivhaus, 2020). The first New Zealand Passivhaus home completed only in 2012 (Passivhaus, 2020). The existing housing stock to the same standard is only beginning to gain traction, with 160 buildings to the EnerPHit standard and only 45 are detached family homes (Passivhaus, 2020). In New Zealand, only one detached family home to the EnerPHit standard is currently under construction as an external and internal retrofit (Passivhaus, 2020). Therefore, identifying the research gap, especially for external retrofit of detached New Zealand homes to a far greater design standard. 


\section{Passivhaus Database}

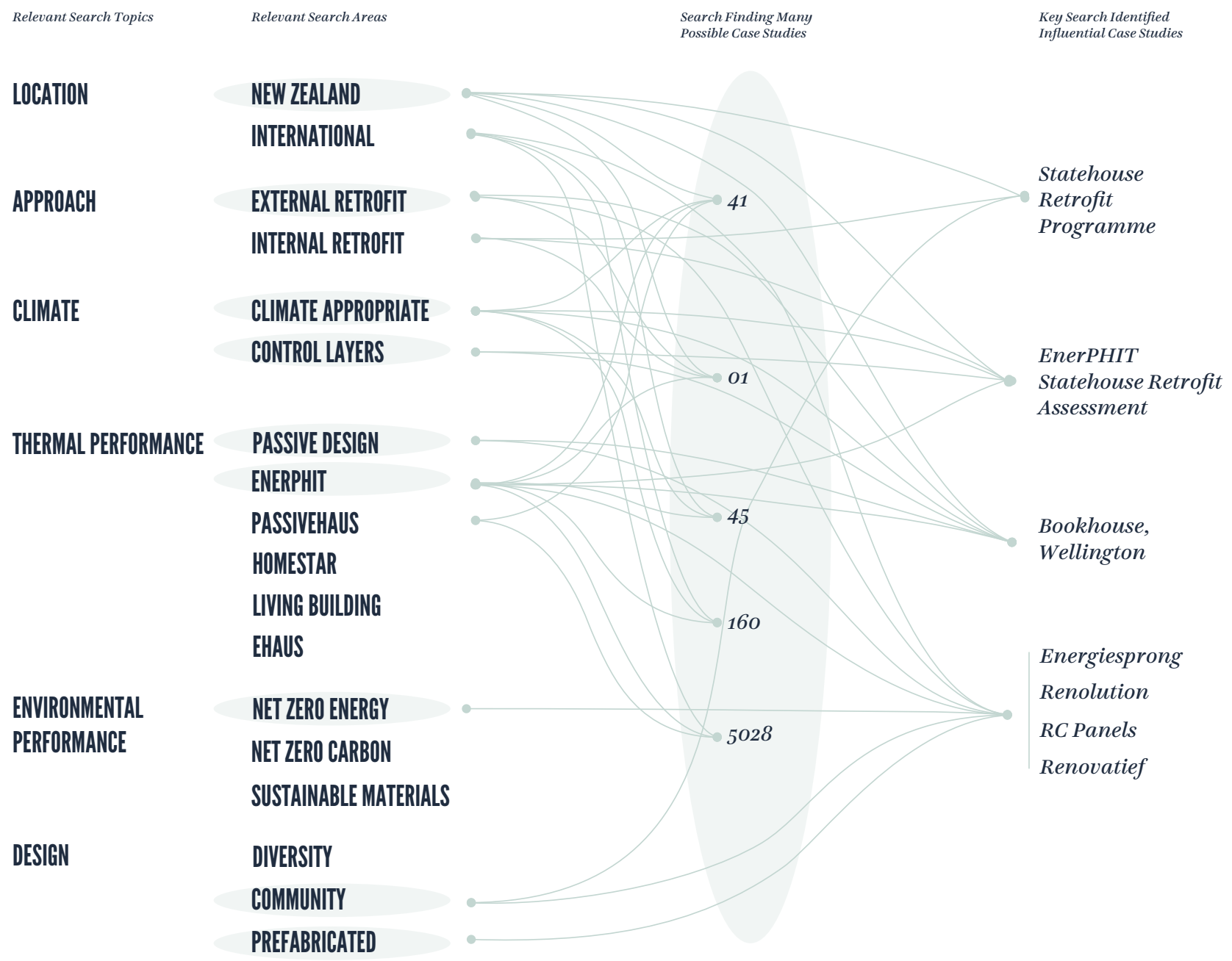

Fig 3.2 Diagram of Passivhaus database findings in relation to 


\section{(i1)}

\section{EnerPHit State House Retrofit}

\section{Who:}

Paola Leardini and Manfredo Manfredini

\section{When:}

2015

\section{Where:}

Auckland, New Zealand.

\section{What:}

1940's 3 Bedroom State House EnerPHit retrofit assessment.

\section{Why:}

Leardini and Manfredini (2015) critiqued the current retrofit approach. The current approach adds heating and some base standard insulation to the envelope but disregards energy use and environmental impact and can fail to address the existing stock needs ( $p$. 234).

\section{How:}

Leardini and Manfredini (2015) applied the EnerPHit (Passive House Retrofit) principles to a typical 1940's state house. The home was one of the most common housing types developed in the 1940s, of timber frame, weatherboard cladding, suspended timber floor, and tiled roof (p. 238). The study involved an interior retrofit in determining whether an application of the EnerPHit principles could be achieved. The research compared various improvement levels of insulation to full window and airtightness upgrades with the low performing standards in compliance with the New Zealand Building Code.

\section{Findings:}

Leardini and Manfredini (2015) found a retrofit to the EnerPHit standard to New Zealand state housing could be achieved in theory. The study found a reduced heating demand, improved indoor comfort and moisture control with insulation installation to the ceiling, floor and walls, and a replacement of the windows to low-e, argon filled double glazed timber windows. However, concern to control the strategy, manage thermal bridging, and ensure a continuous airtightness to the thermal envelope was critiqued to potentially vary the actual building performance and, therefore, the study's success (p. 244).

\section{Critical Reflection:}

The study's findings highlight the need for aiming beyond the minimum of New Zealand current building standards. The outcome proves the upgrade to the state homes can be achieved to a high standard and therefore supports the thesis investigation. The concern to control airtightness and thermal bridging are likely to require a high time cost to manage the existing walls' details. The outcome highlights the benefit an external envelope could provide with more control over the detail design, envelope continuity and connections, and add a layer of protection to the home. Although to ensure a continuous envelope, the existing home construction may need to be compromised. 


\section{State House Retrofit}

Who:

New Zealand Government

\section{When:}

2020

\section{Where:}

New Zealand

\section{What:}

New Zealand Statehouse Retrofit Programme (New Zealand Government, 2020a).

\section{Why:}

The New Zealand Government (2020a) aim to improve existing poor condition state housing for warmer, drier, healthier homes with a \$500mil to upgrade programme.

\section{How:}

The New Zealand Statehouse Retrofit Programme (New Zealand Government, 2020a) uses an internal approach. The homes retrofit involves stripping out the home to install insulation to the walls, ceiling and floor, improve the airtightness, and add double glazing, ventilation and heating. The programme's retrofit work requires the occupants to move out, resulting in greater housing demand and disruption to people.

\section{Critical Reflection $\mathcal{E}$ Findings:}

The outcome of the retrofit increased the house performance providing healthier homes for occupants. However, the retrofit work improves the thermal performance only to the minimum New Zealand standard. A higher standard of house performance would have more occupant, environmental and energy benefits. Additionally, the retrofit work displaces occupants from their homes and communities during the slow construction process. The New Zealand Government announced its investment into the pilot research retrofit programme during the thesis research. The announcement supported the relevant gap in New Zealand for investigation of improving the housing stock for occupants. 


\section{Energiesprong}

Who:

Energiesprong

\section{When:}

2014

\section{Where:}

The Netherlands.

Energiesprong projects have now been built in the Netherlands, the United Kingdom and France, with projects also planned in Germany, Italy and New York State, US.

\section{What:}

An external retrofit strategy to achieve net-zero energy without occupant displacement.

\section{Why:}

The uncomfortable living conditions of much existing housing require high energy use and cost to heat, mainly due to heat loss and moisture. The homes result in inefficient energy use and wasted energy.

\section{How:}

Energiesprong (n.d.) is an external retrofit strategy for existing housing to achieve net-zero energy. The method overlays prefabricated external wall and roof panels to existing row houses and apartments. Efficient heating and cooling modules are installed into the homes for smart management of energy. The panels are modified to suit the exact details of the home modelled from 3D scanning technology to inform panel prefabrication. The extensive scaling and prefabrication of the strategy help manage the cost and performance levels (Transition Zero, 20, p.
24). The strategy's application is complete in less than a week, and therefore, the occupants do not need to leave their homes. Post occupancy evaluation of energy use understands occupant behaviours and provides an opportunity to educate and manage energy use in the houses (Energiesprong, 2019).

\section{Critical Reflection:}

The Energiesprong strategy was applied to mediumdensity row housing and is a different housing type to the detached New Zealand state house. The core concept of Energiesprong is fundamental to inform the thesis research, however, the application of a method to detached New Zealand housing will have different design challenges.

The prefabricated panels built for pragmatic performance often lack variation between homes amongst the medium density housing. The thesis research proposes building upon the successful strategy and provide a more tangible home experience and use for the occupant.

\section{Findings:}

Energiesprong uses digitalisation and prefabrication to improve existing homes' performance and achieve net-zero energy. The success of the case study proves an external retrofit approach without occupant displacement is achievable. The challenge is to use the case study learnings to inform a similar method to New Zealand existing state houses. 


\section{(04)}

\section{NZ External Retrofit}

\section{Who:}

Workspace Architects Ltd \& Sustainable Engineering Ltd

\section{When:}

2014

\section{Where:}

The Book House, Wellington, New Zealand

\section{What:}

New Zealand Statehouse Retrofit Programme (New Zealand Government, 2020a).

\section{Why:}

The Book House alterations restored the worn and mouldy apartment block (Sustainable Engineering Ltd, 2019, p. 1).

\section{How:}

Sustainable Engineering Ltd (2019) used a hygrothermic model to analyse the existing building performance and inform the design for improved building performance. "The walls and roof were insulated, ventilation installed and double-glazed, thermally-broken windows fitted. The interior was completely refitted, right down to wall linings and floors; and the floor plan was modernised" (Sustainable Engineering Ltd, 2019, p. 2). Sustainable Engineering Ltd (2019) explained how the hygrothermic model revealed the need for an external thermal envelope to avoid moisture buildup between internal insulation and the concrete wall. The design outcome applied external insulation panels to form the thermal envelope allowing greater control of joints and building control layers (pp. 3-4).

\section{Findings \& Critical Reflection:}

The retrofit case study was to a different building and construction typology to the thesis research site. However, the project identified an external thermal envelope at a performance standard built beyond the minimum code requirements as achievable in New Zealand. The external thermal layer effectively managed control layers and joint connections due to increased continuity control around the exterior. The control layers and understanding of the existing building was fundamental to the success of the retrofit work. Building science consultant Jason Quinn articulates the project's findings and for retrofit construction in the future, "New Zealand buildings are too often cold, damp and unhealthy. Retrofitting old stock for the sake of people's health is important. But buildings are complicated and just adding insulation risks making older buildings perform worse than before. It is crucial to understand moisture and heat transfer and how added levels of insulation will affect a building's drying capacity" (Sustainable Engineering Ltd, 2019, p. 2). The approach to retrofit existing housing externally needs to understand the current home performance to increase home performance successfully. The apartment block alteration work still required occupant displacement due to the alteration scale to the building.

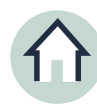

EXTERNAL RETROFIT 


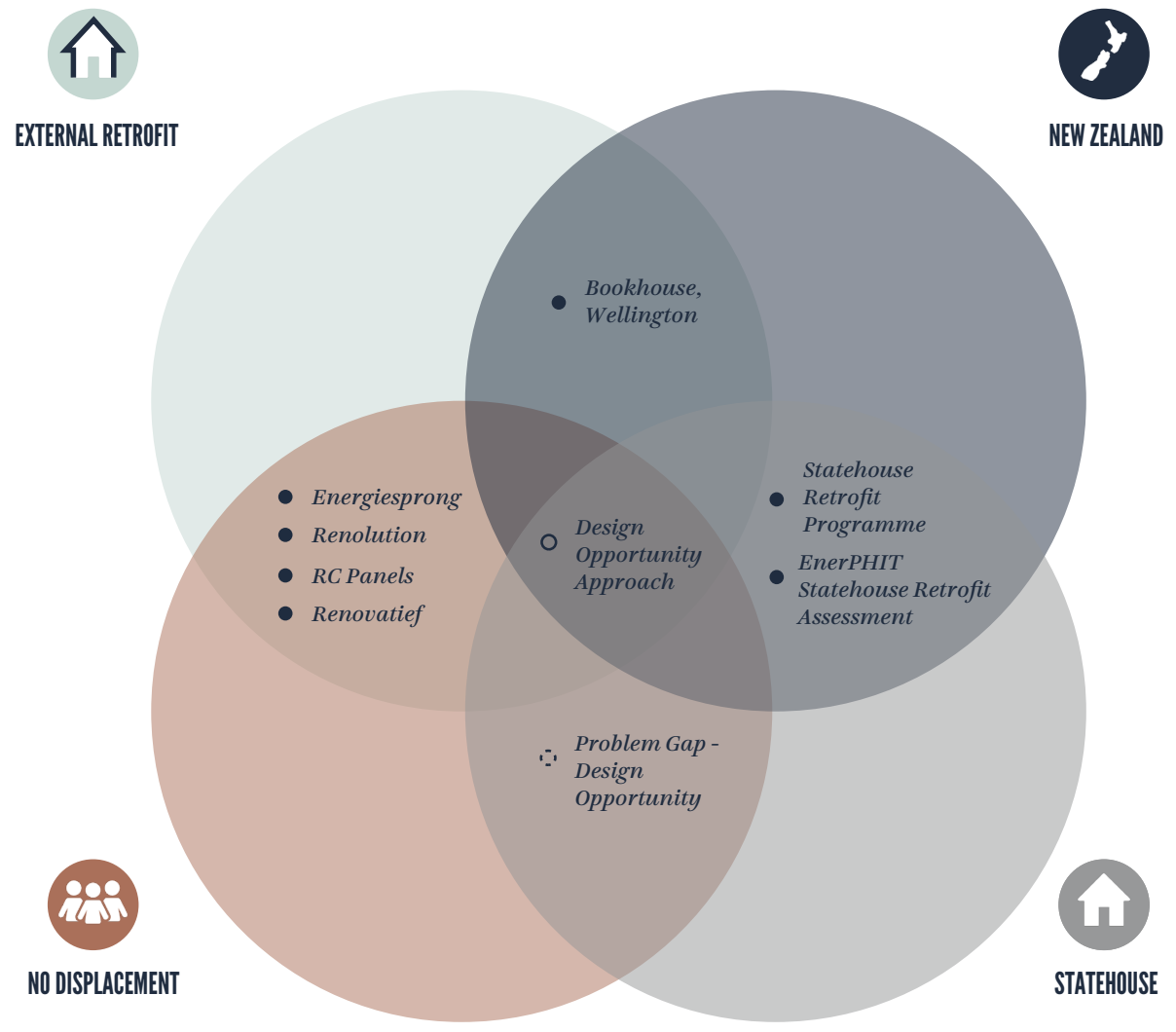

Fig 3.3 Diagram locating key case studies within the research drivers to identify the research gap 


\section{Critical Reflections G Findings}

Currently, external retrofit practices without occupant displacement in New Zealand are yet to be closely studied. In New Zealand, existing housing is improved with interior retrofits but require occupants to move elsewhere while construction occurs. The current New Zealand Statehouse Retrofit Programme (New Zealand Government, 2020a) identified in Chapter 2.0 utilises the internal retrofit approach to somewhat improve the home's thermal performance to the lower New Zealand standard of design. The homes benefit from the increased improvement of insulation, airtightness, double glazing and ventilation. However, a higher requirement for improvement would have more significant occupant, energy and environmental impacts, as discussed in Chapters 2.0. Another study, the EnerPHIT Statehouse Retrofit Assessment undertaken by Paola Leardini and Manfredo Manfredini (2015), took the approach a step further and tested the 1940s-1960s state house retrofit to the EnerPHIT standard. The research tested a higher thermal performance increased potential to retrofit the home. The study found a more effective retrofit can be achieved in New Zealand state houses and therefore supports the thesis research to attaining a higher level retrofit for housing. Unfortunately, both of the key New Zealand studies require occupant displacement for the retrofit to occur. An external retrofit approach in Wellington, New Zealand, has been undertaken to improve the existing building's performance. The Book House case study by Sustainable Engineering Ltd (2019) examined the upgrade to the apartment block in Wellington, New Zealand, with an external envelope. The building alterations were established from hygrothermic modelling to understand the existing building performance and propose a beneficial solution. The outcome required a thermal envelope to the building exterior, and found more control to joints and continuity of the envelope could be achieved. The alterations proved an external thermal envelope beyond the minimum New Zealand standards achieved in New Zealand. Although, the scale of the work to project still required occupant displacement.

Global case studies have proven successful external retrofit outcomes where occupant displacement is not necessary. Energiesprong (2019) was a fundamental case study for thesis research. The case study externally retrofits existing housing to a higher thermal performance standard for net-zero energy. Their approach consists of prefabricated wall and roof modules installed externally to existing medium-density housing and the outcome proved high-performance external retrofits without occupant displacement are attainable.

The selected case studies highlight the possibility of an appropriate external retrofit strategy not to displace occupants to be achievable in a New Zealand context. The design research will need to resolve the process to apply a similar external retrofit approach appropriate to the detached existing housing stock of New Zealand.

\section{Findings:}

- New Zealand current approaches require occupant displacement.

- Lack of research for detached housing type

- High-performance standard of retrofit is achievable.

- Successful international external retrofit cases

- Occupants can remain in homes \& prefabrication reduces onsite time and impact.

- International retrofits achieve net-zero energy in varying climates.

- Pragmatic retrofit response overlooks the opportunity to integrate program components and envelope experience. 


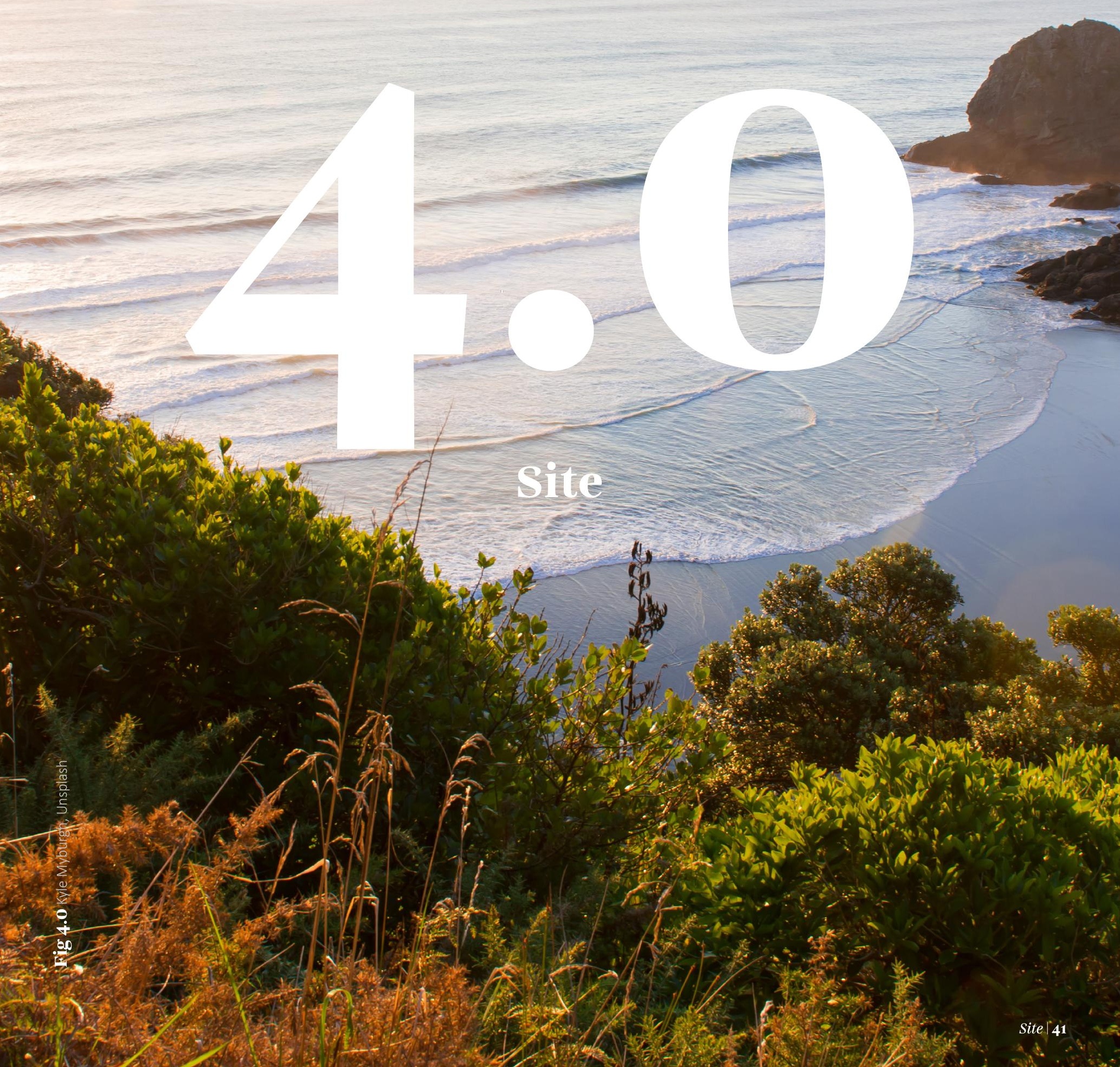




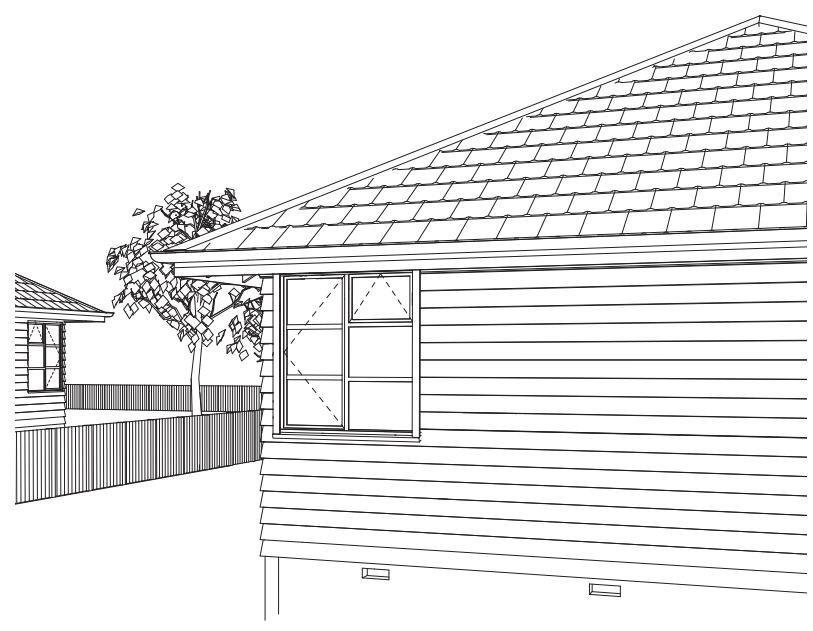

The following Chapter fulfils the research objective:

Fig 4.1 Digital model of state house developed for understanding

Investigate the existing 1940s-1960s housing typology to inform design decisions. The objective was to understand the 1940s-1960s housing typology, an available housing typology for reuse, to identify the house's issues for the areas to address and inform the design framework (Chapter 5.0). 


\section{Site}

Homes in New Zealand perform significantly below effective home performance design. As discussed in Chapter's 2.0-4.0, international standards and design approaches have proven effective in providing higher-performing homes in climates far more drastic than New Zealand. The 1940s-1960s State House in New Zealand, a result of the Labour Government housing scheme, was widely produced around New Zealand and an iconic home typology (Ferguson, 1994, p.117; Firth, 1949, 6; Schrader, 2005, p. 15). The houses were generally not insulated, resulting in poor thermal capacity to negatively affect occupant health (BRANZ, n.d.). However, the homes' sturdy construction, standardised key components and overall uniformity (Ferguson, 1994, p. 128; Firth, 1949, p. 40; Schrader, 2005, p. 88) provide a more consistent housing typology as a site for the research. The standardisation of house components encouraged more opportunity for diversification amongst the houses while maintaining efficient production by partial prefabrication methods (Firth, 1949, p. 39). The widespread housing typology is an available resource for reuse with generally consistent detailing to improve homes' thermal performance. 


\section{State House Critical Assessment}

\section{Advantages:}

- A mass-produced housing stock in New Zealand.

- A part of existing New Zealand urban fabric.

- Generally of solid construction (NZ timber).

- The typical detailing and construction resulting from partial prefabrication and standardisation.

- A large roof slope and eaves for shedding water.

- Has sufficient sub-floor ventilation and ground clearance.

- It is the occupants existing home.

\section{Disadvantages:}

- The neglected and poor condition of homes may not be feasible to apply an external strategy.

- The existing internal damage impacts the applied strategy.

- The alterations over time may affect the design strategy approach as the home may no longer be in its original state.

\section{Critical Reflection:}

- The research scope assumes a moderate level of maintenance to the homes. It would be ready to receive an external retrofit as the houses' condition will vary, and some may need an additional preparation.

- The use of 3D scanning to gain the full model of the home will allow for adaption of the external strategy to the home's exact form, especially as the homes may have been altered over time and not be of the original construction. Also, depending on the construction period, some detailing and material variance are likely. Therefore, the overall control layer management for thermal performance would be affected to some degree.

- For the research, the scope is limited to the original home as a controlled base. There is a future for the research beyond the scope to address a broader range of home variance. 


\section{Existing Issues}

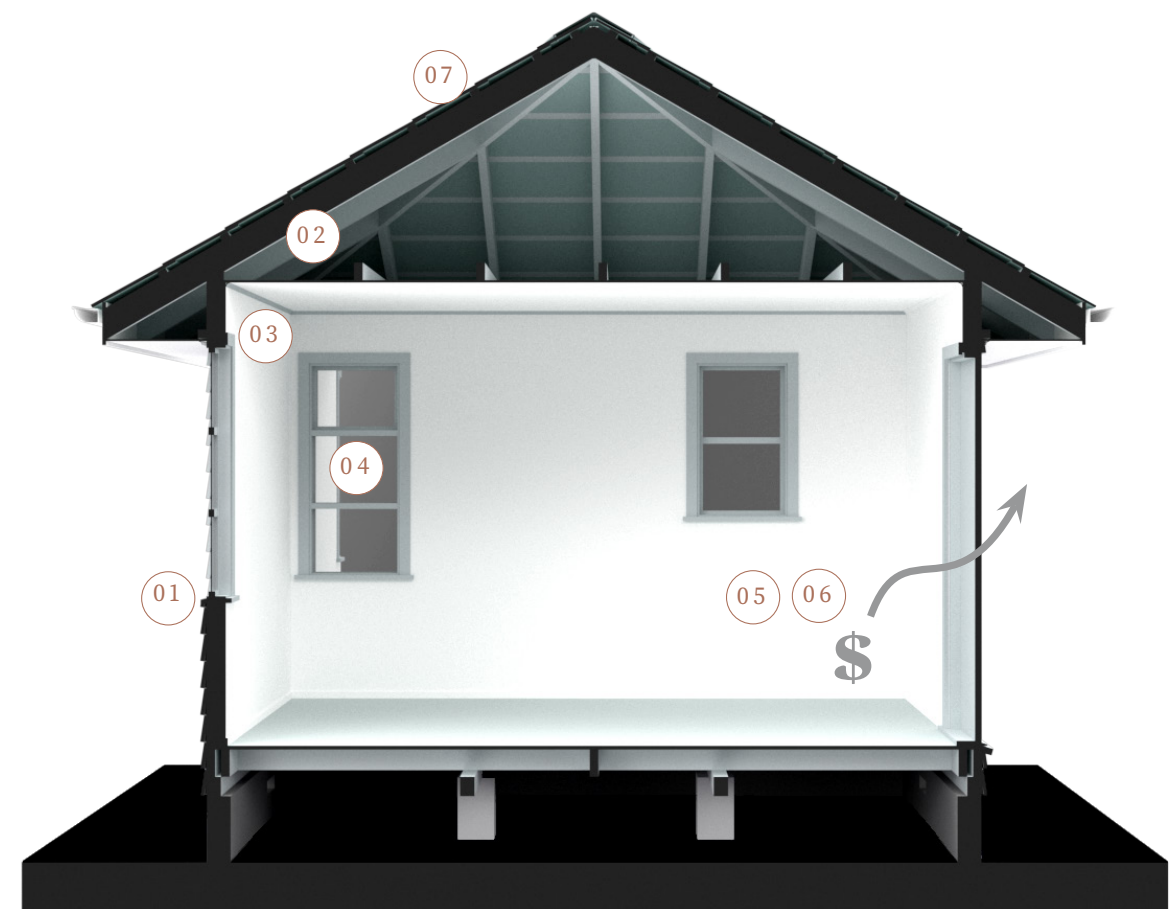

Issues
(01) Poor airtightness
(02) Lack of insulation
(03) Thermal bridging
(04) Low performance windows \& doors
(05) Expensive to heat result of constant heat loss
(06) Energy poverty - occupant inability
to afford heating
(07) External claddings wearing out

Fig 4.2 Diagram of issues identified in existing state house 


\section{1}

POOR AIRTIGHTNESS

Issue: The timber windows and doors constructed in the state homes tended to allow air movement in the house and provide natural ventilation. It helped to remove internal moisture reducing some damp and mould. The poor airtightness, combined with the lack of insulation made the homes colder overall due to heat loss or cold draughts entering the house (BRANZ, n.d.).

Remedy: (BRANZ, n.d.).

- Install PEF rod \& add air deal between window and opening.

- Install foam seals to gaps in sashes and window frames.

- Use heavy curtains.

\section{Critical Reflection:}

The remedies would be sufficient if the airtightness were the only issue. However, in increasing airtightness, ventilation needs to be added to ensure internal moisture does not build up. Otherwise more significant dampness and mould issues would arise.

\section{2}

\section{LACK OF INSULATION}

Issue: The original homes are most likely to contain no insulation, likely resulting from misunderstanding the New Zealand climate (BRANZ, n.d.).

Remedy: (BRANZ, n.d.).

- Roof - various insulation options added with access to the roof space such as; blanket and segment insulation (wool, glass wool or polyester); rigid/semi-rigid board; or loose fill insulation (glass wool, sheep's wool, mineral wool or paper).

- Wall - Remove exterior cladding or internal wall lining to install insulation. Insulation must allow a gap for water drainage between the insulation and cladding. Blown-in insulation may be doable only in homes with wall underlay and to allow a drainage gap.

- Floor - The homes generally have accessible subfloors and therefore, installation of insulation is achievable. Currently, expanded polystyrene can be inserted between joists with a lining over to protect if sub-floor is open, or bulk insulation with a lining and fixing sheet.

\section{Critical Reflection:}

Access to external walls to retrofit insulation is difficult and requires disruption to occupants. It generally does not occur unless major alterations are done. Even then, the capacity of insulation is generally of the minimum standard as per New Zealand regulations. The roof and sub-floor have easier access to install insulation, but it is typically of low minimum standard. There is an opportunity to increase the ceiling and subfloor's insulation capacity and design a more effective and efficient method of insulating the external wall envelope. 


\section{3}

\section{THERMAL BRIDGING}

Issue: Timber framing conducts heat through the wall in the form of thermal bridging and is a pathway of heat loss in the home (Cox-Smith, 2009, p. 16).

Remedy: (Cox-Smith, 2009, p. 16).

- Install thermal breaks to restrict the thermal bridges.

- Increase insulation.

- Increase frame depth.

- Use materials of higher thermal resistance

- Design to reduce timber connections and quantity needed.

\section{Critical Reflection:}

The above remedies are to be taken into the design process to inform the external retrofit construction. An exterior retrofit would reduce thermal bridging through the framing by breaking the path of thermal conductivity. However, it will be challenging to eliminate thermal bridging from working around the house's existing construction detailing.

\section{LOW PERFORMING WINDOWS \& DOORS}

Issue: Poor thermal performance of the existing single glazed openings (BRANZ, n.d.).

Remedy: (BRANZ, n.d.).

- $\quad$ Retrofit insulating glazing units (IGUs), either by full window replacement, partial replacement of glazing or sashes, or adapting the timber joinery to take IGUs.

- Secondary glazing (plastic, glass or low-E) magnetically attached to the existing window (found to outperform some IGU retrofit methods due to the frame's additional insulation).

\section{Critical Reflection:}

The windows are to be upgraded to increase window performance. Both current upgrading methods impact the occupants, and how the upgrade is integrated into the home must ensure adequate thermal performance and minimise occupant disruption. 


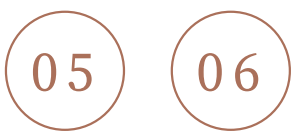

\section{ENERGY POVERTY}

Issue: High energy demand of homes result in a high cost by occupants to pay for energy. The high cost of maintaining energy demands can be too great for the occupant. Therefore the occupants reduce or stop using energy services at the expense of comfort, health and well-being (White, 2019, p. 55).

Remedy: (White, 2019, p. 56).

- Increase energy efficiency.

- Increase insulation home.

- Install more efficient heating sources.

\section{Critical Reflection:}

The increase of the home thermal performance increases the home energy efficiency. The increased thermal performance will need to be combined with an efficient heating source and energy generation methods to reduce energy poverty.

\section{7}

\section{WORN CLADDINGS}

Issue: Wall claddings may be worn in areas more susceptible to water egress depending on the level of maintenance undertaken. Deteriorating claddings and flashings need attention to maintain the home lifespan and manage weathertightness of the home (BRANZ, n.d.).

Remedy: (BRANZ, n.d.).

- Retain or replace the cladding or areas of damaged cladding depending on the availability of exact materials.

\section{Critical Reflection:}

Exact matches of existing cladding may be challenging to install without compromising exterior or weathertightness. It is achievable to replace but unlikely to integrate into the existing seamlessly, therefore, needing design compromises. There is an opportunity to design a strategy to solve the problem of improving the external envelope without compromising design, weathertightness or disrupting the occupant. 


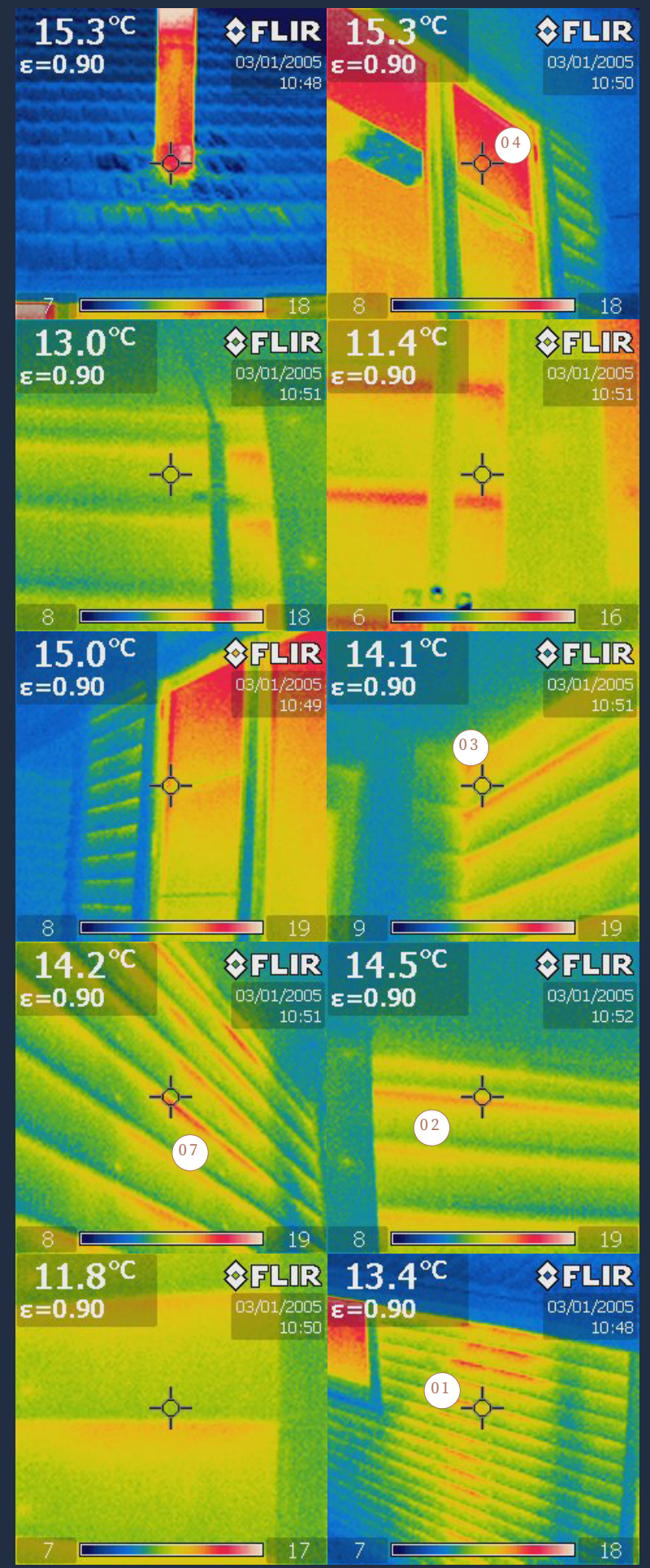

\section{THERMAL TESTING}

1955 weatherboard \& tile, timber construction

\section{Issues}

01 Poor airtightness - Walls, cladding gaps, windows, roof

Lack of insulation - Note - flat has minimum level of roof \& sub-floor insulation

03 Thermal bridging - particularly in internal corners, connection to roof, \& windows

04 Low performance windows \& doors, timber frame single glazed

05 Expensive to heat - result of constant heat loss

06 Energy poverty - occupant inability to afford heating

(07) External claddings wearing out Externalchadings wearing out

Fig 4.3 Thermal imaging heat loss research of 1955 timber framed, weatherboard and concrete tile roof home in Wellington. (Author's house). 


\section{Thermal Imaging}

The research involved a thermal imaging analysis and was undertaken to understand heat and air movement of the house typology. The author's home was used as a case study for research investigation. The house is a state house of 1955 construction located in Wellington and consists of timber-framed construction, weatherboard and concrete tile roof. Some underfloor and roof insulation is installed, and therefore it does not depict the full scale of the common housing defects. However, the home served as a tool for further understanding the construction and how it performs to inform the design research. The investigation used a thermal imaging camera to identify heat loss in the home. Figure 5.4 shows the images captured one evening after the fireplace had been running for a few hours to show a more accurate reading of heat movement through the home.

The issues found to align with the written research of the home typology. The issue areas identify critical focal points for the concept design and the more complicated areas to address.

\section{Exercise findings:}

- Heat loss through walls and cladding.

- Particular heat loss in internal corners where meets with roof.

- Heat loss around the window frame and along with gaps in weatherboards.

- Heat loss through roof tiles and especially around the area of the chimney.

\section{Critical Reflection:}

The exercise provided further understanding; however, a more detailed and calibrated test could be done to improve the results accuracy. For the scope of the thesis, a base visual understanding backed up the considered research. Therefore, it was less beneficial to take the exercise any further to design the overall concept. 

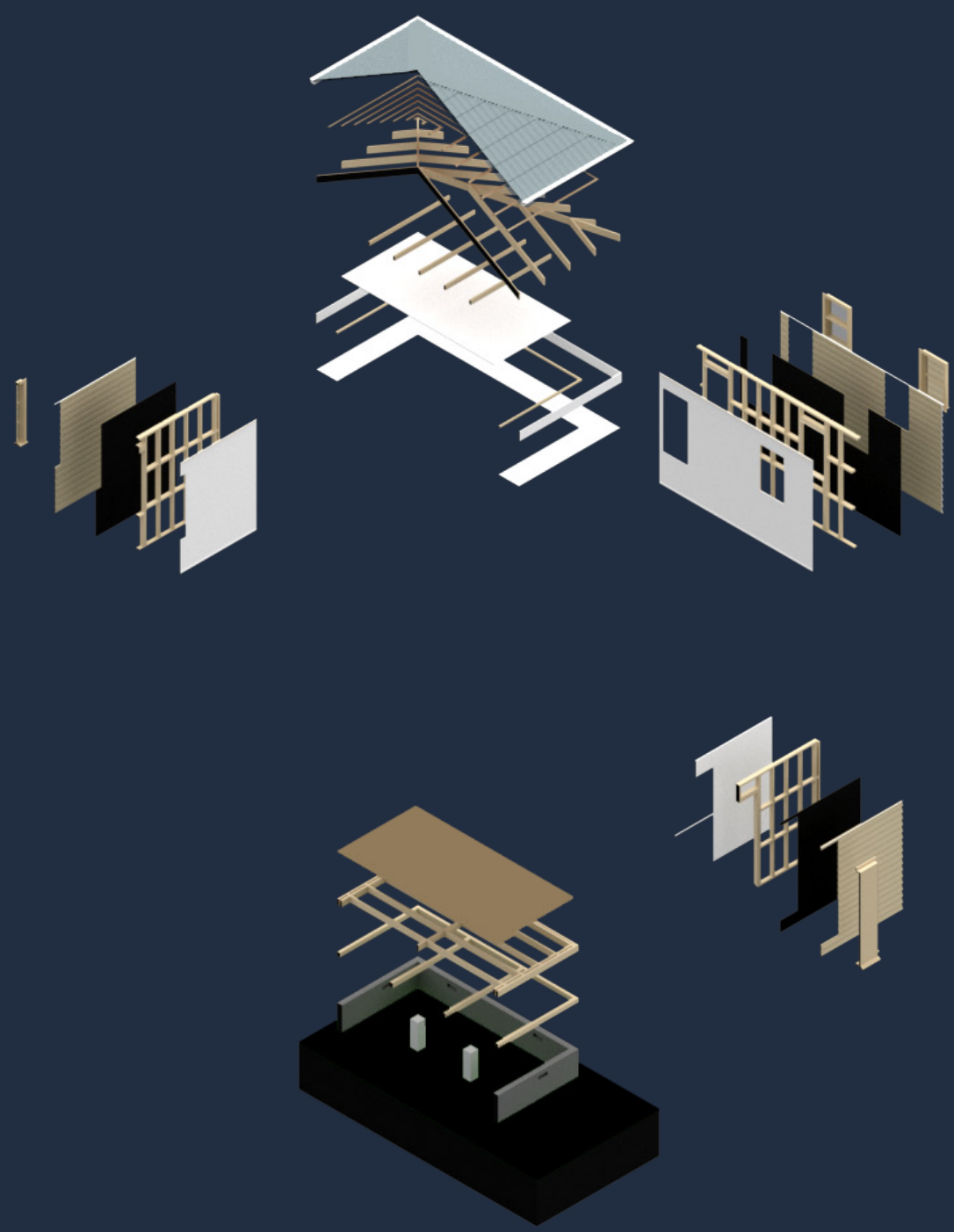

Fig 4.4 Detailed digital model developed of 1940s-1960s state house to understand construction 


\section{Digital model}

The research involved constructing a detailed digital model of an original 1940s-1960s state house typology to understand construction techniques. The exercise provided further understanding of the site for research.

The specific house typology for research was of timber weatherboard and tile roof construction, the most common housing typology. $40 \%$ of the homes were timber weatherboard construction (Firth, 1949, p. 70). Each home would be 3D scanned for accuracy and apply a design strategy to adapt to varying houses appropriately. 


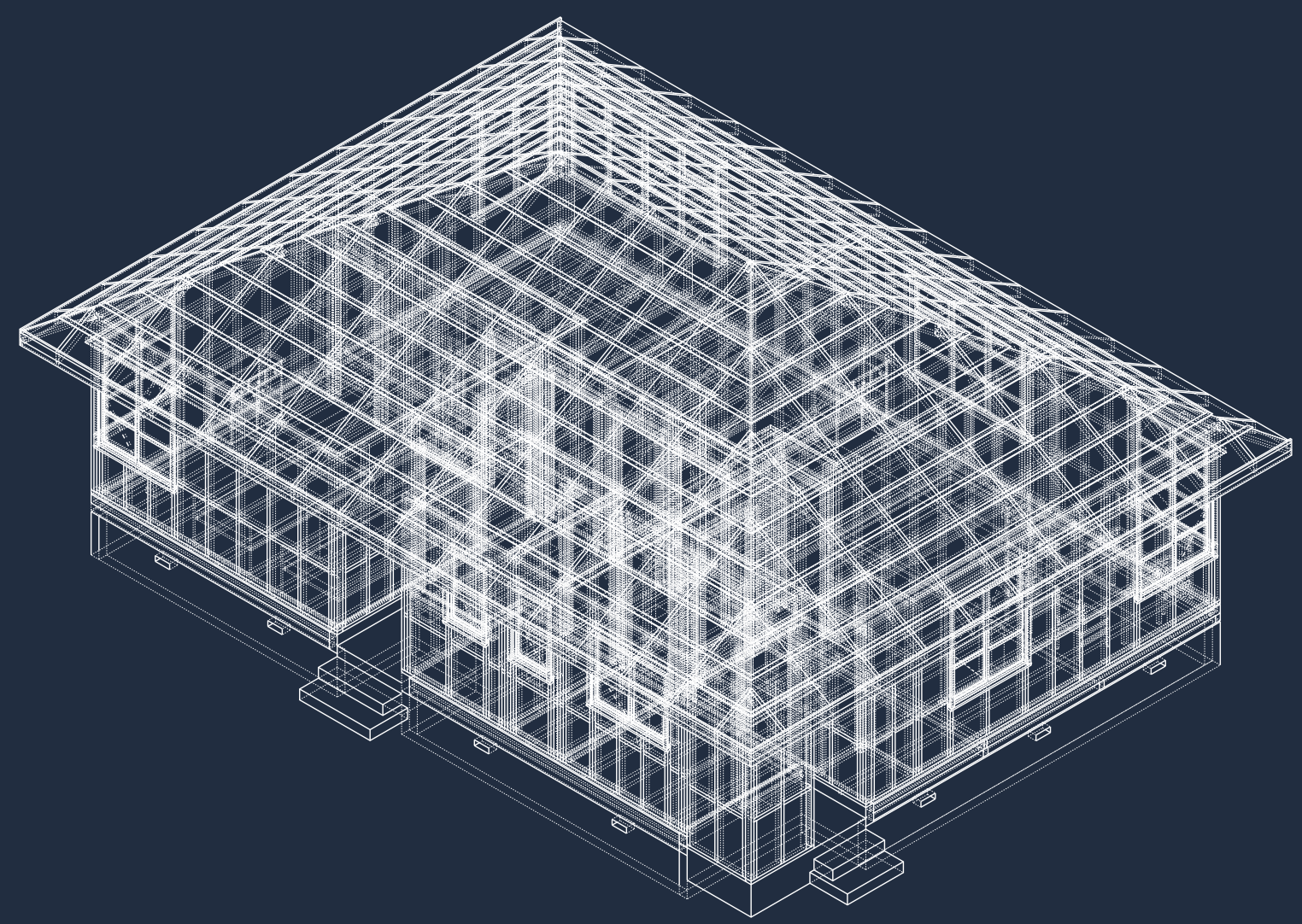

Fig 4.5 Detailed digital model developed of 1940s-1960s state

house to understand construction 


\section{Findings}

- The six critical issues identified to inform the design framework (Chapter 5.0) to drive the design, particularly airtightness, insulation, thermal bridging, windows and doors, to improve energy efficiency.

- The standardised house components will provide a standard base for design, although variations across the homes will occur, and therefore, the design should adapt accordingly. 3D scanning technology scans the existing building and produces a point cloud for an accurate digital model of the existing home and could be used for an exact digital interpretation of each home. The design will then be able to be adapted appropriately to each existing home. The approach also widens the strategy to existing homes beyond the scope of the state house. 

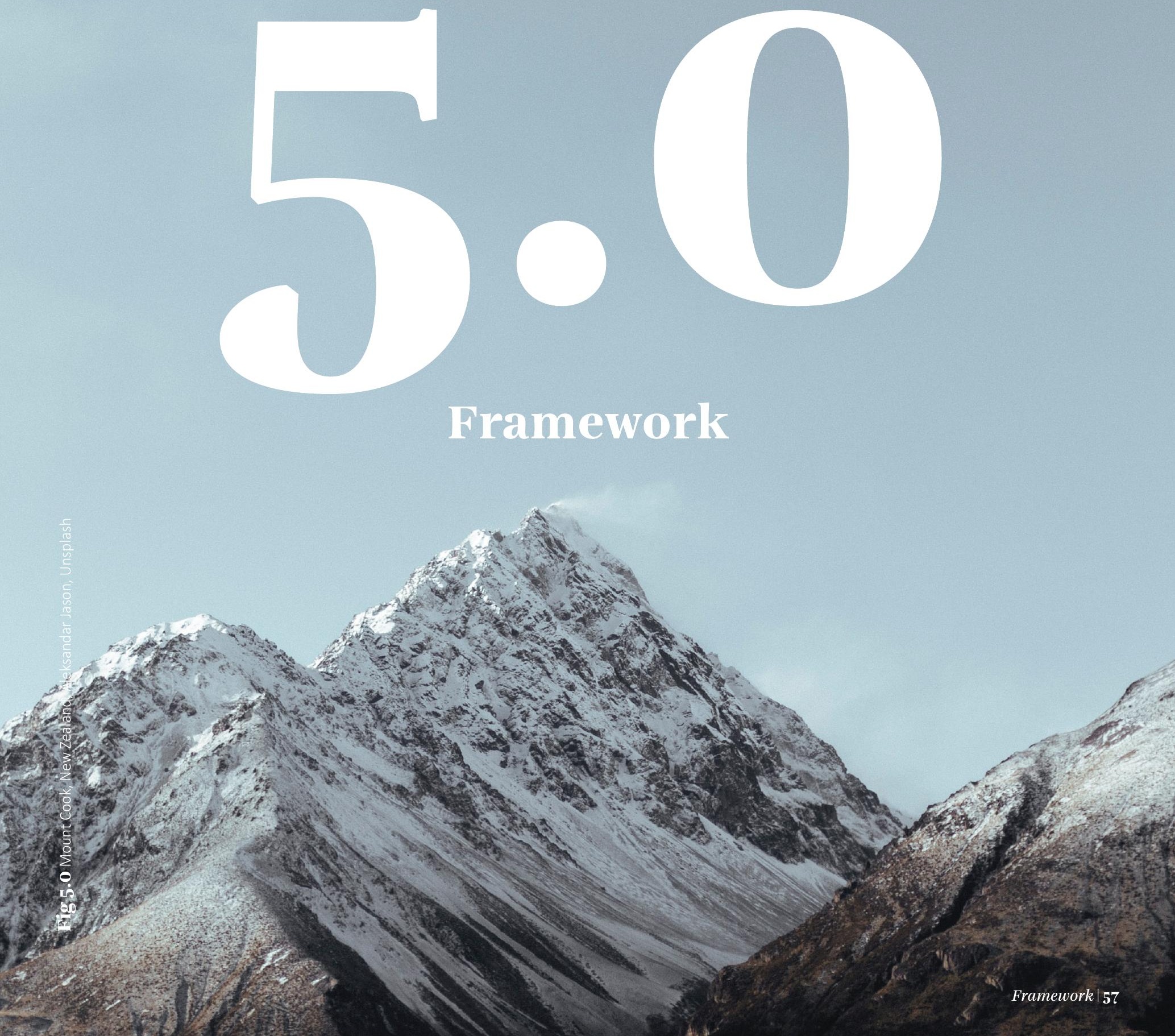


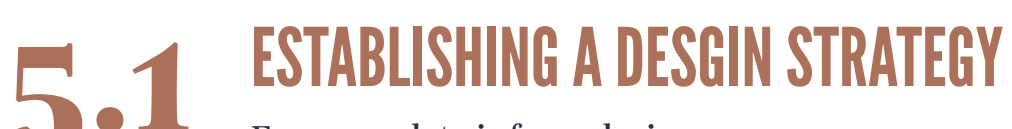 \\ Framework to inform design}

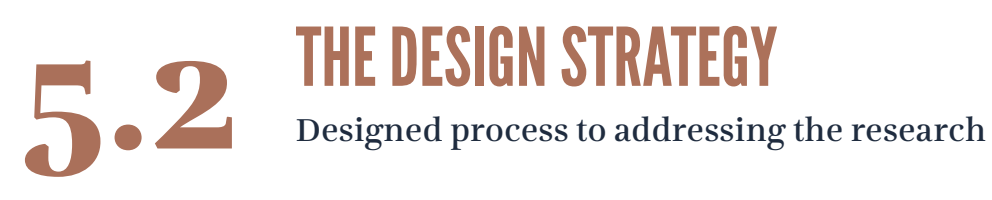

$5 \cdot 3$ SUPPORTIVE FINDDNGS \& ANALIYISIS 


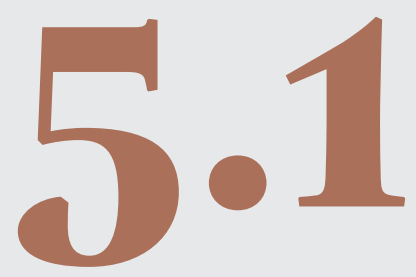

Establishing

a Design

strategy 


\section{Establishing a Design Strategy}

The following chapter fulfils the objective: Propose a design strategy for inefficient 1940s-1960s housing in New Zealand to increase the home's thermal performance without occupant displacement.

The chapter establishes a framework to inform a design strategy process addressing the existing housing occupant environment. The framework sets limitations to direct the design process.

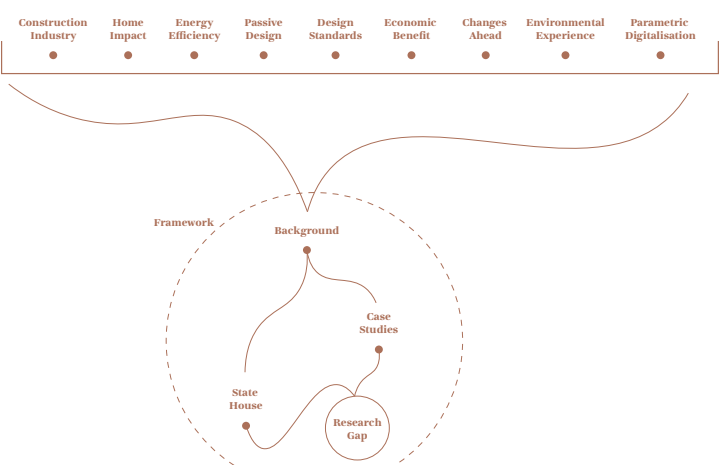

Fig 5.1 Establishing a framework - part 1 of Methodology 


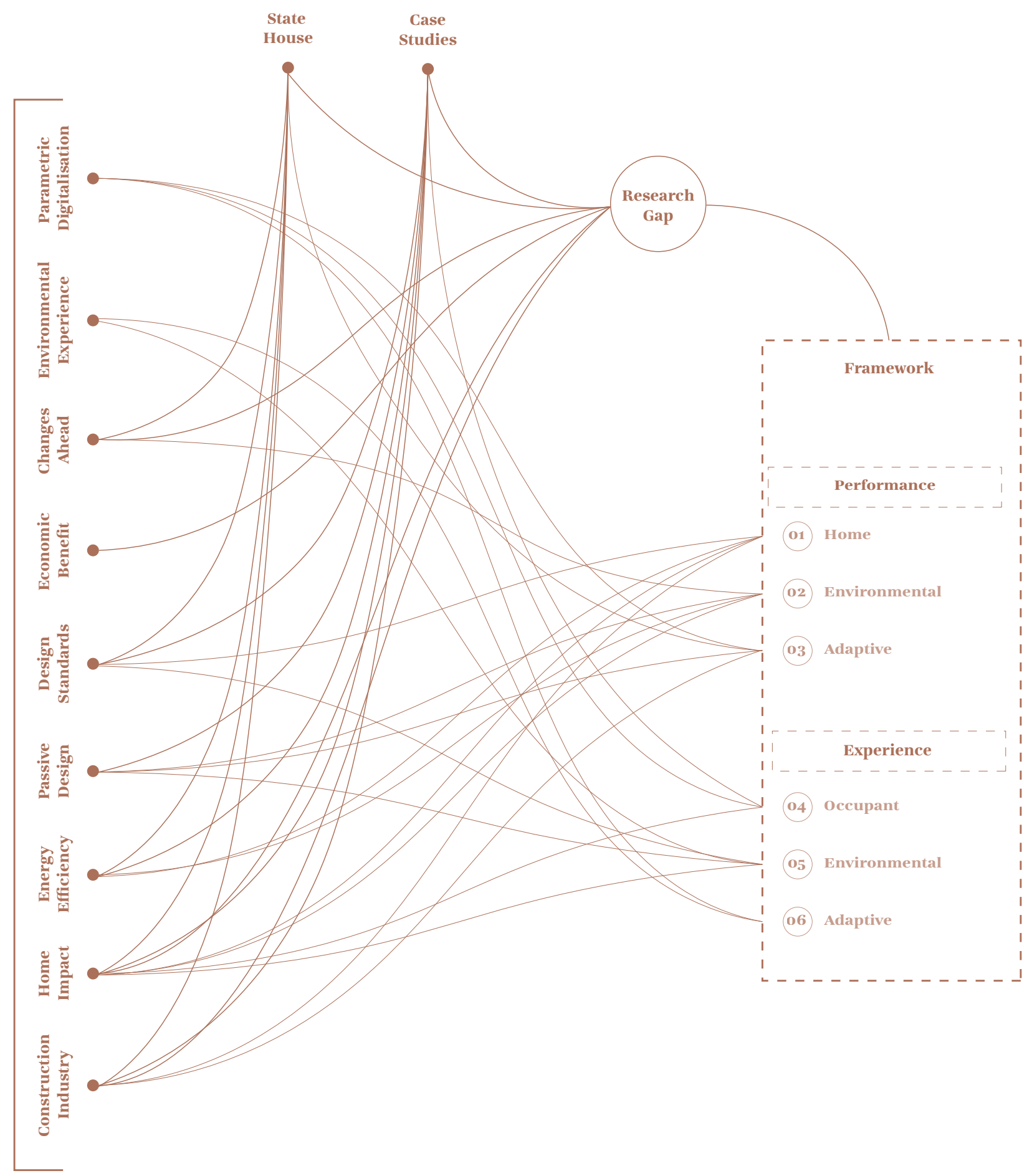

Fig 5.2 Diagram establishing the framework informing the design strategy 


\section{Framework}

\section{Performance}

1.0 Home Performance
1.1 High thermal performance design principles
1.2 Continuous envelope
1.3 Limit thermal bridging

\subsection{Environmental Performance}

2.1 Use the existing housing resource

2.2 Passive design techniques

\subsection{Adaptive Performance}

3.1 Adaption relative to site and environment

3.2 Optimise and streamline design, construction and strategy process

3.3 Optimise material use and fabrication methods

\section{Experience}

4.0 Occupant Experience

4.1 No occupant displacement

4.2 Limit disruption on-site

4.3 Respond to client brief
5.0

\section{Environmental Experience}

5.1 Functional program

5.2 Encourage the human-nature relationship

\subsection{Adaptive Experience}

6.1 Aesthetic design diversity

6.2 Occupant program brief

Fig 5.3 Diagram of design framework informing the 


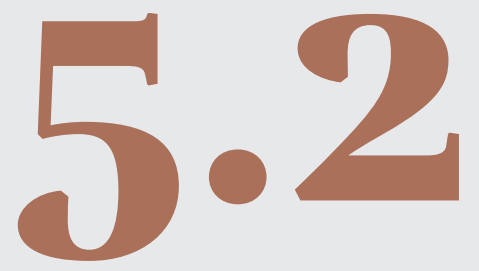

The

Design

Strategy. 


\section{The Design Strategy}

The design strategy is a process designed to radically improve the thermal performance of existing New Zealand houses to enrich peoples home experience in response to the research question.

Fig 5.4 The design strategy process diagram 


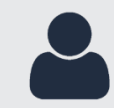

OCCUPANT NEED FOR

HOME UPGRADE

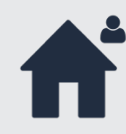

OCCUPANT BEHAVIOURS

\& APPLIANCES

$\ominus$

OCCUPANT
SELECTIONS

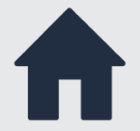

EXISTING HOME II

POOR CONDITION

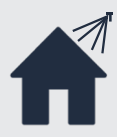

UNDERSTANDIUG

\& ANALYYSIS

n

파.

R. REFNEBASE STRATEG

AS APPROPRIATE

\section{E}

PARAMETERS ADAPTED

- OUUSE, CUNIEXT

OCCUPANT

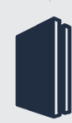

PROGRAM DESIGI

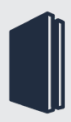

BASE PERFOMANCE

\section{(1) III}

STRATEGY

COMPOSITION

APPLIED TO HOME

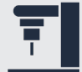

CONSTRUCTION \&

PREFABRICATION

亩

CONSTRUCTION 
OCCUPANT

ESTABLISH 1.0

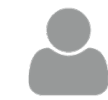

OCCUPANT NEED FO

HOME UPGRADE

INITIAL ANALYSIS 2.0

Existing energy use behaviours

Home appliance efficiency identify upgrade area

OCCUPANT BEHAVIO
APPLIANCES
INDEPENDENT SELECTIONS 3.0
Program $\mathscr{F}$ use
Materials
Design aesthetic
Level of intervention

INDEPENDENT OUTPUT $\quad 5.0$

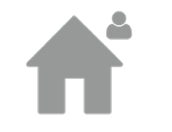

EXISTING HOUSE

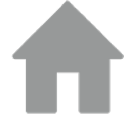

EXISTING HOME IN

POOR CONDITION

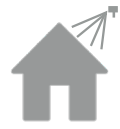

UNDERSTANDING

\& ANALYSIS
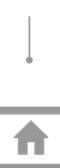

INTERPRET DATA \& REFINE BASE STRATEGY

AS APPROPRIATE
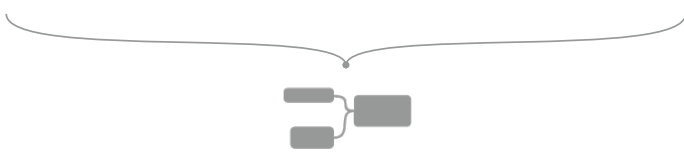

\subsection{APPLYSELECTIONS}

The base strategy selections made through the Grasshopper parametric script $\mathrm{c} 0$ applied to the

PARAMETERS ADAPTED

- HOUSE, CONTEXT \&

\section{OCCUPANT}

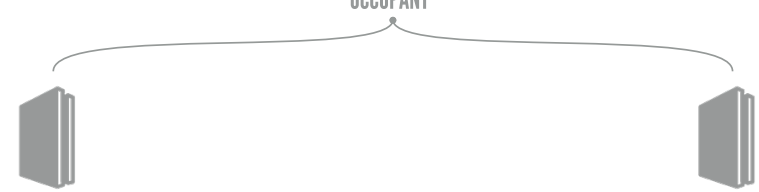

51 INDEPENDENT OUTPUT

3 D Scan

mic analysis

Site conditions

3.1 INDEPENDENT SELECTIONS

Digital model from 3 D scan

Envelope control \& material

selection from hydrothermic, site and climate findings

tection of technical detail method

from library of developed details

responding to varying housing ypologies home

Fig 5.5 Further detail of the design strategy concept

PROGRAM DESIGN

BASE PERFOMANCE

DESIGN

6.0 HOME APPLICATION

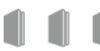

STRATEGY

COMPOSITION

APPLIED TO HOME

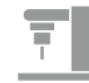

7.0 CONSTRUCTION \& PREFABRICATION

Prefabrication of panel units to

be installed onsite

CNC cut as appropriate $\mathcal{B}$

CONSTRUCTION \& off-site construction for control

PREFABRICATION gains

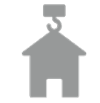

ON-SITE CONSTRUCTION

\subsection{ON-SITE CONSTRUCTION}

As per squencing strategy to manage on-site occupant disruption

Energy module install

On-site time

Application to existing 
OCCUPANT

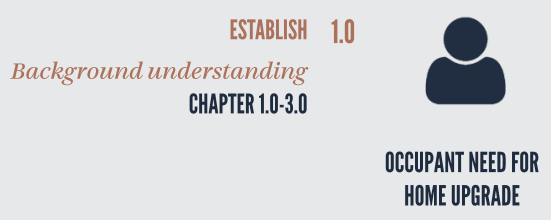

Concept designs of potential

program components

CHAPTER 8.0

HOME UPGRADE

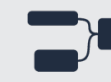

- HOUSE, CONTEXT \&

OCCUPANT
PARAMETERS ADAPTED
EXISTING HOUSE

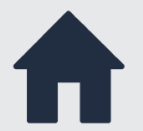

1.1 ESTABLISH

Background understanding CHAPTER 1.0-4.0

EXISTING HOME IN

POOR CONDITION

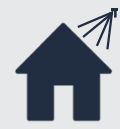

UNDERSTANDING

\& ANALYSIS
2.1 INITIAL ANALYYSIS

Develop base house

understanding to inform initial

concept

CHAPTER 4.0
4.0 APPLY SELECTIONS

Develop an adaptable parametric script for house and program

variation

CHAPTER 9.0

5.1 INDEPENDENT OUTPUT

Concept design of base component CHAPTER 7.0

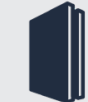

BASE PERFOMANCE

Fig 5.6

$\begin{array}{ll}8.0 & \begin{array}{l}\text { ON-SITE CONSTRUCTION } \\ \text { Base component design } \\ \text { sequencing } \\ \text { CHAPTER 7.0 }\end{array} \\ \text { ON-SITE } & \end{array}$




\section{Critical Reflections}

- The design strategy was the design of a process to improve the thermal performance of homes for an enriched home experience.

- The theoretical process was established from research and design exploration, therefore it is expected that the strategy process would evolve with further development.

- Each step of the process would need to be designed, tested and developed. For the scope of the thesis components within the strategy process were explored to test possible design experience and performance outcomes and propose a visual output of the strategy.

- The key components of the strategy for further development within the thesis research are the base component, program component and the adaption component. 
Design Process

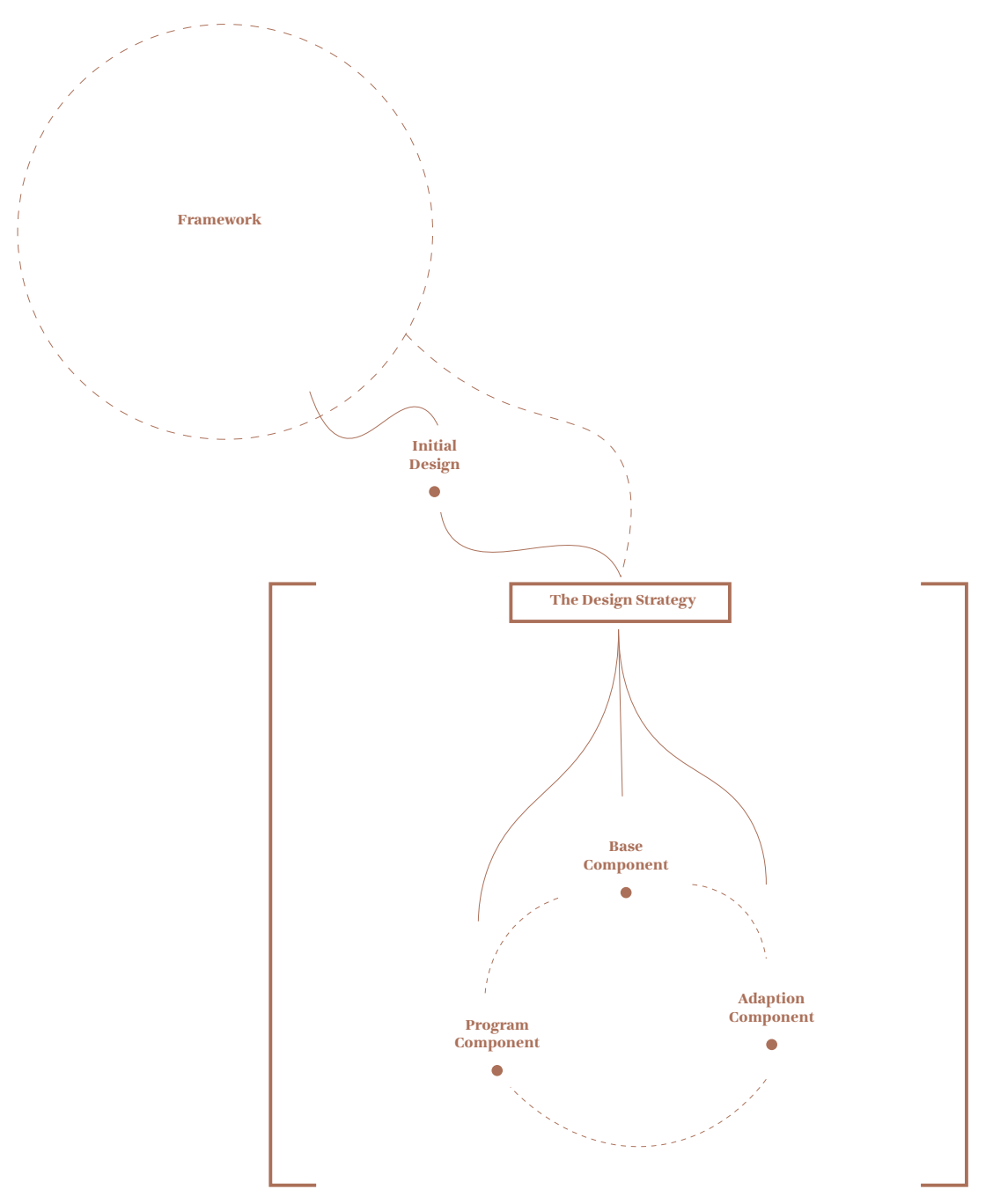

Fig 5.7 Design process method to investigate the design 
The following section assesses further relavant background research (Chapter 2.0) to identify further findings to support the use of the framework and inform design research.

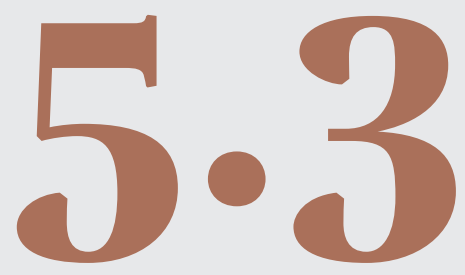

\section{Supportive Findings $\mathbb{E}$ Analysis}




\section{Design standards}

Various design standards exist for design well beyond the New Zealand standard to aim toward sustainable design, net-zero energy, and occupant comfort. Key guidelines relevant for retrofitting existing homes are;

- EnerPHit - The Passive House guidelines appropriate for existing homes. The variation of design amongst existing buildings provides more significant thermal efficiency challenges, particularly around managing thermal bridging around existing construction components (Passive House Institute, 2015b). Very highperformance standards and effective design principles to follow. However, more labour intensive to design and test for the high standards, but the effort would be worthwhile once a series of solutions for the existing housing typologies developed.

- eHaus Pacific - Design guidelines tailored to follow PassivHaus principles for New Zealand homes to a lower performance standard. The guidelines do not achieve net-zero energy but support a lower-cost alternative for a home performance similar to Passive House (eHaus, 2019). A more achievable standard compared to Enerphit for New Zealand, however, therefore less efficient overall.

- Homestar - Design tool to measure the health, warmth and efficiency of New Zealand homes specific for the local conditions (NZGBC, 2020).
Inspired by higher international standards, Homestar provides a rating scale to measure how well the home achieves the criteria. An approach less rigid than the higher Passive House standards, more achievable but less effective.

- Living Building Challenge - A holistic design framework to enhance the relationship between people, community and nature to reconnect, restore and generate the living world. The green standard aims for the designed built environment to sustainably create positive environmental impacts. The positive environmental impact is to improve the surrounding environment, social equity, biodiversity, climate, culture and place (International Living Future Institute, 2019). The framework follows excellent holistic imperatives to drive the design and requires a rigorous design to fully achieve all imperatives. If the design were to be developed to detail in the future, a very effective design strategy to New Zealand homes could be produced.

The standards establish a relevant and appropriate framework for the design strategy (Figure 5.3). 
Passiv Haus Pinciples ( 5 basic principles) (Passive House

EnerPHIT

(5 basic principles) (Passive House

Homestar

(7 Categories)

(NZGBC, 2020)

eHaus Pacific

(eHaus, 2019).

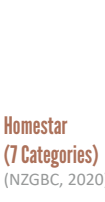

Living Building Challenge (7 Petals, 20 Imperatives) (International Living

Future Institute, 2019).

\section{Thermal insulation}

Thermal bridge free design

Airtightness

Passive House windows

Ventilation with heat recovery

Efficient heat generation

Renewable energy sources

NZ eHaus windows \& doors

Density \& Resource Efficiency

Energy, Health \& Comfort

Water

Waste

Management

Materials

Site

Innovation

Place - Ecology; urban agriculture; habitat; human living

Water - Use; net positive

Energy - Net positive; energy \& carbon reduction

Health \& Happiness - Indoor environment; performance; access to nature

Materials - Responsible; net positive waste; sourcing

Equity - Inclusion; Universal access

Beauty - Eduction \& inspiration; Beauty \& Biophilia
Design of strategy to insulate 8 manage heat loss existing

Design of strategy to reduce existing thermal bridging

BASE STRATEGY DESIGN

Design of strategy to increase existing airtightness

Replace existing with highe performing windows

Integrate into overall strategy, beyond design scope of thesis

Heat generation as appropriate for overall strategy, outside design scope Integrate into strategy as appropriate, outside design scope

Replace existing with higher performing windows

Use of existing housing stock

Thermal envelope design to reduce energy, impact health $\&$ comfor

Water efficient fittings ơ design, outside thesis scope

Construction waste, strategy design to optimise fabrication to limit waste

Safety of site of construction, prefab allows control, beyond research scope Responsible selection for lowered environmental impact

Ecological enhancement opportunity for program

Initiative to reduce environmental impact by using existing resource

Connection ơ relation to natural environment program opportunity

Realign value of water use and energy outside thesis scope

Renewable energy source, reduce energy demand by improving existing

Spaces for species to thrive, improve indoor of program design opportunity

Ecologically restorative $\mathcal{G}$ transparent, limit investigation for research scope

Design for all inclusion, supporting life ơ richness

Need for beauty \& connection between people \& nature

Fig 5.8 Diagram findings of influenticial higher performing design standards benefitial for home and occupant to inforn design 


\section{Passive Design}

Well insulated \& airtight to optimise internal heat gains

Minimise heat transfer through glazing

Use of low mass, tightly sealed, well insulated construction

Orientate glazing North (with overhangs for excess summer exsposure) for passive solar heating gain

Lower night indoor comfort temperature to reduce energy consumption

Extend outdoor living area with sunny wind-protected outdoor spaces

High mass interior surfaces to store winter passive heat \& summer coolth

Optimise floorplan, north windows and roof wind protection

Optimise floor area to avoid excessive heating and cooling

Vented attic over well insulated ceiling

Additional insulation for consistent indoor temperature

Tree planting to not shade \& restrict passive solar gain to windows

Form of ventilation \& heat recovery for indoor air quality

Garage \& storage location on coldest wind side to help insulate

Insulating curtains for night time heat loss

Exterior wind breaks and planting for protection from cold
Design of strategy to insulate and manage heat loss existing

Replace existing windows for higher performing

Material selection \& construction method of strategy

Glazing orientation limited by

existing building design, shading design opportunities for wall program as appropriate

Impact of occupant behaviour education and stragey for home, beyond design scope

Opportunity for the design of wall program to use the design strategy to enhance existing living area $\mathrm{o}$ experience

Interior design $\mathcal{F}$ material selection of existing outside scope of research

Floorplan, window location and roof form to be as existing

Floor area to be as existing
BASE STRATEGY DESIGN

PROGRAM DESIGN
Internal ceiling insulation to be integrated into design strategy

High insulation standard for occupan comfort and health

Consider impact of program selection and integration of vegetation

Increase in airtightness will require addition of heat recovery ventilation system for air quality \& occupant comfor

Locate program storage on South side of building where appropriate to site

New internal window dressings to reduce heat loss, beyond project scope

Opportunity for wall program to

strategically improve cold wind impact on home 


\section{Environmental Experience}

Visual Connection with Nature

Non-Visual Connection with Nature

Non-Rhythmic Sensory Stimuli

Thermal \& Airflow Variability

Presence of Water

Dynamic \& Diffuse Light

Connection with Natural Systems

Biomorphic Forms \& Patterns

Material Connection with Nature

Complexity \& Order

Prospect

Refuge

Mystery

Risk/Peril
View of nature $\mathfrak{G}$ living

Senses connection - sound, smell, touch, taste

Non-rhythmic light, sound, experiences

Mimic nature

See, hear or touch

Varying light \& shadow

Seasonal and temporary changes

Patterns \&̊ textures

PLAY

Climb

Store

Processing, local ecology $\mathfrak{G}$ geology

Bar

Sensory information similar to nature order

View over distance

Retreat place - protected from behind and overhead

SUSTAIN

Partial obscurity to entice or sensory stimulation

Vegetation

Table

Cook

Fig 5.10 
03

Good Health $\mathcal{E}$

Well-being

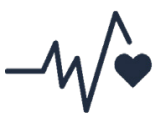

Focus on improving the health \& well-being for occupants

09

Industry, Innovation $\mathcal{G}$ Infrastructure

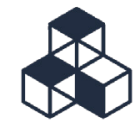

Innovation toward designing with existing resources to reduce construction climate impacts.

(13)

Climate Action

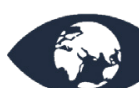

Strategy design to high

performance standard resulting

in reduced energy use and

emissions

Material selections, reuse and

circular economy to strategy

to existing building optimising

existing resources

\section{7}

Affordable $\mathcal{E}$ Clean Energy

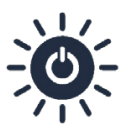

Overall design strategy for net-zero energy use in home,

proposed for strategy but beyond research scope.

Evaluation \& education for

occupant behaviour to support

passive home design

$$
\text { (11) }
$$

Sustainable Cities $\mathcal{E}$ Communities

\section{解画}

Strategy design toward a long term adaptable and circular

strategy to support the long-term sustainability of communities.

(15)

Life on Land

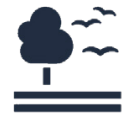

Responsible material selection and construction methods

Enhance biodiversity of

environment through integration

of natural resources to support
08

Decent Work \&

Economic Growth

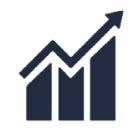

Home improvement creating

jobs and supporting economy. Encourage skills, learning and ownership through potential training scheme opportunities within strategy to address complex socio-economic issues.

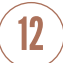

Responsible Consumption $\mathrm{f}$ Production

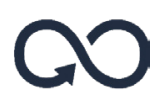

Use of existing \& available resources to reduce waste Overall goal to work strategy toward circular economy principles, material selections and reuse but beyond scope of thesis

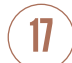

Partnership for the Goals

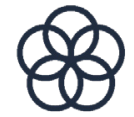

Build upon international strengths and unite rather than reinvent.

Value of overall strategy but outside of thesis scope

Fig 5.11 Assessment of th design research strategy in response to the 9 Sustainable Development Goals, Author's image with icons adapted from World Green Building Council Sustainable Development 


\section{Concept Business Model}

Fig 5.12 The following two page diagram frames the design

strategy within the concept business model inspired by Ash Maurya's

Problem

Solution

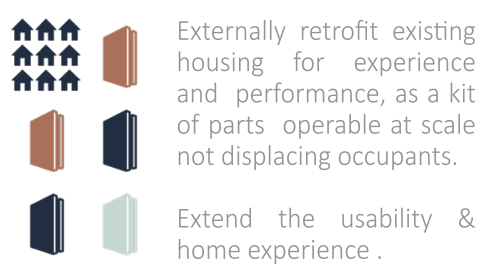

hint

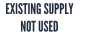

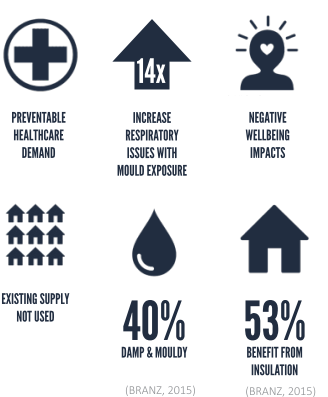

(5s) (b) ims

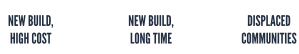

$x$ :3)

$39 \%$ MefFelers

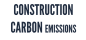

Existing

Alternatives

Retrofit (displacing occupants) Demolition \& Rebuild

Ân

(3) Global:

External wall \& roof retrofits for net zero energy
Strategy applied \& operating at scale to NZ homes

Key Metrics

High-level

Concept

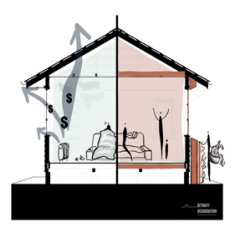

Home revitalisation for experience \& performance 


\section{Unfair Advantage}

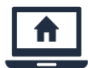

.

Parametric design for home

Prefabrication - limit cost, site 产 time, material use
Customer Segments

Homeowners, Landlords, HUD,
Kāinga Ora
( $)$ Net zero carbon

(4): Net zero energy

\section{Cost Structure}

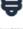

\section{Channels}

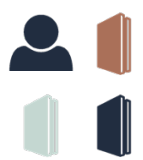

Understanding occupant needs \& responding with a functional \& beautiful architectural strategy

\section{Early Adopters}

Detached (or semi-detached)
existing housing, poorly
insulated resulting in
unhealthy \& undesirable living
conditions

\section{Revenue Streams}

Energy savings as a result of
improved performance from
achieving net zero energy

(\$\$) Maintenance budget 


\section{BASE EXPLORATION}

Approaches to the envelope \& base strategy

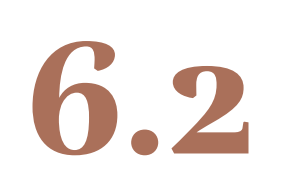

\section{RESPONSIVE EXPLORATION}

Future thinking of materials, construction \&o performance influence on design using digital tools

\section{3}

\section{INTEGRATED EXPLORATION}

Holistic $\&$ wider impact opportunity of strategy to regenerate $\&$ revitalise 
The following chapter researches an initial design exploration to invesitigate how the thermal performance of existing New Zealand houses could be radically improved to enrich peoples home experience. The initial background research and subsequent framework formed a base for a wide design exploration.

The initial designs explored three key areas of possible focus for the research:

- The Base Exploration looked at the base strategy approach and how to address the envelope itself for the broad concept at a pragmatic level.

- The Advanced Exploration looked at addressing the problem beyond current material, construction and technology abilities. It used the poor performing home to influence and inform the design using digital tools and proposing future possibilities.

- The Holistic Exploration looked at the holistic and wider opportunity for impact through the strategy. The possibility to use the design strategy to regenerate life, health and wellbeing for people not limited to ecology, biophilia, choice, community, environmental regeneration, and adaptability.

The breadth of the exploration opened many design opportunities to then be critiqued for direction, scope and further refinement of the strategy. 


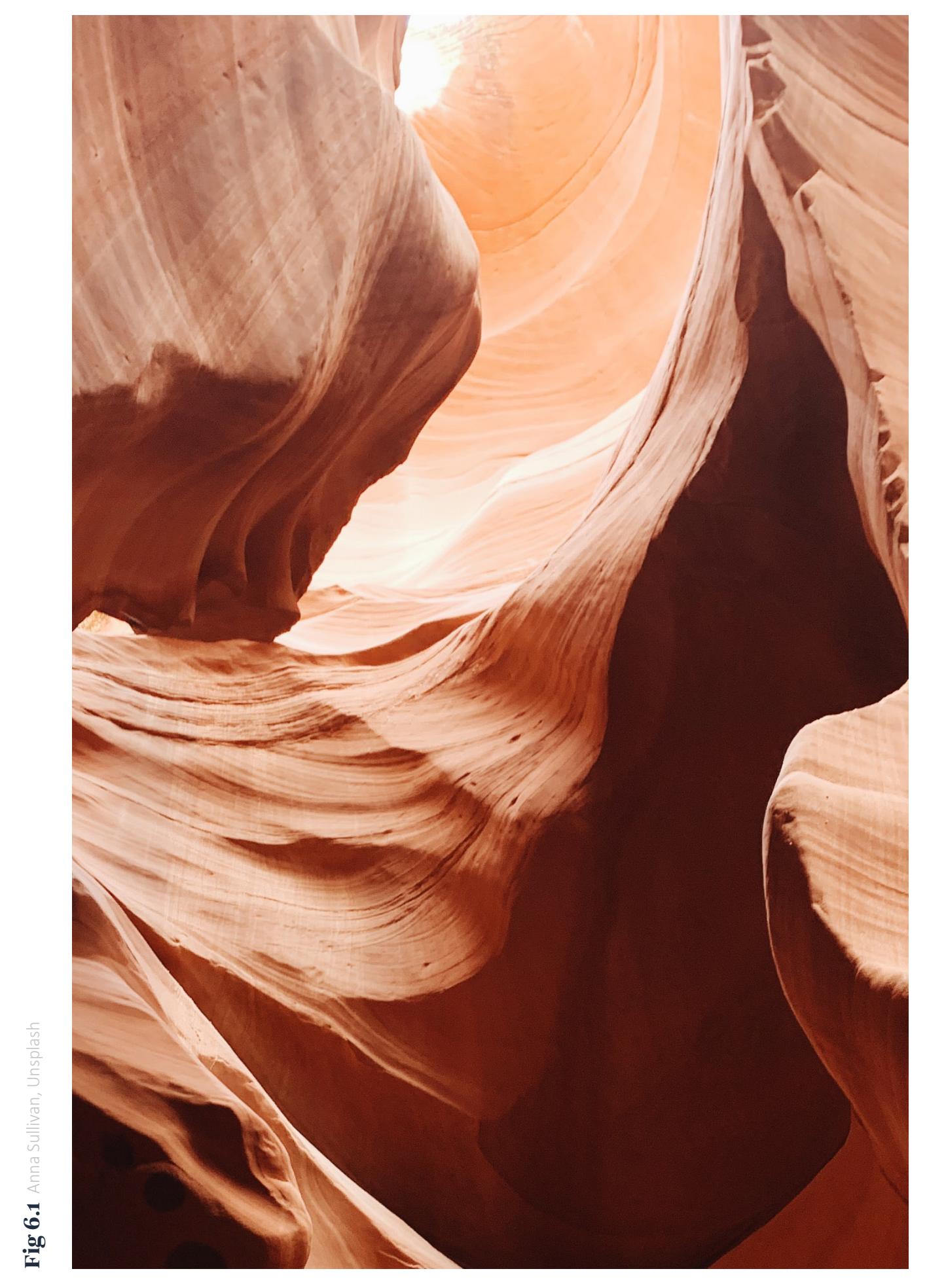




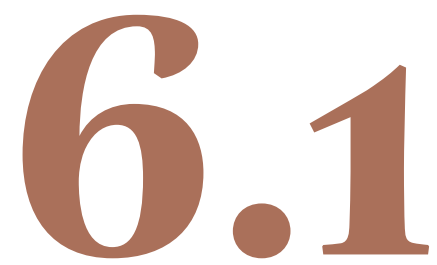

Base Exploration 

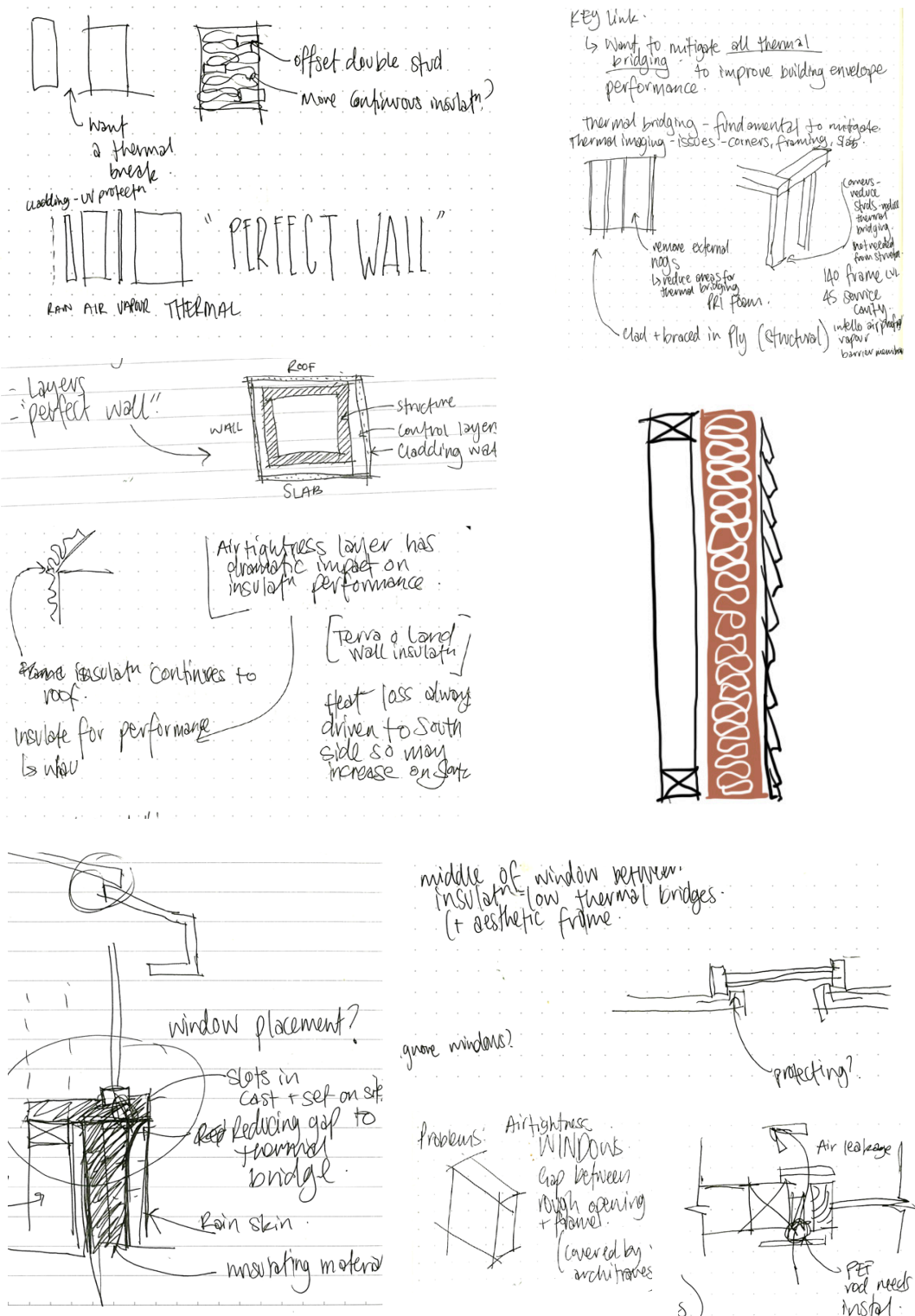

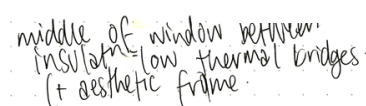
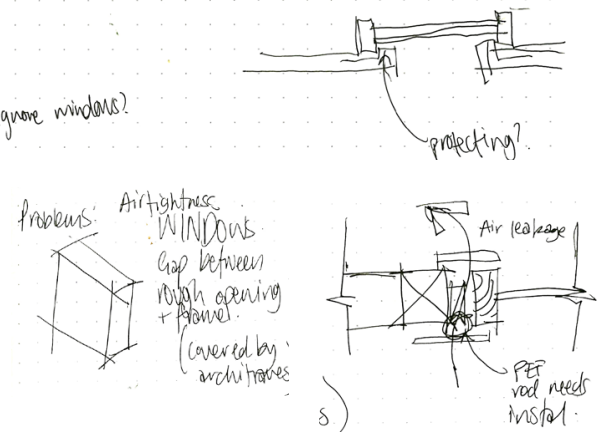

j)

rod needs

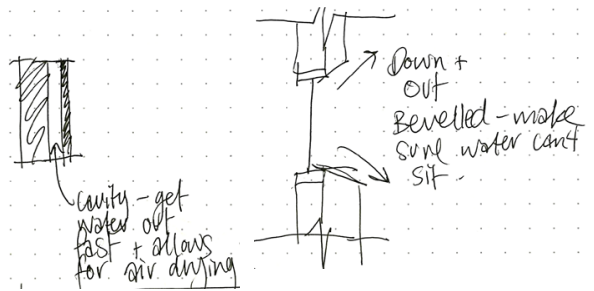

Add seal to gap

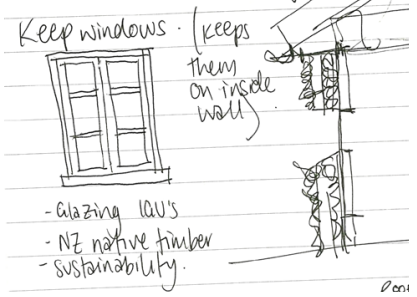

Fig 6.2 Base exploration concepts 


\title{
Base Exploration
}

\author{
The base exploration explored the external envelope \\ for the initial approach to retrofit without displacing \\ the occupants. \\ The passive design learnings, control layer design \\ principles, case studies and existing home learnings \\ influenced the external wall design. The design \\ process began to outline key issue areas of a \\ continuous envelope and detailing around the eaves \\ and windows. The following process of strategies \\ addresses a continuous external envelope.
}




\section{Continuous Envelope}
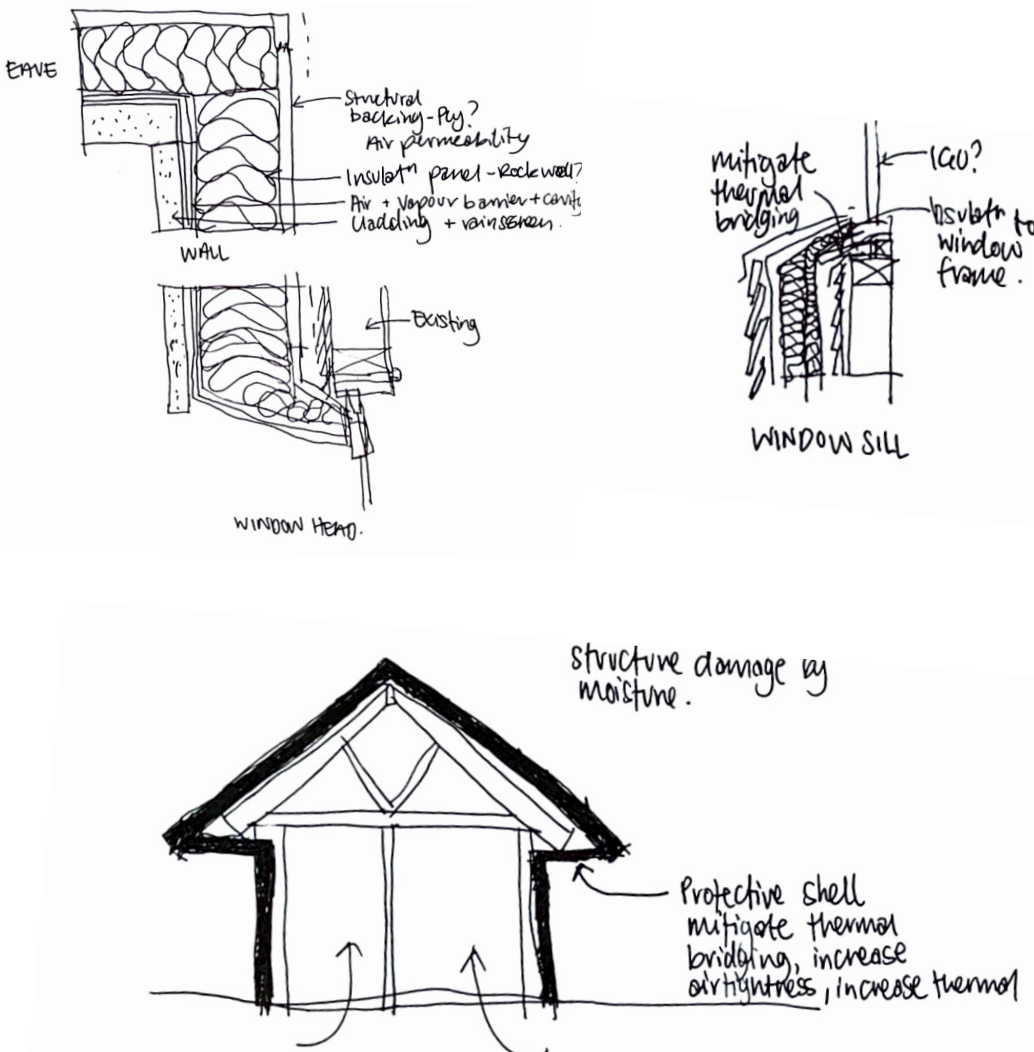

Pro's - Chamgein house around maisture?

- Control on thermal deaging do too?

insulaten tairtiontuess pigy,

- Adaptoble to hutuess Scope-would be arrea to

housing to multiple

con's

move material?

(Tonule in house identity consider further.

- for sake of desigen

limit to voof t walls?

Fig 6.3 Continuous envelope design process 


\section{Critical Reflections \& Findings}

The concept investigated a continuous envelope around the existing home through a fully external strategy. The result would be a new shell for the home.

\section{Advantages:}

- Creates opportunity for upgrading home appearance.

- Allows more streamlined connectivity between control layers of the new system around the existing home.

- The system could be prefabricated and installed on site with limited disruption to occupants.

- The strategy could be more easily adapted to differing housing types.

\section{Disadvantages:}

- May require uneccessary additional materials to encase the home resulting in a higher financial and carbon cost.

- The eaves region could be problematic with connection to the window.

- The state home design often involves the windows extending to the eaves and therefore there is likely to be insufficient space above the window for an external system. Part of the eave lining could be removed to create required space for the system.

\section{Findings:}

- Further development could explore removing the eave to gain appropriate clearance above the windows for more wall design opportunity. 


\section{B2}

\section{Remove Eaves}

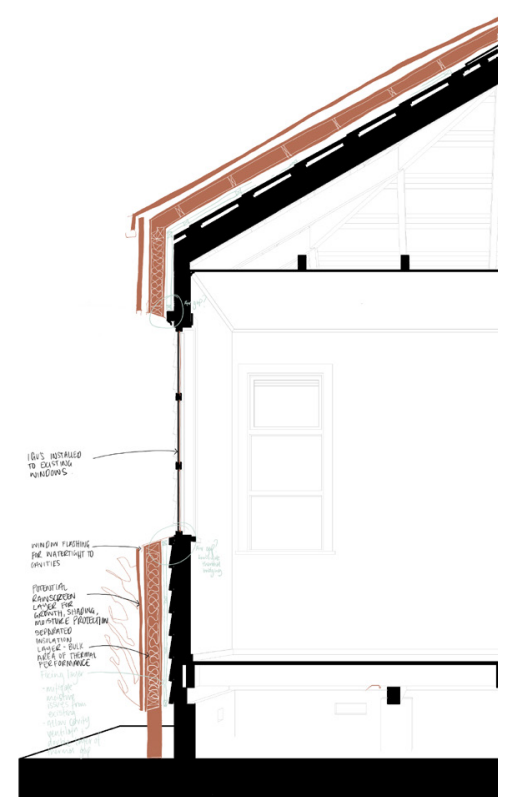

Approach - Remove eanes to create

a continuous thick blanket

to walls + roof

- Wall loyer system brild up

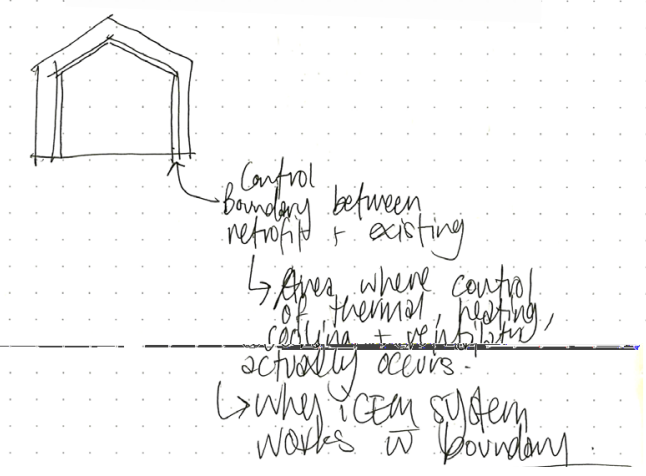

Fig 6.4 Eave removal design process
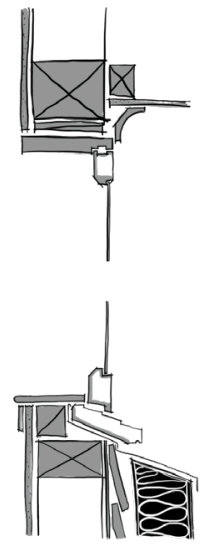

-SIP Style Pand?
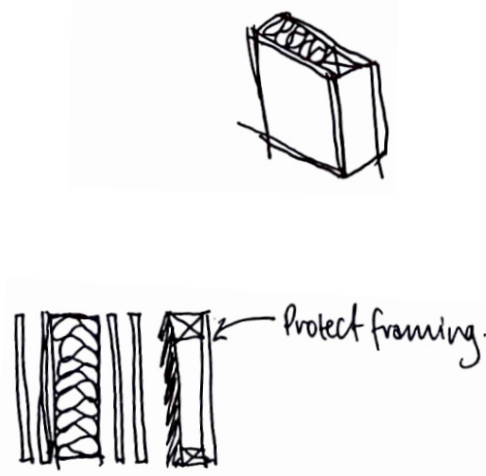

control layer

system

continous

to wallst roof 


\section{Critical Reflections \& Findings}

\author{
The general concept explores a continuous envelope \\ around the existing home by removing the eaves \\ overhang to control the connections of the external \\ strategy. The removal of the eave overhang mitigates \\ the issues identified in B1 and B3 where control of \\ moisture, penetration and sufficient space above \\ windows could be controlled for a continuous \\ envelope.
}

\section{Advantages:}

- Continuous connectivity between the roof and wall control layers.

- $\quad$ Space gained above the window allows sufficient space for the insulating system to be installed.

- Creates opportunity for upgrading home appearance.

- Adaptable design for differing housing types.

- The system could be prefabricated and installed on site with limited disruption to occupants.

\section{Disadvantages:}

- The approach would require more on-site time for eave overhang removal. Although, the time and cost may be compensated by increased installation efficiency of the design and prefabrication.

- The eave removal approach would change the appearance and give a new identity to the homes. It would move beyond the home identity, perhaps a step too far in revitalisation for communities or a welcomed renewal into the current day.

\section{Findings:}

- The concept is likely to require more work than necessary to achieve improved home thermal performance. 


\section{External Wall \& Internal Ceiling}
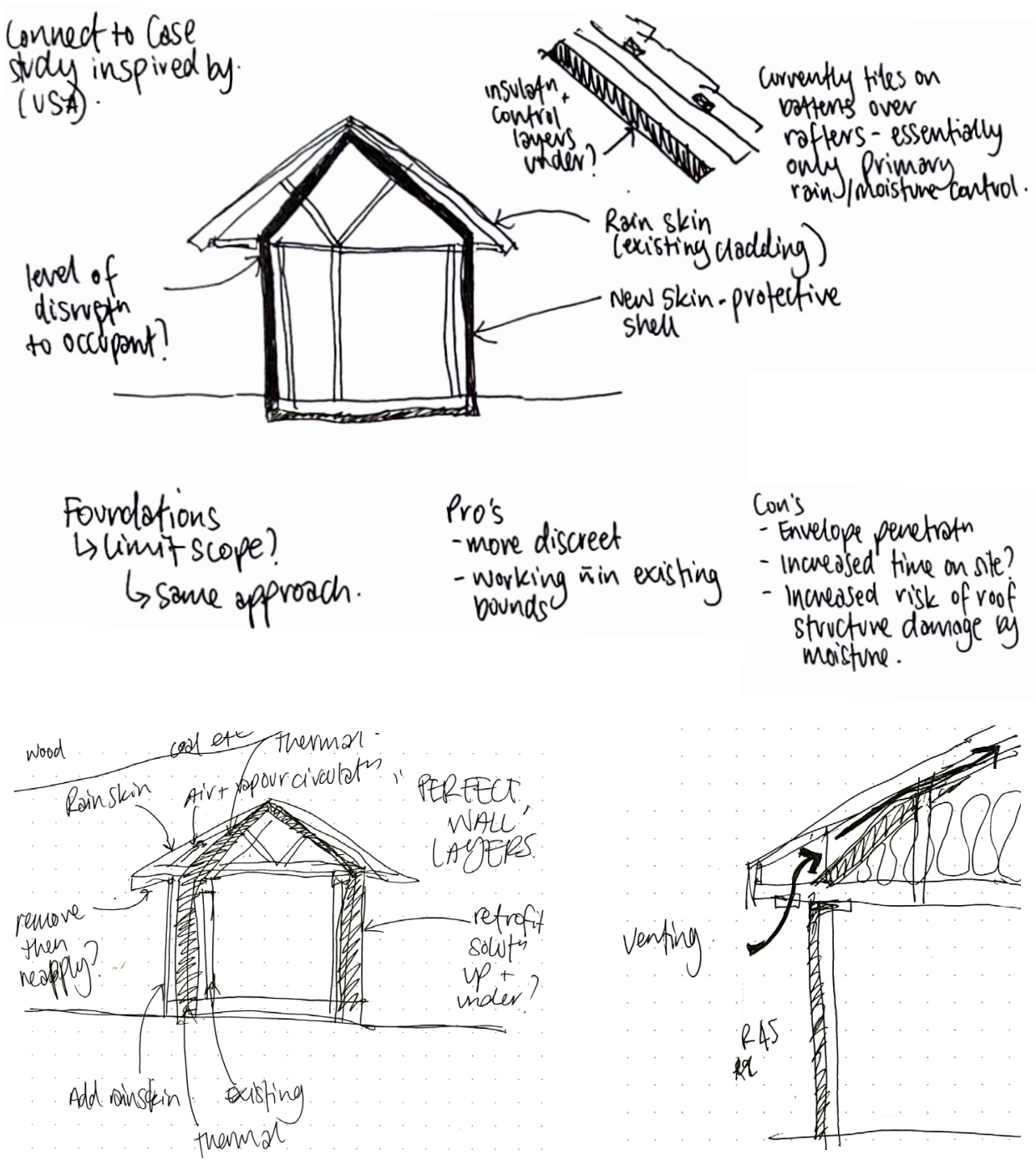

Fig 6.5 External wall and internal ceiling insulation design 


\section{Critical Reflections G Findings}

The concept explores a continuous envelope around the existing home through external wall and floor control layers and connect with internal control layers through the eaves to the underside the roof. The existing roof then would become a rain screen to the new control layer strategy. To result in a protective shell to the home.

\section{Advantages:}

- Continuous envelope above the ceiling, avoids ceiling lighting pentrations.

- Mitigate roof leakages and damages, essentially acting as a new roof barrier able to shed water down to the new walls to the exterior.

\section{Disadvantages:}

- Penetrates eaves to connect to the underside of the roof increasing onsite time, cost and occupant disruption. Additionally, a potential increased risk of roof structure damage by moisture.

- Installed beneath the roof line requiring more materials materials and more complicated installation due to the roof slope, to insulate the uninhabited ceiling cavity.

\section{Findings:}

- Further investigation to connect directly above the ceiling space while maintaining control layer connectivity, to reduce unnecessary excess material use. 


\section{B4}

\section{Detail Exploration}
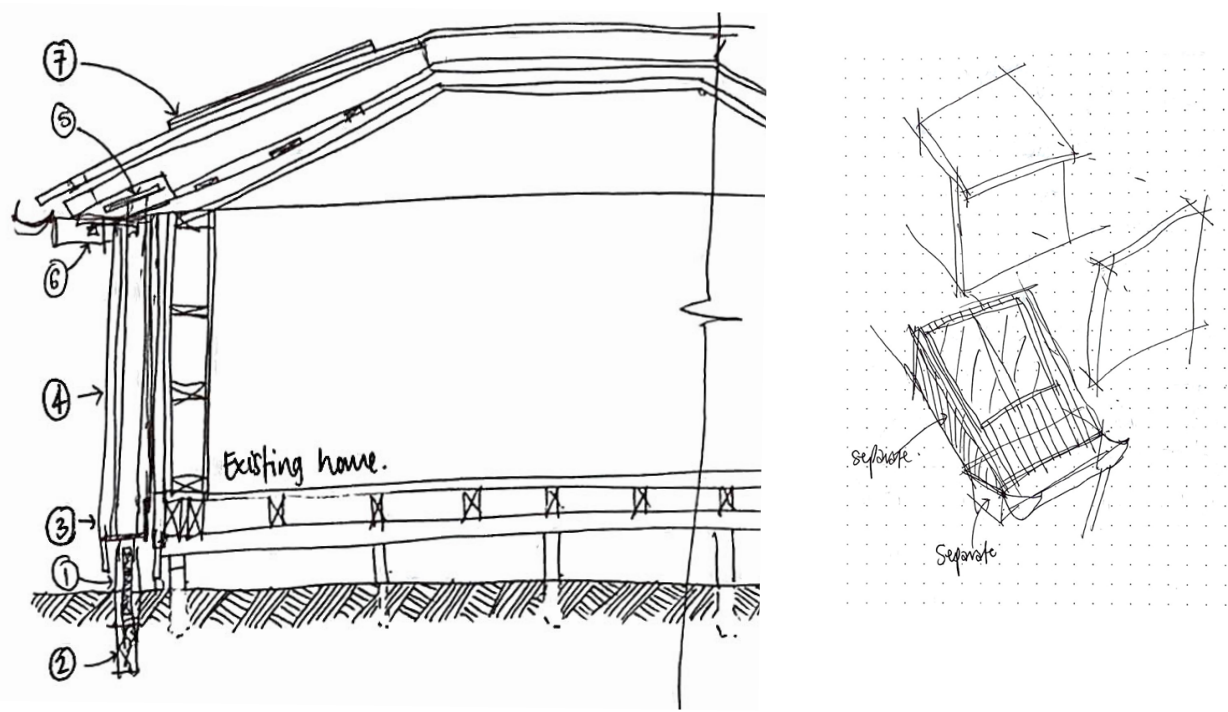

(1) Base woll support counecting to centrod support. sted type colimen slofting

$$
\text { Connection }
$$

(2) Foundation slot connection driven into ground.

lead type substence-Liquifties wi fricts. insbll wall + liquidfiction allows adjusturent (wind up syglem) before sefting once aligned.

(3) Bose of woll system overlaps

(4) Wall system - prefobricated to be instelled on sile in modules. wock system to connect together. Connect on corners supports.
(5) Top woll plate connecting roof support to colimn support. slot steel sustem w' same connelting longuage.

(6) Eave slot System, gutter, connect to central support system.

(7) Roof system- supported over existing roof batfens where appropriate, $\bar{w}$ new insulated panel system + po ponels (where appropriate).

(8) Capping corner system to streanline

Fig 6.6 The following sketches of the detail exploration design 

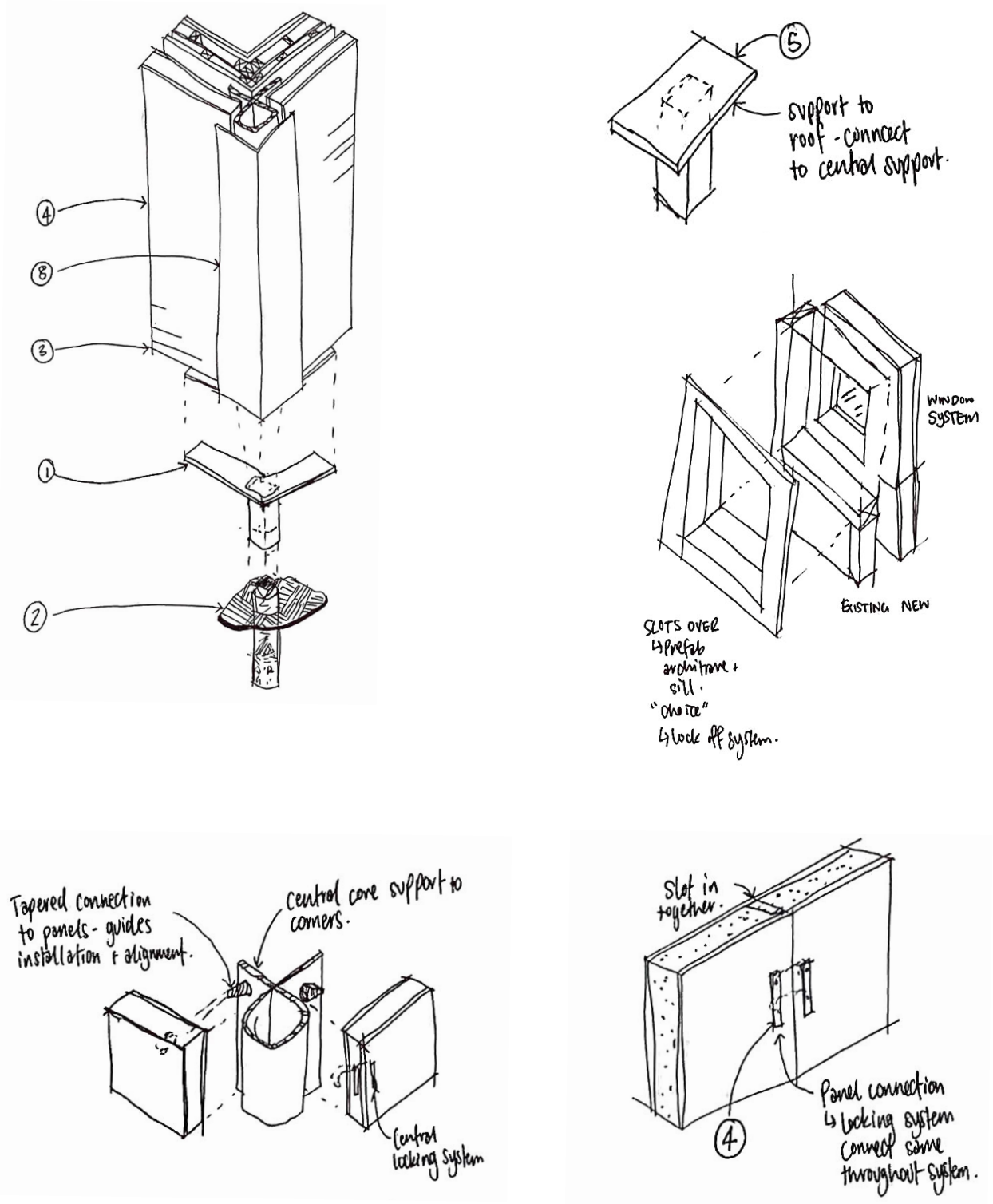


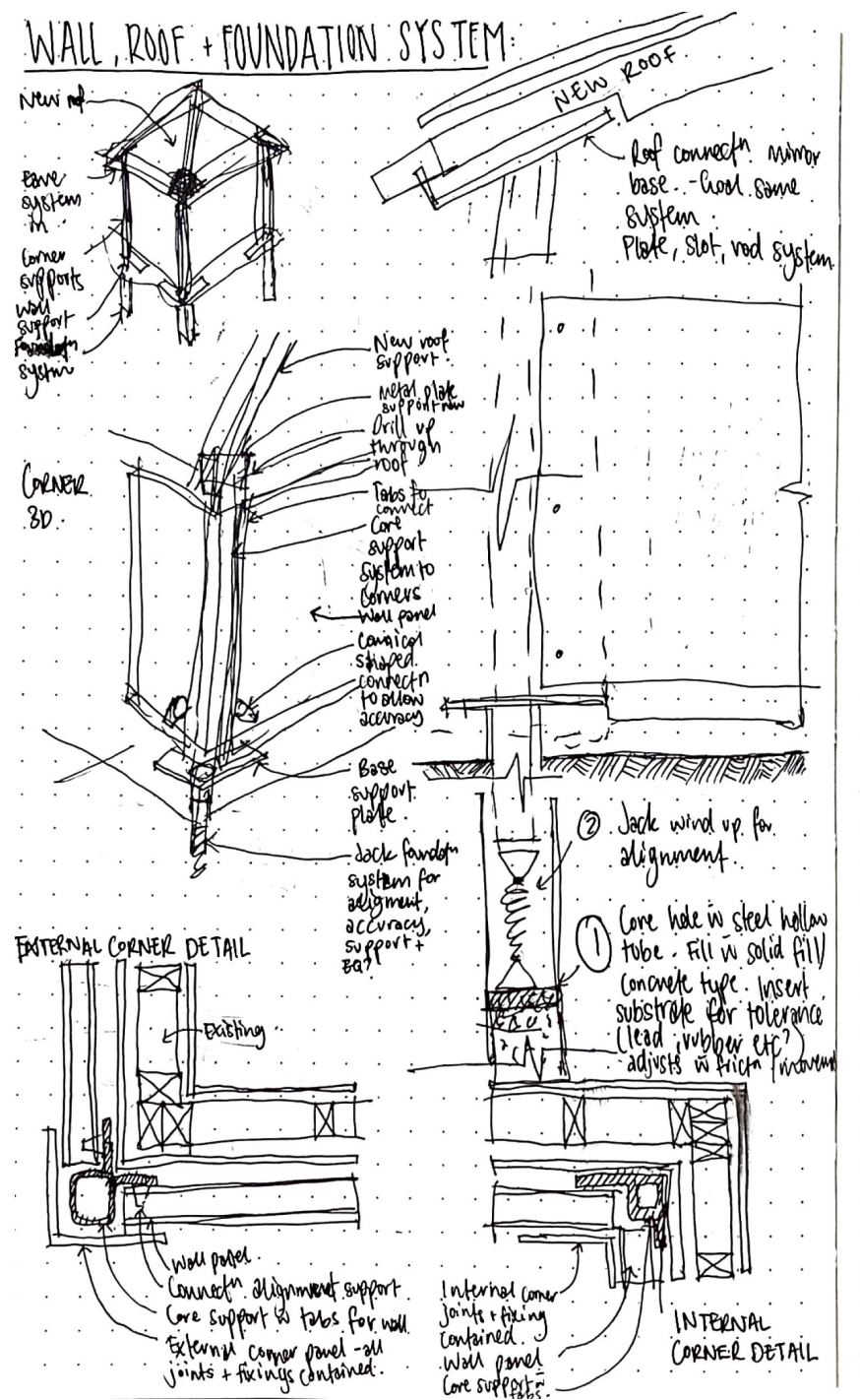

EXPLODED DIAGRAM

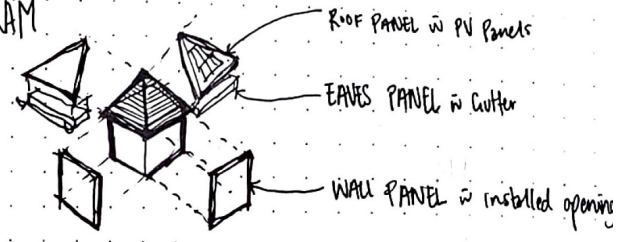

- lack sustem thwoughowt

Core support

cicerry roof

Li Gumen gravita loods

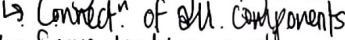

lo Same backing sustem

- Jack system - accuracent toleronce

$\rightarrow$ lead? type frictr adjustmant

for pok - wind vo then set once fricte of jade movement. has stopped.

$\triangle A$ AsO EQ impact? $\rightarrow$ Insfired by base ialat.
sustems.

G. Same wind up sustem.

- Connectr sustem to waslls.

4. From coore system.

4 overlap for cinternal. external corners.

L. Potentid-pottem lengrane? 4. Wreste panel corner Hifology 4. Connectin aligniment for

4. Wal base support to foundato

- Roof sustem to cone support.

h. over existing but load path to new support wolls ta found dt?

- Queval brocina to existing humse

design -Connected to existimg.

- Installan -crone adjustwent piele.

id:-1 Consistent system

structure-consistent

- stresulined
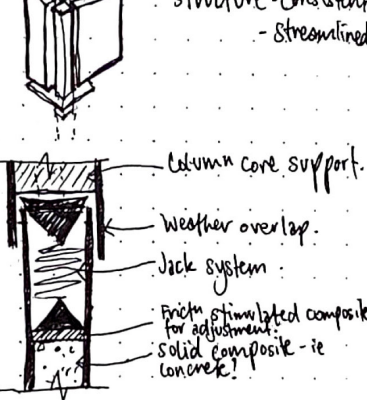


\section{Critical Reflections G Findings}

The detail concept of a self-supported core structural system connecting from the foundation through the walls. The walls and roof interlock to form the envelope. The core system worked as corner edge support to the roof. The design supported both the walls and roof to allow for a full external connection to wrap around the existing home.

\section{Advantages:}

- Continuous connection between components.

\section{Disadvantages:}

- The core structural system jointing the system together to form the self-supported system likely overly designed.

- $\quad$ The cost and time to install such system would be unnecessarily increased as a result.

\section{Findings:}

- Use of interlocking prefabricated panels and corner joints streamline the design. 


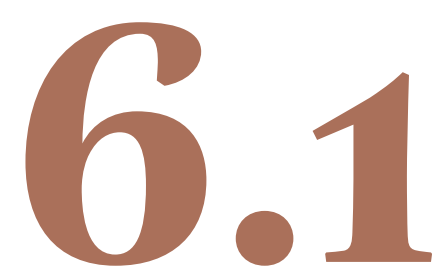

\section{Key Findings:}

- External envelope continuity for airtightness, thermal, water and vapour control.

- Remove soffit lining for more access above the roof and to the roof cavity.

- Keep the walls as the primary strategy and further explore the method of connecting to the roof space and subfloor.

- Refine the strategy without the unnecessary use of excess materials to manage time, disruption, resources, environmental and financial cost.

- All of the initial methods require some level of disruption to the eave junction.

- Materials need to be selected as appropriate for design and environmental impacts. The material itself will likely inform the design of the wall and external strategy itself. However full investigation of materials beyond the scope of the project but crucial for future development. 



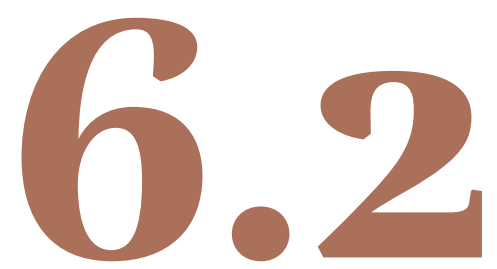

\section{Responsive Exploration}




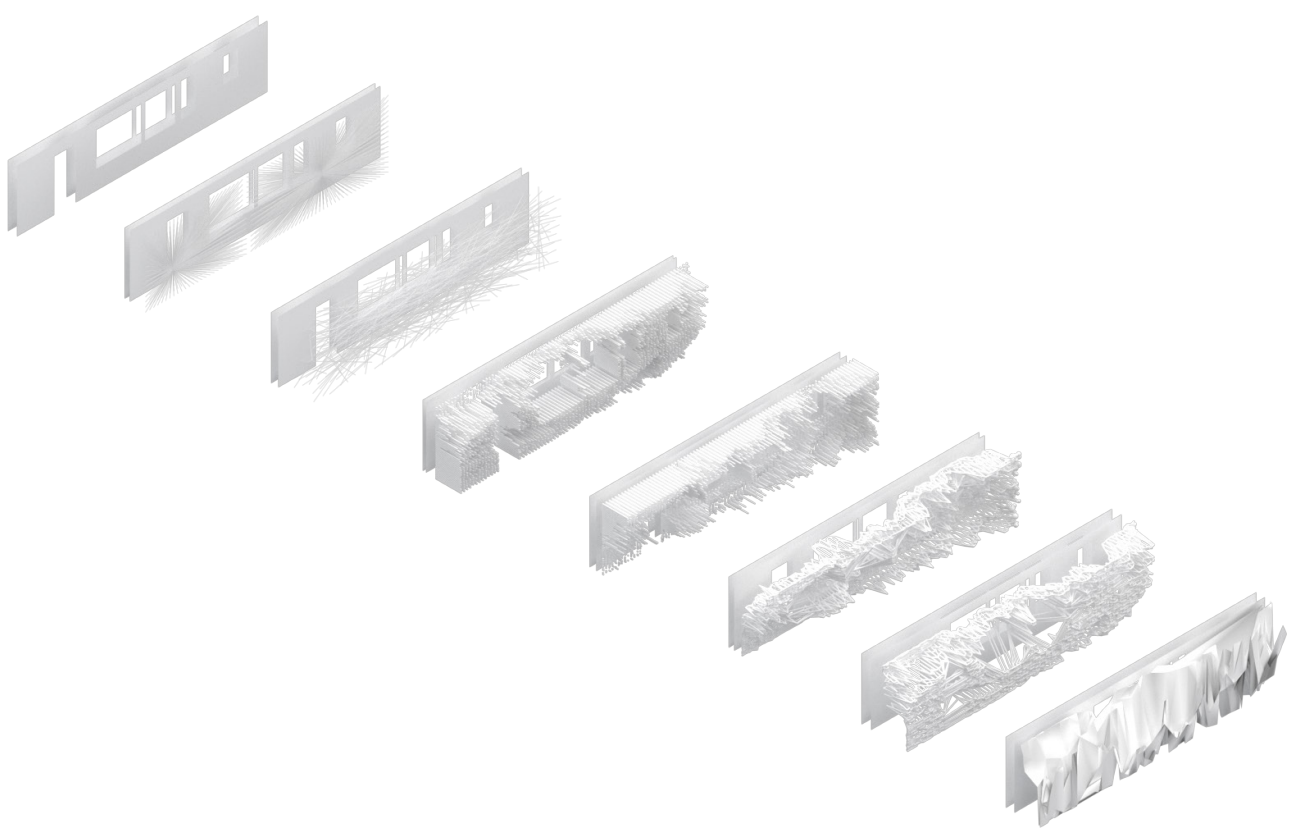

Fig 6.9 Parametric digital models responding to thermal 


\title{
Responsive Exploration
}

\author{
The responsive design approach explores the home \\ defects to inform design using digital parametric \\ design tools. The design of the series was to explore \\ the potential of future technology to respond to the \\ existing home conditions and not limited by current \\ retrofit design approaches and materials.
}




\section{(R1)}

\section{Performance Response}
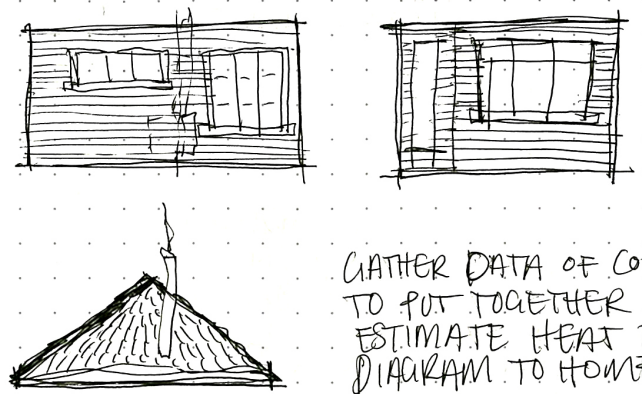

GATHER DATA OF COMPONEAT TO POT TOGETHER AN ESTIMATE HEAT MAP. DIAGRAM TO HOME.

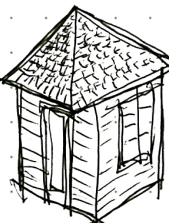
Bring together elements - learnings. assumpting from collection. of image
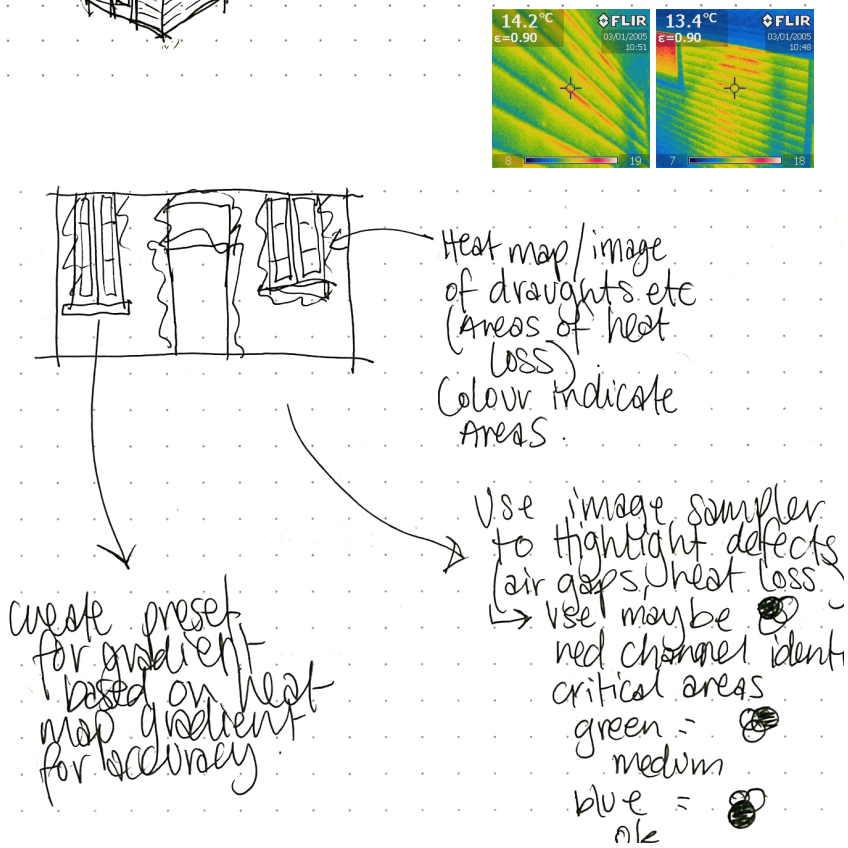

Fig 6.10 Concept design for responding to thermal imaging 


\section{R2)}

\section{Parametric Performance}

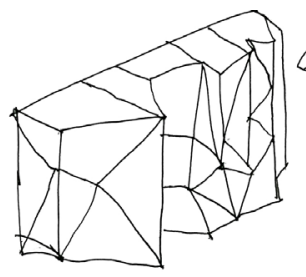

$\lessdot$ creote as

solid

then break

up into

eqoal blocks
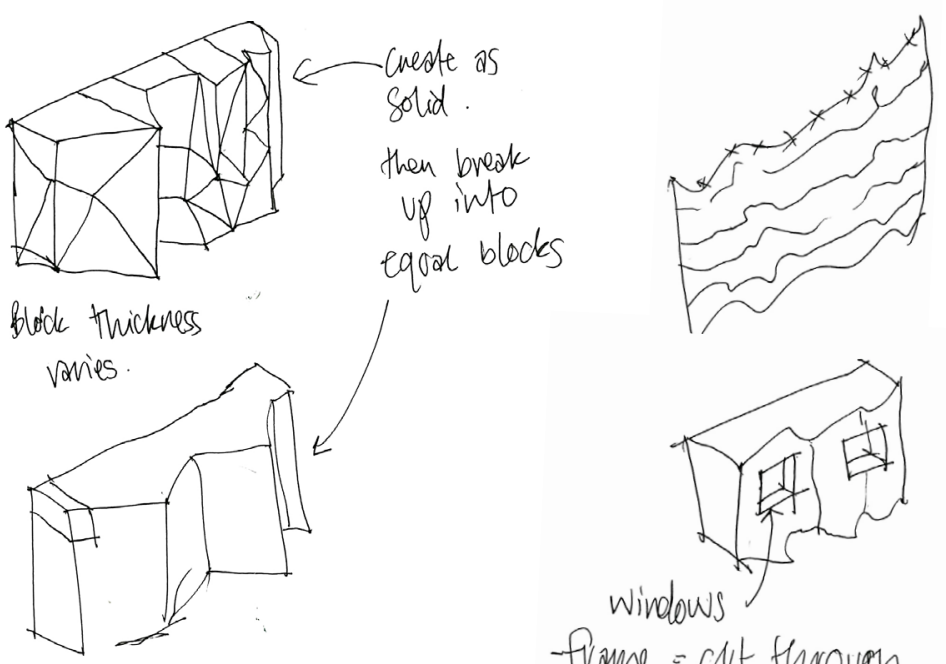

windows

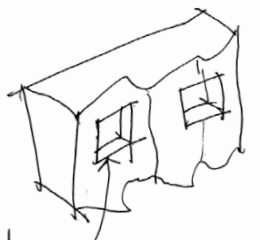

- fiame = cut through
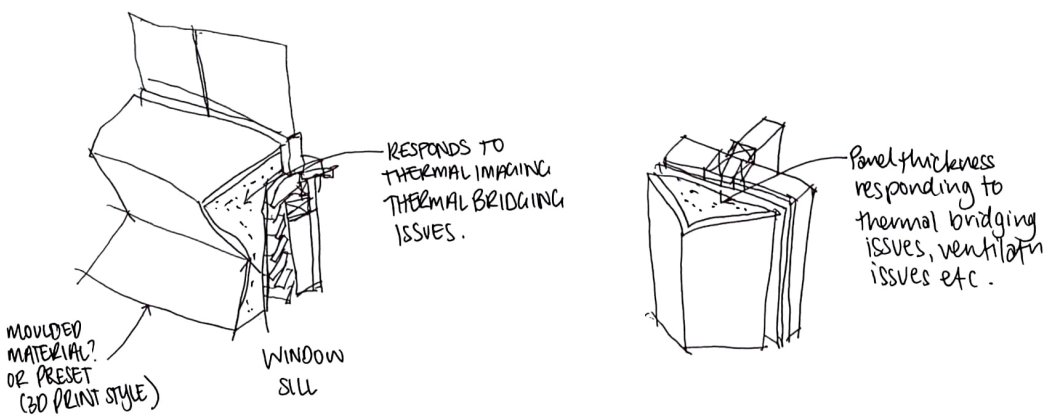

Fig 6.11 Concept design for responding to thermal imaging

using parametric digital tools explored wrapping around the 


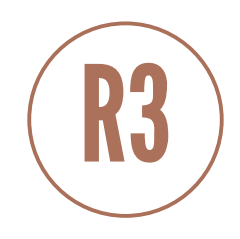

\section{Parametric Performance}
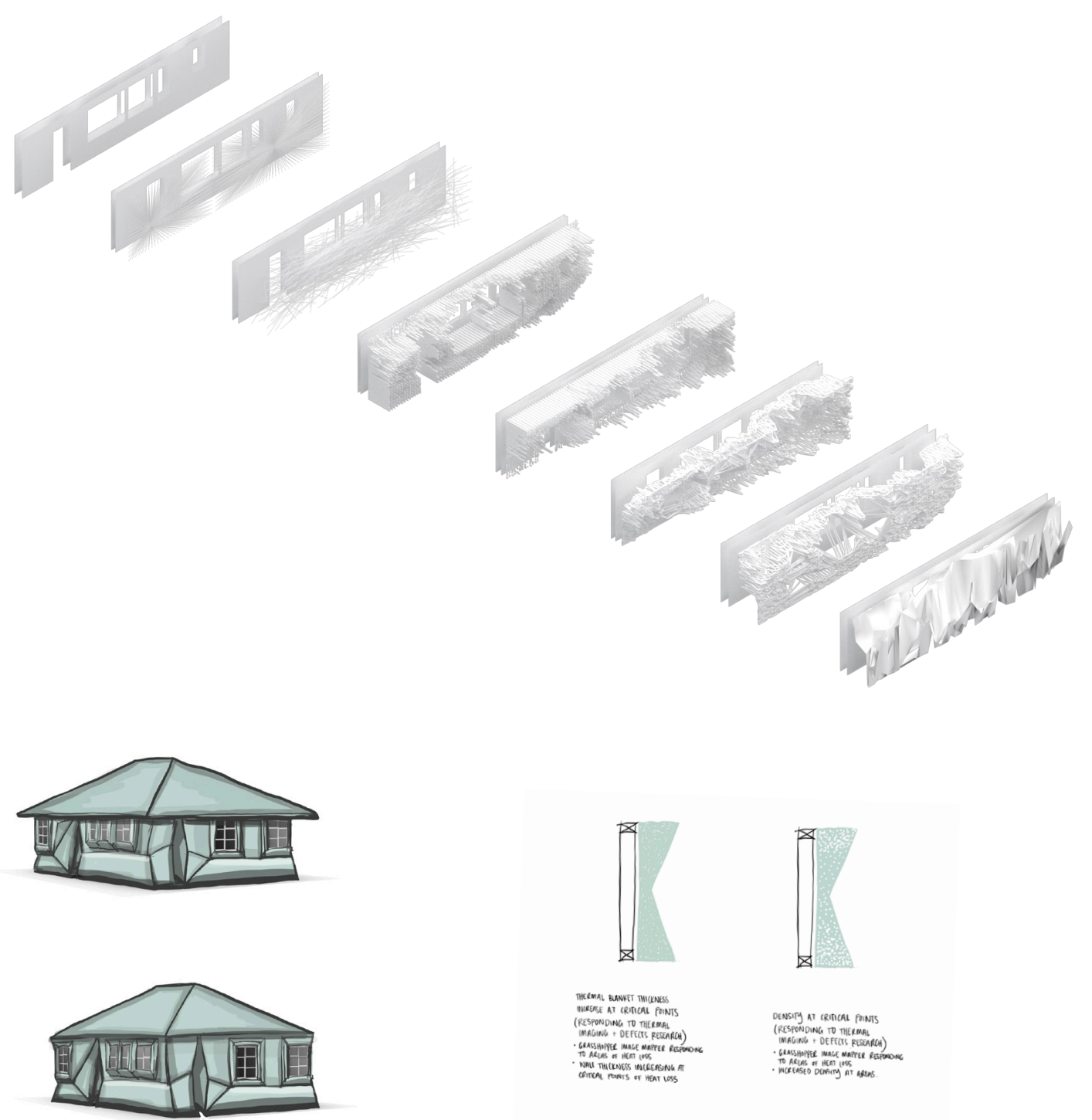

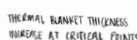

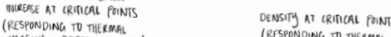

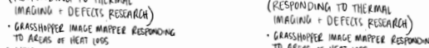

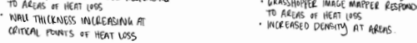

Fig 6.12 Concept design for responding to thermal imaging 


\section{Critical Reflections G Findings}

The design concept utilised the thermal imaging analysis in Chapter 4.0 to inform a dynamic response to the envelope performance issues using Grasshopper parametric design tools. The colours generated became parameters for insulation thickness.

The concepts tested a series of wall responses to indicative thermal and airtightness inconsistencies. The design used the thermal image spectrum to inform a performance design response modifying parametrically to envelope issues areas. The R3 concepts explored the idea of varying insulation density as a response. A possible method of managing excessive use of resources and reducing some cost of the strategy by adapting the insulation as necessary for performance.

\section{Advantages:}

- Push the boundaries of current design practice.

- Explore parametric digital tools informing adaptable design to produce unique wall outcomes.

- Reactive to thermal inconsistencies to develop appropriate control layer mitigation.

- Anticipate design possibilities for underdeveloped technologies.

- Controllable resource use with digitalisation.

- The design exploration visually expressed the notion of a pragmatic thermal response.

\section{Disadvantages:}

- Design aesthetic unresolved and potentially unnecessary design intervention.

- Further investigation needed of the realities of wall fluctuation performance.

- Unique wall outcomes require individualised prefabrication.

- Slower construction of each individually responding panel may require too much on-site time.

- Uncertainty of the performance effectiveness of varying the insulation density.

\section{Findings:}

- The parametric response provided a base for further investigation of parametric design adaptability to be integrated into the overall design strategy.

- The outcome highlighted how the existing wall performed and particular areas for focus.

- Attention to window thermal bridging and treatment of windows is crucial for the design strategy.

- Initial design responding to wall performance could function pragmatically and for home use experience.

- Further material and technology construction development opportunites. Materials, such as renewable Mycelium, could be set into a flexible and adaptable mould to each exact form needed responding to the parametric design. Another approach could explore robotic 3D printing to form the wall panels to minimise material waste. 


\section{R4}

\section{Technology E Reuse}

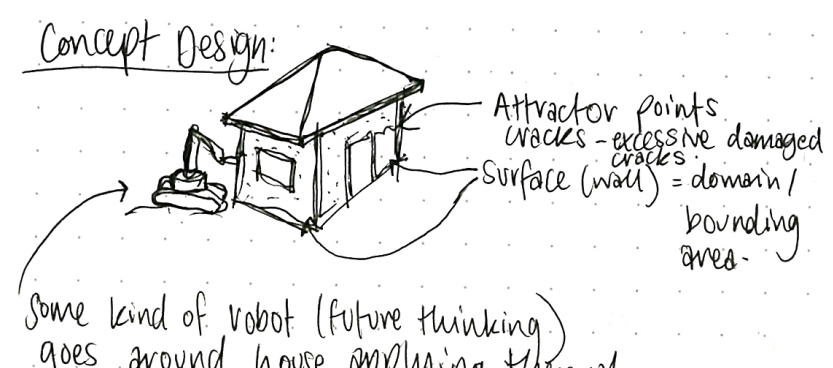

goes around house applying thermal
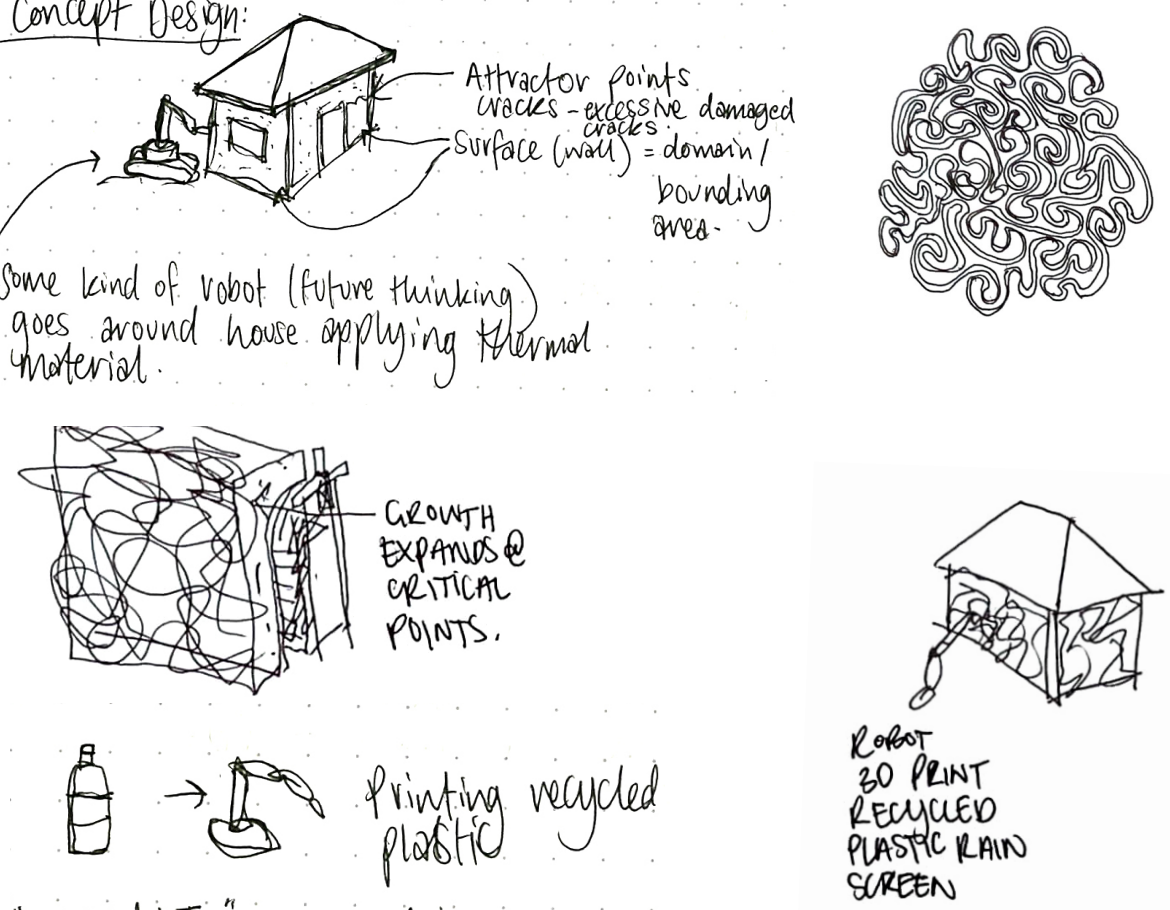

"NMT" - Recycled/zero
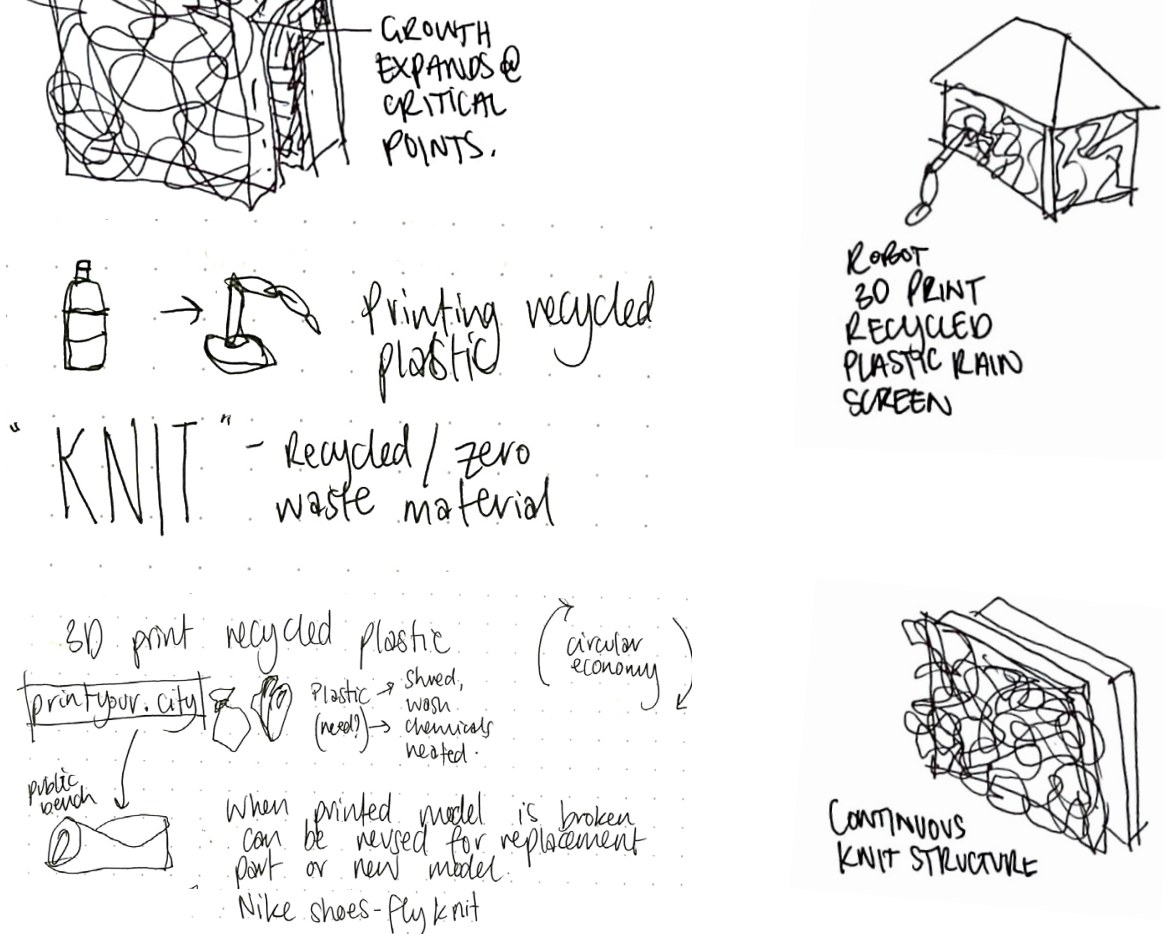

Fig 6.13 Concept design for 3D printing of recycled waste 


\section{Critical Reflections \& Findings}

To further explore the thermal imaging response, the design concept explored robotic 3D printing of recycled waste material for on site fabrication. The concept proposed robotic digital technology to print the external envelope in-situ. The aim was for a zero-waste construction method through a continuous print to the home. The design could use a construction technique similar to fly knit technology approaches with the intention of future technology and materials development.

\section{Advantages:}

- Effective use of resources to limit waste and use only what is needed.

- Exploration of reusing available materials.

- Vast possibility for architectural aesthetic exploration with digital tools.

- Design boundaries pushed by considering possible technologies.

- Parametrically adaptable to design variability.

\section{Disadvantages:}

- Robot cost, accessibility, site conditions, particularly hilly sites, on-site construction environment could provide very difficult and therefore greatly vary the outcome of the strategy.

\section{Findings:}

- Design concept beyond the scope of the project, however a possible area for future exploration.

- Propose and explore a similar approach but using prefabrication techniques to control conditions of time, cost, materials, site environment during construction

- Parametric digital tools for adaptability to be integrated. 


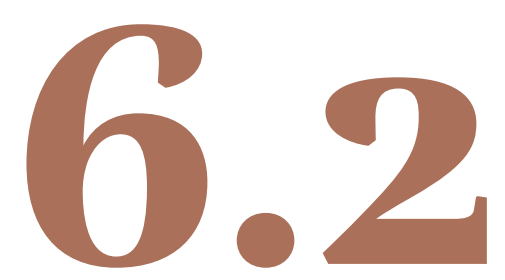

\section{Key Findings:}

- Parametric design tools inform design adaptability.

- Beneficial for a wider scope of possible design strategies to retrofit the existing home.

- Learnings of issue areas from parametrically responding to existing wall performance.

- Mitigate thermal bridging and heat loss in wall defects particularly around window detailing.

- Thermal imaging and performance testing to be integrated into digital tools and parametric design strategy.

- Construction and prefabrication techniques able to control and manage conditions of time, cost, materials, site environment during construction.

- The parameters of the system adapt as appropriate to the digital model of the existing home.

- An appropriate retrofit system could adapt with parameters such as wall thickness, size, materials, wall use and geometry. 


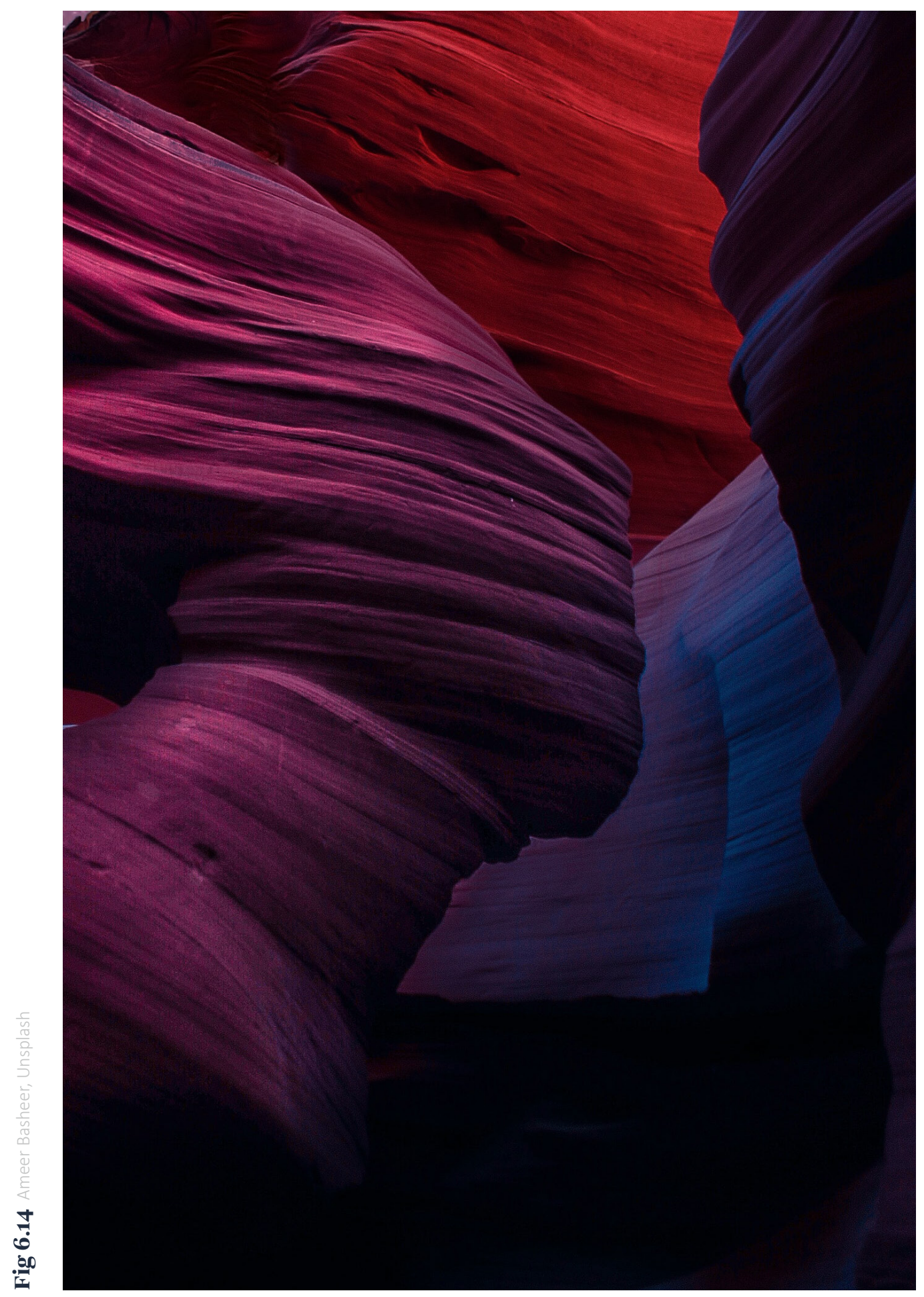

$112 \mid$ etee 


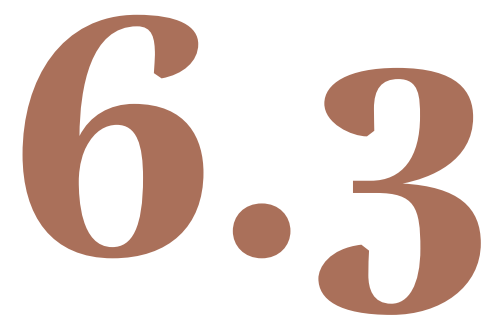

\section{Integrated Exploration}




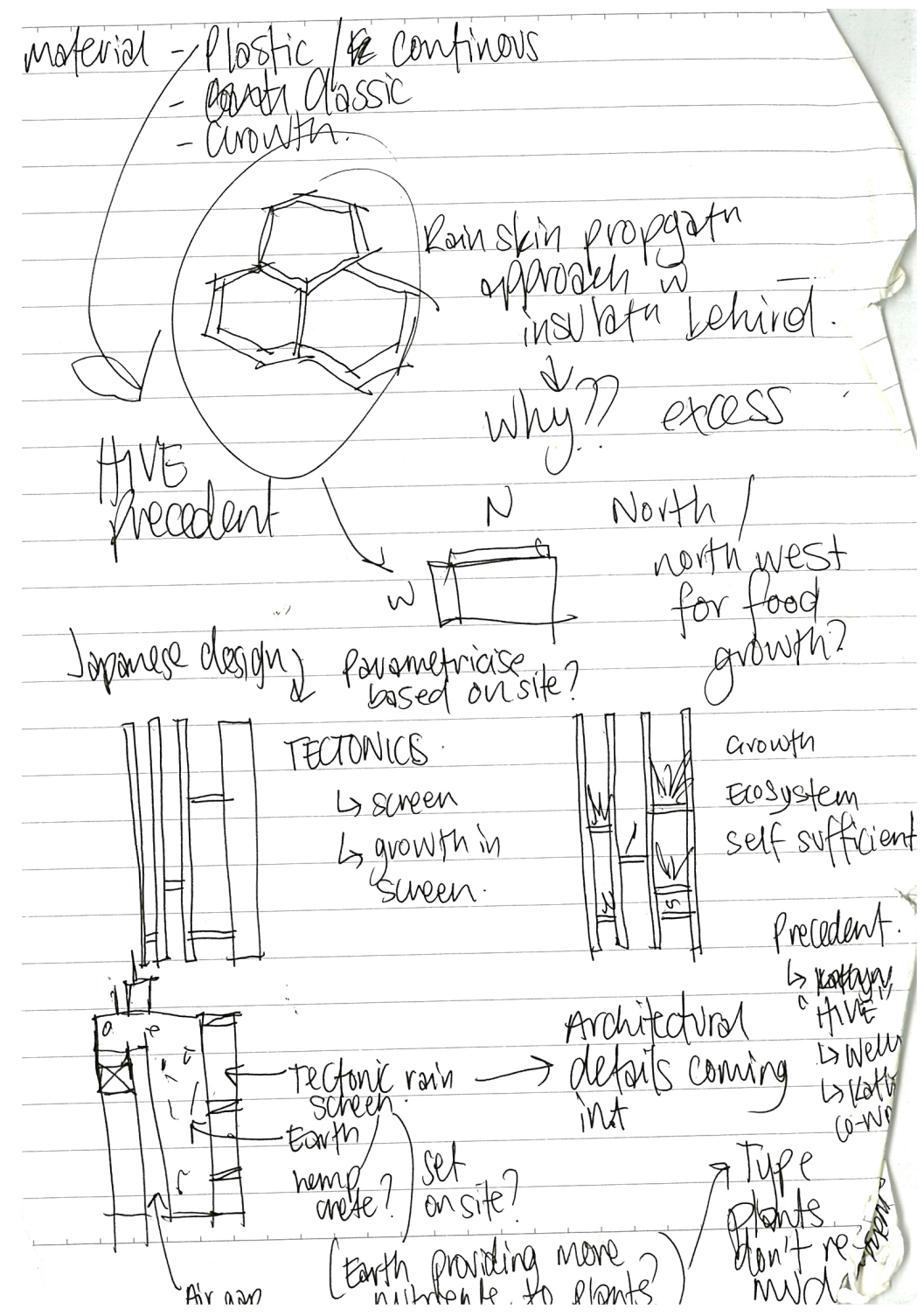

Fig 6.15 Concept series to create greater home 


\title{
Integrated Exploration
}

\author{
Identified in Chapters 2, the impact of housing \\ directly affects the occupant's health and well-being. \\ The design series explores how the wall could create \\ experience beyond performance and pragmatic \\ function for a greater holistic regeneration for \\ occupants, community and the environment. \\ Particularly to explore opportunities for growth, life, \\ urban agriculture and biophilia, and explore design \\ aesthetic variations to encourage occupant choice \\ and diverse design outcomes. The concept series \\ explores the combination of wall function program \\ and elements to form the overall strategy.
}




\section{(11)}

\section{Materiality, Use $\mathcal{F}$ Aesthetic}

WALL VARIATION - CHOICE + DIFFERENIATION
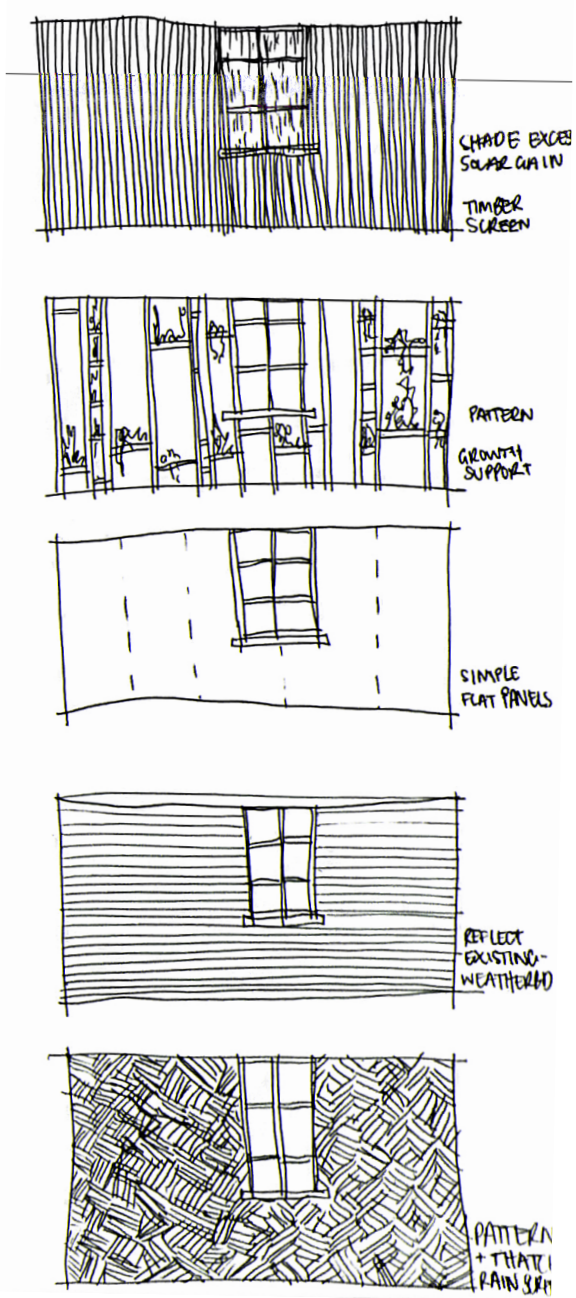

Fig 6.16 


\section{Critical Reflections \& Findings}

The design concept explored the variation of wall panels, potential functions and use. Material design, pattern and visual expression began to explore how the wall could be used beyond performance and opportunity for architectural enrichment.

\section{Advantages:}

- Various material combinations possible.

- Integration of passive design techniques such as shading where necessary into wall design.

- Integration of vegetation, pattern and edible gardens.

- Opportunities to explore home experience and diversity as appropriate for home and occupant needs.

\section{Disadvantages:}

- Variations may not work so well throughout the housing typologies or depending on site conditions and orientation (planting may not be realistic if limited sun access).

- Material compatibility with existing home and aesthetic.

\section{Findings:}

- Further exploration of how the design could be integrated into the existing home aesthetically and functionally.

- Further exploration for intention of selection for wall choice, use and outcome.

- Further development of the design around windows and openings. 


\section{(12)}

\section{Construction, Detailing $\mathfrak{G}$ Growth}
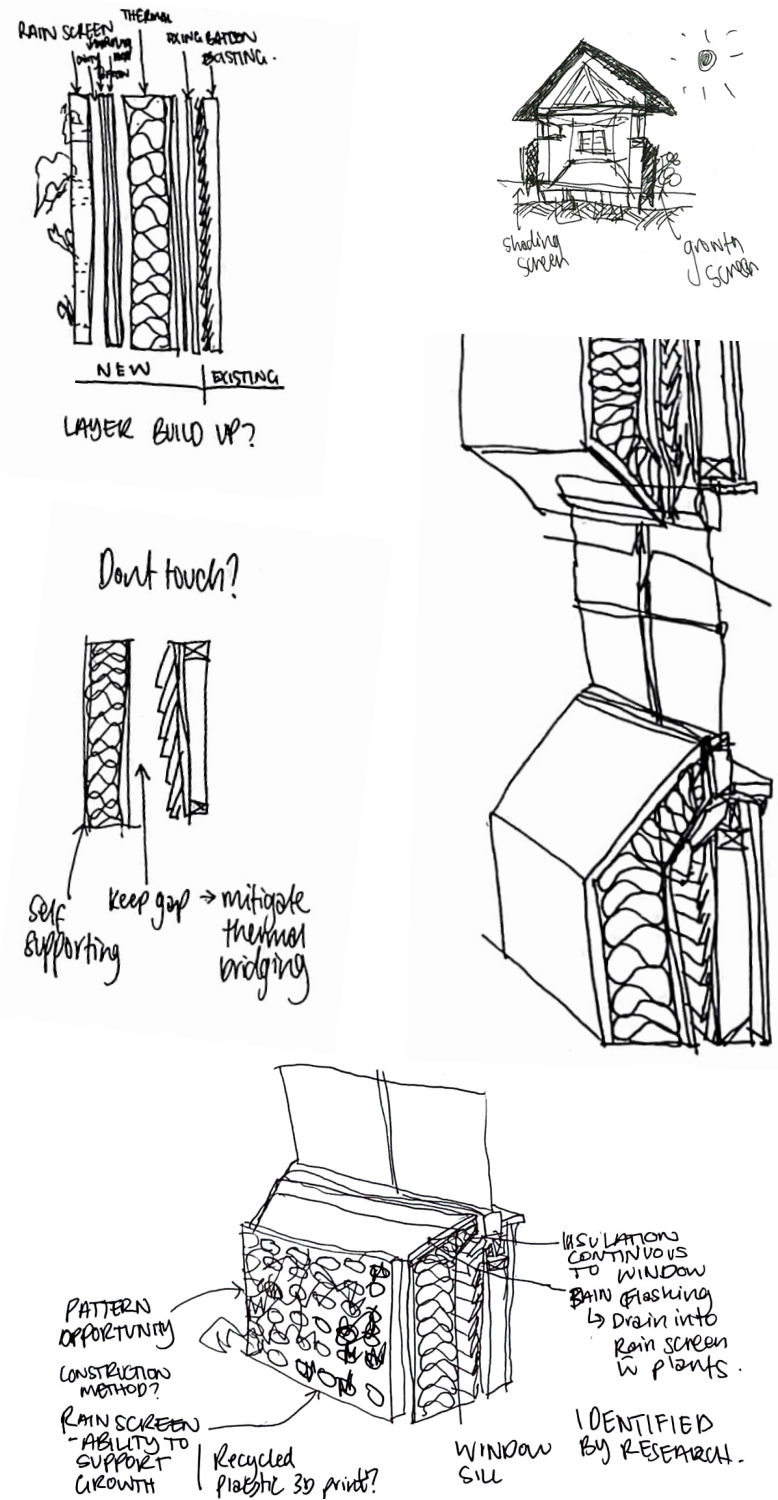

Fig 6.17 


\section{Critical Reflections \& Findings}

The design concept explored potential detailing of wall and program integration. Particularly how to address thermal bridging and heat loss around the window to then integrate usable program and aesthetic components with the detailing.

\section{Advantages:}

- Program addition enriches design strategy complexity and occupant benefit with greater purpose beyond simply improving wall performance.

- Vast aesthetic variations and possibilities. Constrained by the purpose of the program.

- Attention to detail around key problem areas such as thermal bridging around the windows.

\section{Disadvantages:}

- Added layer of program adds complexity for construction.

- Added cost and resource use with additional wall components. However, potentially balanced out by benefit of wall features.

- Continuity between varying program and materials.

\section{Findings:}

- Further exploration of continuity between wall layers and components to integrate program.

- Further detail exploration of construction particularly around openings and how to address thermal bridging and mitigate heat loss while ensuring a usable window. 


\section{3}

Design Program Integration
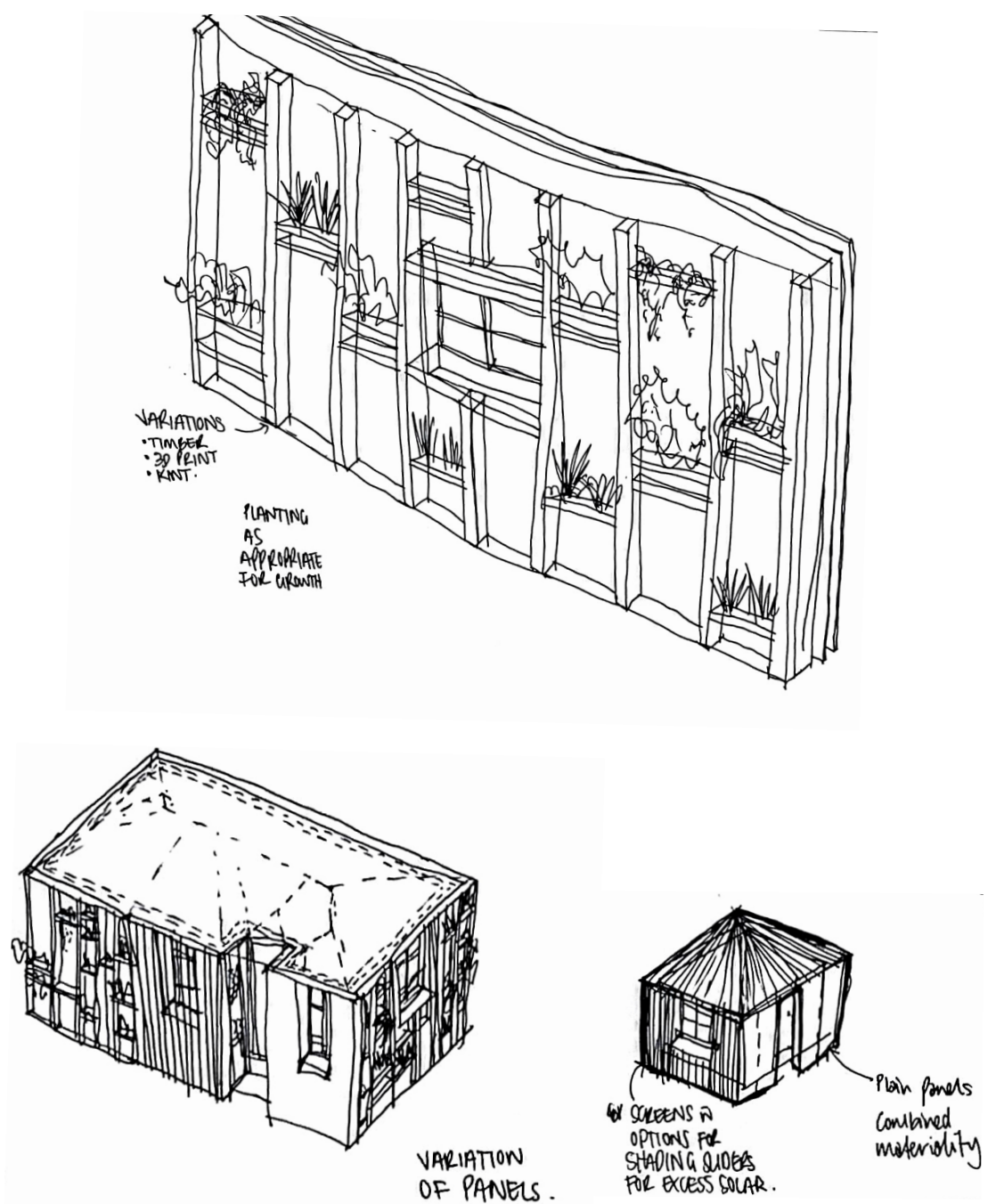

Fig 6.18 concept series of program integration collective 


\section{Critical Reflections G Findings}

The design program further explored how to integrate the initial design explorations and apply them collectively to the existing home. An exploration how varying design aesthetics and function may work collectively to inform the overall design strategy and enrich the home experience.

\section{Advantages:}

- Opportunity to further explore how the design elements combine and come together.

- Opportunity to greatly enrich home and occupant experience.

- Design strategy effective impact on occupants with integration of program beyond wall performance.

- Vast aesthetic variations and possibilities. Constrained by the purpose of the program.

- Value of the home and of the design strategy is increased by the enrichment for occupant experience and health and well being.

\section{Disadvantages:}

- Construction and continuity between differing program elements and materials.

- Added layer of program adds complexity for construction.

- Potential increase in cost and resources. May be able to be balanced by material selections, technologies, construction techniques and added value from strategy.

\section{Findings:}

- Environment enrichment and home experience a key component of the design strategy to be further explored and developed.

- Construction and detailing needs development to achieve continuity between program elements.

- Possibility of design strategy to positively impact people, health and well-being beyond performance of the home.

- Exploration needs development of program types, use, materials, construction and limitations. 


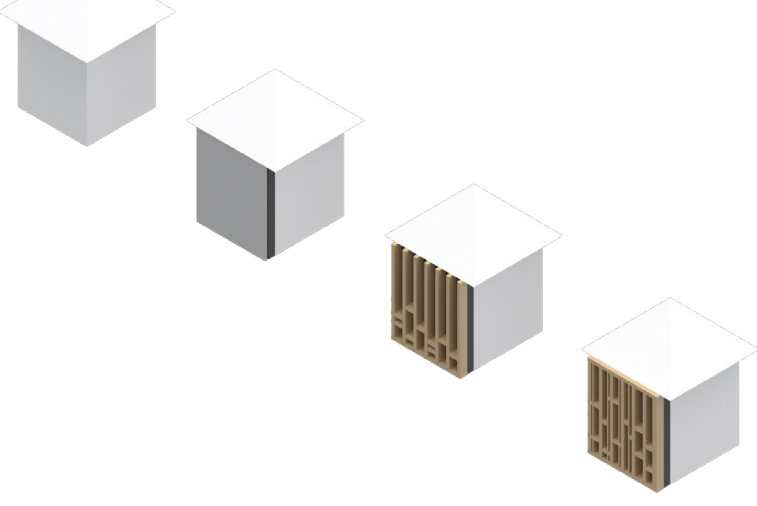

Fig 6.19 Exploration of timber paneling to form a screen

as a design strategy. The screen could be used to support

plant growth. The paneling could be explored further for

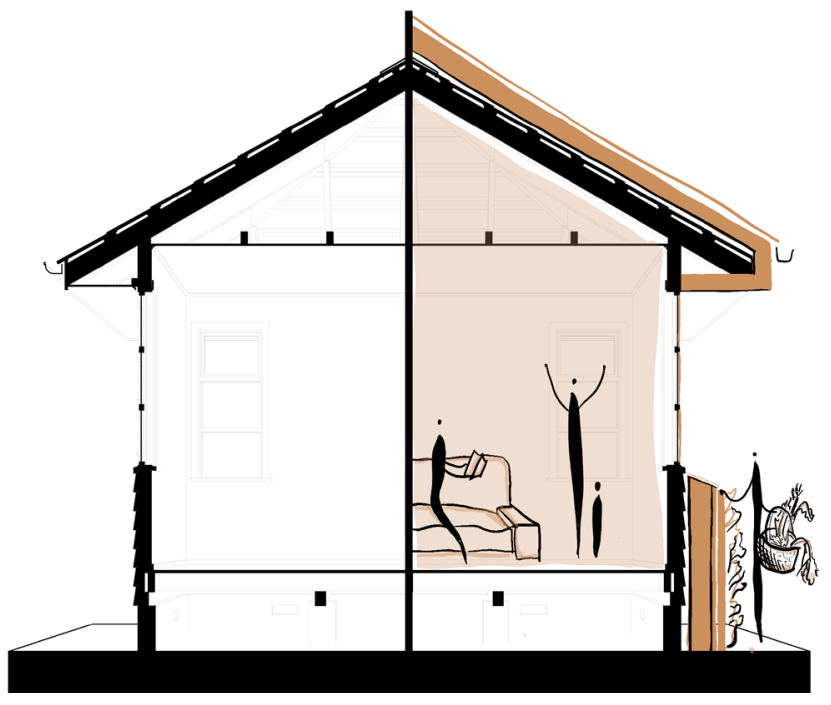

Fig 6.20 Exploration of self-sufficiency, urban agriculture anproach considers biophilia environmental regeneration for community and ecology restoration. 


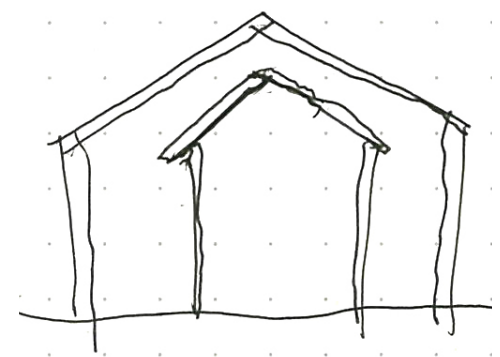

Fig 6.21 Future strategy approach to expand the home beyond the research scope of the thesis however a possible future development. 


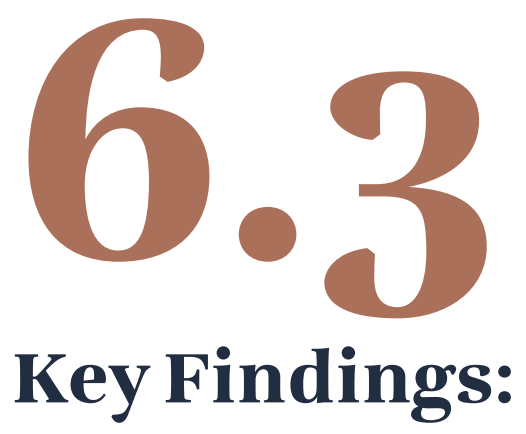

- Gap in research for integration of program and therefore a fresh design opportunity for the design strategy.

- Holistic intervention enriches and revitalises the occupant experience, the greater community and the environment while responding to the pragmatic performance needs of the home.

- Program design opportunity to explore further as an feasible addition to the existing home

- Benefits on people, health and well-being beyond performance of the home.

- Design and program aesthetic variations for diversity, identity, material use, construction and intended function to be further explored

- Construction and detailing of varying program elements and feasibility of integration to be further explored

- Development of detailing around openings for thermal bridging and heat loss to further explore program integration.

- Future exploration of adapting the home as the occupant needs change. With the aim to enhance the life of the home as well as existing material and resource use. 



\section{Critical Reflections G Findings}

\section{Critical Reflection:}

- A key issue area for the application of an external envelope was around the eaves and window head. Therefore, the eaves lining at least needs to be removed as a less invasive option compared to fully cutting off the eaves or an unsuccessful wrap around the eaves to support envelope continuity.

- The thermal imaging design response would take the project in a direction beyond the scope of the research. However, it could be an avenue worth exploring in the future to manage the representation and visual impact of the strategy. The digital tools and parametric design used to explore the approach are fundamental to the overall scheme of the strategy.

- The collective program integration concept explores how the home could be enriched beyond the performance of the strategy. Greater development was needed to inform use and continuity between the components.

\section{Limitations:}

- The process identified the limitation to focus the research on the wall strategy as the most consistent throughout housing typologies and as the opportunity location to integrate program with the envelope.

- The process identified the limitation to inform the strategy for parametric adaptability however limit the heat loss design response as beyond the research scope.

- Design aesthetics, pattern, materiality to inform program to be limited to manage the design exploration. However, the design process highlights the benefit of an adaptive design strategy. Therefore, greater design exploration would be assumed for future development

- The level of design exploration at concept level only and does not claim the options explored are the only possible methods of exploration but some considerations. 


\section{Findings:}

The initial design process identified the possible breadth of design opportunities within the design strategy for further development. Figure 6.19 highlights key findings from the design series to inform further development.

The following outline key findings influencing further development:

- $\quad$ From the base exploration designs it was found the more effective approach was to focus on the external wall strategy and propose an approach for the ceiling and floor strategy integrated into the existing home to limit the disruption to the existing home and occupants.

- The lack of space between the eaves and window head was problematic to provide enough space for heat loss and thermal bridging mitigation above the openings.

- The detailing and construction of the envelope to support envelope continuity around the connections are fundamental to develop further. Particularly around the openings and

connections between elements such as wall to roof and floor components to address thermal bridging and heat loss.

- The digital tools and process used to explore the responsive exploration particularly the adaptability of parametric design, to be used for developing an adaptable design strategy.

- The opportunity to explore program and use beyond the performance proposes potential to enrich the home and experience for the occupant, home and environment.

- The further development of architectural expression, identity, aesthetics, environmental and biophilia contributions through design approaches for envrionmental enrichment.

- The program components could collectively form an overall concept strategy for the existing home 
Design Series

Relevant Search Areas

(1.0)

BASE EXPLORATION

(2.0)

ADVANCED EXPLORATION

(3.0)

HOLISTIC EXPLORATION

ENVIRONMENTAL REGENERATION

IDENTITY \& EXPRESSION

PEOPLE LIFE BIOPHILIA

SITE ORIENTATION SOLAR

ADAPTABILITY

PREFABRICATED
Findings \& Take forward

Forward Design Development

Large scale intervention,

focus scope of research

Potentially excessive intervention, disrupt occupants

BASE STRATEGY DESIGN

Limits research scope, feasible for real world application

Findings relevent to develop further, reconsider overdesign

Crucial for future research, cautious of project scope

opportunity for future research, cautious of project scope

PROGRAM DESIGN

Use of digital tools to inform design

Use of digital tools to inform design

Important area to take forward, cautious of project scope

Architectural impact,

cautious of project scope

Important area to take forward,

cautious of project scope

ADAPTABILITY DESIGN

Crucial to influence design, further

development for future

Digital tools ability of adaption

Important area to be explored, beyond project scope

Fig 6.22 

Overview

7.1

7.2

$7 \cdot 3$
CONCEPT DESIGN EXPLORATION

Envelope detail concepts

\section{THE BASE COMPONENT}

Conceptual design outcome 
The following Chapter fulfils the research objective: Propose a design strategy for inefficient 1940s-1960s housing in New Zealand to increase the home's thermal performance without occupant displacement. The objective was to develop an envelope retrofit design concept for the 1940s-1960s state house to improve thermal performance and energy efficiency while not displacing the occupants.

The issues of the 1940s-1960s state house typology affecting occupant health and wellbeing were investigated by building upon the base model investigation (Chapter 4.0), with findings informed by case studies (Chapter 3.0), the design framework (Chapter 5.0) and initial design findings (Chapter 6.0). The concept proposes how the base component functions within the design strategy (refer to Chapter 5.0).

Fig 7.1 Integrated section diagram highlighting focus areas developed in the base component with key design findings

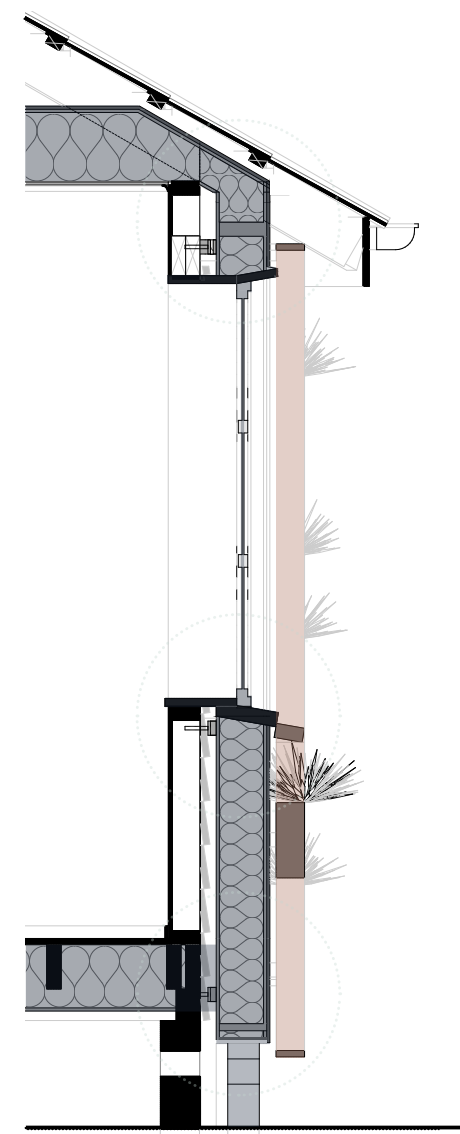


The thermal envelope is the critical area of heat loss between the interior and exterior environments

(Figure 7.2). The concept design exploration investigates the continuous envelope around the existing state house that could be designed not requiring occupant displacement.

\section{Concept}

Design

Exploration 


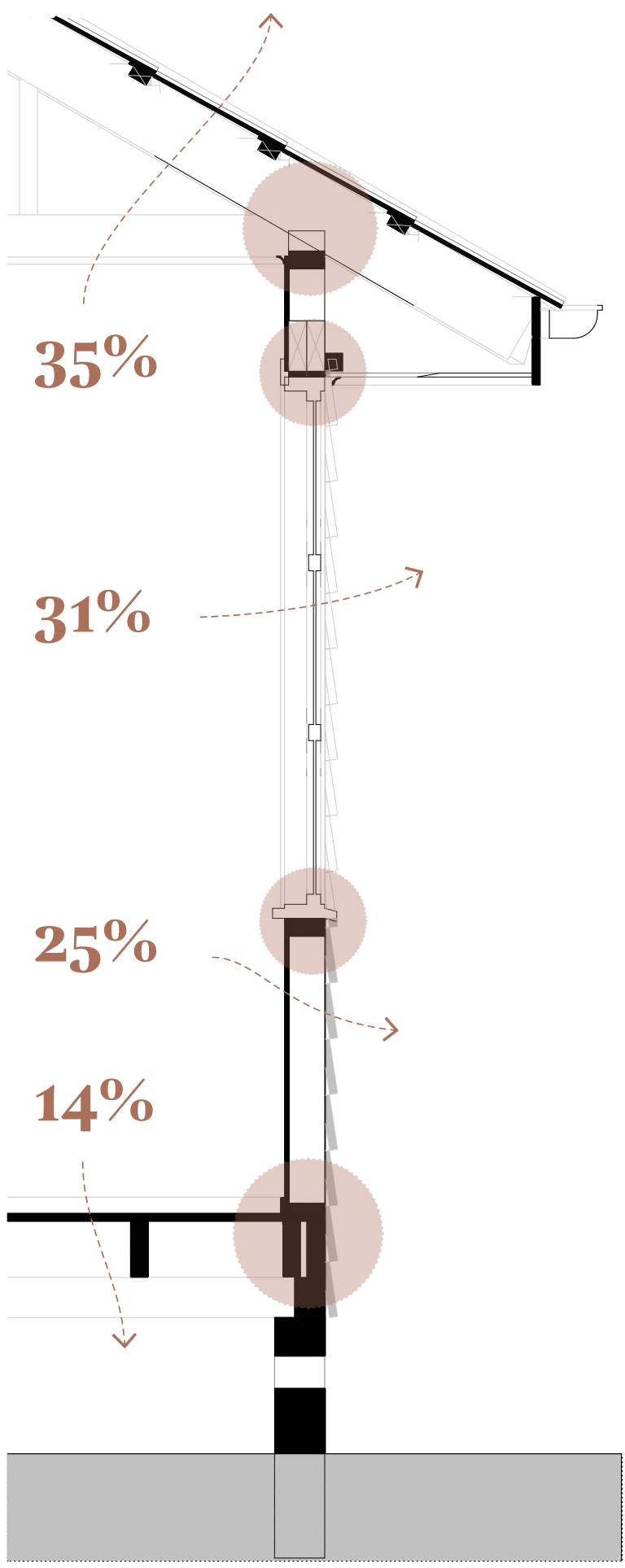

Identified thermal bridging

$\mathbf{0}$ Envelope heat loss

(White, 2017, p. 87)

Fig 7.2 Diagram of envelope heat loss and hermal bridging inform-

ing design of base component 


\section{Envelope Control Layers}

The construction and detailing of the external envelope are fundamental to either strengthening the home's thermal performance or worsening the problem (refer to Chapter 4.0), as highlighted by Quinn (Sustainable Engineering Ltd, 2019, p. 2). The Perfect Wall concept by Joseph Lstiburek (2010) outlines the importance of the four control layers, water, air, vapour and thermal, in the form of a continuous envelope to the building to protect the building's structure (p. 1). Performance engineering research in New Zealand emphasises the importance of the four fundamental principles' to inform successful building enclosure performance (Mclsaac, 2020; Quinn, 2018). The control layer principles outlined the importance of envelope continuity and influenced the base component design to prioritise envelope continuity within the investigation. It was assumed the prefabricated wall unit would be constructed following the four control layer principles similar to that of the panels used in the Energiesprong case study (Chapter 4.0) by RC Panels (2021).

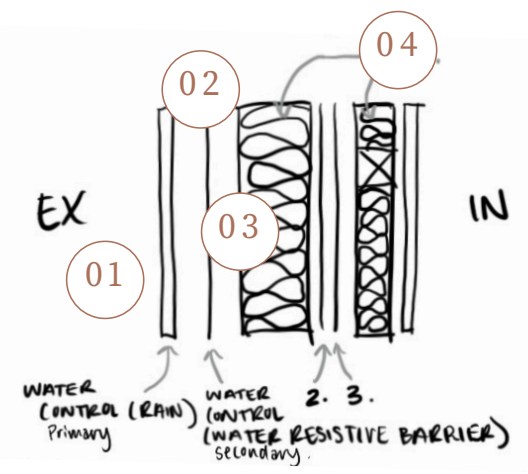

(01) WATER CONTROL

Ideally two levels of control

(02) AIR CONTROL

Manage air leakage \& moisture movement

(03) VAPOUR CONTROL

Moisture control, drying needed with more insulation

(04) THERMAL CONTROL

Must get first three layers right, reduce contact of moist air with cold surfaces

Fig 7.3 Diagram of control layer findings 


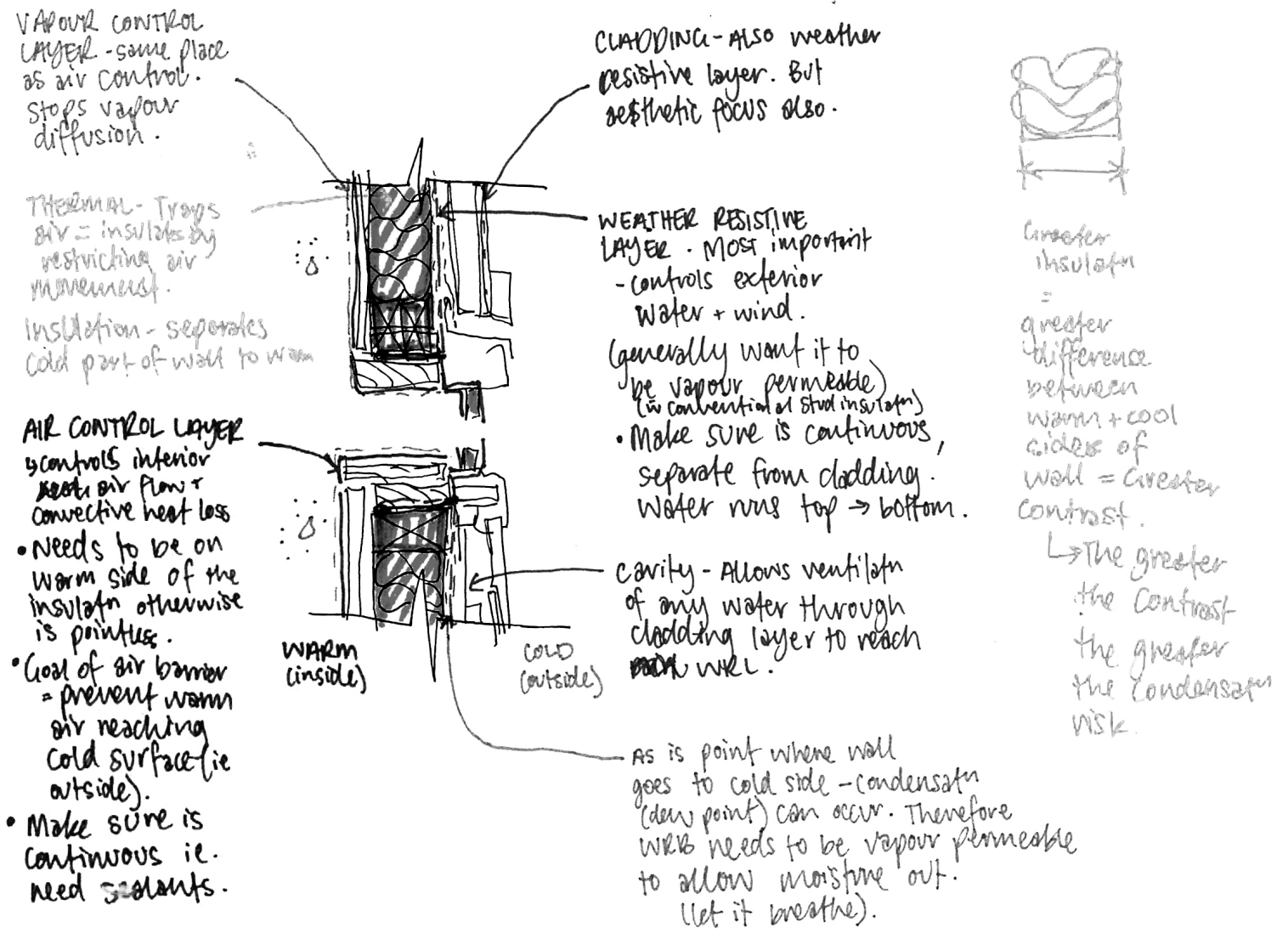

Fig 7.4 Sketch process to understand control layer concepts of 


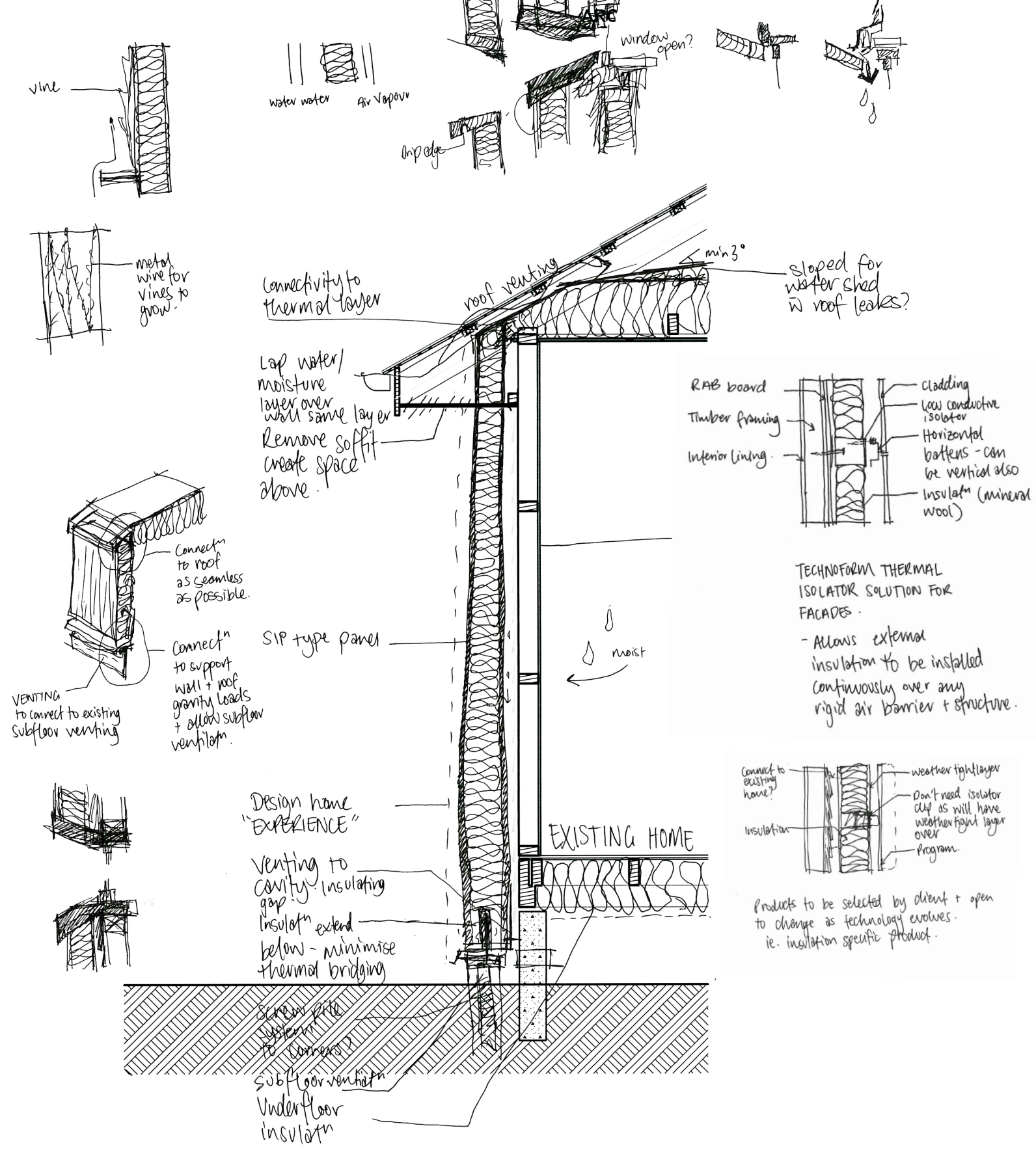

Fig 7.5 Sketch process thinking working out possible envelope 

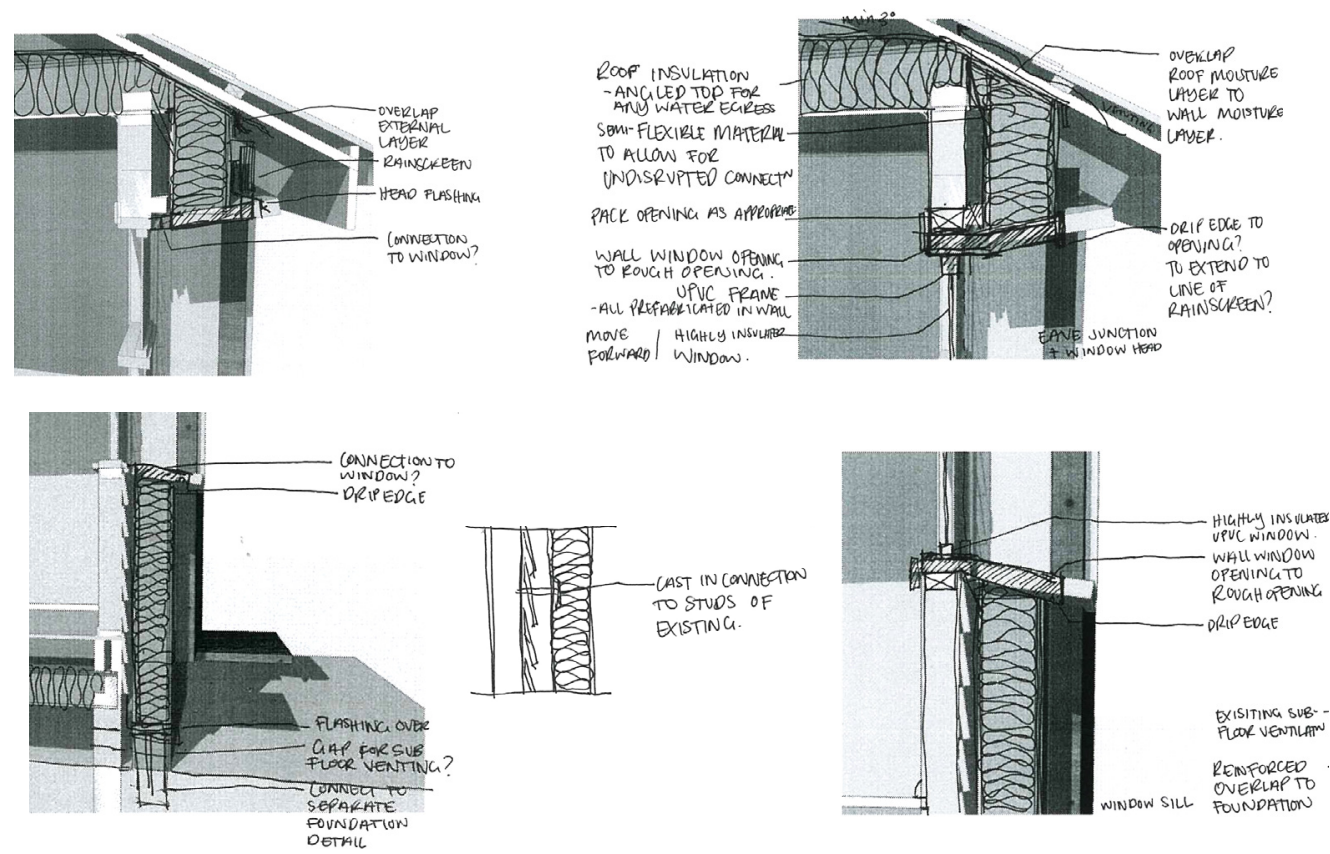

Eoundatn
(1) alustall point supports (piles efo)
. underfbor insulatin

(2) underflbor insulatin beavers

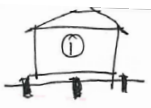

(3) Install unit

cwindory.
vnits first)
bset then

coof see sips instain precess. wall

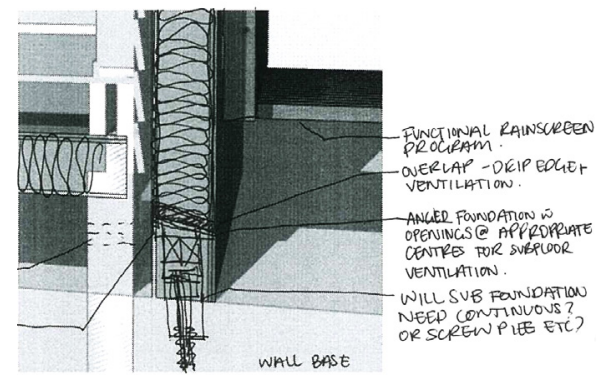

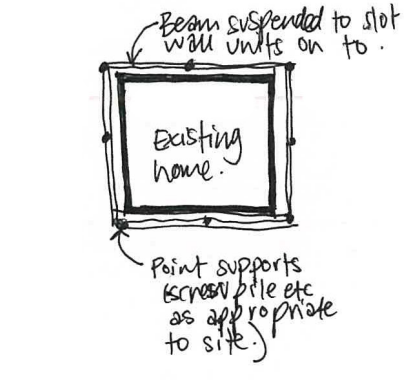

ASSUME CONCEPT LEVEL OF DETALLING ONUY FOR SCOPE OF THESIS. CRITIQUE ERRORS IN DETALLING
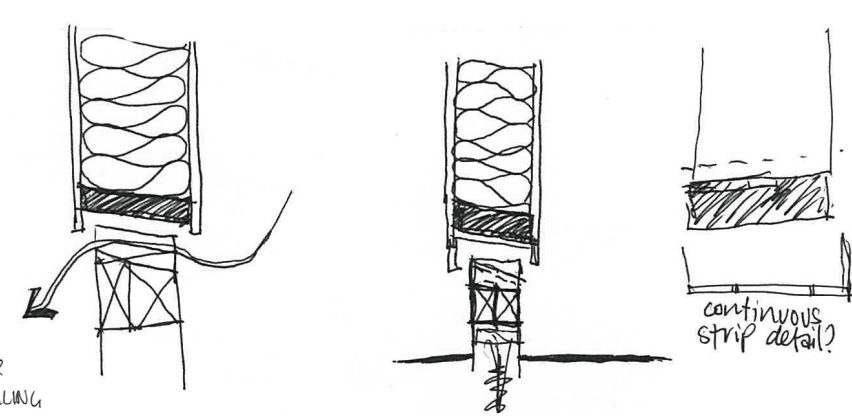

Fig 7.6 Concept process sketches for the detailing of a contin- 

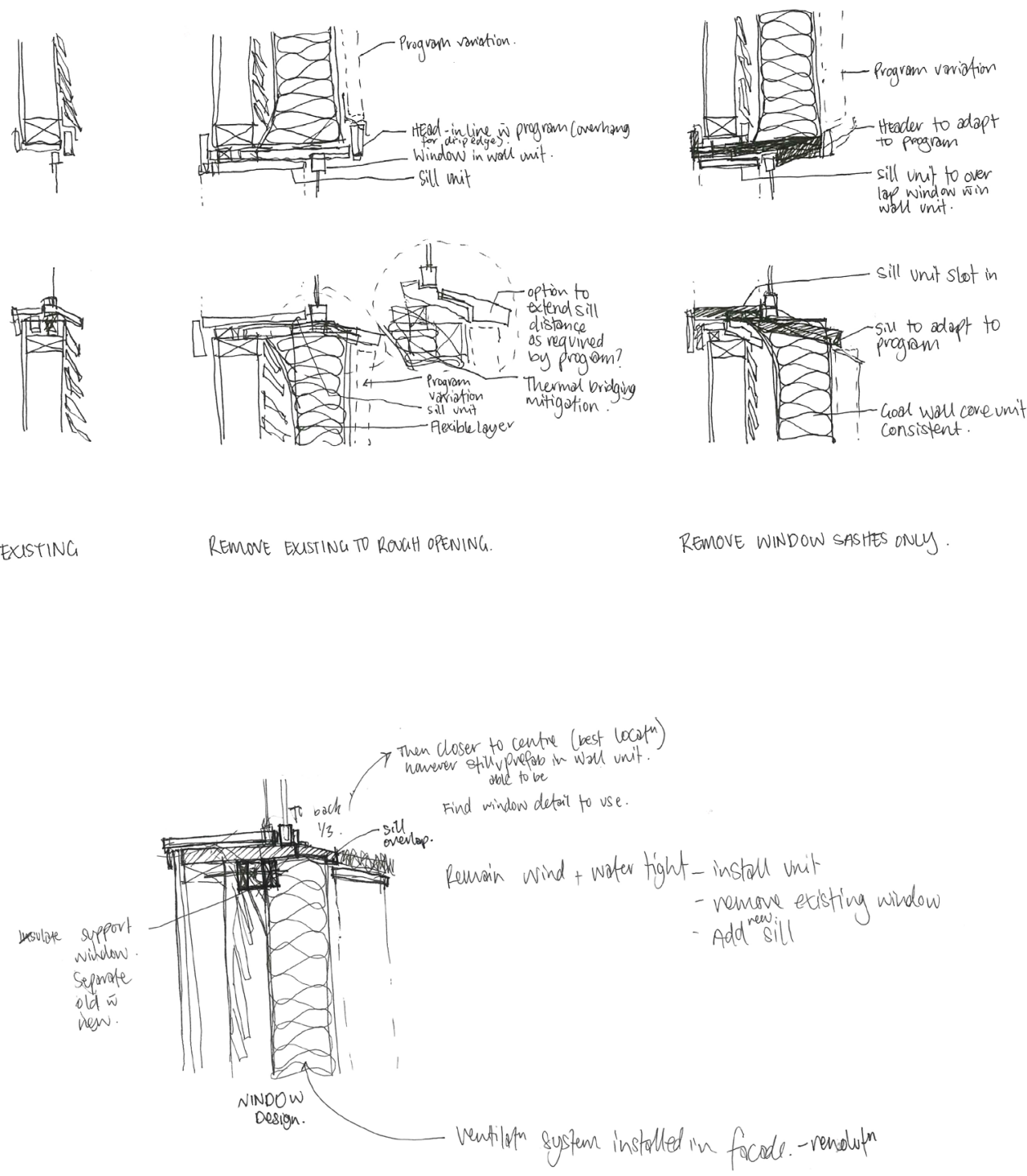

Fig $\mathbf{7 . 7}$ Concept process sketches for the addressing window 


\section{Critical Reflections}

- A design considered greater wall overlap to the windows to limit thermal bridging. However, the approach would only work for fixed windows. The overlap would restrict the window from opening.

- A design to keep the existing windows was briefly compared as the least likely solution to disrupt the occupants and potentially limiting upfront costs and on-site time. An option considered aligning the new wall to the window as near as possible. However, the performance standards would still require additional glazing units and, therefore, likely to disrupt the occupant greater than with window replacement. The outcome suggests removing the window and replacing it with an integrated, prefabricated wall unit.

- The existing window removed, and the opening bridged by the new window and sill unit. Design of the thermal bridging and insulation development supporting greater control of the heat transfer. The new windows are likely to have higher upfront financial costs. However, the increased energy efficiency and thermal reduces operational energy costs for the longterm benefit. 
The replacement of the window openings is a problem area during wall unit installation to manage the least occupant disruption. The following sequence series critiques possible approaches to installing the wall unit before or after removing the existing window.

\section{Opening Sequence Exploration}




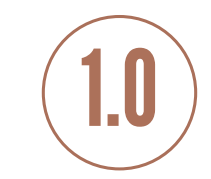

\section{Openings Strategy 1.0 \\ Base unit installed after window removed}

(1.1)

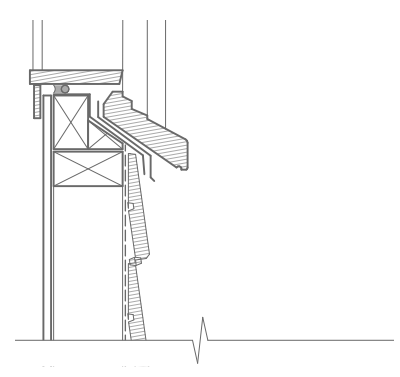

(1.2)

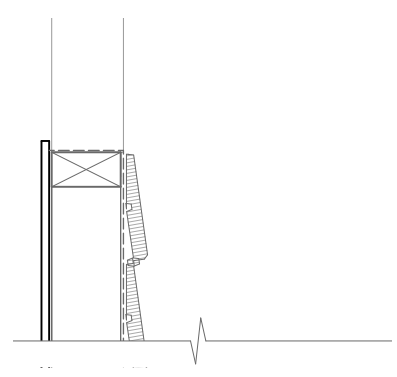

Existing window

(1.3)

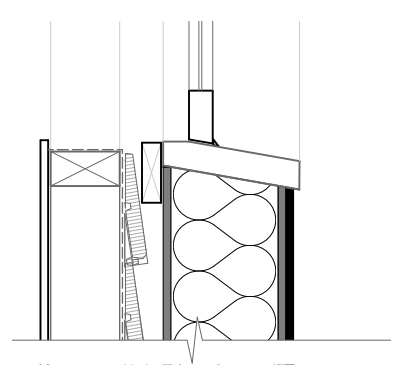

Remove existing window Seal existing framing with flexible flashing tape

\section{Base unit installed}

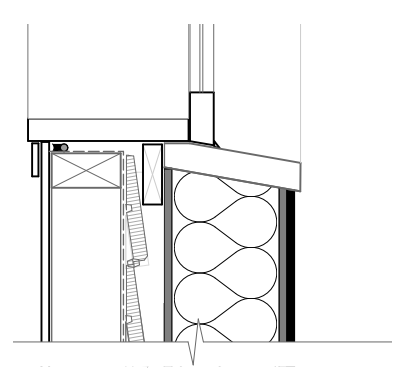

Window sill insert installed Seal joint between sill and existing wall

(1.4)

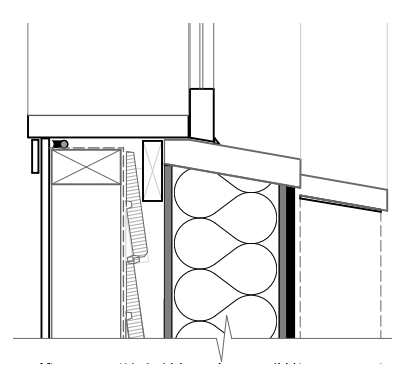

Adaptable program unit installed to Base Unit 


\section{Critical Reflection:}

The approach requires removing the existing window before installing the base unit. Therefore creating some occupant disruption. Further exploration would explore the option to limit occupant disruption by potentially removing the existing window after the base unit is installed.

Fig 7.8 Concept sequence of base unit installed after window 


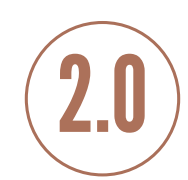

\section{Openings Strategy 2.0 \\ Base unit installed before window removed}

(2.1)

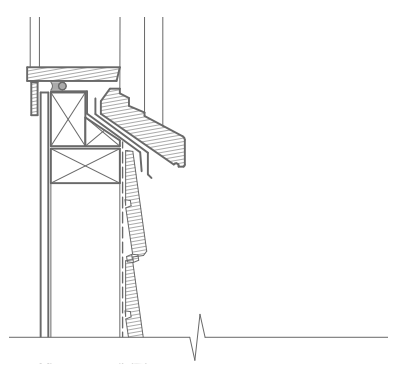

Existing window

(2.2.

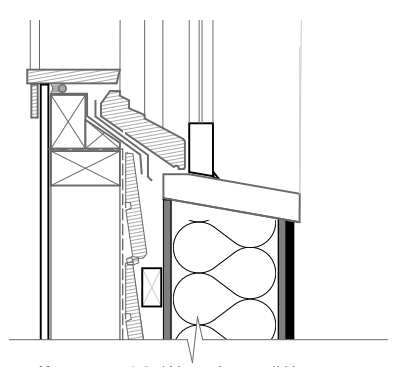

Base unit installed below existing window

(2.3)

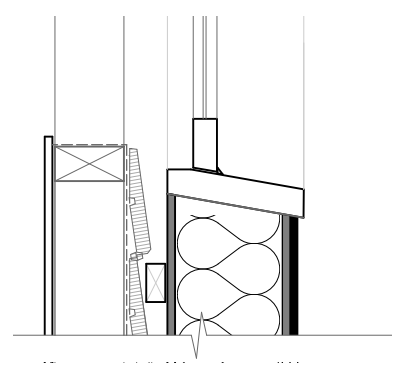

Remove existing window Seal existing framing with flexible flashing tape

(2.4)

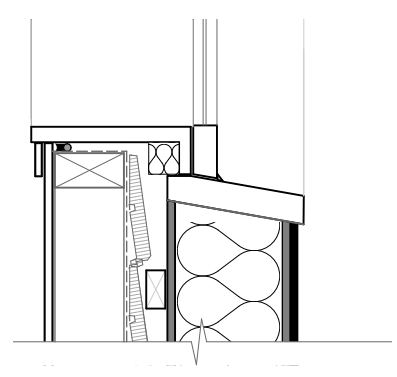

Window sill insert installed Seal joint between sill and existing wall

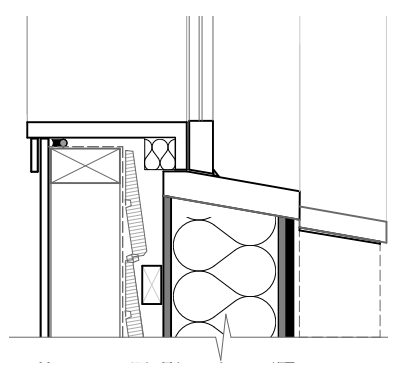

Adaptable program unit installed to Base Unit 


\section{Critical Reflection:}

The approach allows for the windows to be removed after the base unit is installed. The approach aims to limit occupant disruption by having a fully enclosed home at all times.

To fit below the existing window the new window was designed to be installed under the existing sill. Therefore the interior jamb and sill component would need to extend to meet the lower base unit.

The frame of the window would then need to be larger to extend at least above the sill component. Therefore impacting the overall window aesthetic.

Going forward a variation of the aesthetic should be refined to suit the existing home. Particularly an approach to reduce the need to install the window lower could help to resolve the visual impact and tricky installation of the jamb and sill component.

Fig 7.9

removed 


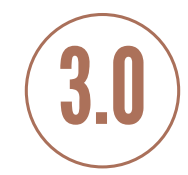

Openings Strategy 3.0

Base unit installed before window removed

3.1

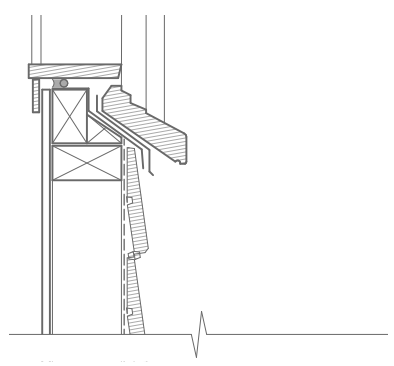

Existing window

3.2

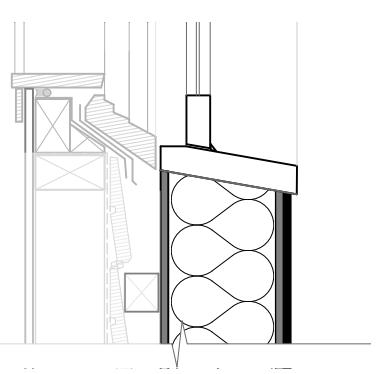

Base unit installed at greater distance from existing wall to accomodate window sill and surrounds

3.3

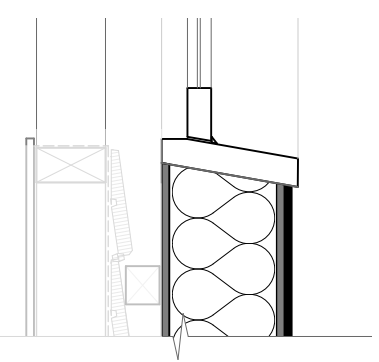

Remove existing window Seal existing framing with flexible flashing tape

3.4

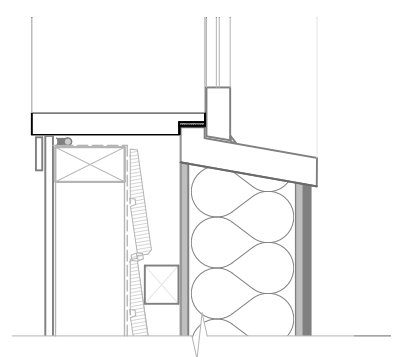

Window sill insert installed Seal joint between sill, existing wall and base unit

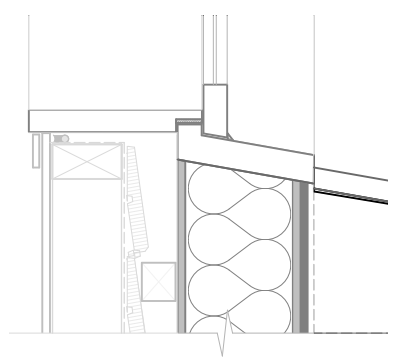

Adaptable program unit installed to Base Unit 


\section{Critical Reflection:}

The approach allows for the windows to be removed after the base unit is installed. The approach aims to limit occupant disruption by having a fully enclosed home at all times.

The designed approach would require more labour to cut through all of the opening window sills, increasing on site time and labour cost. Potentially creating greater disruption to the occupant with onsite construction noise, time and the finacial impact.

Going forward a further development should explore an approach that does not require any adaption to the existing home as per the initial design framework.

Fig 7.10 Concept sequence of base unit installed before 


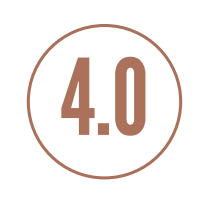

\section{Openings Strategy 4.0 \\ Base unit installed before window removed}

(4.1)

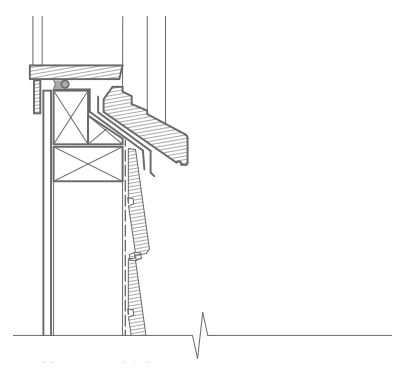

Existing window

(4.2)

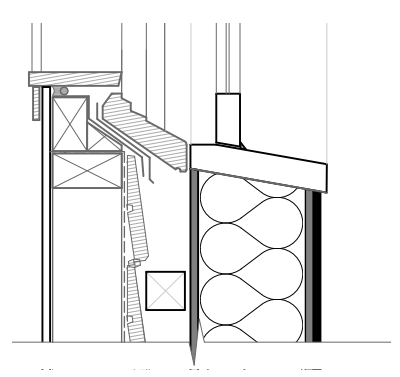

Trim existing window sill

Base unit installed

(4.3)

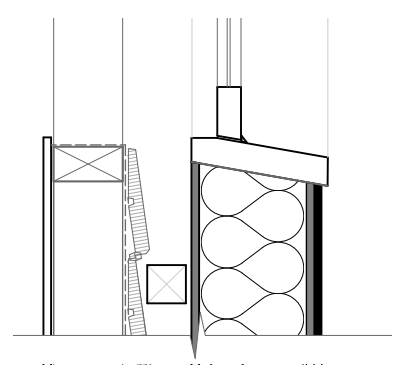

Remove existing window Seal existing framing with flexible flashing tape

(4.4)

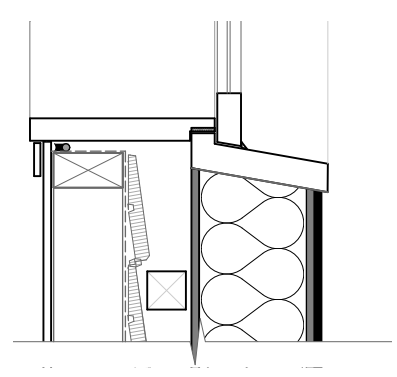

Window sill insert installed Seal joint between sill and existing wall

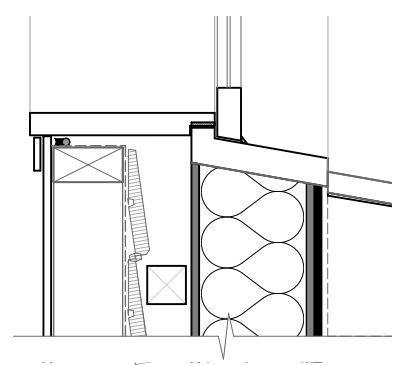

Adaptable program unit installed to Base Unit 


\section{Critical Reflection:}

The approach allows for the windows to be removed after the base unit is installed. The approach aims to limit occupant disruption by having a fully enclosed home at all times.

The approach results in the base unit and program being pushed out further away from the existing wall. Therefore increasing the overall depth of the wall, the depth under the eaves, and visual aesthetic. The designed approach would allow for more adaptability between housing variations and typologies. Particularly around the window construction as the connecting battens and the sill insert could be extended to suit and adapt around each individual home. Especially with an accurate 3D scanned digital model of the home to design an appropriate solution.

Going foward the designed approach would need greater developement to ensure the effectiveness of the design. The openings explorations are not the only possible solutions but are some potential methods to approach the problem.

Fig 7.11 Concept sequence of base unit installed before window removed 


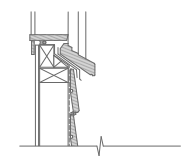

(1.1)

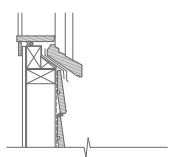

(2.1)

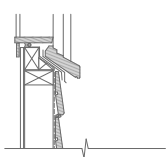

(3.1)

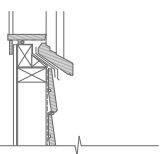

(4.1)

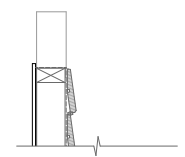

(1.2)

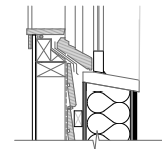

(2.2)

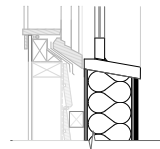

(3.2)

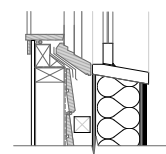

(4.2)

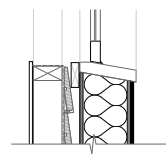

(1.3)

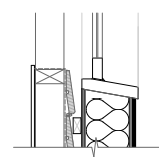

(2.3)

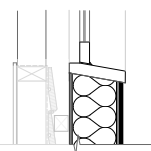

(3.3)

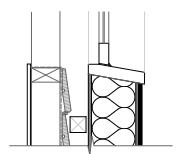

(4.3)

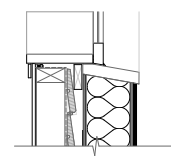

(1.4)

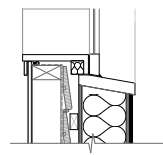

(2.4)

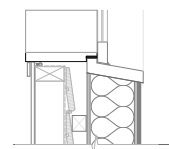

(3.4)

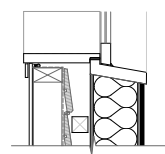

(4.4)

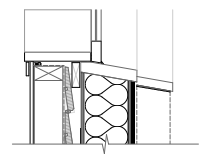

(1.5)

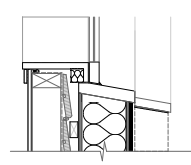

(2.5)

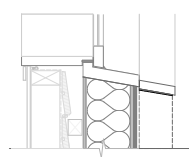

(3.5)

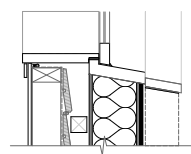

(4.5)

Fig 7.12 Window openings detail concept series 


\section{Findings}

\section{Critical Reflection:}

The approach to install the base unit before the existing windows are removed would reduce occupant disruption by:

\section{Advantage:}

- Maintaining weathertightness throughout construction process. Helps to mitigate the issues from weather and site conditions for the on-site construction process.

\section{Disadvantage:}

- The window removal would occur inside the home and have to be removed inside the house, likely creating greater disruption with noise, debris, the possible inability to manoeuvre the larger windows through rooms. Additionally, the work required to remove the windows could become difficult if the base unit is in the way to use tools effectively, potentially making the removal process more difficult.
The approach to install the base unit after the existing windows are removed would reduce occupant disruption by:

\section{Advantage:}

- The construction removes the windows externally. The work could be undertaken cleanly and with sufficient space to remove the windows and provide a cleaner state for the base unit to be installed.

\section{Disadvantage:}

- The weathertightness for the occupant would be compromised during the process. A solution to minimise the impact could be to stage the removal and installation process within the same day and stage the installation around the perimeter of the home.

\section{Outcome:}

Therefore the approach to remove the windows before the base unit is installed may actually work out to be a better and less disruptive solution overall. 
The following explores the concept base component design and identifies the key design findings revealed in the process.

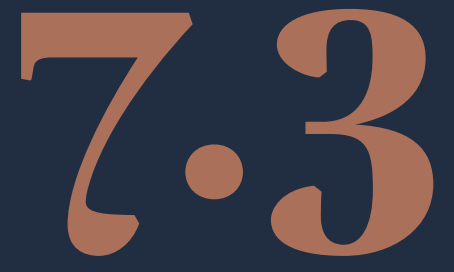

\section{The}

Base

Component 


\section{The Base Component}

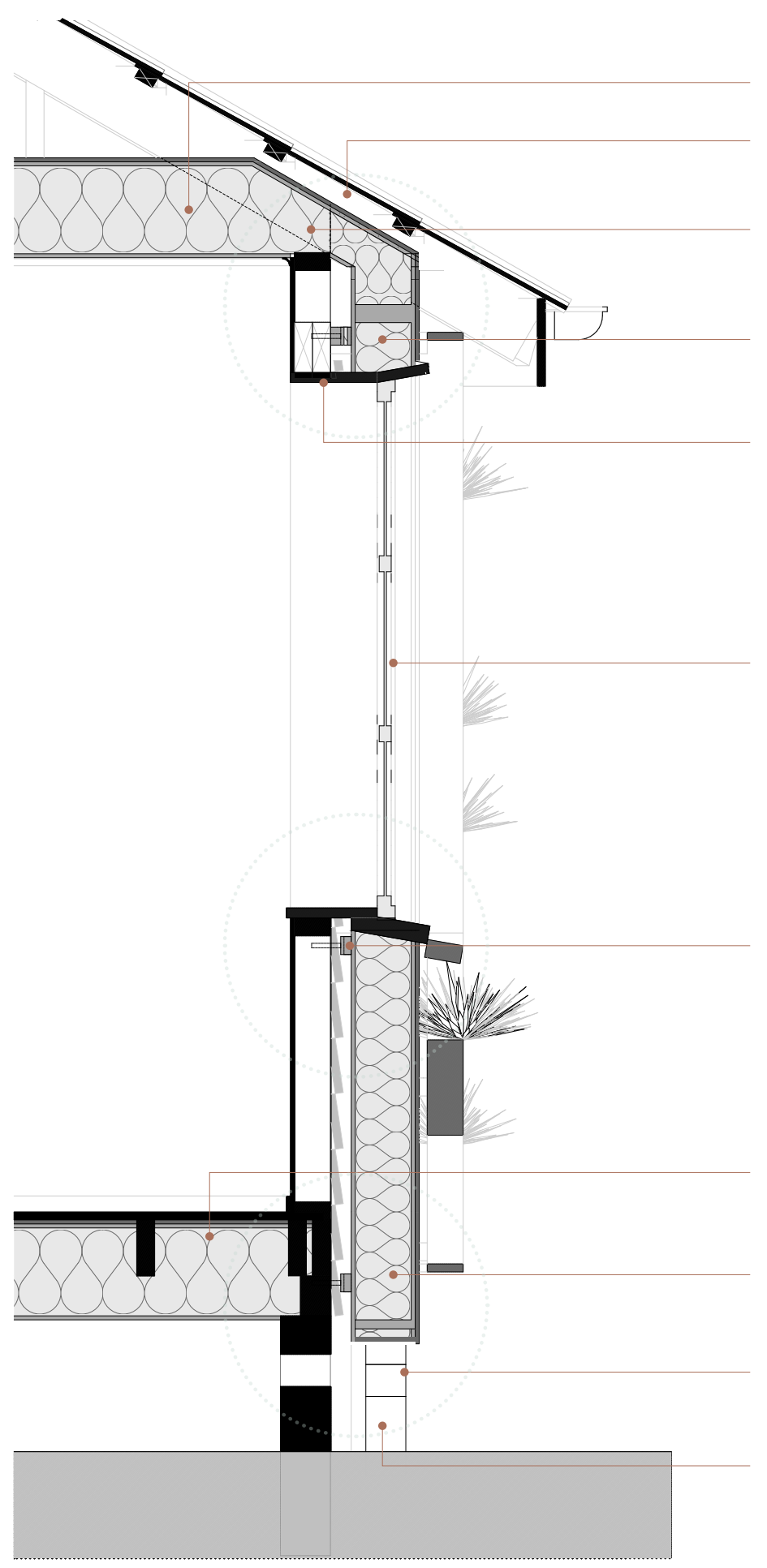

Ceiling insulation

Ensure ventilation to roof cavity

Continuous envelope as reasonable as possible between ceiling and wall

Soffit removal for sufficient access above the window

Window inner liner unit installed into existing window opening after wall unit installation

New thermally broken high performing window prefabricated into wall unit, centrally aligned in wall to reduce thermal bridging

Wall unit connection thermally broken clip system to exisiting. Installed prior to wall unit to align with precast clips to wall unit.

Insulation to subfloor

Wall unit extended beyond thermal bridging area at floor level Ventilation to subfloor and wall cavity for drying and drainage Foundation system to support wall if neccessary - future development

Fig 7.13 Integrated section diagram highlighting focus areas 


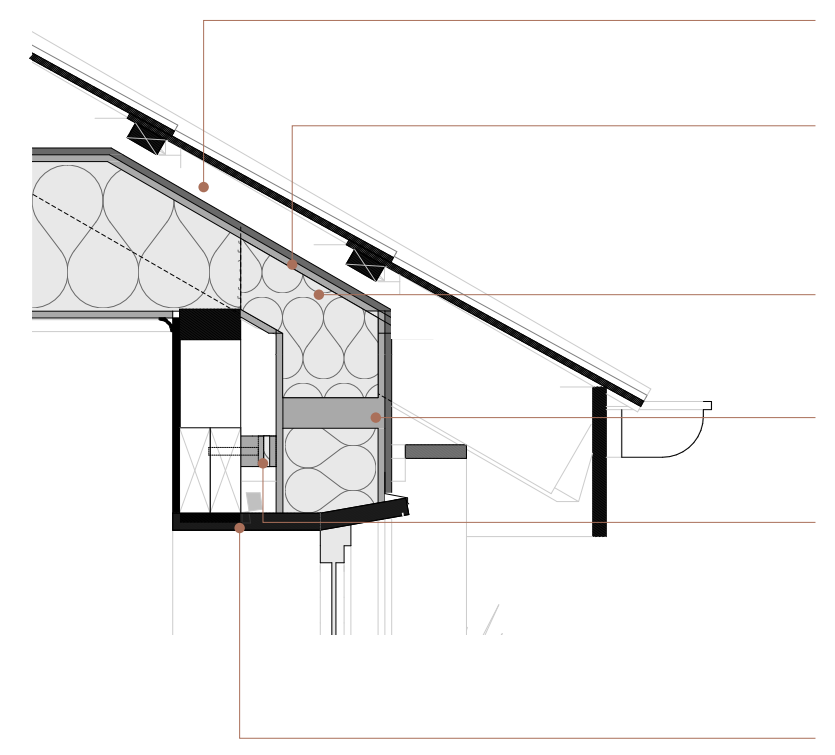

Ventilation to roof cavity

Continuous envelope as reasonable as possible between ceiling and wall

Connecting unit installed prior to wall unit

Wall unit head. Connects to soffit unit below rafter line.

Wall unit connection thermally broken clip system to exisiting. Installed prior to wall unit to align with precast clips to wall unit. See window head detail

\section{WALL TO CEILING} Base Unit Design

Fig 7.14 


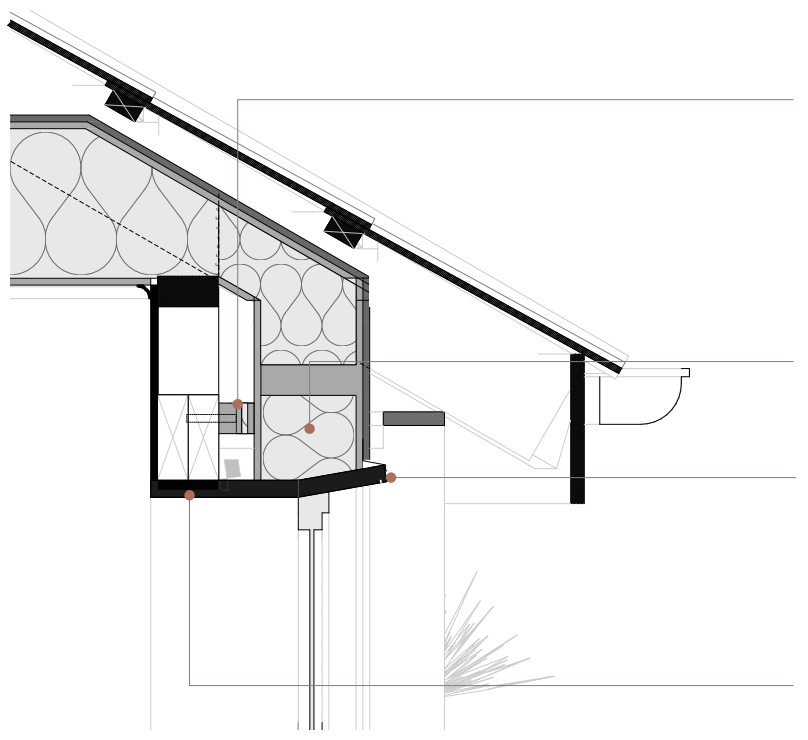

Wall unit connection thermally broken clip system to exisiting. Installed prior to wall unit to align with precast clips to wall unit.

Soffit removal for sufficient access above the window

Flashing to overlap window head, window head with drip edge slanted to allow greater opening to window

Window inner liner unit installed into existing window opening after wall unit installation

\section{WINDOW HEAD}

\section{Base Unit Design}

Fig 7.15 


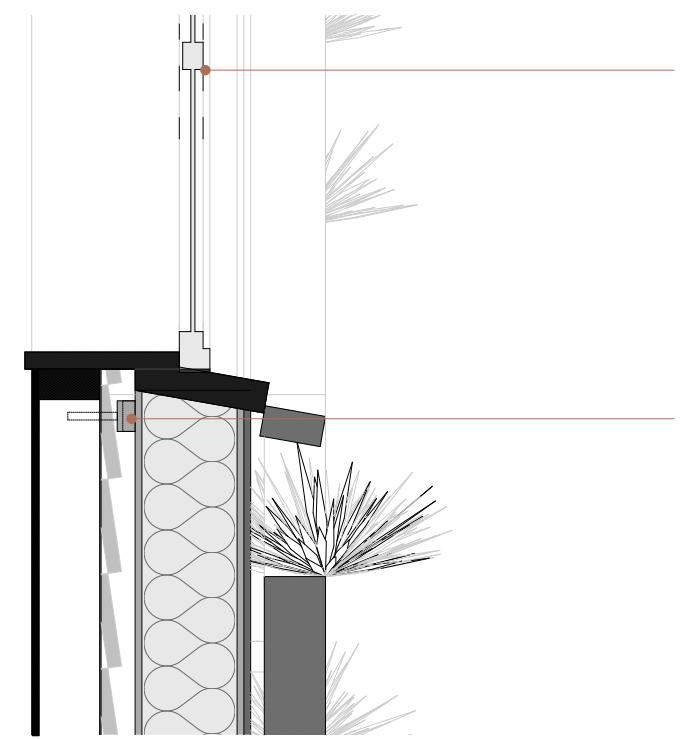

New thermally broken high performing window prefabricated into wall unit, aligned to mitigate thermal bridging

Wall unit connection thermally broken clip system to exisiting. Installed prior to wall unit to align with precast clips to wall unit.

\section{WINDOW SILL}

Base Unit Design

Fig 7.16 


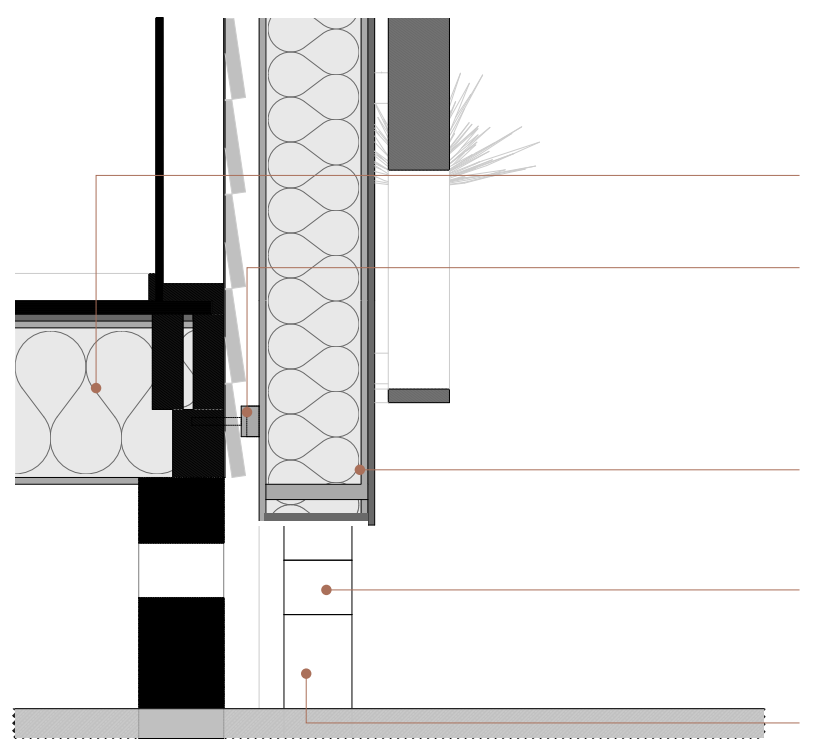

Insulation to subfloor

Wall unit connection thermally broken clip system to exisiting. Installed prior to wall unit to align with precast clips to wall unit.

Wall unit extended beyond thermal bridging area at floor level

Ventilation to subfloor and wall cavity for drying and drainage

Foundation system to support wall if neccessary - future development

\section{FOUNDATION} Base Unit Design

Fig 7.17 


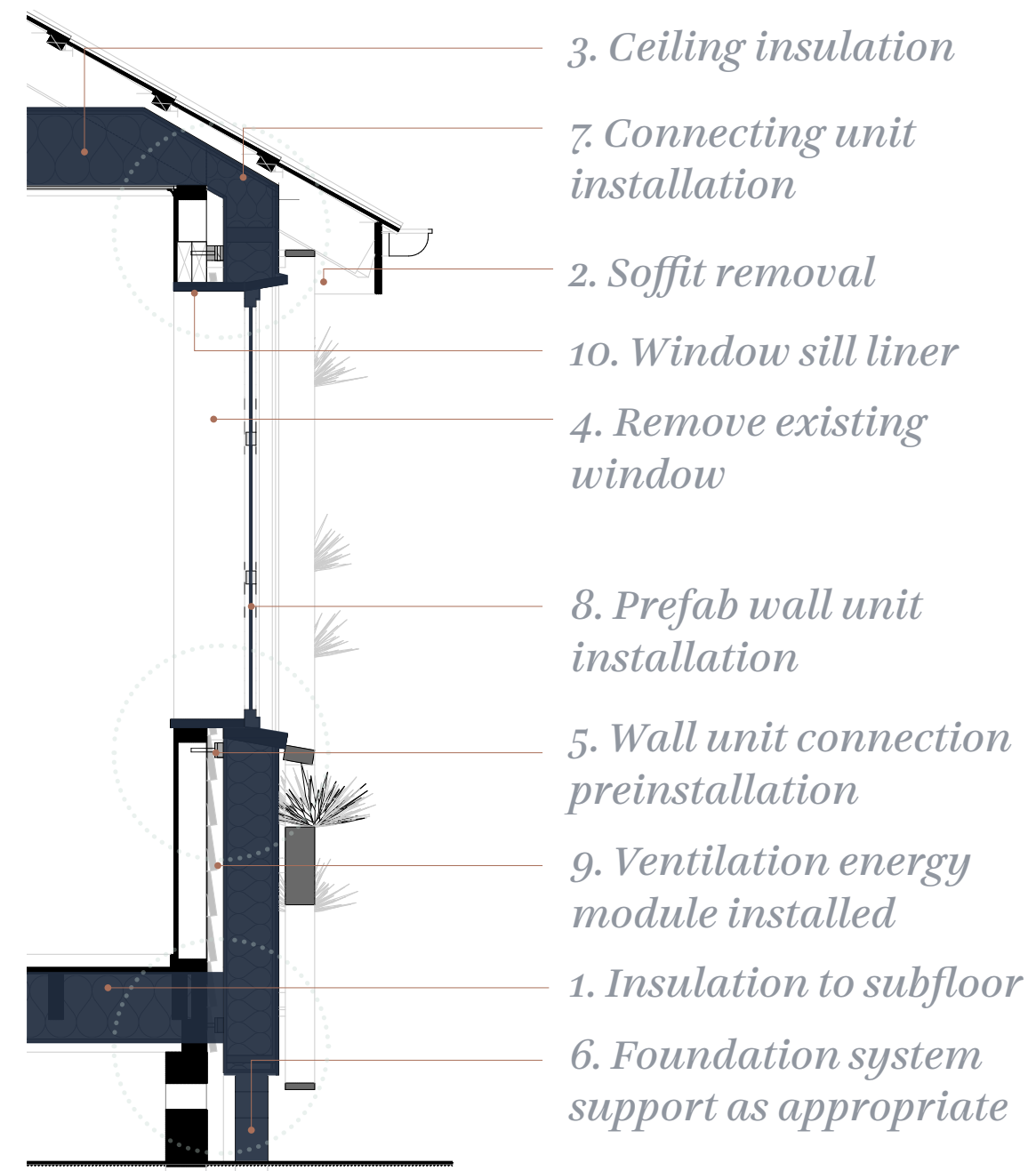

Fig 7.18 


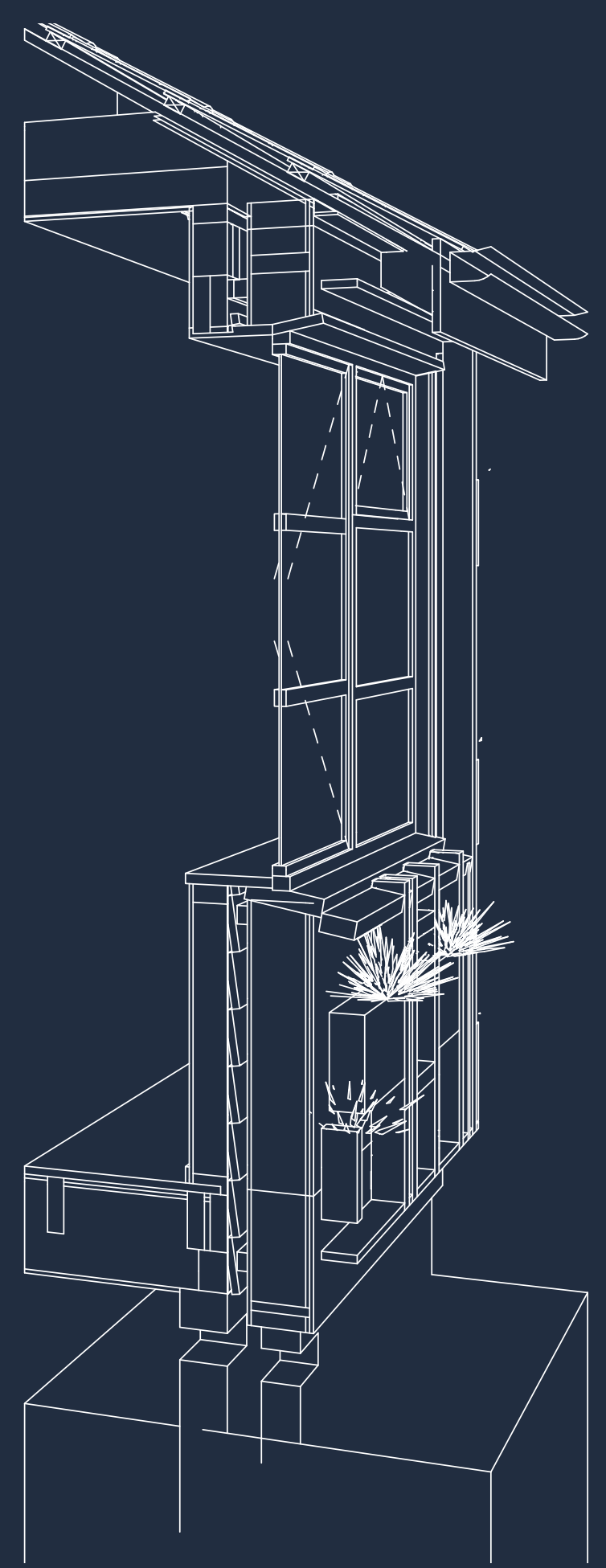

Fig 7.19 Concept 3D section of base component design 


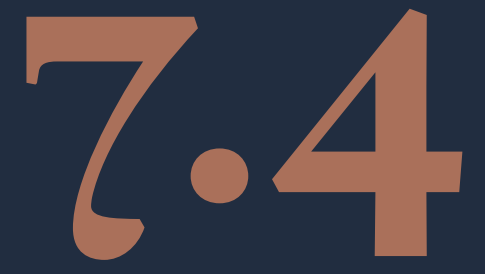

Findings $\mathbb{E}$ Reflections 


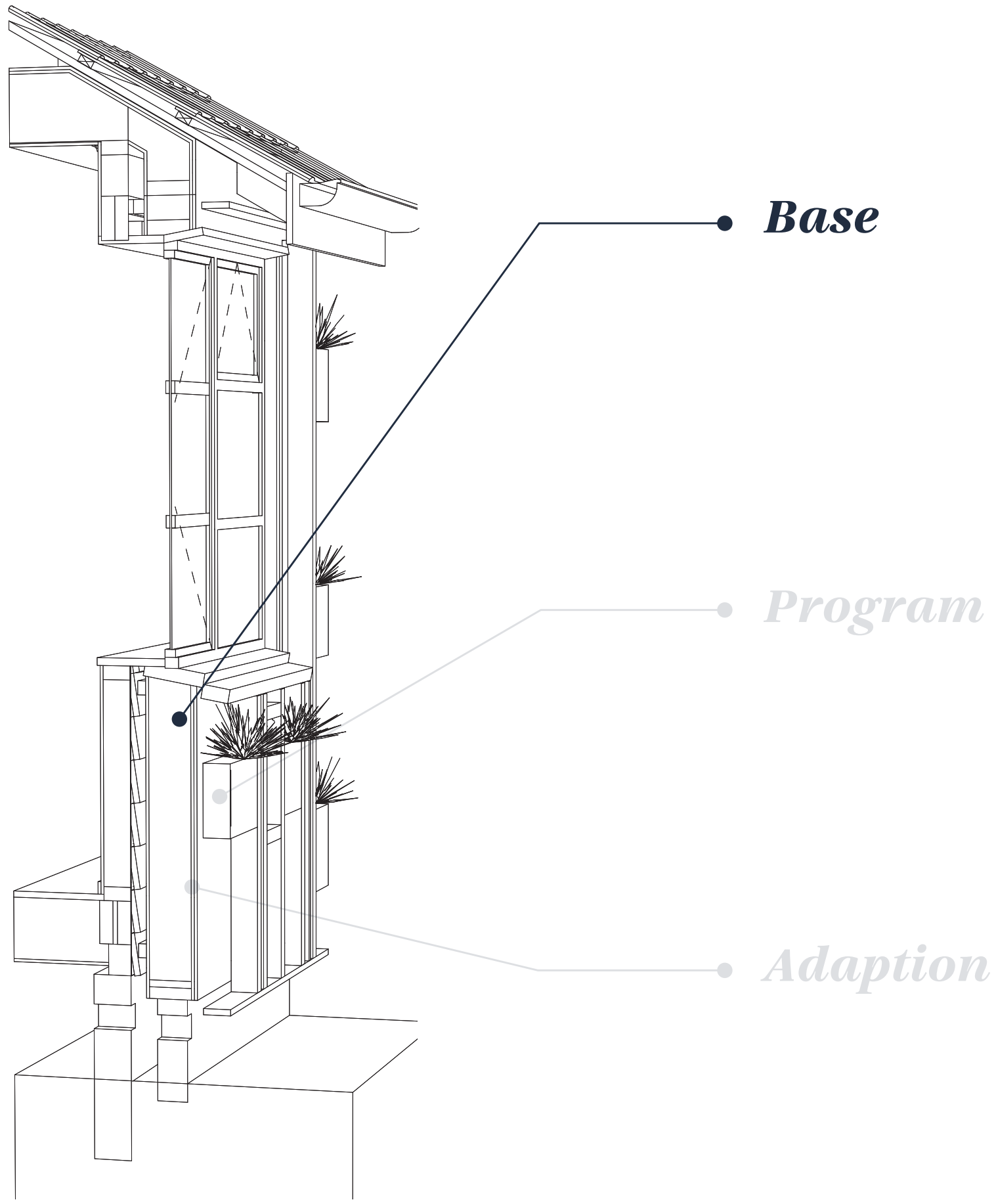

Fig 7.20 Diagram highlighting base component 


\section{Critical Reflections}

- Envelope Continuity - The research finding to develop a continuous envelope was challenging to achieve around the existing house. Particularly connecting to the subfloor insulation across the existing foundation wall but allow appropriate ventilation to the wall cavity. The ceiling to wall connection has more continuity, although the rafters would still compromise it. Ultimately the envelope strategy is a far more significant improvement to thermal performance.

- Control Layers - The assumed simplified control layer structure for the retrofit was sufficient to explore the base component concept to explore a retrofit solution without displacing the occupants. Further, the development would explore the detail construction, material properties, material compatibility and selections to ensure adequate building envelope performance.

- Wall - The wall unit component was the primary focus in the design exploration. The unit serves as a base to integrate the program component onto for home enrichment. Additionally, the wall unit is the area most likely to cause occupant disruption and therefore, the prefabricated unit design worked to cause the least disruption. The wall unit mitigates thermal bridging by breaking the path of thermal conductivity by a thermally broken cavity separation to the existing wall.

- Ceiling - The design concept assumed a high level of insulation according to the design standards assessed in Chapter 5.0 as a simple and less invasive insulation design as explored in Chapter 7.0. The insulation and control layers must continually integrate with the connecting eave unit. Sufficient space to ventilate the ceiling cavity extends above the connection eave unit.
- Floor - The design concept assumed a high level of insulation according to the design standards assessed in Chapter 5.0 as a simplified floor insulation solution. A continuous connection to the wall was not achieved around the existing foundation wall. However, the wall unit was designed to extend below the floor level to overlay the wall insulation beyond the subfloor to manage the base wall thermal bridging. The wall base is not to obstruct vents to the subfloor and to allow sufficient venting to the subfloor.

- Windows - The design concept assumed high performance windows into the prefabricated wall unit as found the most beneficial longterm solution for energy efficiency and occupant health and well-being. Although the removal of the existing windows will cause some disruption to the occupants. The opening sequence exploration found the approach to remove the windows before the base unit installation as a method least disruptive to occupants, especially with a sequential methodology addressing each elevation at a time. The window location aligned toward the centre to reduce thermal bridging was found to be the most efficient location (New Zealand Green Building Council, 2020, p. 63). The window sill insert could be extended to suit and adapt to each home for adapting to each window size and depth.

- Adaption - The concept would allow for more adaptability for program, between housing variations and typologies.

- Future - The design approach would need further development refine and test the design performance of the envelope. 


\subsection{WALL PROGRAM DEVELPMENT \\ Design of parametric script}

\subsection{PHYSCALL MODEL EXPLDRATION \\ Visualisation of program component applied to existing home}

8.3 DIGITAL DEVELOPMENT

8.4. $\begin{gathered}\text { PROGRAM BRIEE SERIES } \\ \text { Designo oppramerticscript }\end{gathered}$ 


\section{BLURRING BOUNDARY.}

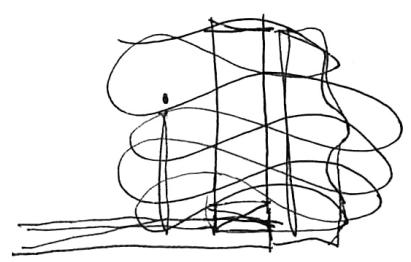

Fig 8.1 Extending the home experience to the external envelope, Author's sketch.

The following Chapter fulfils the research objective: Propose an architectural response to enrich the environmental experience. The objective was to use an architectural program to enrich the humannature relationship to support health and well-being. The exploration supported by background research (Chapter 2.0), findings informing framework (Chapter 5.0), and initial design findings (Chapter 6.0). The Chapter also fulfils the research objective: Explore the use of parametric digital tools for adaptability of the design strategy. The objective was to develop the digitalisation of the design adaptable to varying input parameters to result in diverse design outcomes. 


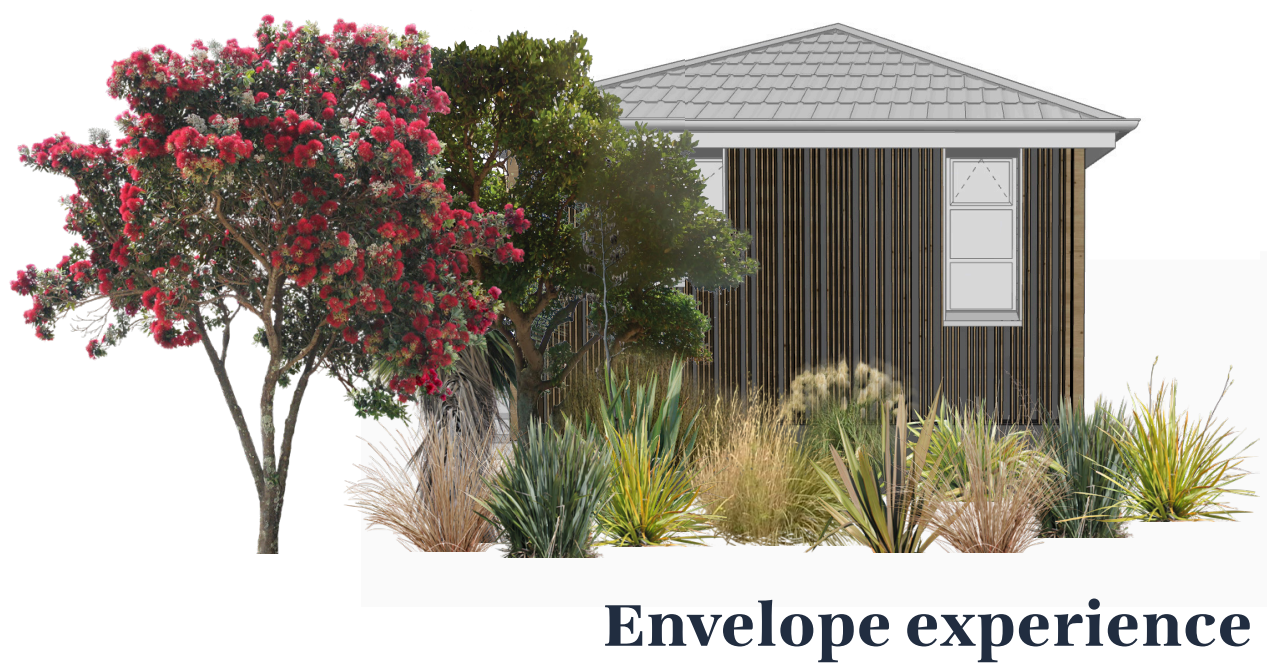

Fig 8.2 The opportunity of the envelope boundary to 
The following exploration investigates and develops conceptual findings of Chapter 5.0 to integrate the program into the wall design for enriched envelope use and environmental experience.

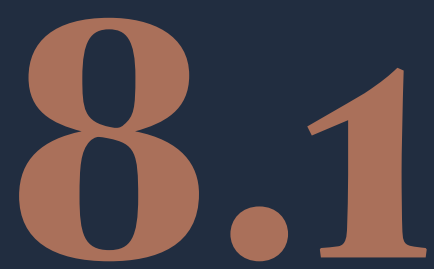

\section{Wall}

Program

Development 


\section{Program beyond performance}

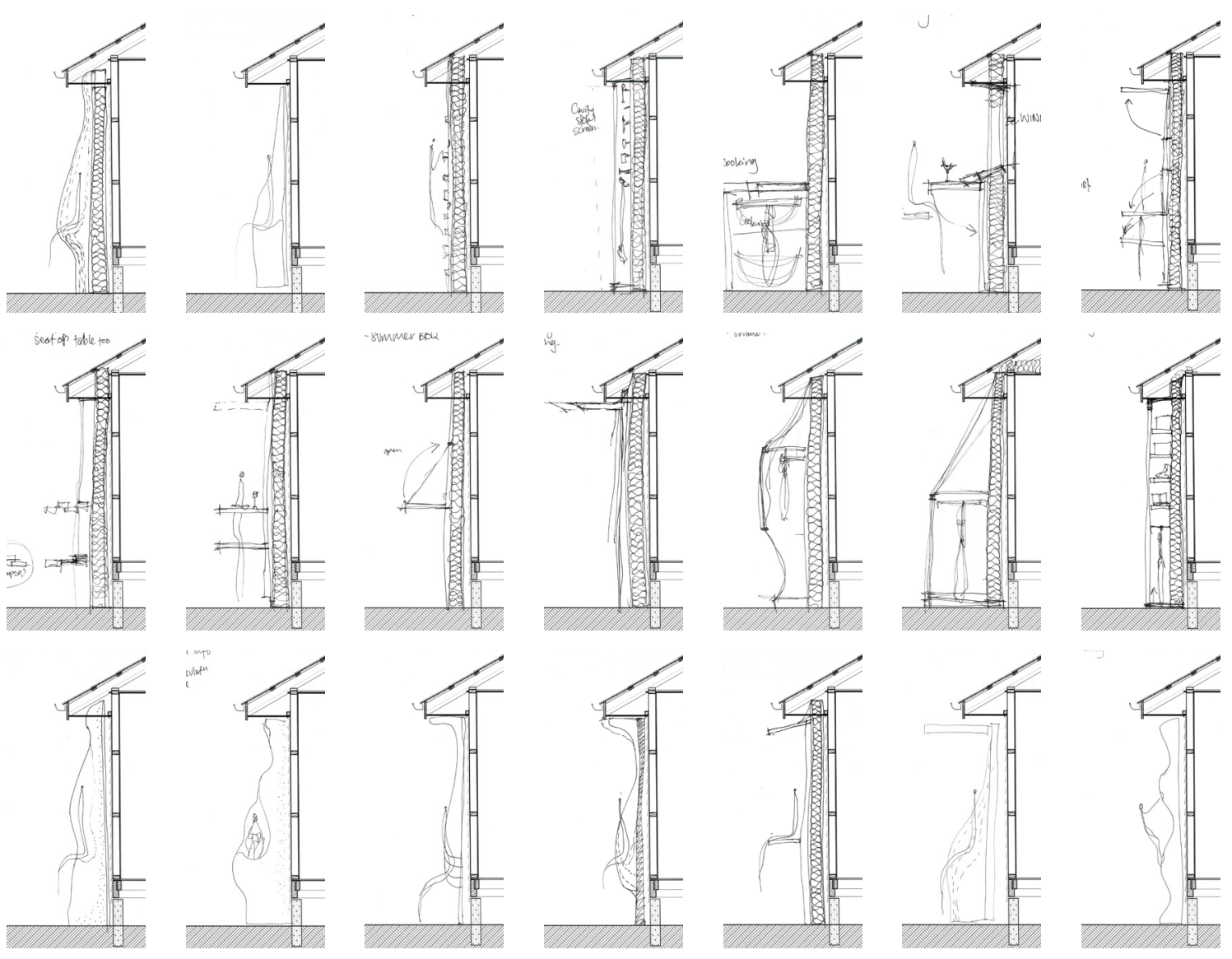

Fig 8.3 A series of section explorations of program beyond performance for occupant experience, Author's sketches. 


\section{Greater holistic experience}
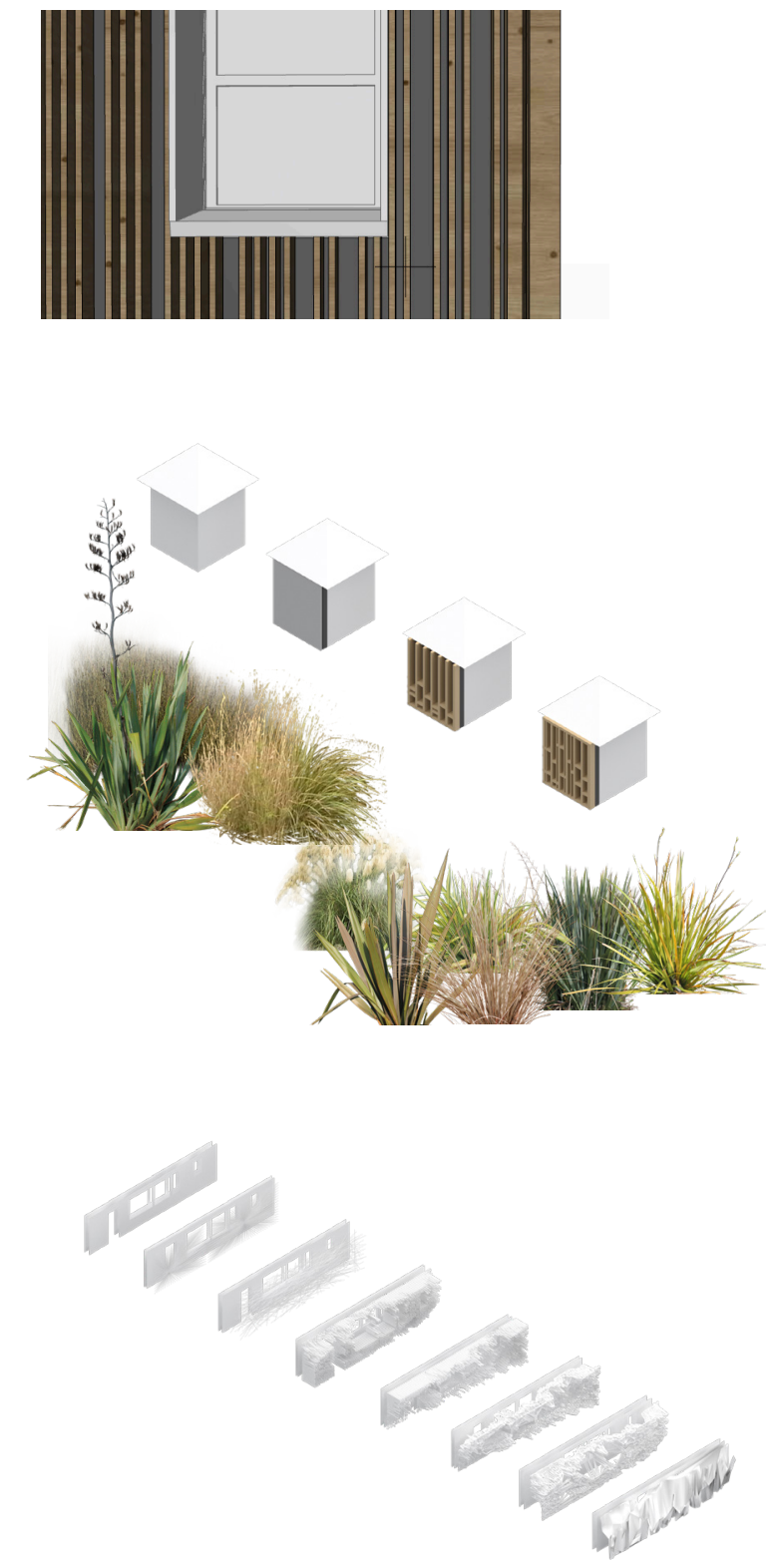

Fig 8.4 Conceptual design beyond the pragmatic wall thermal 

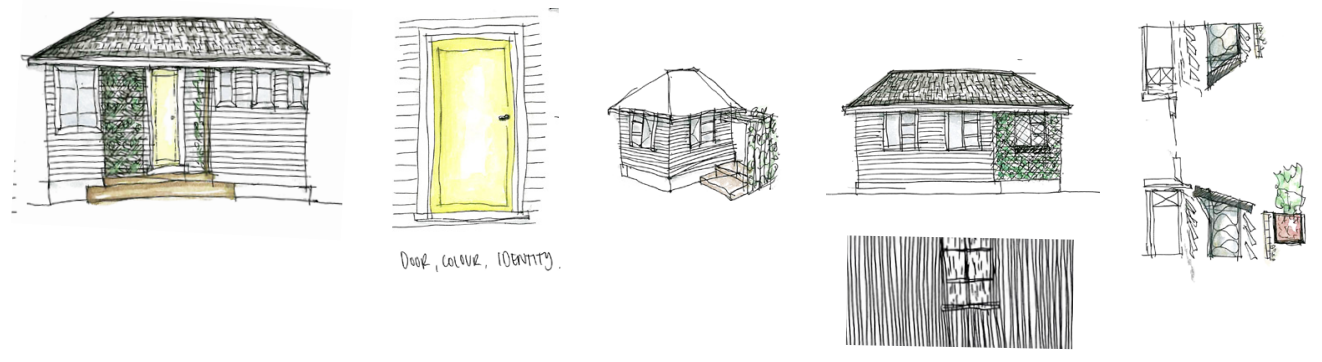

Doof, colver, loentity
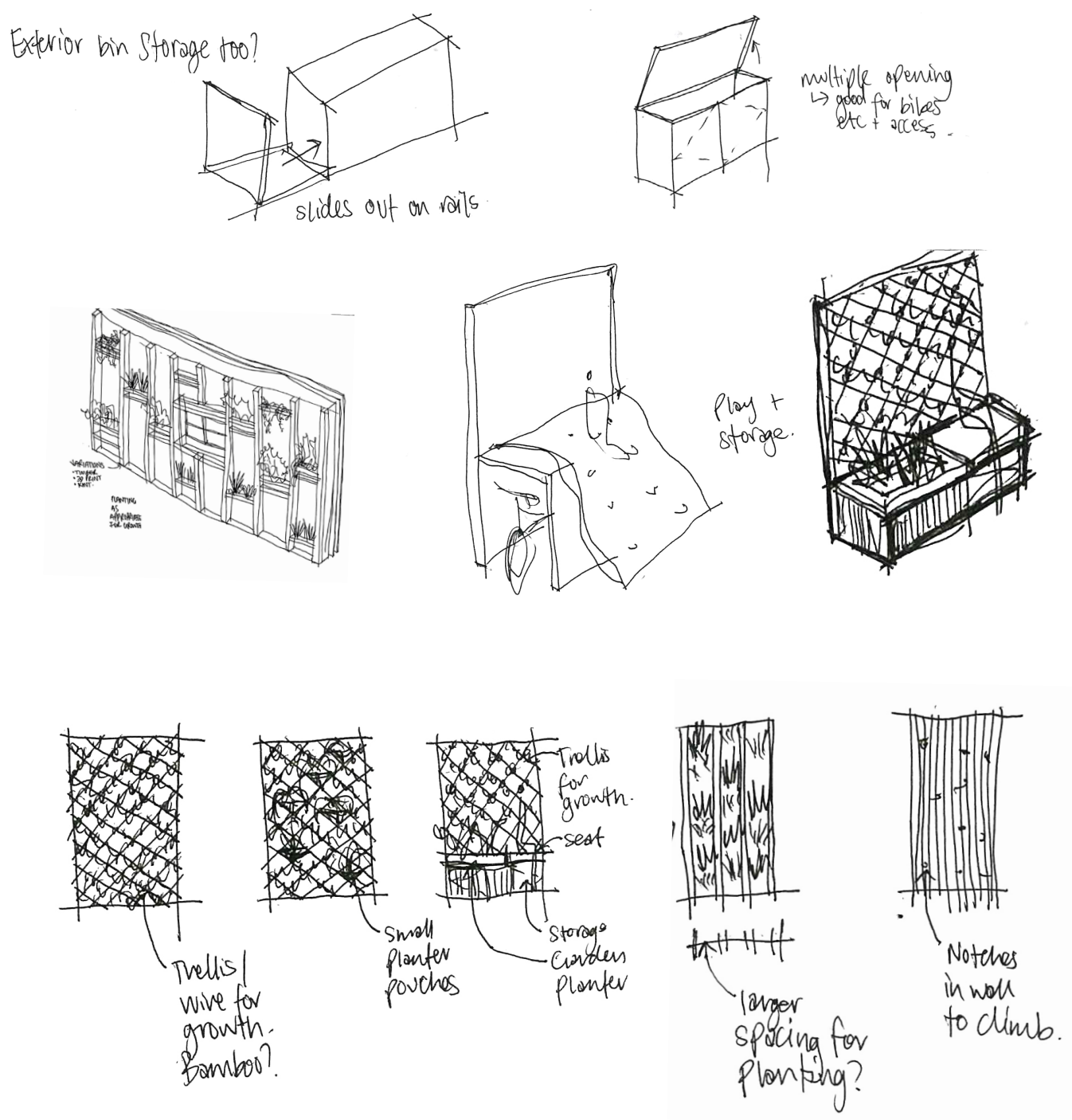

Fig 8.5 Conceptual program explorations, Author's sketches. 


\section{Adaption \& Sequencing}
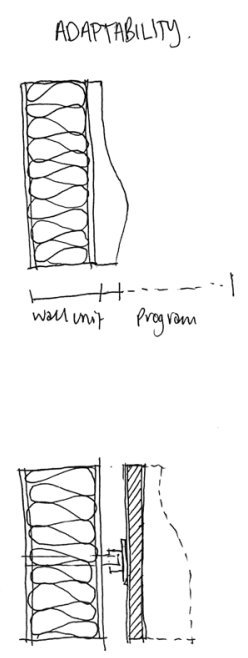

$\left.\right|_{\text {could arso Easily replocadele }}$ be unlocked La As life sboge bar +suapped changes/wanting for repoirs houre refuesh. la fomever oldea-ponels less disupten could be snapped = less disupitn between homes. to thermal envelofe. the resource.
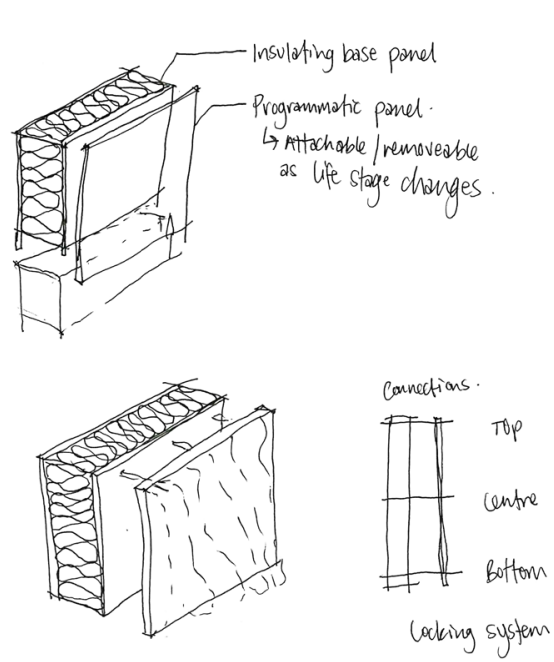

Allows for slaging cost ett

- ie base ù simplified panel cladding

- Then want to sitetc shower - can swap out as reeded.

- Ear back system soeditam? approach - where only paring for added benefits depending on Use?

isues etc $\downarrow$

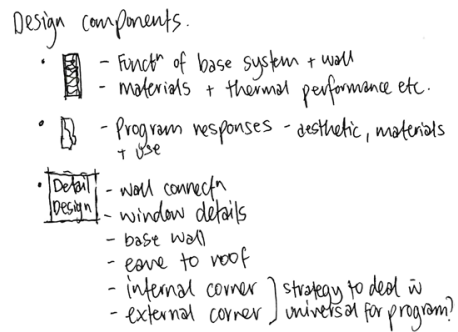

- Program adaptability.

- PJ final case study - Proprose dient

Totentially? - propose a change in their story - ic have boby got trang of gandening, need sforage etc + pram (bolas) - Mavaskar

"FUTURE" - Extension etc

- Align ment-sforage shover plumbing Propose these uses would reed full

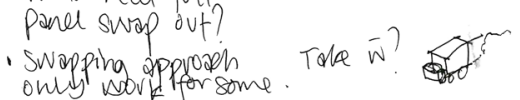

ADAPTION DIAGRAM
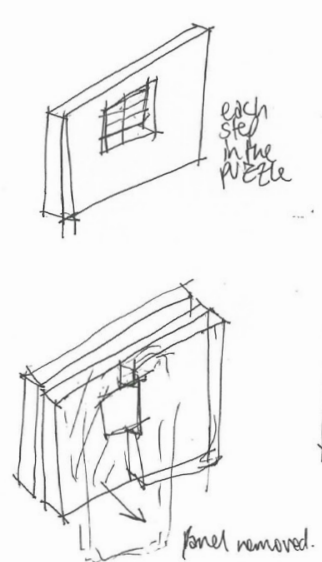

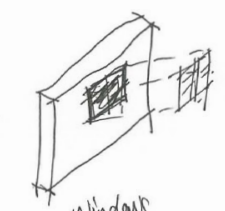

windors

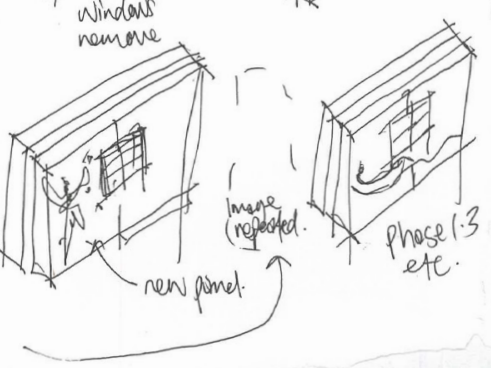

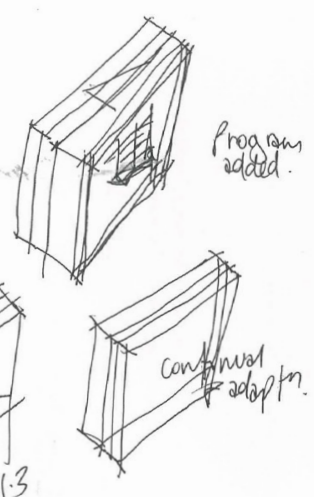

Fig 8.6

of wall adaptability and sequencing, Author's sketches 


\section{Wall Integration}
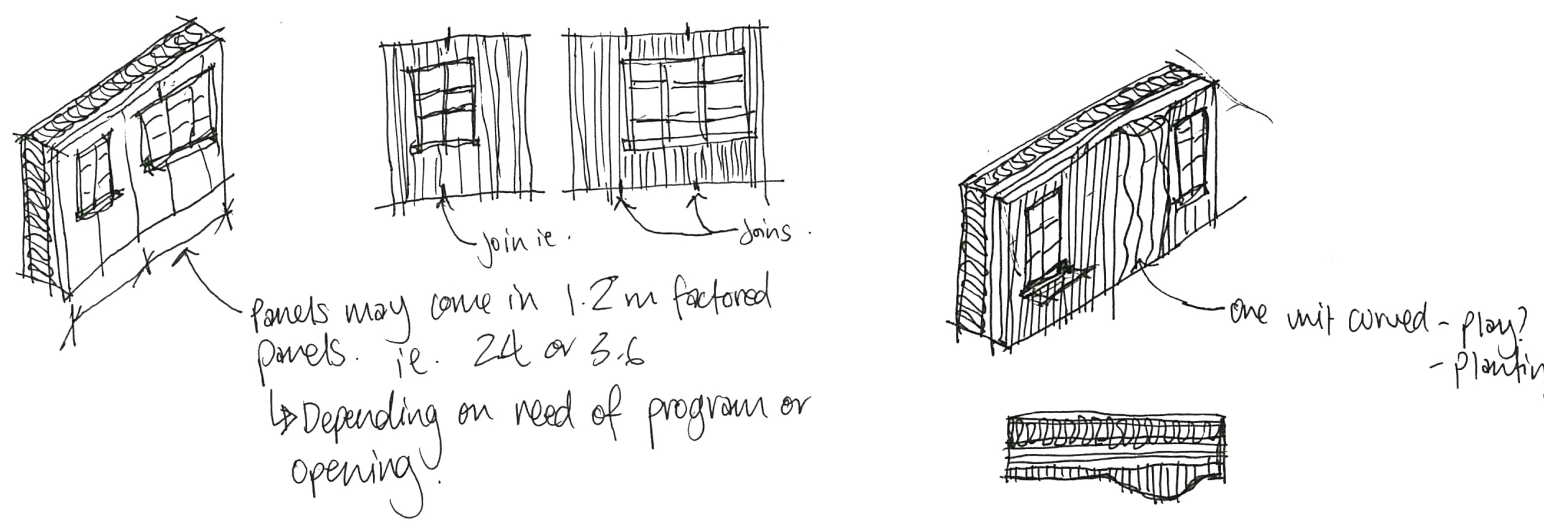

Fig 8.7 Concept understanding implications of integrating pro-

gram wall units together, Author's sketches.

\section{Critical Reflection:}

- The connection between differing panels would need to cohesively integrate, mainly through material combination, wall thickness and program function.

\section{Findings:}

- Opportunity to integrate program uses together.

- Opportunity to develop standardising wall panels to support cohesive integration. 


\section{Program Integration}
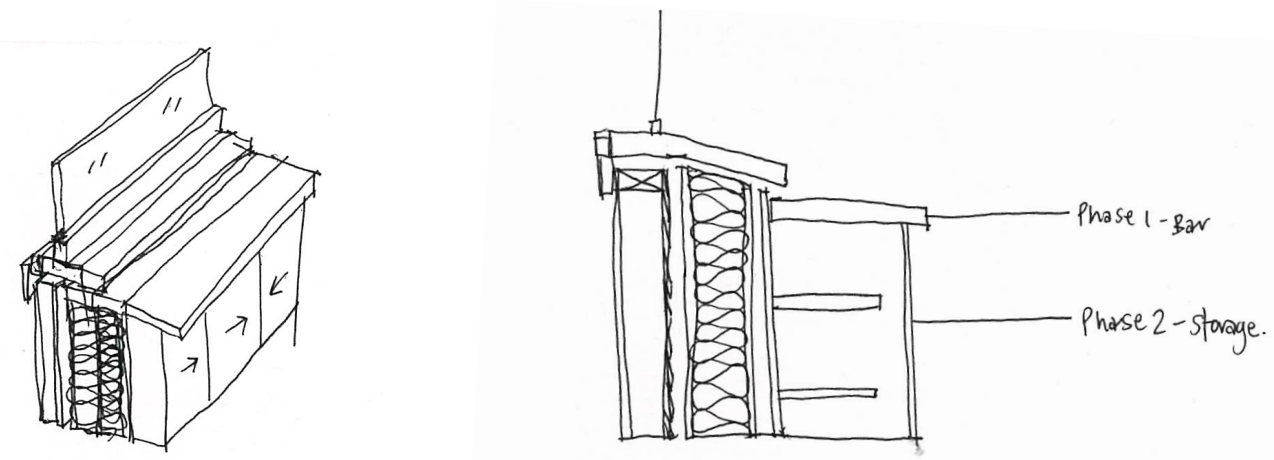

Fig 8.8 Concept understanding implications of integrating pro-

gram uses together, Author's sketches.

\section{Critical Reflection:}

- The program integration could occur as part of the initial construction or to potentially be added later on as occupant needs changed.

\section{Findings:}

- Opportunity to integrate program uses together.

- Opportunity to stage the integration of program added as needed over time. 
The following physical models shifted medium to consider how the program could integrate with the envelope.

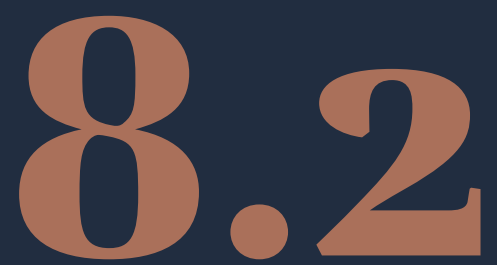

\section{Physical} Model Exploration 

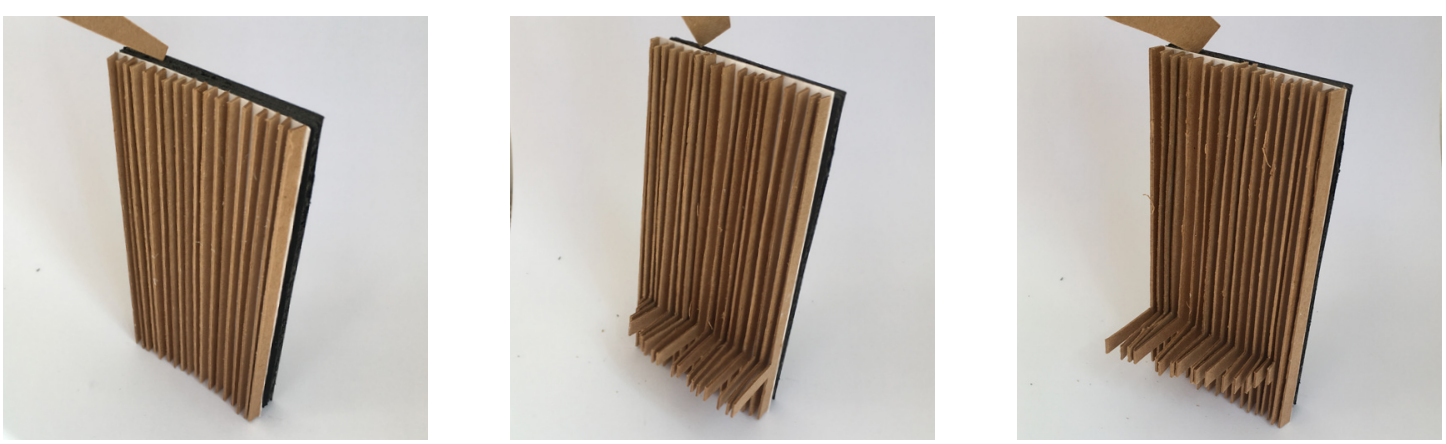

Fig 8.9 Physical program integration within wall panels, the 

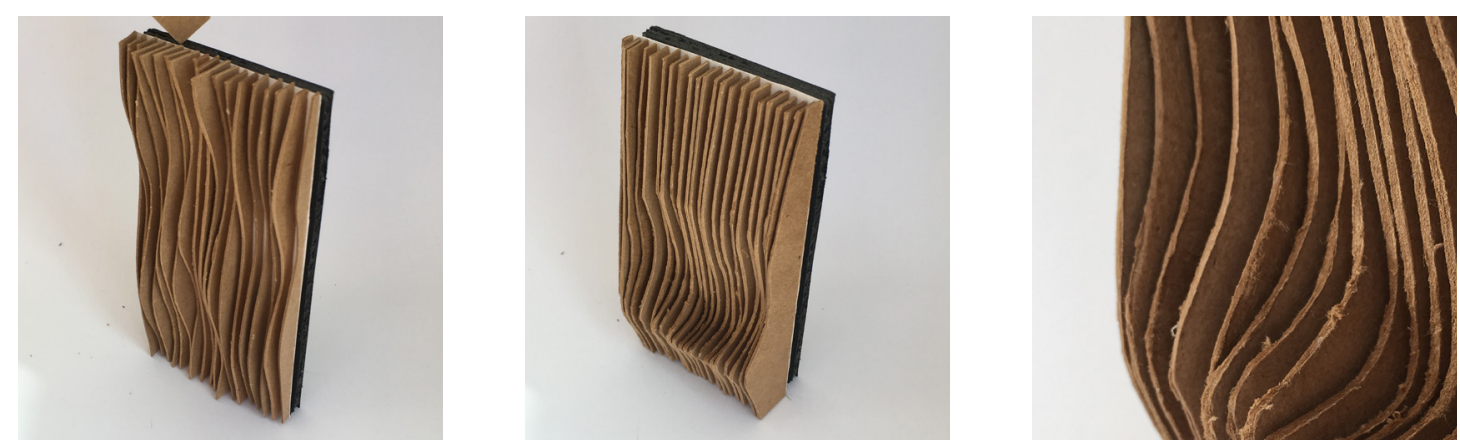

Fig 8.10 Physical program integration within wall panels, the idea for the program to blend within the envelope. Author's Image 


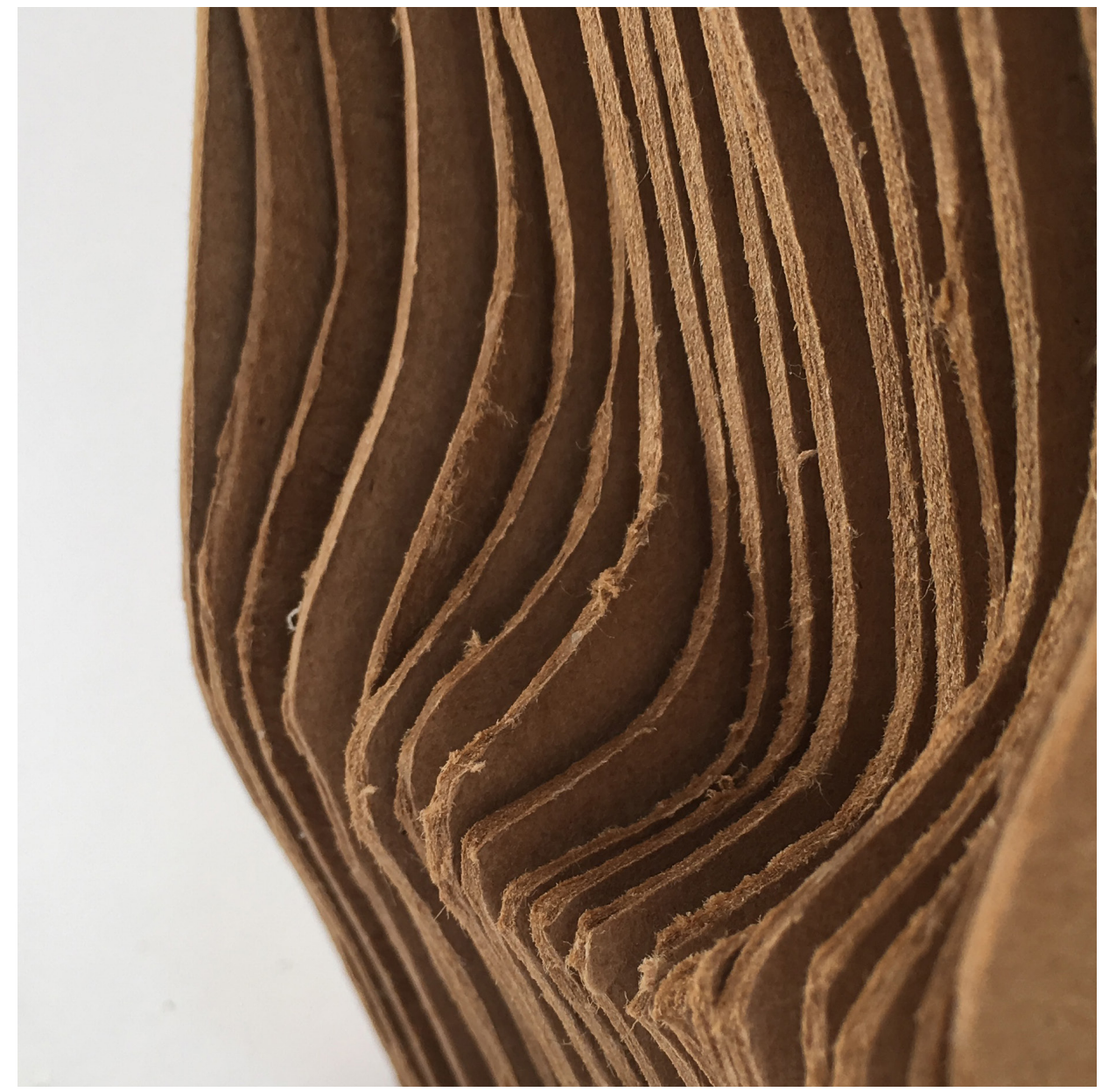

Fig 8.11 


\section{Critical Reflections G Findings}

- Physical modelling was a useful tool to shift to a tangible design mode. It identified the higher labour time of such style of design.

- The integration suggests how the program could seamlessly integrate within the overall wall strategy to the home.

- The curved wall elements integrate seating into a dynamic wall surface. However, each element's construction would only be feasible with optimised digitisation for construction for the best use of materials and a feasible construction time.

- The program output could vary greatly depending on visual appearance, materiality and intended program use. 
The following digital models develop the initial investigation of the integrated seating within the wall envelope and with multiple program types.

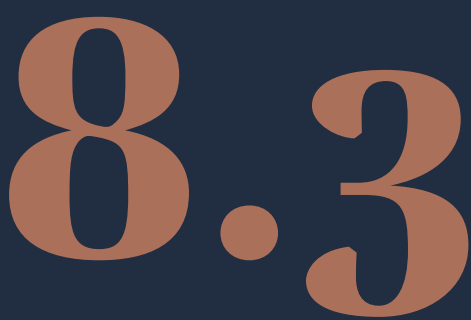

\section{Digital \\ Development}




\section{Program variation $\mathcal{E}$ integration into wall}

Fig 8.12

integration, Author's Image

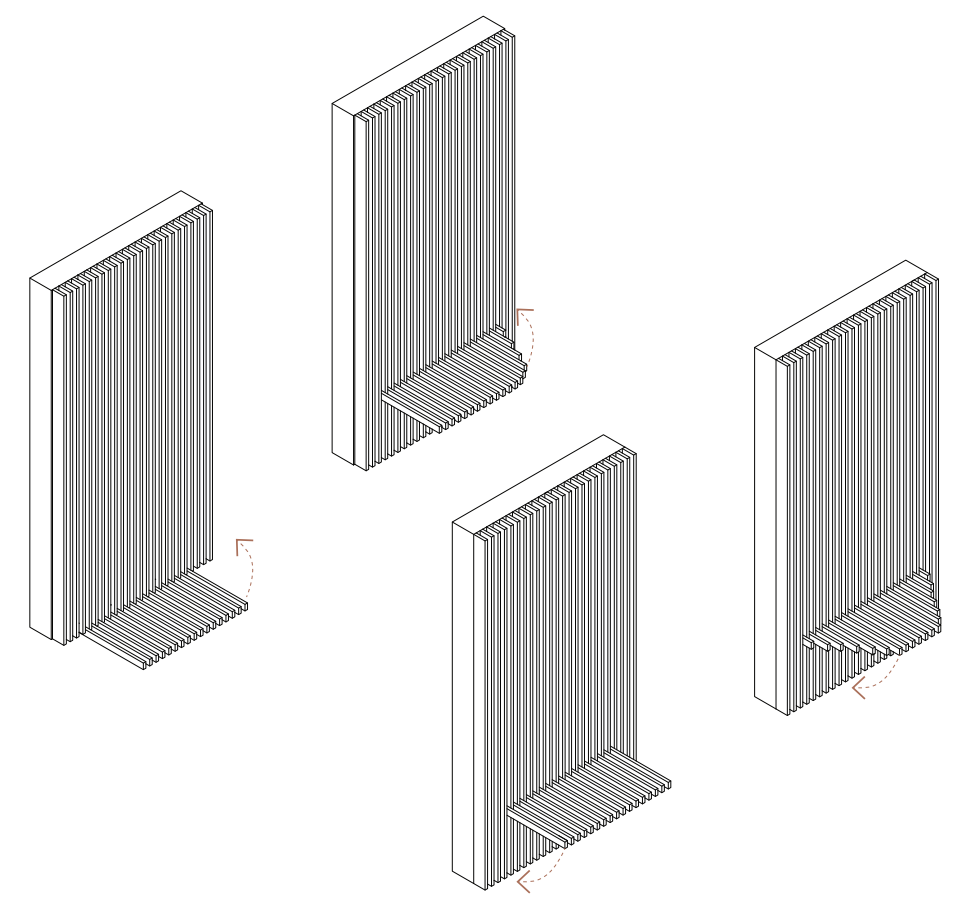




\section{Integration between program units}

Fig 8.13 seating integration of program between wall

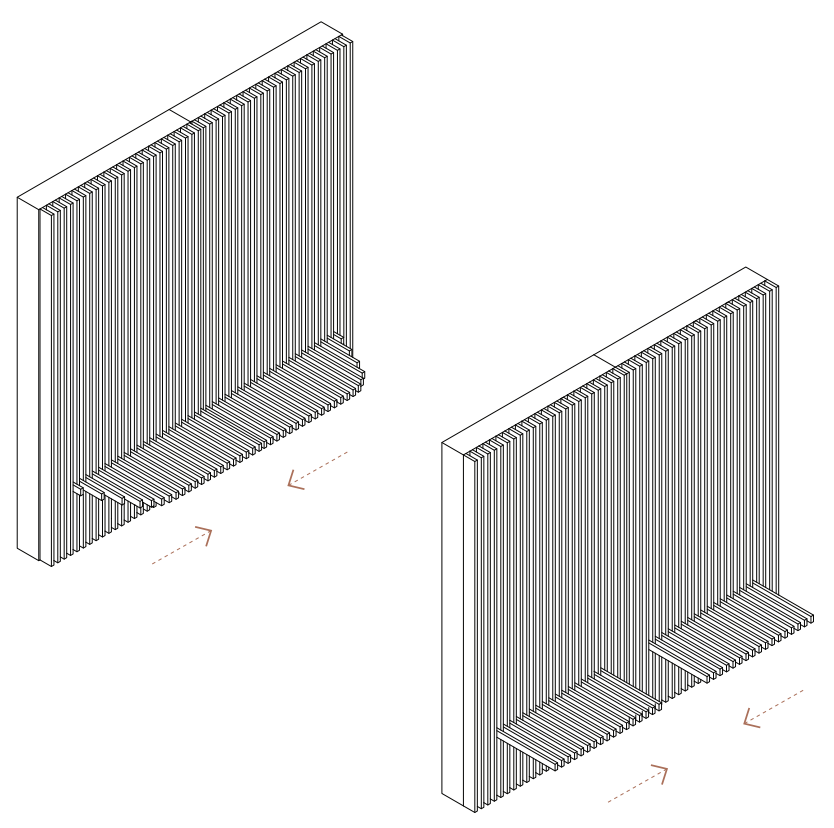




\section{Integration between program units - multiple functions}

Fig 8.14 Seat \& Table Explorations, opportunity for integration of program

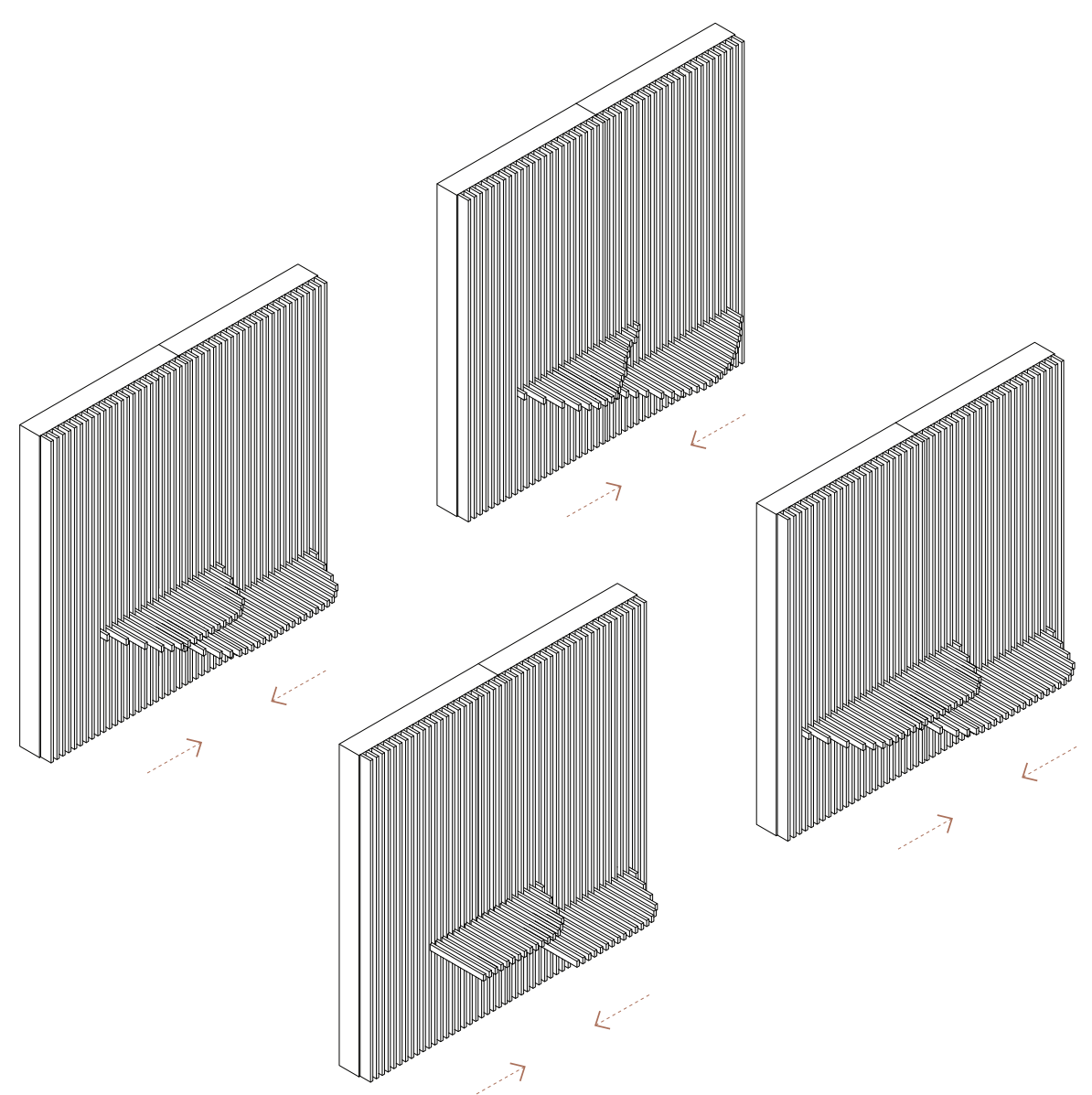




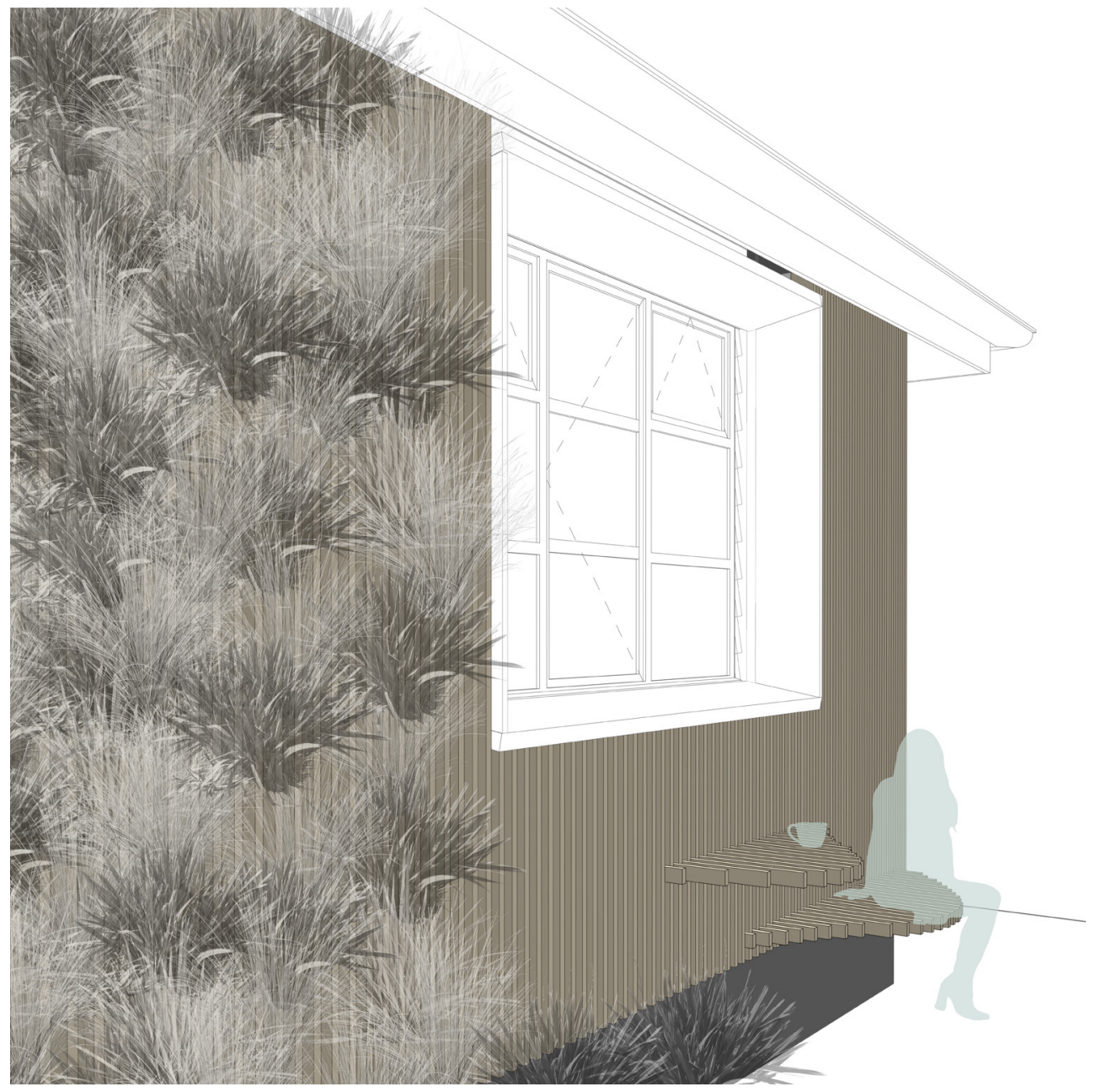

Fig 8.15 Program unit initial design visualisation, Author's Image 


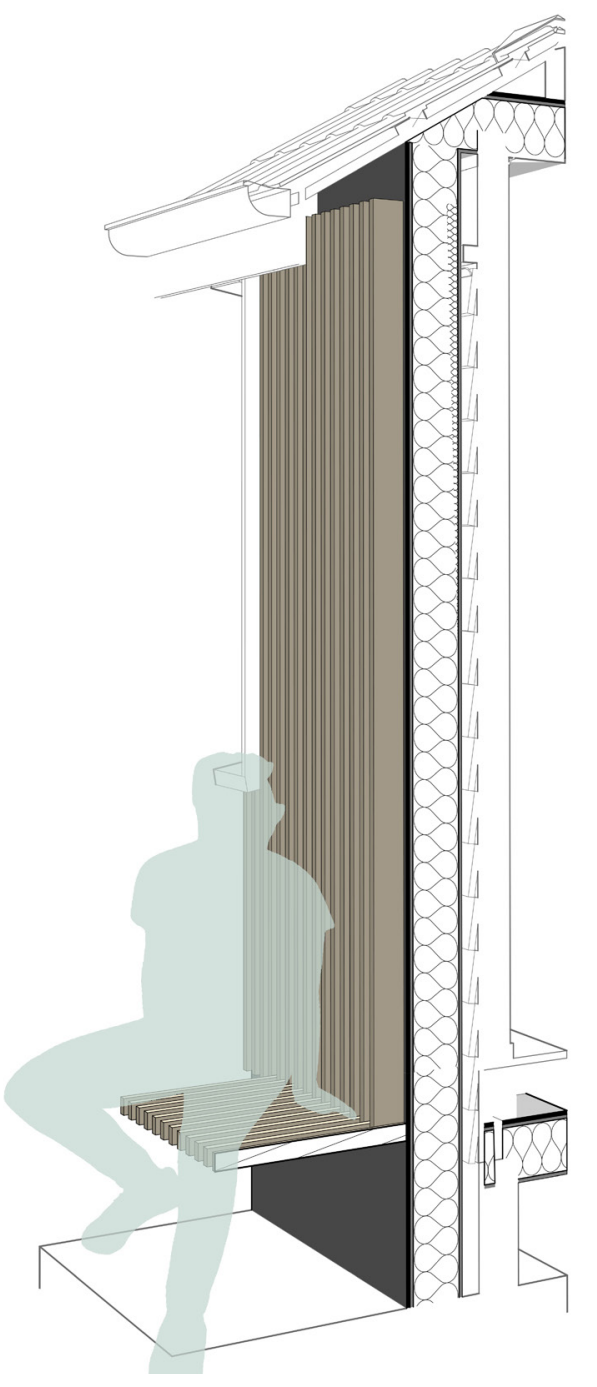

Fig 8.16 


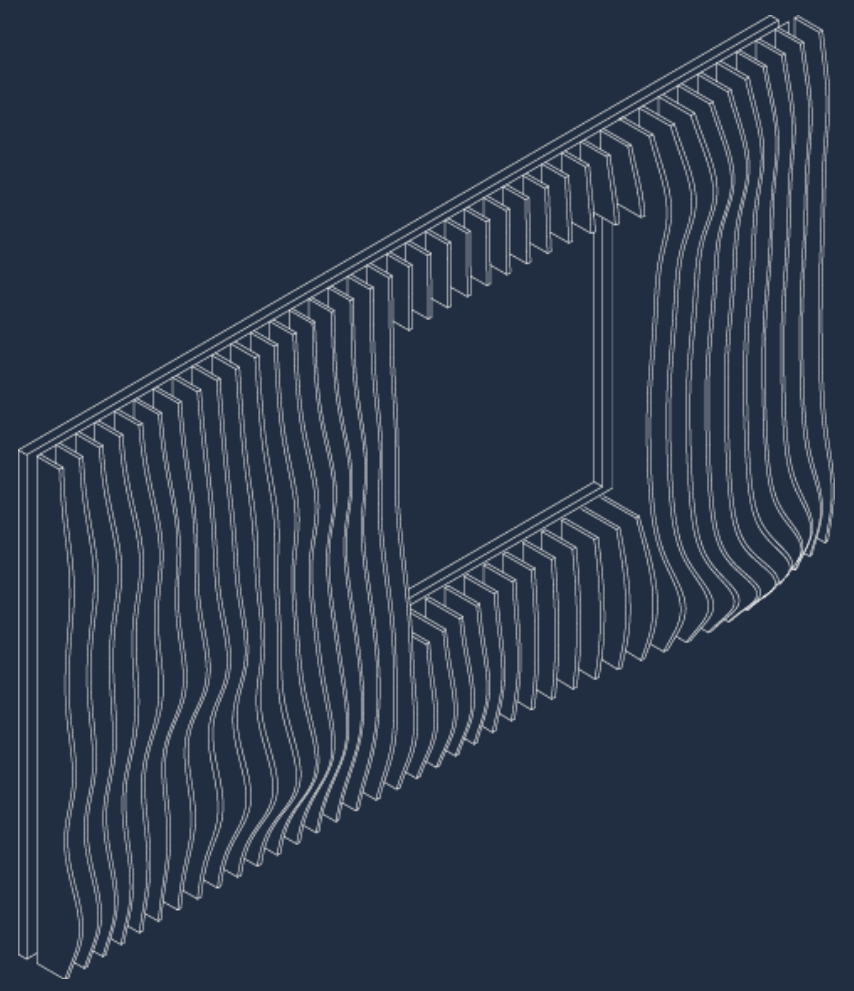

Fig 8.17 Digital model seating concept, integration of program from physical model, Author's Image 


\section{Critical Reflections G Findings}

- The digital exploration for seating explored the wall integration to fold the seating element into the wall for adaptability. Construction development and material selection would be needed to ensure sufficient structural support.

- The digital explorations revealed the need to develop the connection relationship between program units and how each unit corresponds with its neighbour. The relationship is critical to read the program as a whole.

- Digitisation of the wall units would support the development of a streamlined connection and design between units.

- The integration of adaptable seating and table program into the wall could be tucked away when not used.

- The adaptable program allows for variation in use by occupants as desired and variability to the home visual representation.

- The program integration across units could hide the standardised wall unit resulting from prefabrication. 


\section{Program}

\section{Brief}

Series 


\section{Environmental Experience}

Visual Connection with Nature

Non-Visual Connection with Nature

Non-Rhythmic Sensory Stimuli

Thermal \& Airflow Variability

Presence of Water

Dynamic \& Diffuse Light

Connection with Natural Systems

Biomorphic Forms \& Patterns

Material Connection with Nature

Complexity \& Order

Prospect

Refuge

Mystery

Risk/Peril
View of nature $\mathcal{E}$ living

Senses connection - sound, smell, touch, taste

Non-rhythmic light, sound, experiences

Mimic nature

See, hear or touch

Varying light $\&$ shadow

Seasonal and temporary changes

Patterns $\mathfrak{E}$ textures

PLAY

Climb

Store

Processing, local ecology \& geology

Bar

Sensory information similar to nature order

View over distance

Retreat place - protected from behind and overhead

SUSTAIN

Partial obscurity to entice or sensory stimulation

Vegetation

Table

Cook

Fig 5.10 
The following brief series uses the background research findings established in Chapter 5.0 of design principles to enrich the human-nature experience for beneficial health and well-being outcomes (Figure 5.10). The program brief limits the design exploration to three program categories: Refuge, Sustain and Play. The program categories were further divided into three sub-functions for a restricted variety of programs to enrich the occupant home experience. 
Program Identifier

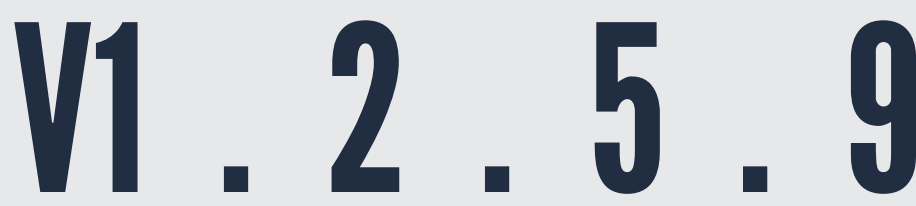

Version

Refuge

Sustain

Play

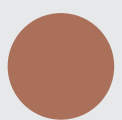

(8)

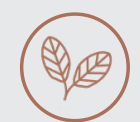

(20)

Fig 8.18 


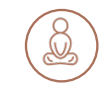

Refuge

SEAT

NOOK

SHELTER

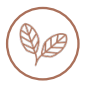

Sustain

VEGETATION

TABLE

COOK

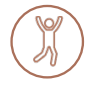

Play

CLIMB

STORE

BAR

NA

Fig 8.19 

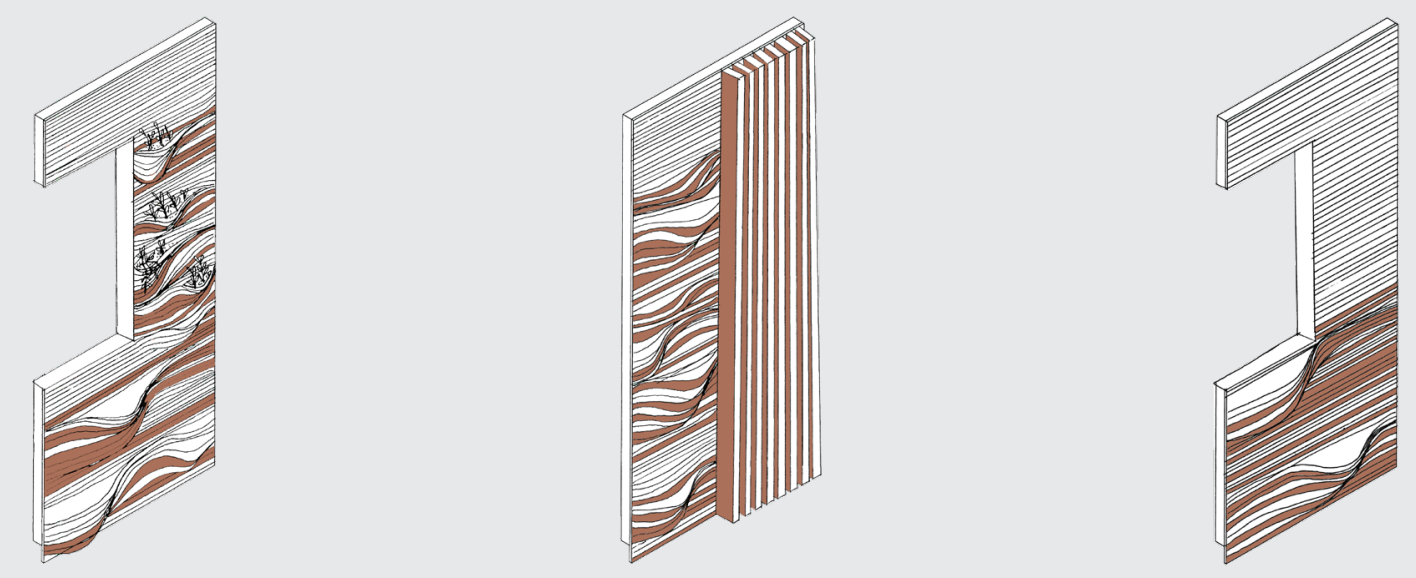

V1.1.4.0

V1.0.5.

V1.1.5.9
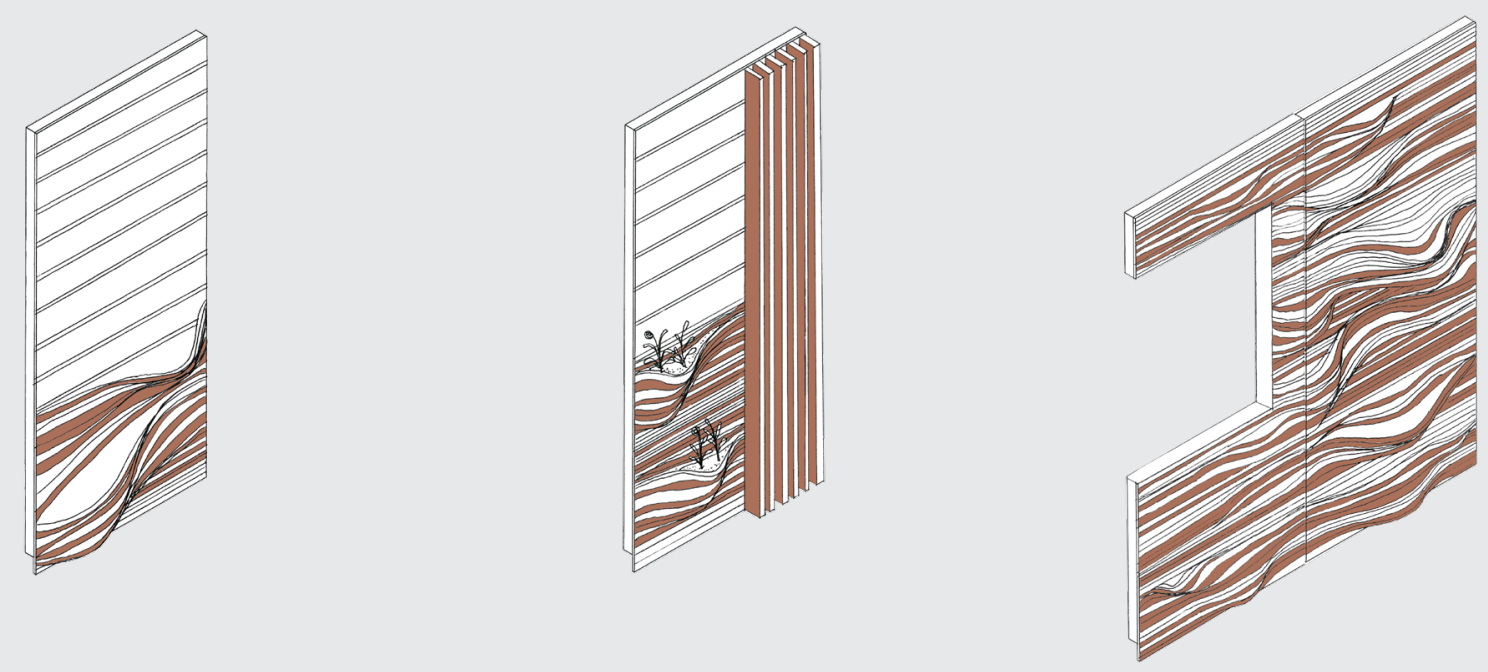

V1.2.5.9

V1.0.4.0

V1.0.0.7

Fig 8.19 

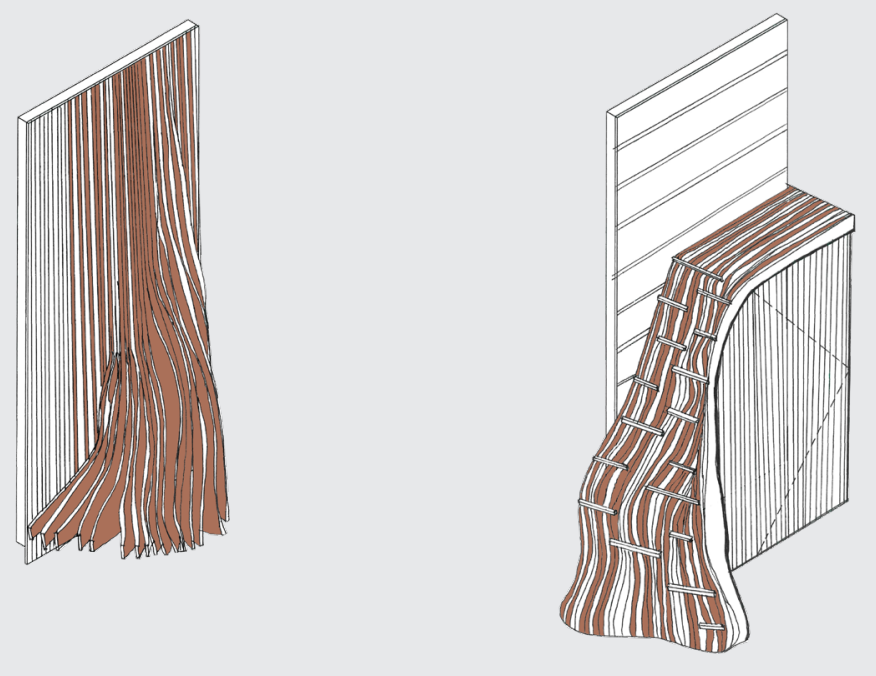

V1.1.0.7

V2.1.4.

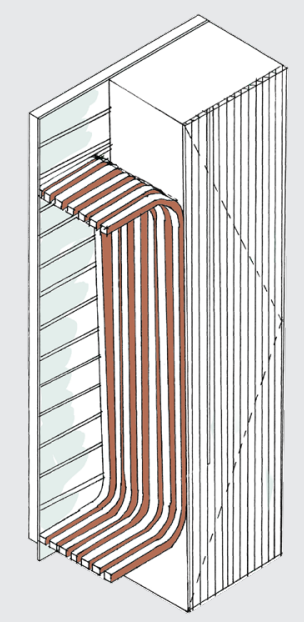

V1.2.0.8

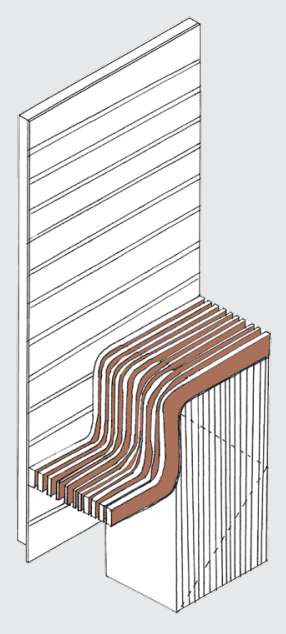

S1.1.5.8

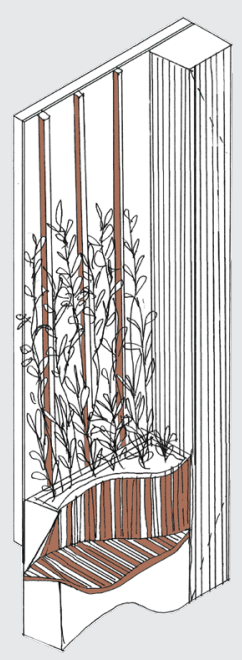

V1.1.4.8 

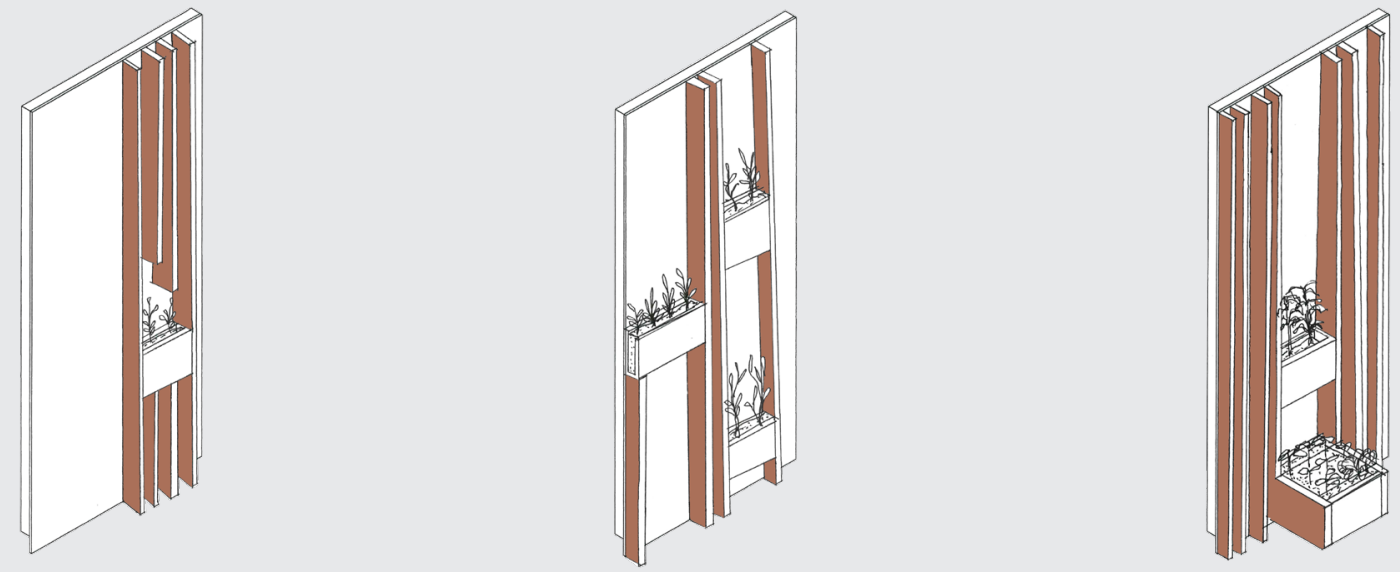

V1.0.4.0

V2.0.4.0

V3.0.4.0
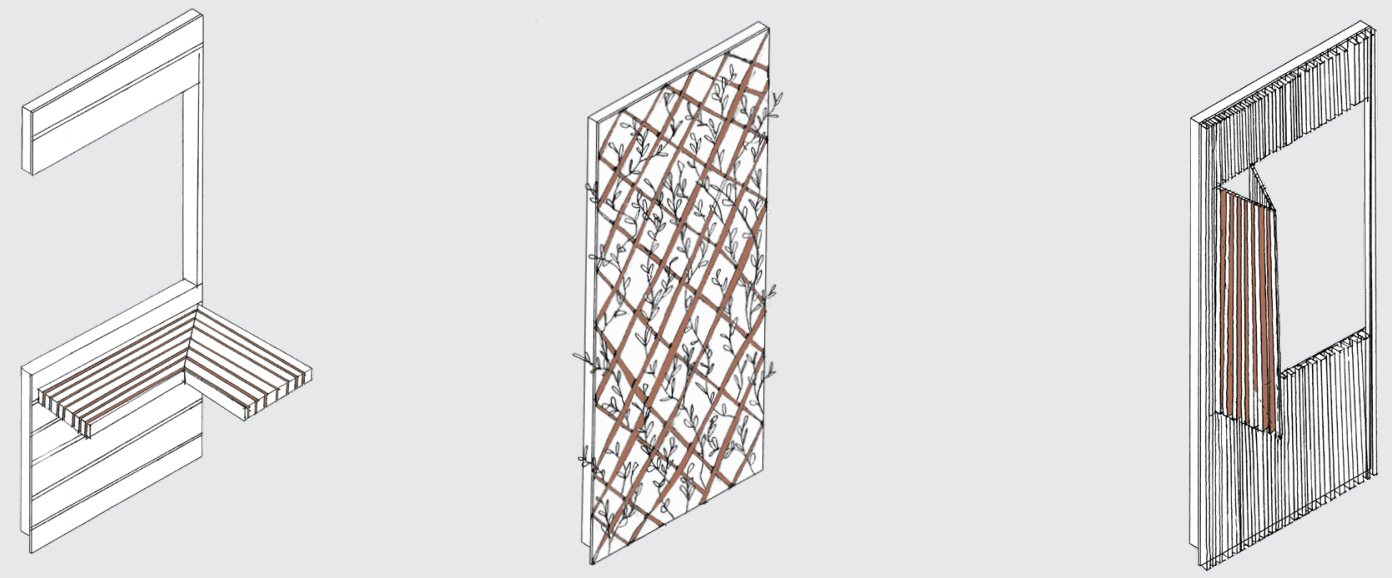

V1.0.6.9

V4.0.4.0

V1.3.6.0 


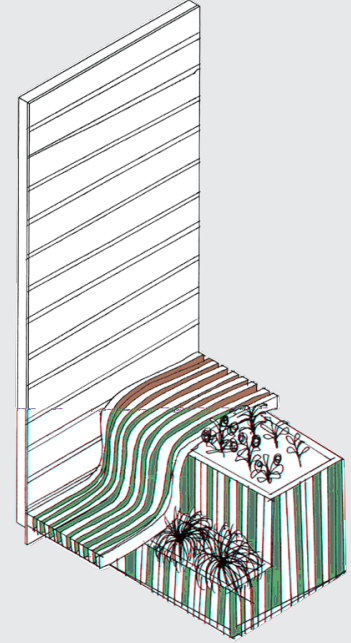

V3.1.4.0

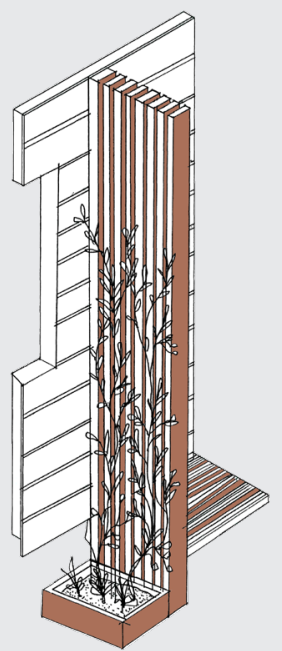

V1.1.4.0

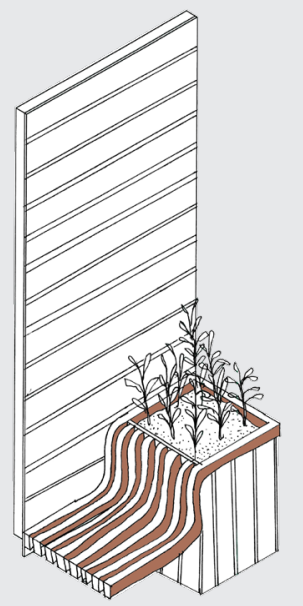

V4.1.4.0

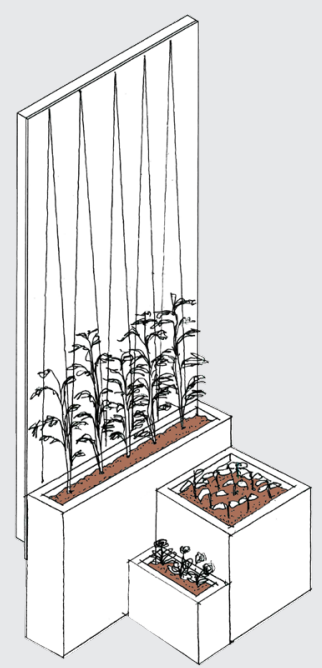

VI.2.0.6

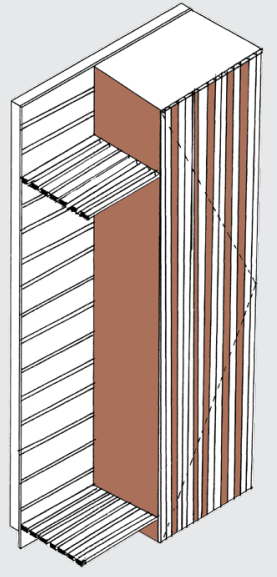

V1.3.0.8

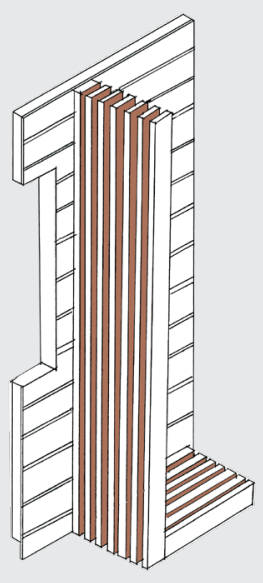

V3.1.0.0 

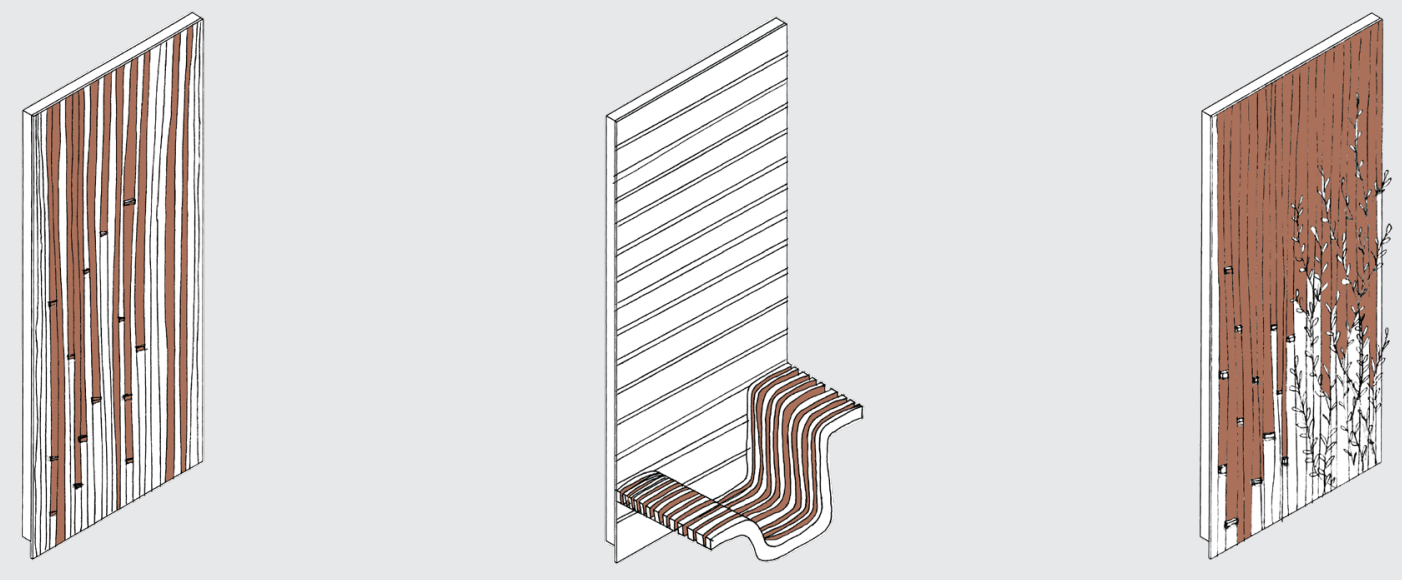

V1.0.0.7

V1.2.0.0

V1.0.4.7
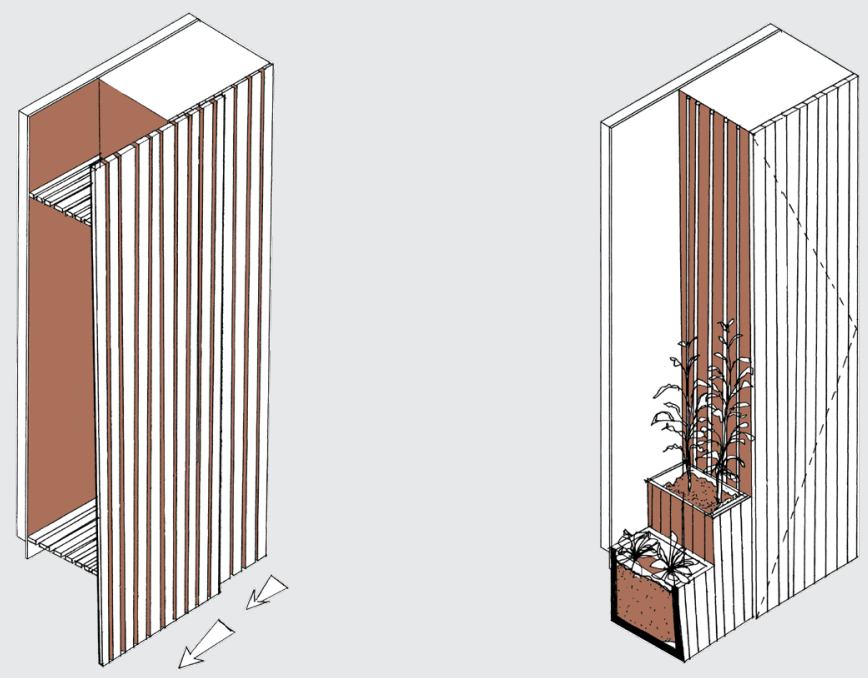

V1.0.4.8

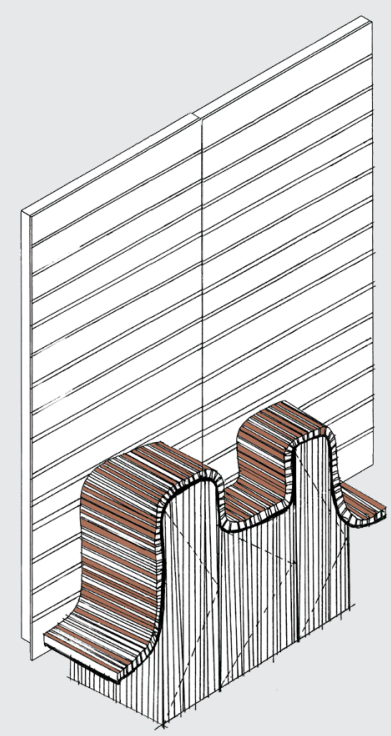

V1.2.0.8

V1.2.0.7 

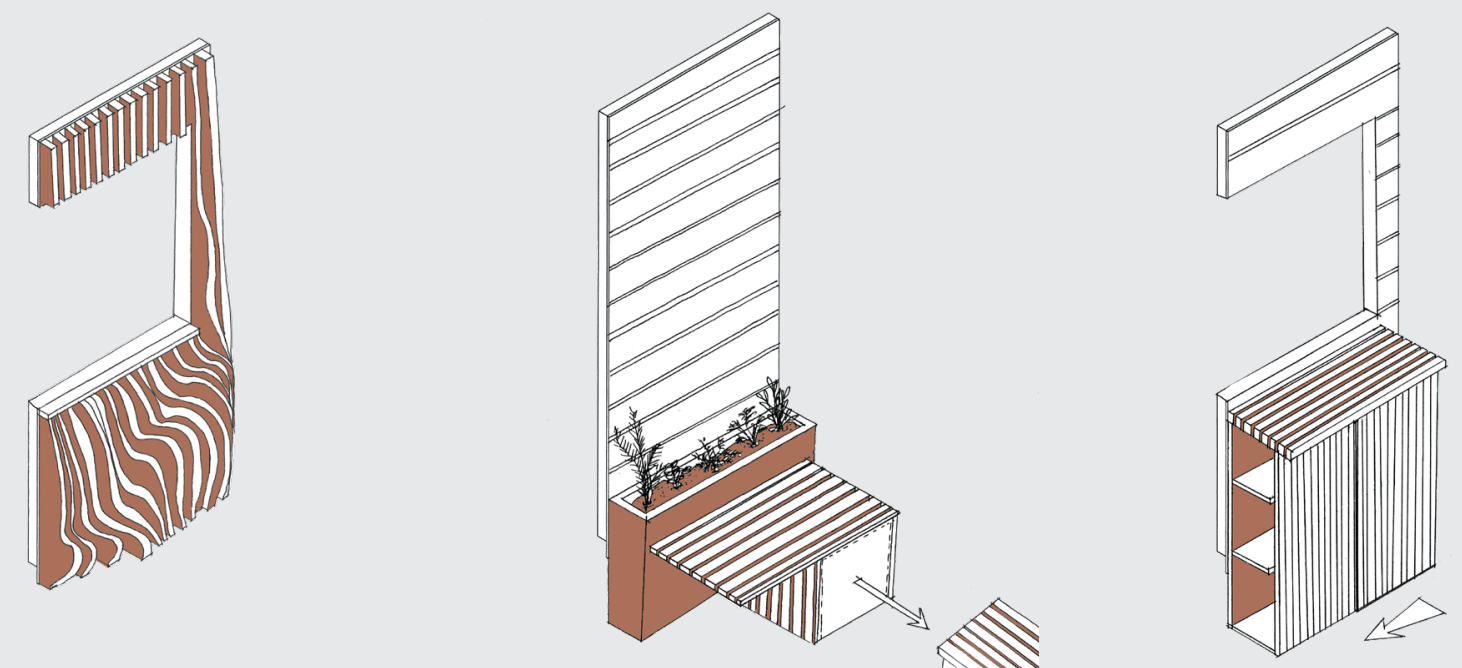

V1.1.0.7

V4.1.4.

V1.0.6.8

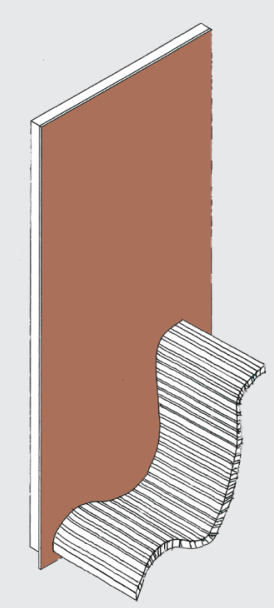

V1.2.0.7

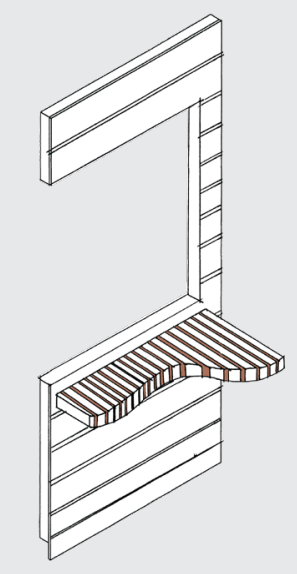

V1.0.6.9

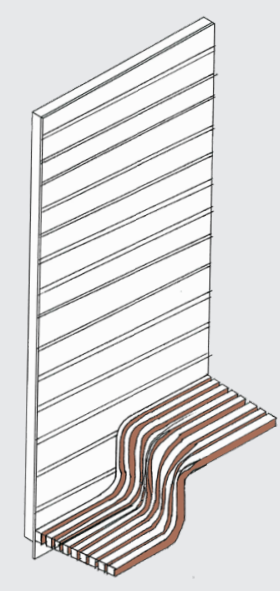

V1.2.0.0 


\section{Experience}

Vegetation providing connection to nature for visual and sensory stimulation, ecology restoration, shelter, as food source

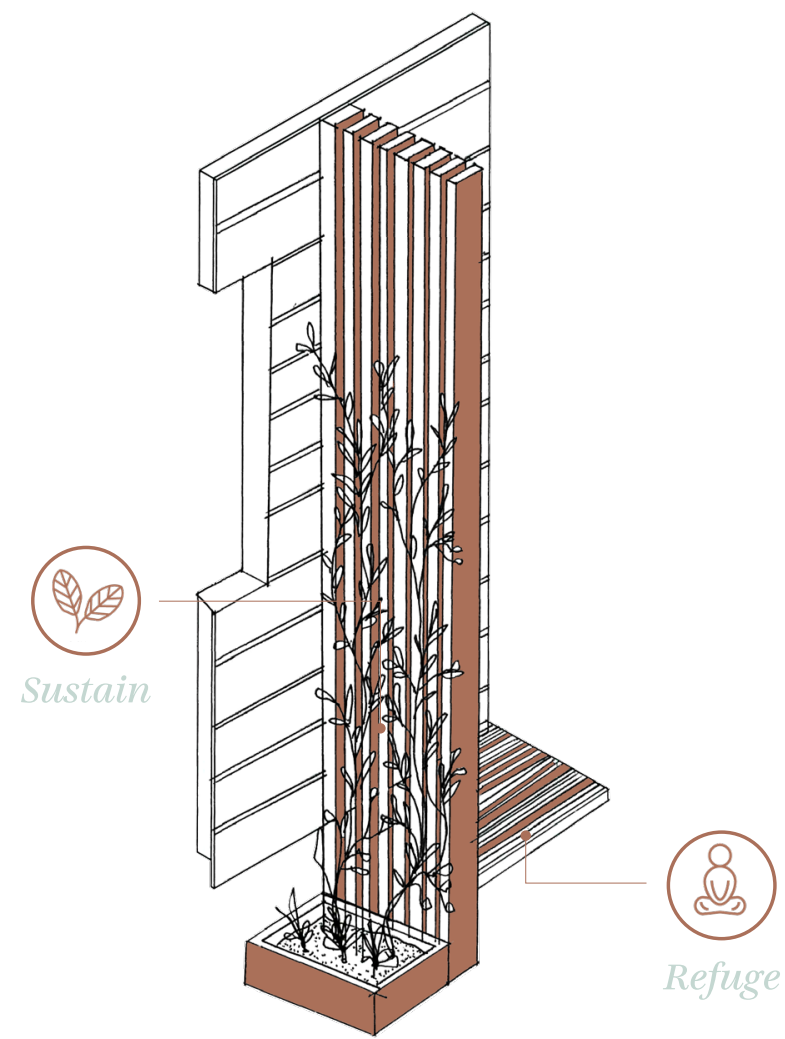

Fig 8.20 
Vegetation providing connection to nature for visual and sensory stimulation, ecology restoration, shelter, as food source

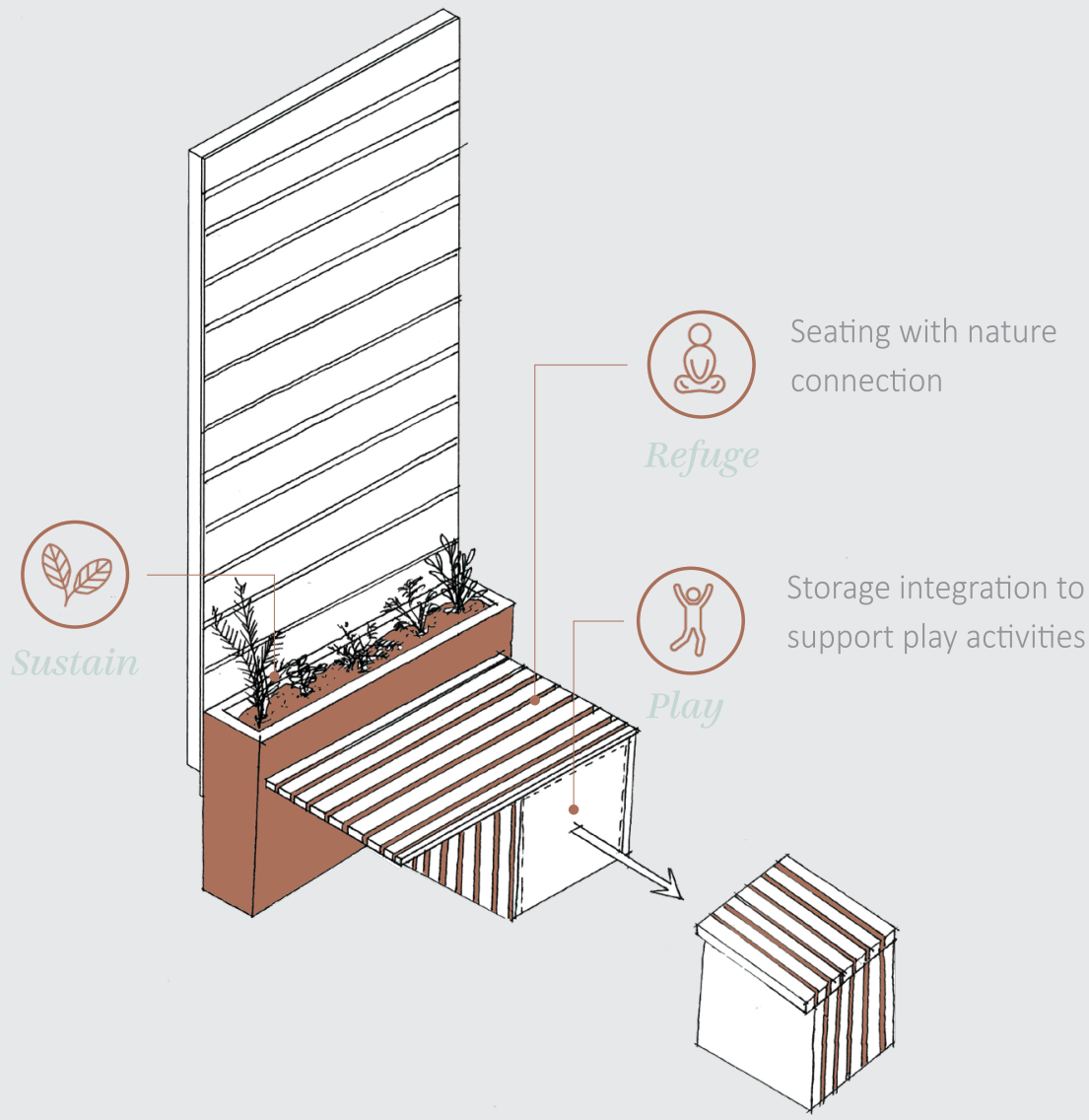

Fig 8.21 


\section{Experience}

Vegetation providing connection to nature for visual and sensory stimulation, ecology restoration, shelter, as food source

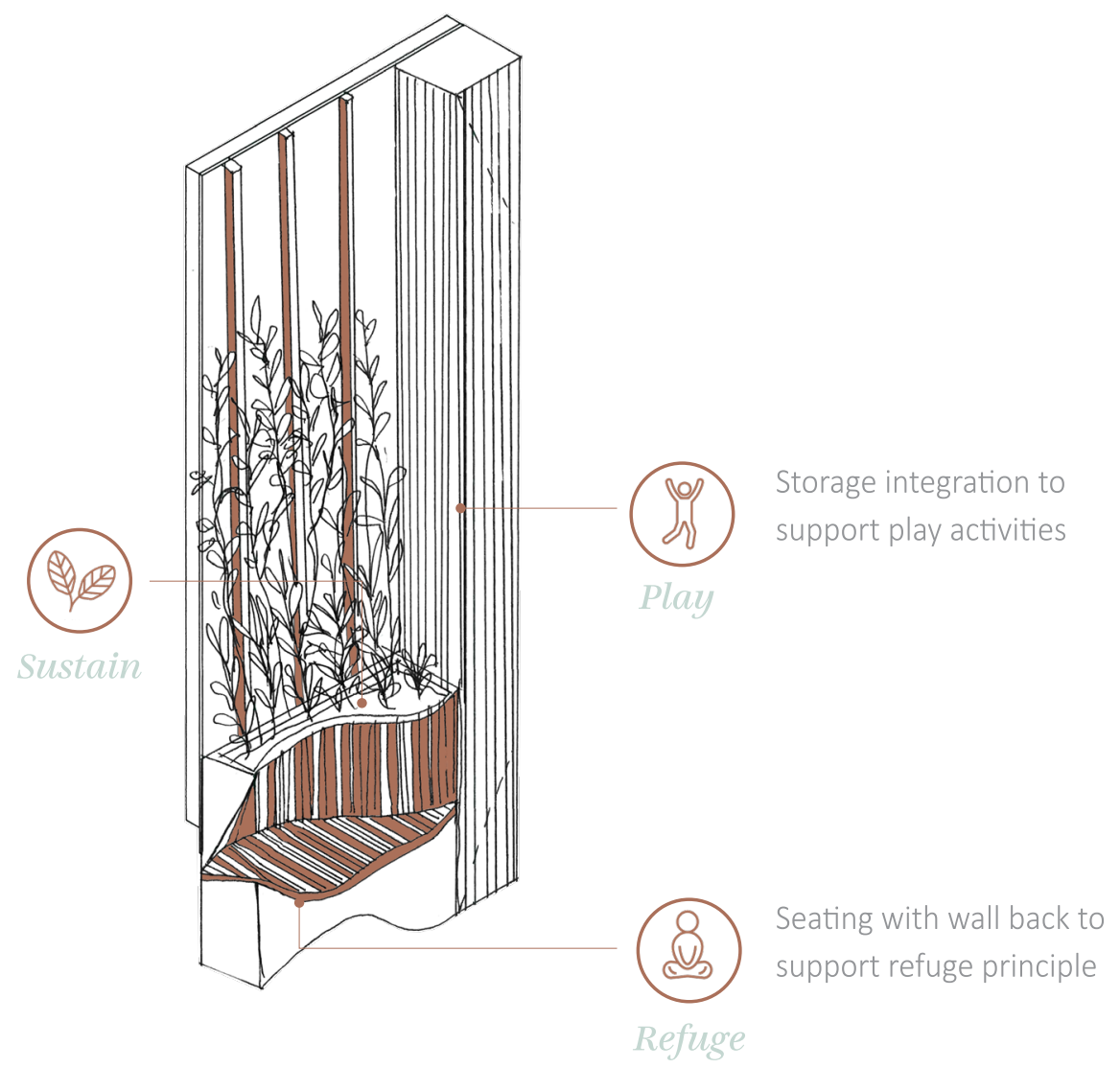

Fig 8.22 Diagram example of the framework 


\section{Integration Concept Example}

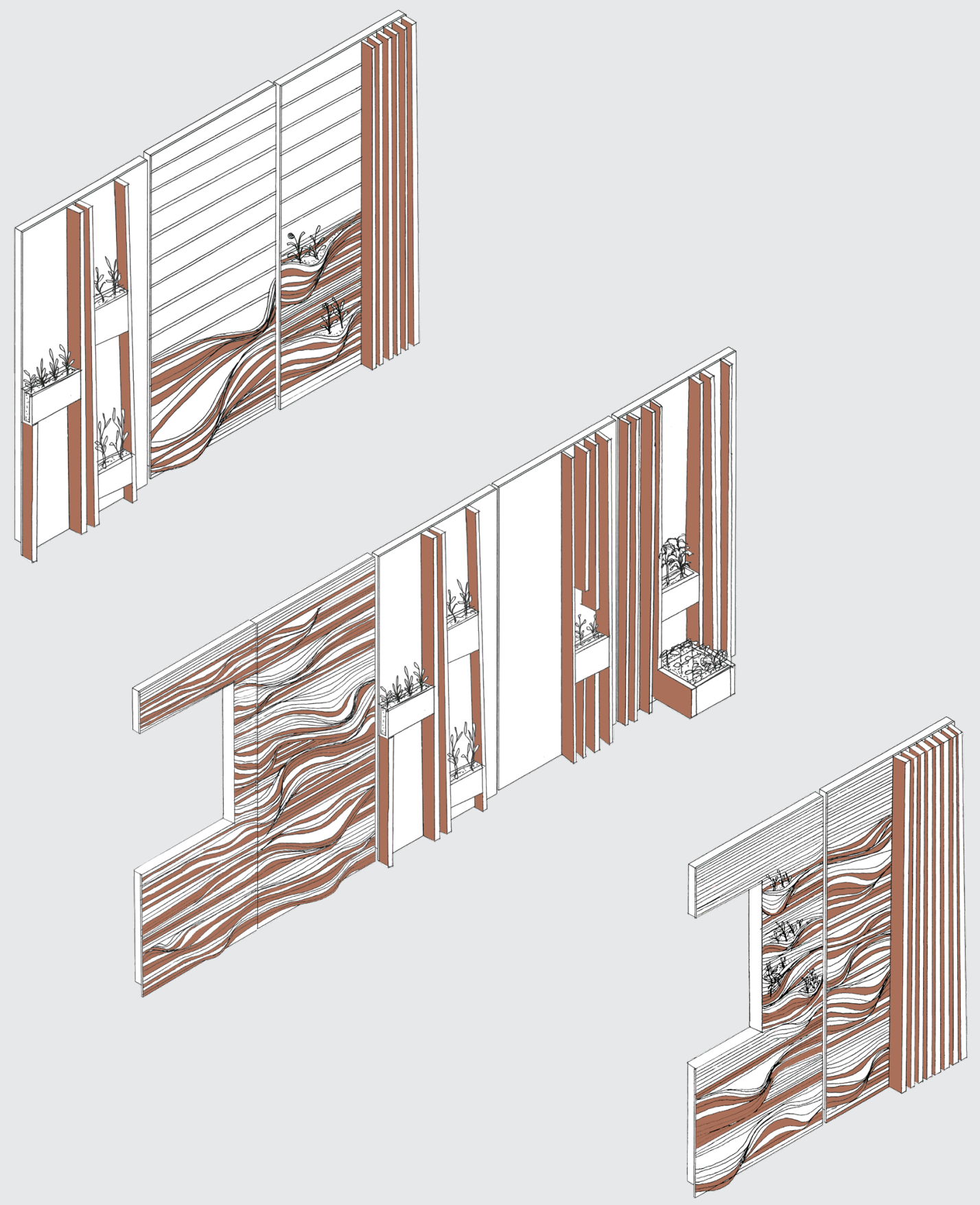

Fig 8.23 

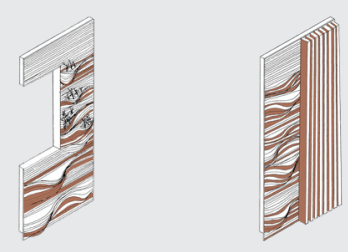

V1.1.4.

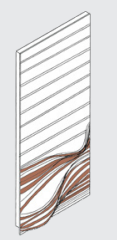

V1.0.5.

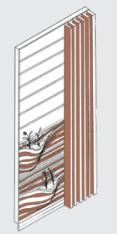

V1.0.4.0
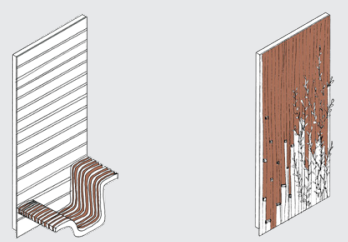

V1.2.0.0
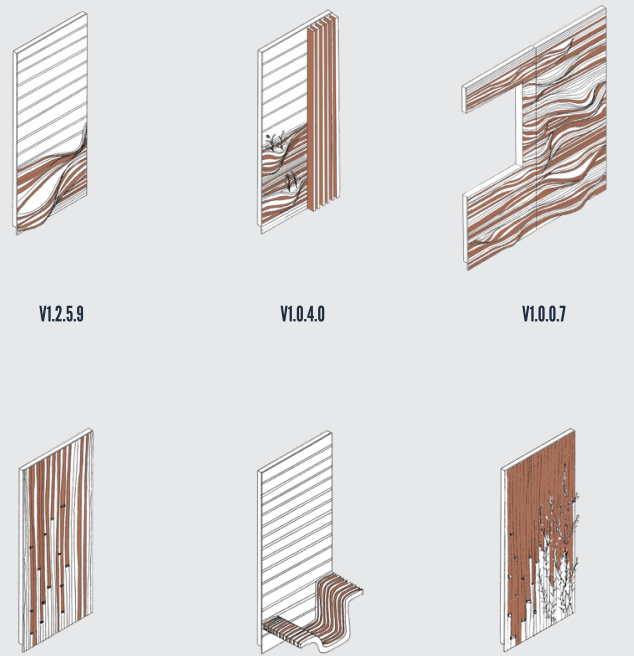

V1.0.0.7

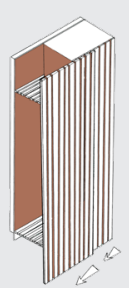

V1.2.0.8
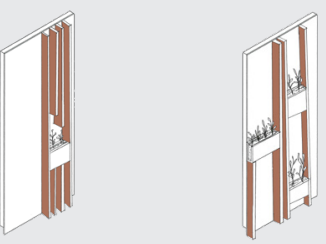

V1.0.4.0

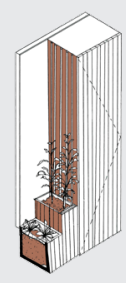

V1.0.4.8
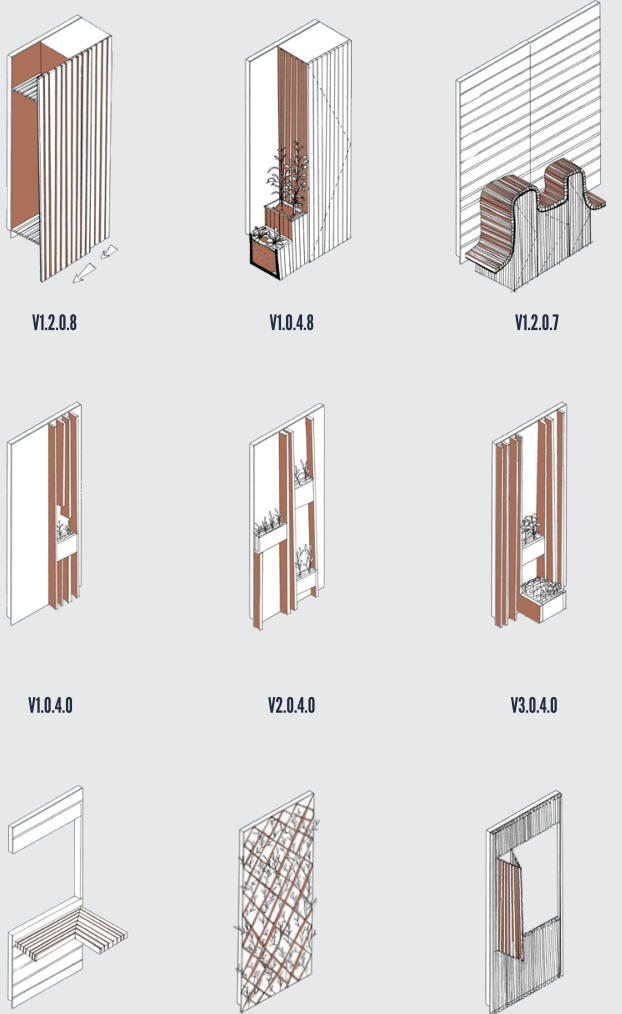

V1.0.6.9
V1.0.0.7

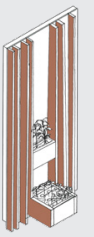

V3.0.4.0

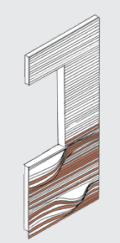

1.1 .5 .9

V2.1.4.

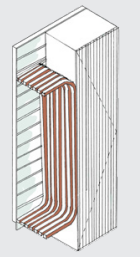

11.2.0.8

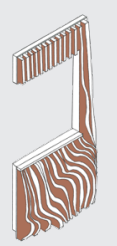

V1.1.0.7

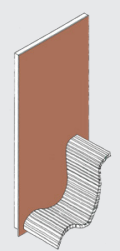

V.2.0.7

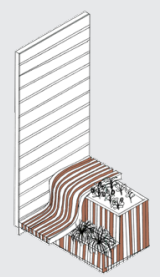

V3140

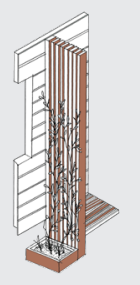

V1.1.1.0
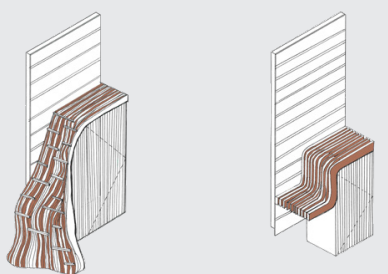

V1.1.0.7

\$1.1.5.8
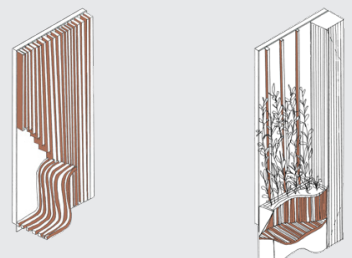

V2100

V1.1.4.
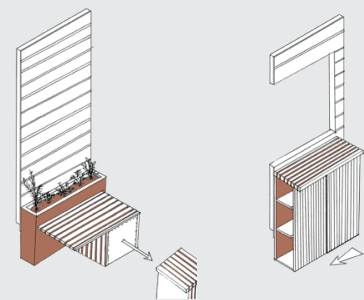

v1.0.6.8
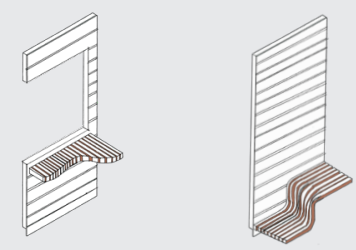

V1.0.6.9

V1.2.0.0
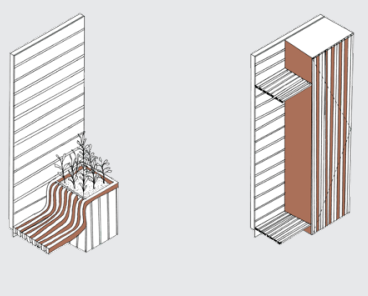

V4.1.1.0

V1.30.8
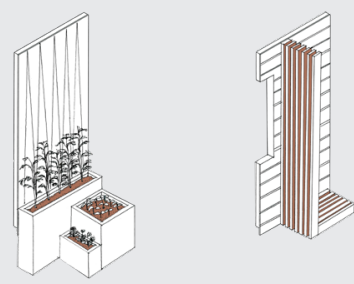

VII. 06

V3.1.0.0

Fig 8.24 


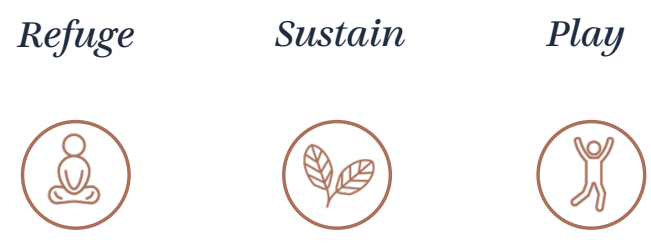

\section{Refuge}

The refuge program type explored variations of form, construction and tectonics, materials, level of comfort, integration with Sustain and Play program types, to create spaces encouraging a connection to nature, such as through visual or non visual stimulation, shading with vegetation to diffuse light and offer protection from the environment, seating with back and overhead protection to enhance refuge principle.

\section{Sustain}

The sustain program type explored variations of uses, tectonics, connection with the base component, and particularly the integration of vegetation for a connection to nature and as a food source. The table and cooking functions encourage social connections, time outdoors and extends the usability of the envelope.

\section{Play}

The play program type explored designs to encourage interaction with the envelope, such as in the form of climbing and interacting with the envelope. The program type often integrated well with additional program as providing a base to extend the play interaction area. The storage program was explored as extending the function of the home and encouraging play by providing sufficient home storage for the likes of bikes, kayaks, tools, and equipment.

\section{Critical Reflection $\mathcal{E}$ Findings}

- The exploration did not address all of the potential environmental experience opportunities but followed the design process to identify possible variations of program. The outcome program series suggests how the process informs the design to reach a range of diverse program outcomes. The advantage allows for great variation among housing and occupant briefs, however, a disadvantage is an increase in construction complexity with the diversity increase.

- Through the design process it was found that designing for one specific program type often resulted in combining multiple uses into the wall. Subsequently resulting in wall designs of greater occupant experience through their intuitive connection with one another. For example it was found that seating and shelter refuge designs tended to be integrated with vegetation and growth functions to create a more enriched experience and support a greater human-nature connection.

- Through the design process it was also found for the design of the program to extend beyond the line of a single wall unit. This considered the program experience with a wider view of possible envelope experiences and outdoor environments created with the program addition. 


\section{Application}
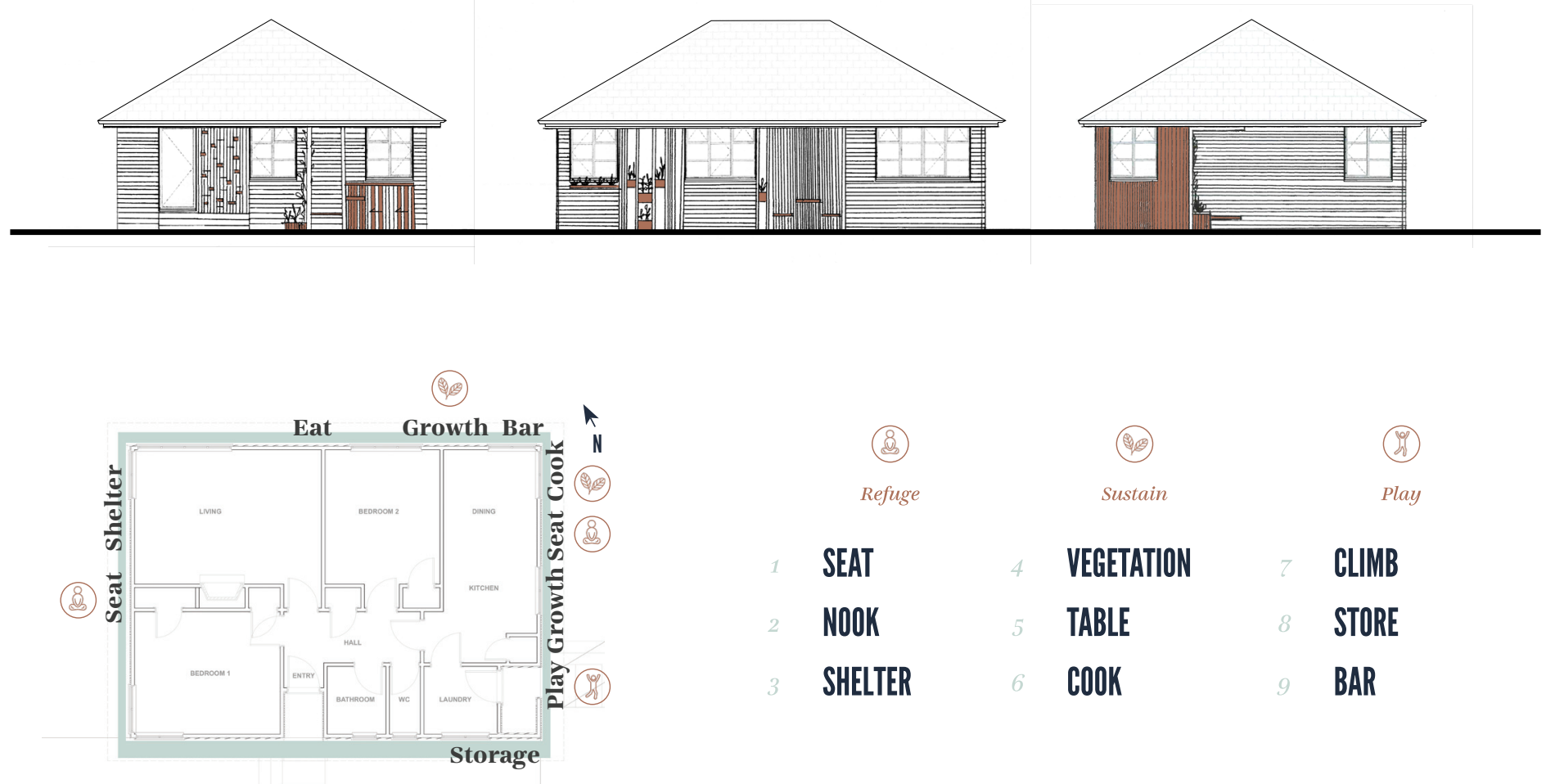

\begin{tabular}{|c|c|c|c|c|}
\hline (B) & & (9) & & \\
\hline Refuge & & Sustain & & \\
\hline SEAT & 4 & VEGETATION & & CLIMB \\
\hline NOOK & & TABLE & 8 & STORE \\
\hline SHELTER & & COOK & & BAR \\
\hline
\end{tabular}

Fig 8.25 


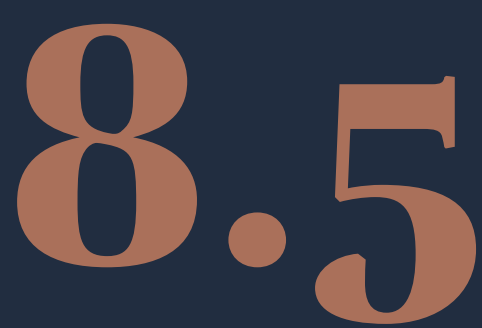

Critical Reflections E Findings 


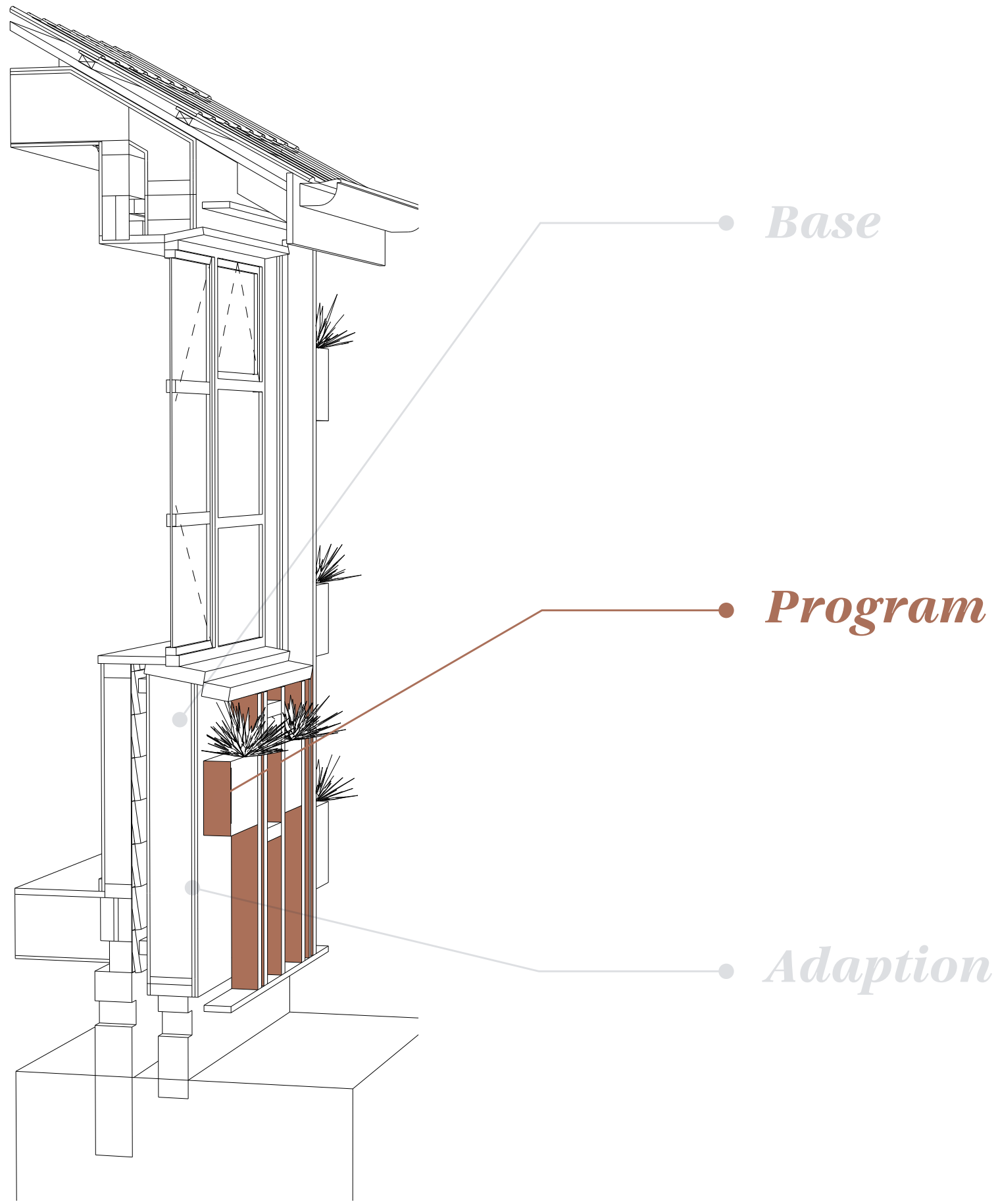

Fig 8.26 Diagram highlighting program component 


\section{Critical Reflections}

- The static design process was useful to inform the initial designs, although it was time-consuming and lacked adaptability as any changes had to be redrawn or remodelled. However, parametrising each design would have taken even longer due to the intensive anticipation involved in the design. The slower static process provided a tool to explore conceptual program designs.

- The breadth of program possibilities required program limitations in the form of a program brief to manage the research scope but highlighted the future potential of vast program variations.

- The program types often combined to result in an integrated program unit. The benefit maximises the envelope capacity to enrich the occupant experience through the overlap of the program. However, the integration increases construction complexity and connections between units. Additionally, the integration may cost more and require more construction time. Although fewer specified program panels applied to the home could mitigate the additional construction time than more panels across the house. Therefore, the outcome may balance out.

- The design output visual aesthetic as applied to the existing home would benefit from further comparison, variation and design development to explore the visual impact of the combined program panels on the home.
- The site conditions, orientation and capacity for a specific program would impact program selections and uses. For example, vegetation would only be useful if sufficient shelter, exposure to sun and water are available. The seating and retreat programs would need appropriate shelter, especially in changing weather conditions.

- The integration of the program and base components are conceptual and needs more significant development to resolve their cohesion.

- The program brief series explored the environmental experience established in the framework to encourage the human-nature relationship. The program series was driven by the principles identified in Chapter 5.0. For example using refuge design. 
$\frac{3}{12}$ co

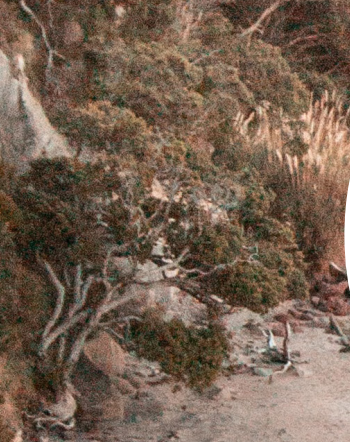

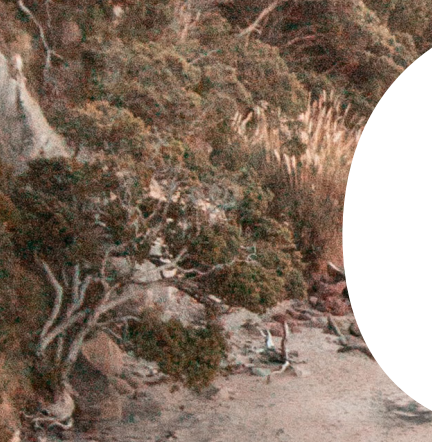
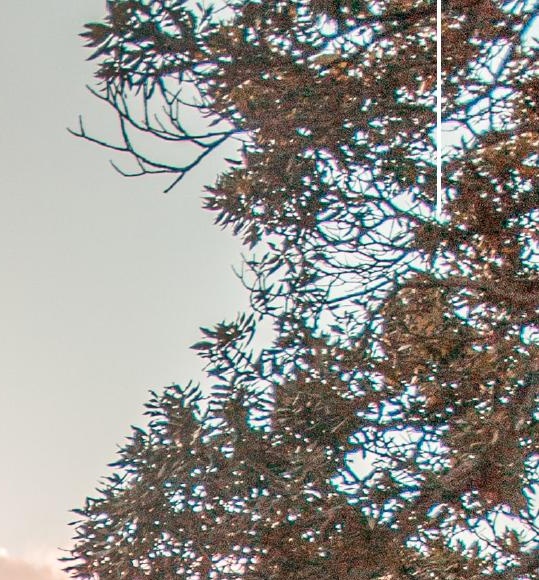

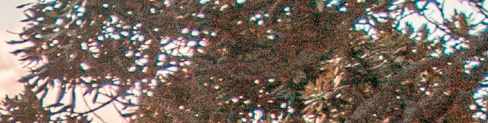

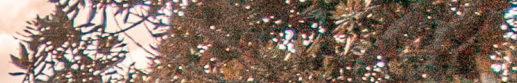

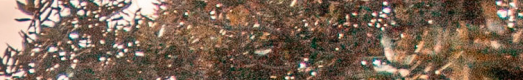

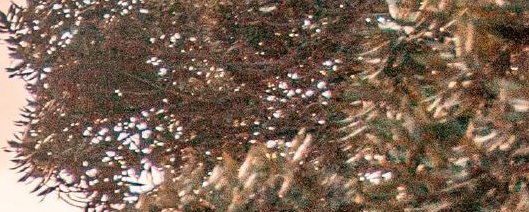

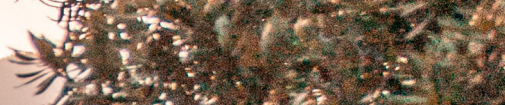
$x^{2}-10+3$

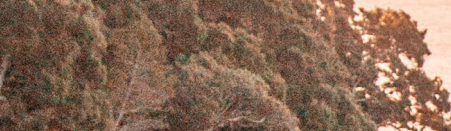
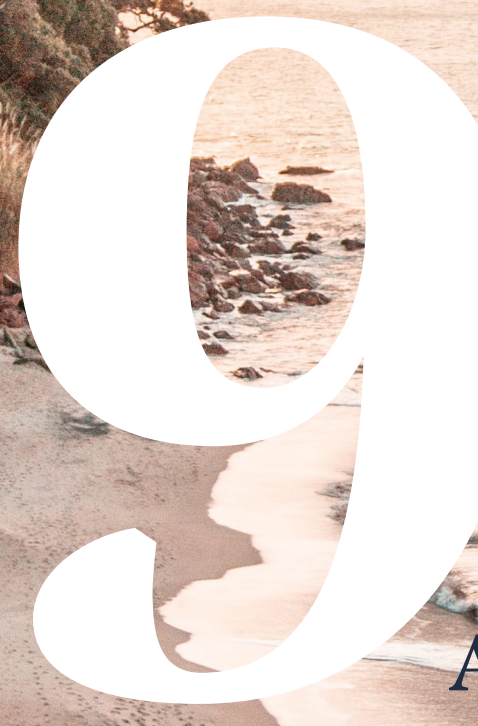

Adaption Component ats.

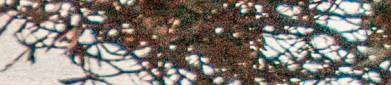

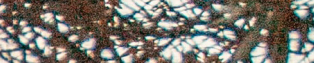

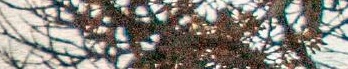

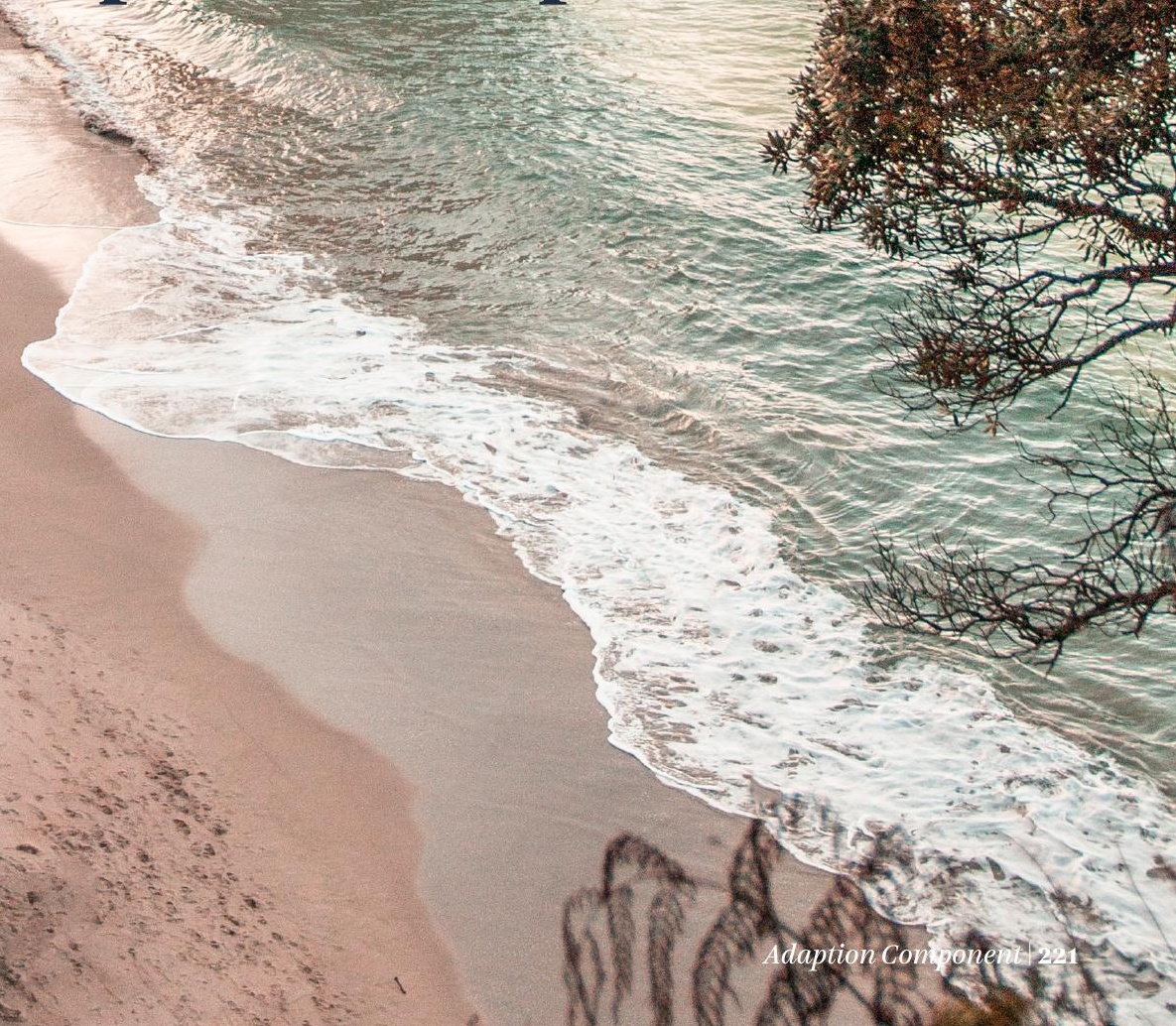




\section{Overview}

\section{1}

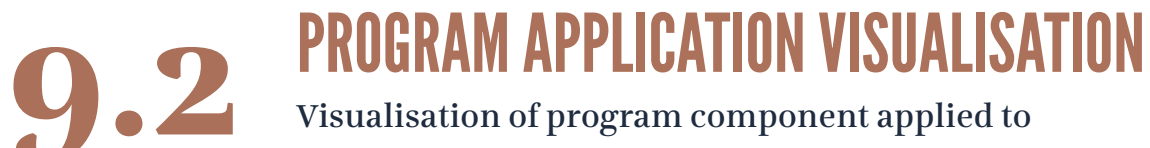 existing home}




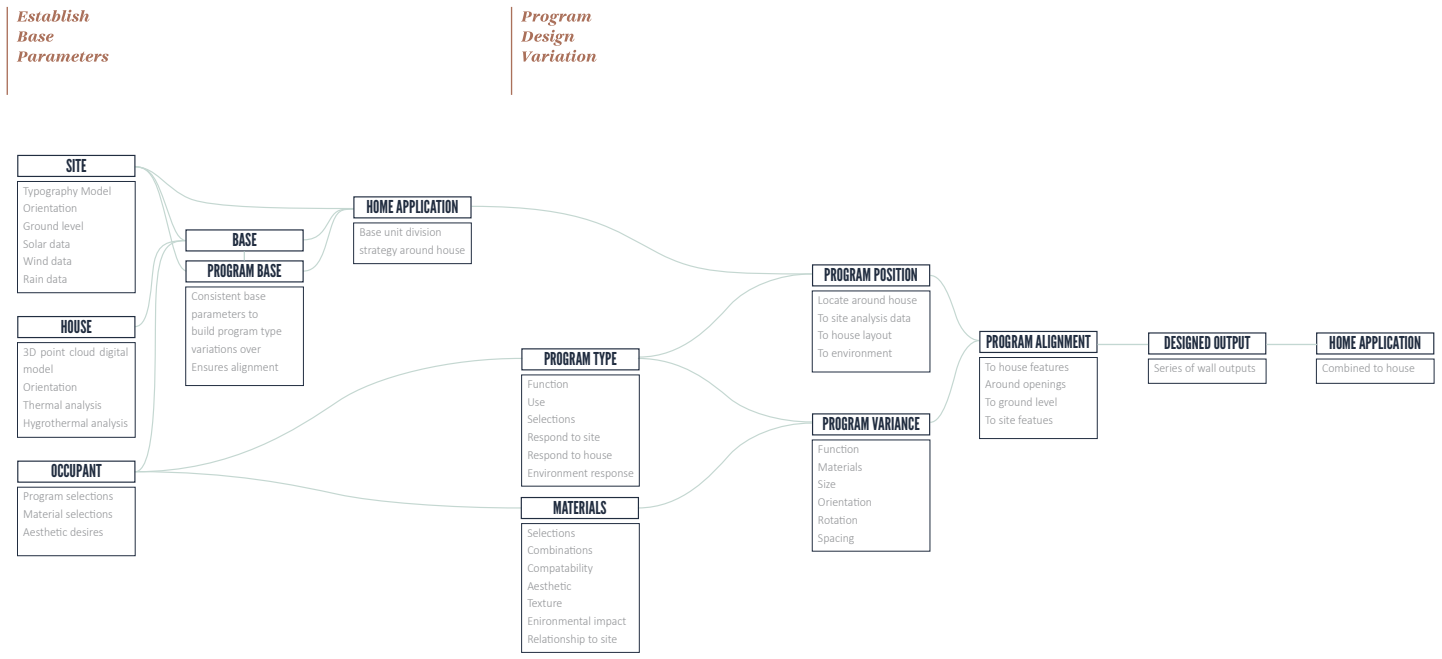

The following Chapter fulfils the research objective:

Explore the use of parametric digital tools for adaptability of the design strategy. The objective was explore the adaption component of the design strategy as the process for adapting the base and program components as appropriate to varying home and occupant performance and experience requirements.

Fig 9.1 Simplified diagram of parametric script key functions, refer to following figure for further detail, Author's image 
The following exploration digitalised the wall and program development using parametric design. The development streamlined the design to respond dynamically to varying input parameters such as the house typology, performance and occupant program selections. The parametric script developed in Grasshopper explored the potential variability of the design. Additionally, parameters such as site conditions and data, typography, performance analysis and materials would further inform the design.

\section{Digitalisation: \\ Parametric \\ Variation}




\section{Parametric Script Diagram}

Establish

Program

Base

Parameters

Design

Variation

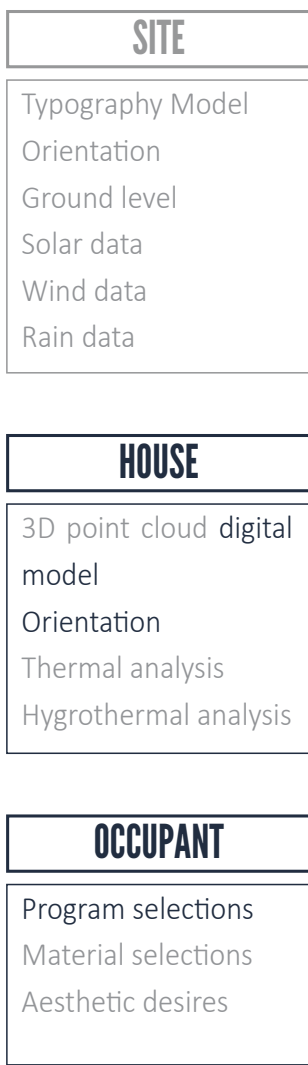

\section{HOME APPLICATION}

Base unit division

strategy around house

\section{PROGRAM BASE}

Consistent base

parameters to

build program type

variations over

Ensures alignment

PROGRAM TYPE

Function

Use

Selections

Respond to site

Respond to house

Environment response

\section{MATERIALS}

Selections

Combinations

Compatibility

Aesthetic

Texture

Environmental impact

Relationship to site 

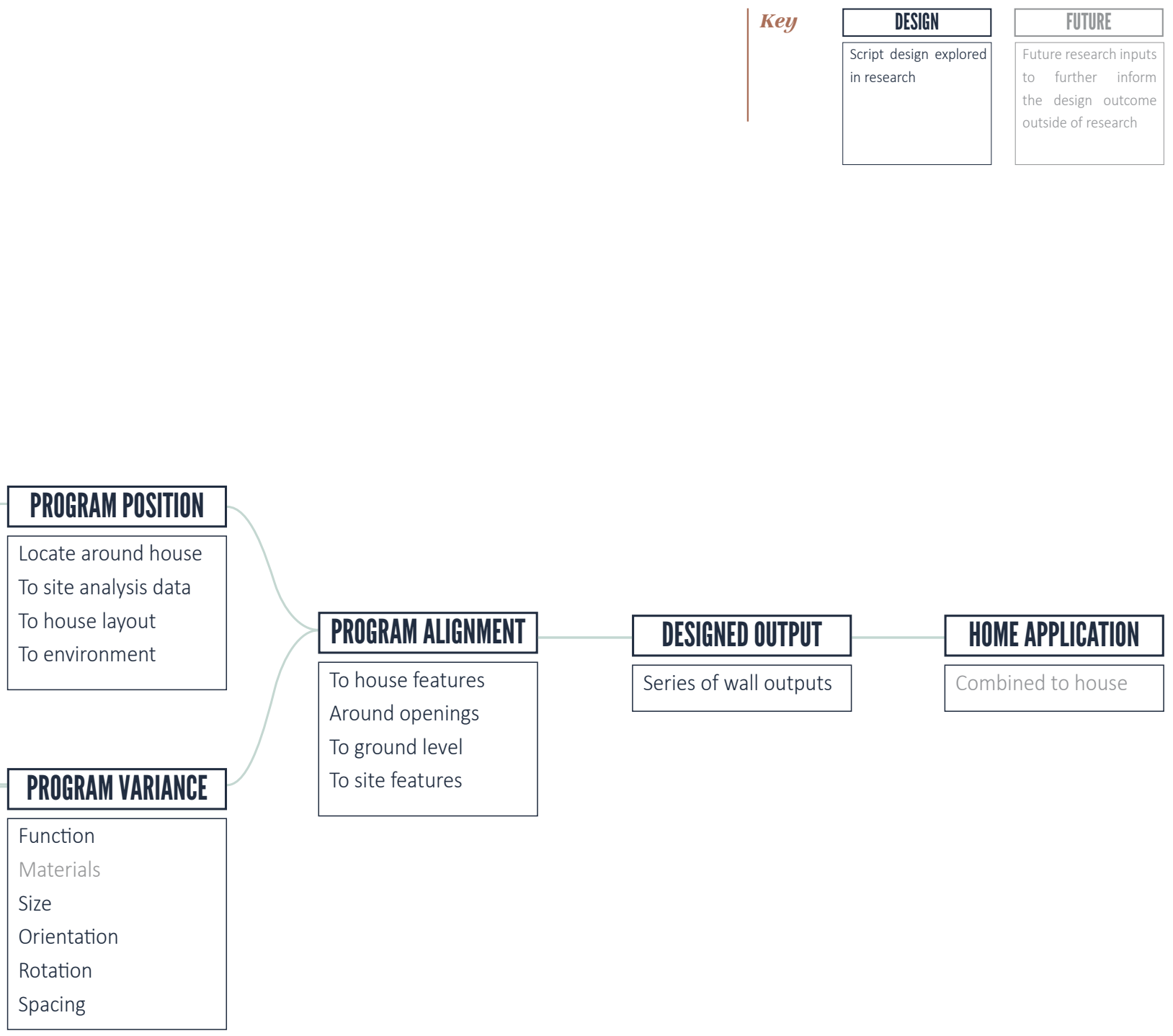

Fig 9.2 simplified diagram of parametric script key functions 


\section{Variation Findings}
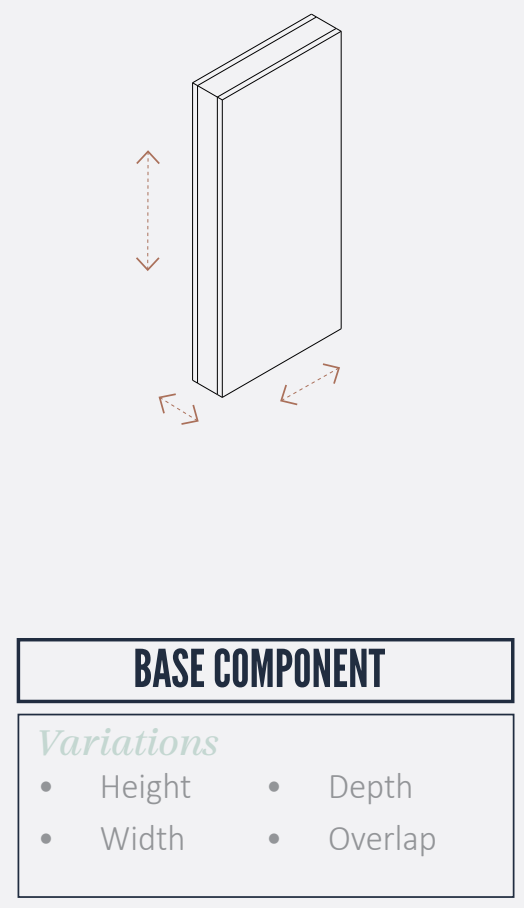

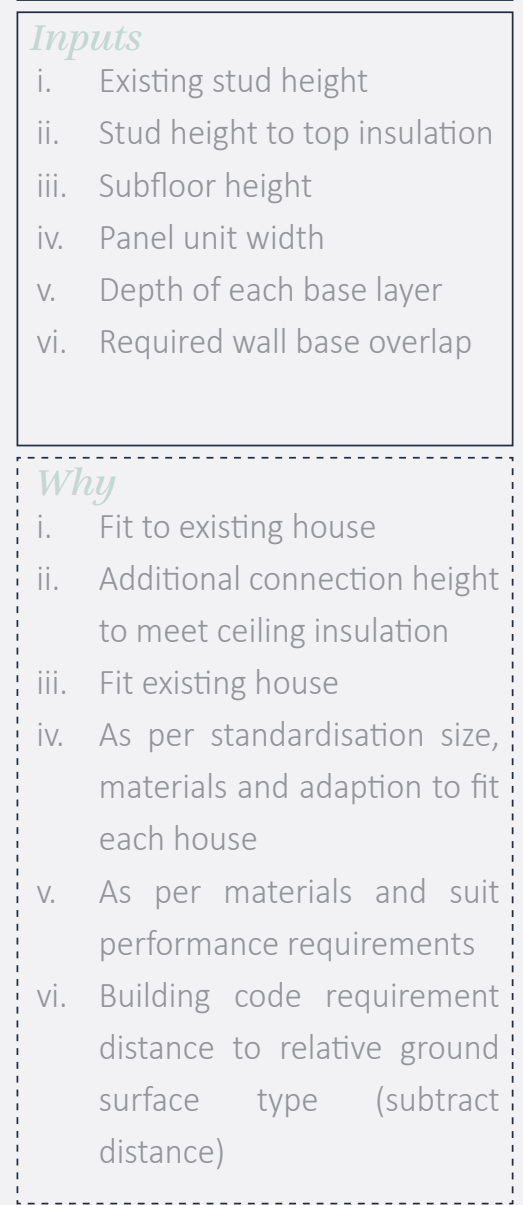

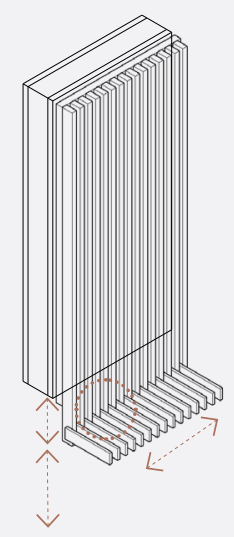

PROGRAM COMPONENT

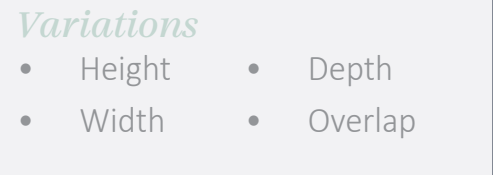

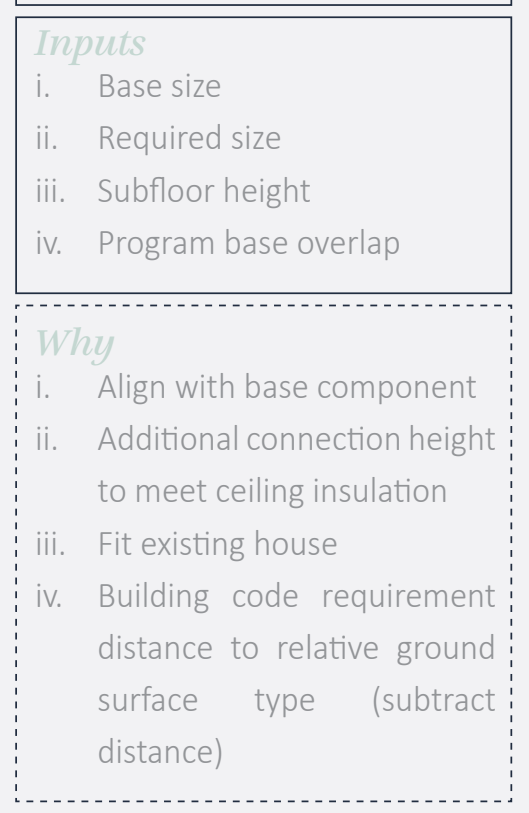




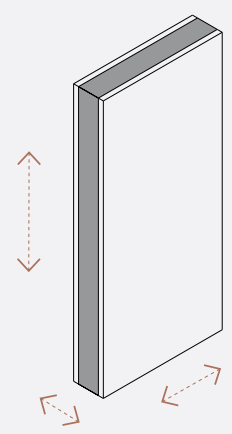

MATERIALS

\begin{tabular}{|l|}
\hline \multicolumn{1}{|c|}{ MATERIALS } \\
\hline \begin{tabular}{ll} 
Variations \\
- & Wall layer composition \\
- & Material size \\
\hline
\end{tabular} \\
\hline
\end{tabular}

\begin{tabular}{ll|}
\hline Inputs \\
i. & Each material layer \\
ii. & Material size \\
iii. & Material type \\
iv. & Program base overlap \\
\hline
\end{tabular}

Why wall composition
i. base
build up of each
ii. Size dictating overall wall
build up and location of
materials
compatibility of materials
for durability
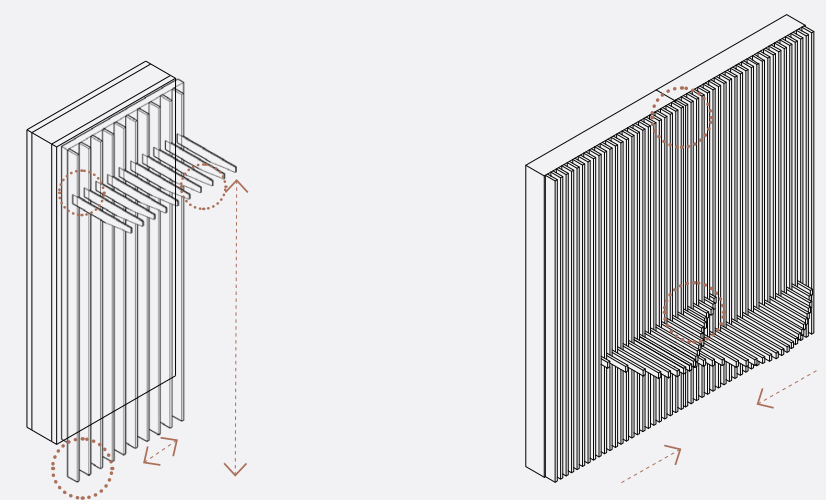

\section{PROGRAM INTEGRATION}

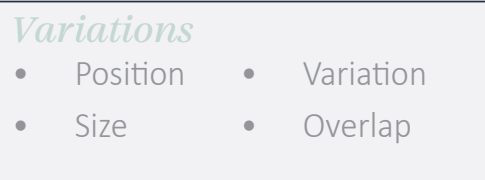

Inputs

i. Position

ii. Size of programs

iii. Variation of program types

iv. Connection overlap between wall units and program

\section{Why}

i. Position of multiple program relationship

ii. Alignment to additional program

iii. Relationship between program types

iv. Develop how the program overlap and connect together between units

Fig 9.3 Findings of parameter inputs and issue areas with the 


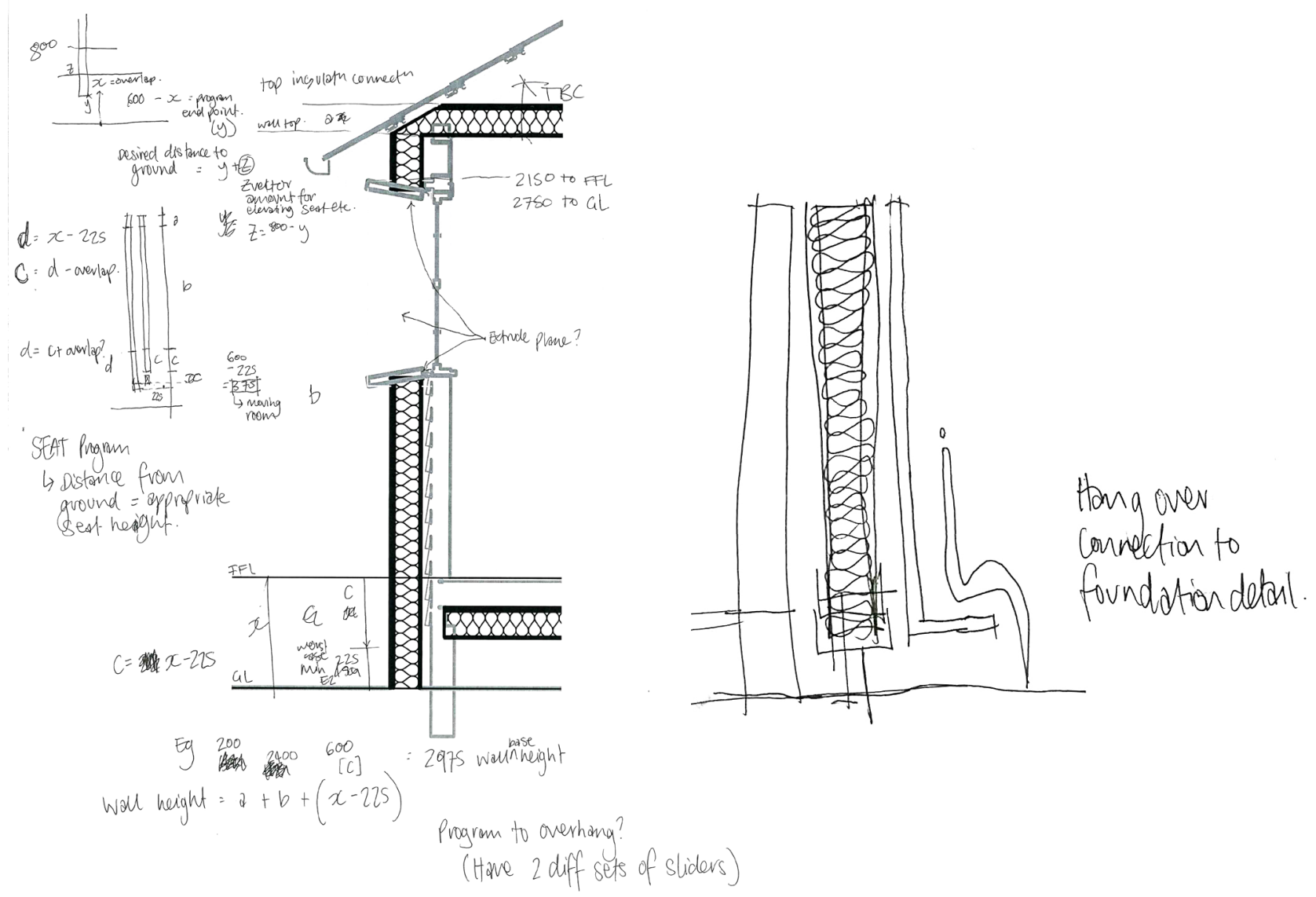

Fig 9.4 Process sketches resolving program overlap 


\section{Testing the Process}

VERTICAL
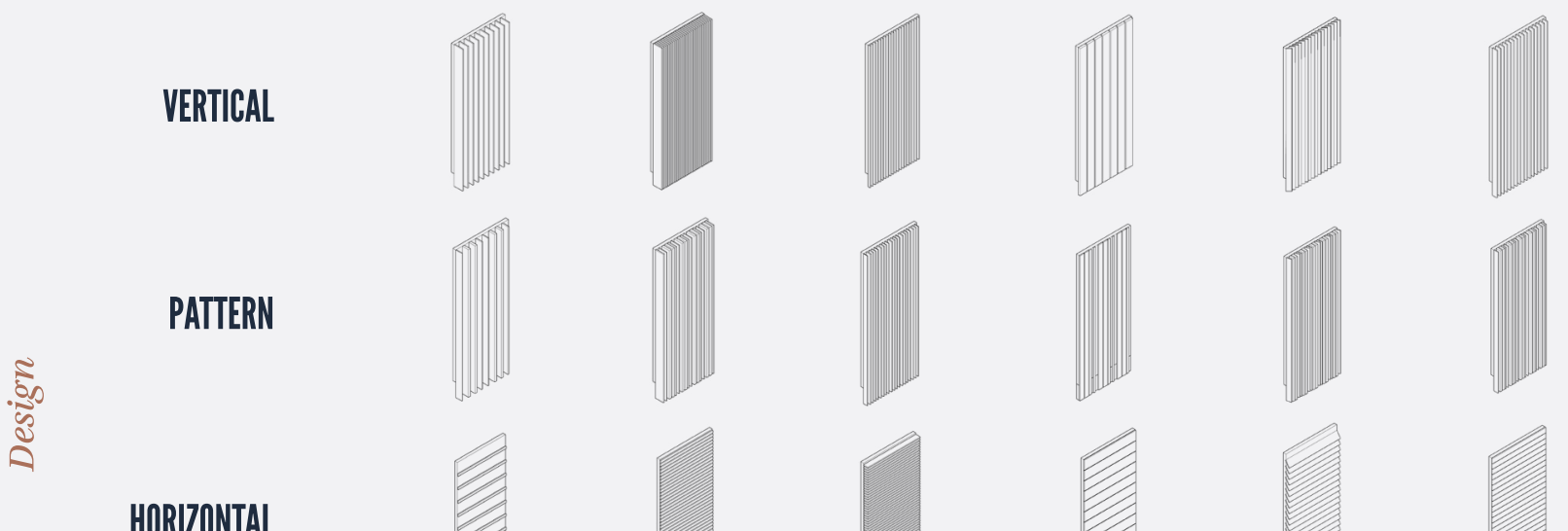

HORIZONTAL
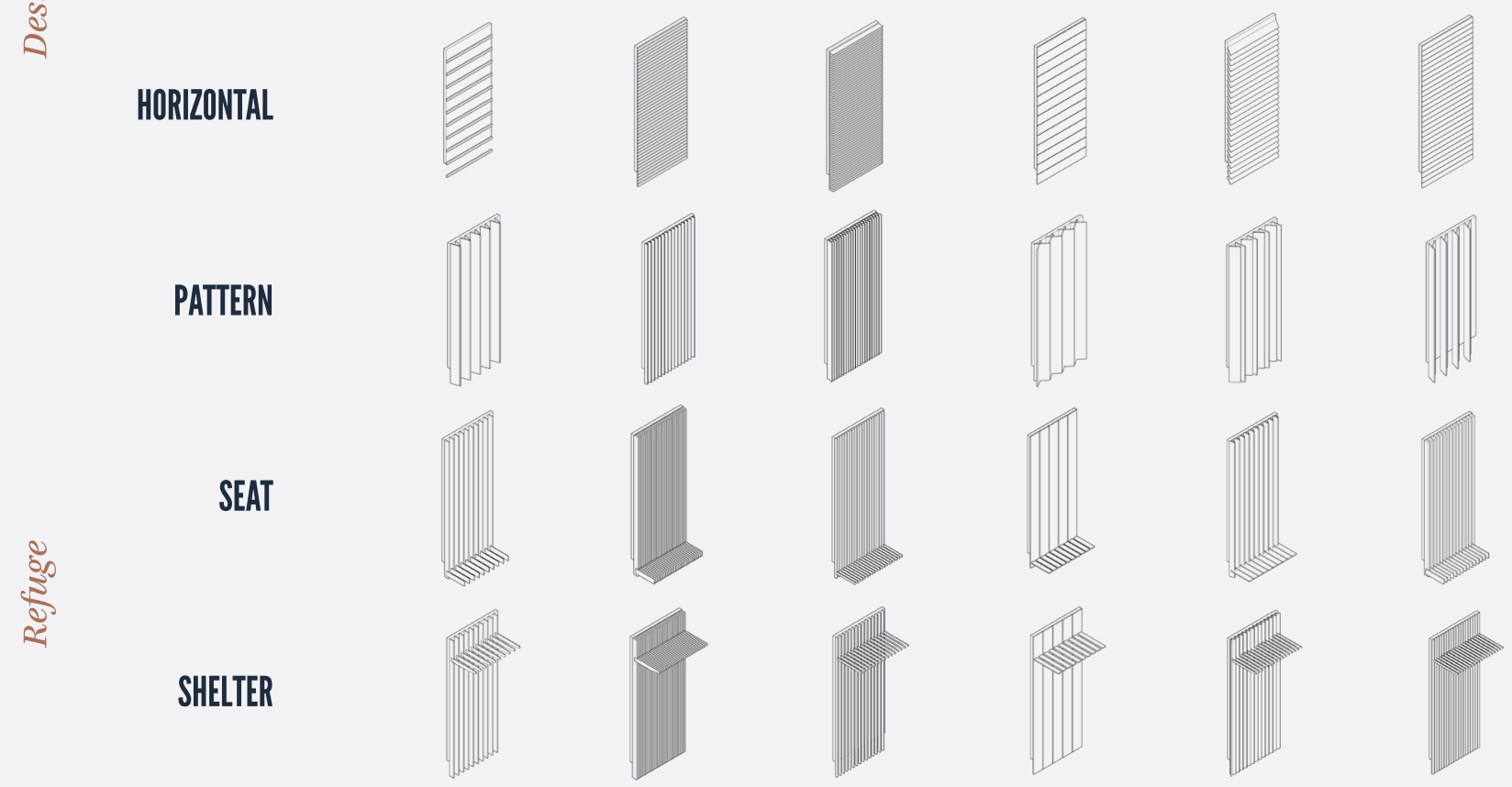

Fig 9.5 


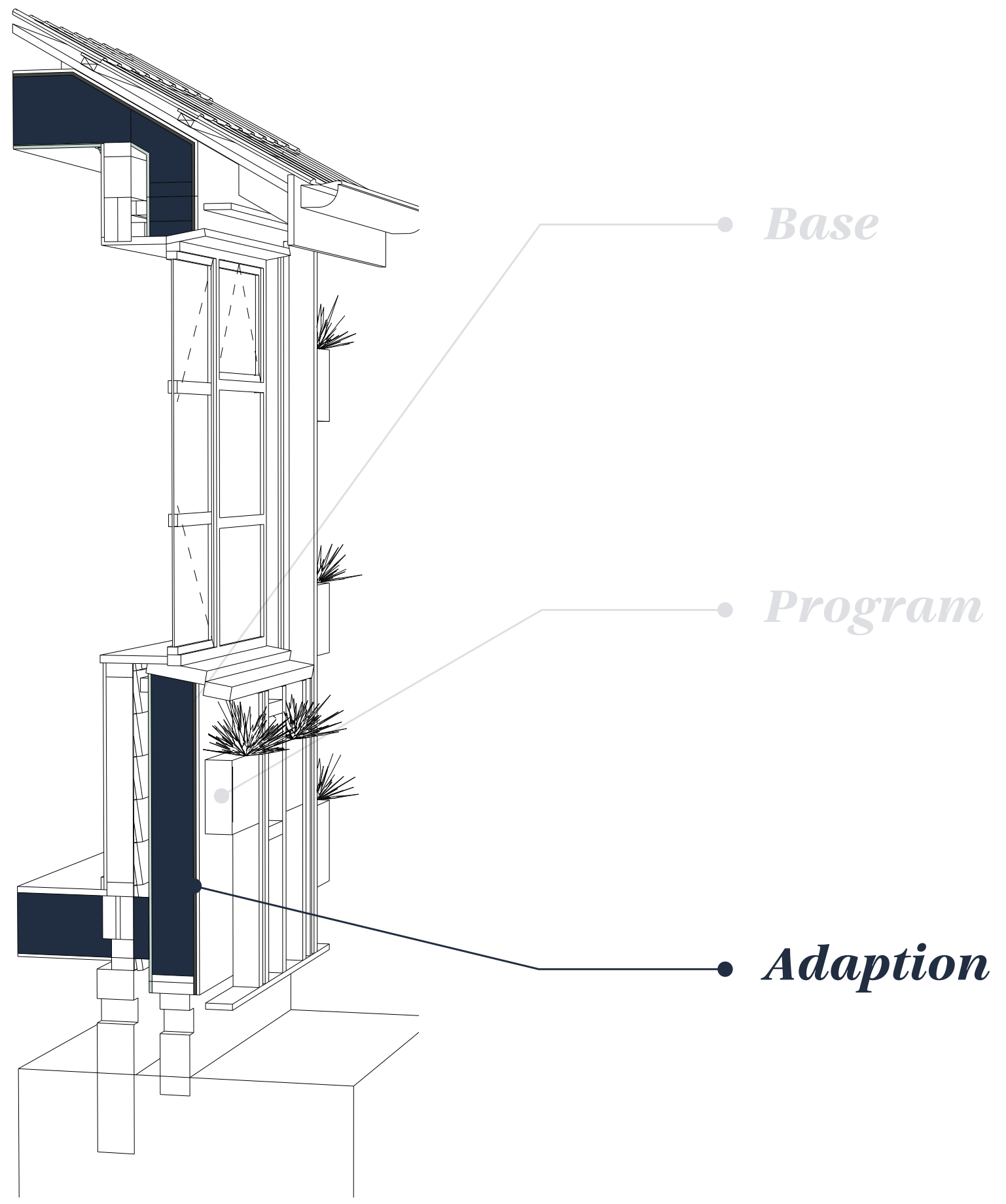

Fig 9.6 Diagram highlighting adaption component 


\section{Critical Reflections \& Findings}

- The design process of constructing the parametric script revealed the breadth of variability to evolve the wall design. The program variance identified in Figure 9.18 tested the process and variability of the developed parametric script. The outcome revealed how variations to the design inputs result use a dynamic design process to produce a breadth of wall design opportunities. The benefit of the process with the design strategy proposes diversifying and adapting the design outcomes according to each occupant brief to result in a varied and individual home strategy application. The advantage of the process helps to mitigate monotony within a mass-scale design strategy. However, the construction complexity increases with the quantity increase of diverse design outcomes.

- The process of designing the script revealed detailed issues to resolve. The issues included detailing between tectonic components of how they connect, overlap and intersect. An example explored in the design process was offsetting the cladding to overlap with the neighbouring wall unit and hide the panel connection. The outcome of the design worked with the connection of the same panel types. However, issues arise when cladding and tectonic elements varied between units.

- The design of the script required anticipation of the relationship between the tectonic elements.

An outcome of the development process identified the relationship between the tectonic elements of having a limit before the design no longer worked. The design was voided when the parameters were increased beyond a realistic size or construction method, causing the wall design elements to intersect. However, with the powerful digital tool, the limitations could be included in the script's design to restrict the parameter's before reaching the limit.

- The powerful design tool has an extensive capacity to precisely control design. The design tool's use within the design strategy has immense capacity to further refine and innovate the strategy components to create an effective method to address existing housing.

- The dynamic and relative relationship between the existing house, site and the position of the program needs to adapt respectively to the other. The intention of a program type may need to respond relatively to wider site, house and environmental parameters. For example, an outcome of the design process revealed seating program types as needing to respond to a wider context beyond design aesthetic variations. The relationship to the ground level at the location of the program applied to the house, determines the seating height as appropriate for the occupant to use.

- Additional outcomes revealed similar relationship needs for the program types which the occupants directly interact with, such as seating, table, cooking, bar, storage and play. The relative height and size adjustments respond dynamically as the necessary parameters are specified.

- $\quad$ Future - The parametric script would be further developed to include site and climate data to inform the program parameters influencing the design. The design could then dynamically adjust and propose a design as appropriate to the specific climate and site features. The program types such as shelter and vegetation would also benefit as appropriate growing conditions could be assessed and identify the optimum location for plant growth and the shelter program could respond to wind and sun data as appropriate. 
The following exploration series applies program variance outputs to the existing 1940s-1960s state

house to visualise the program application in context.
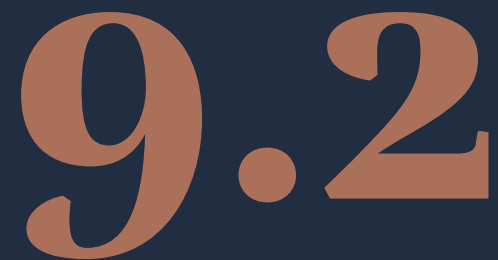

\section{Program} Application Visualisation 
Visualised fragments of program application to home

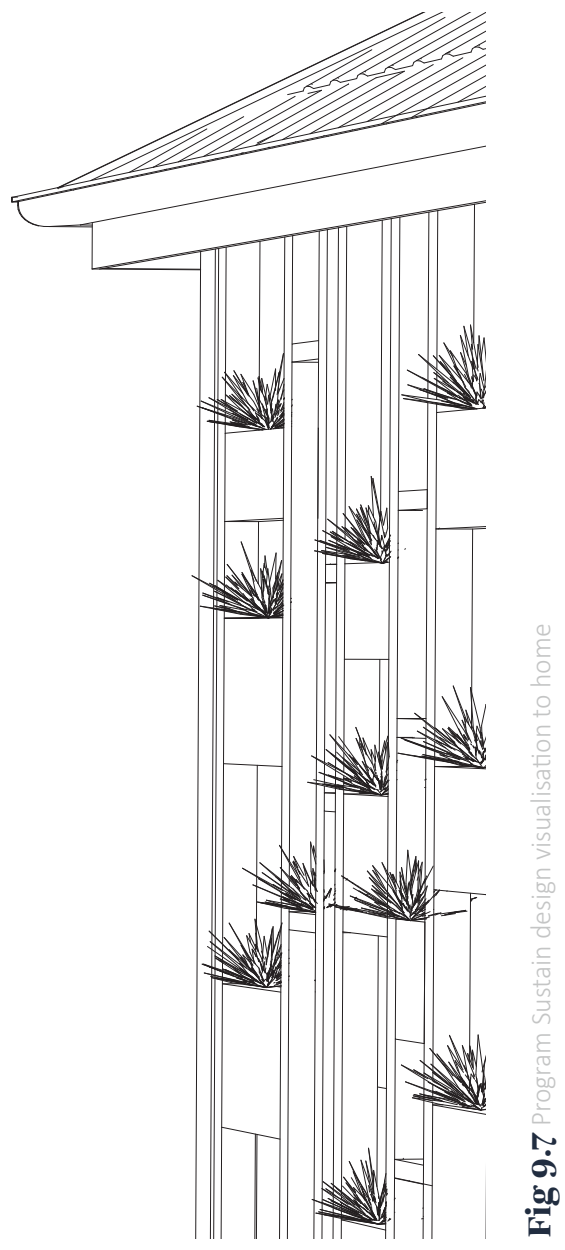




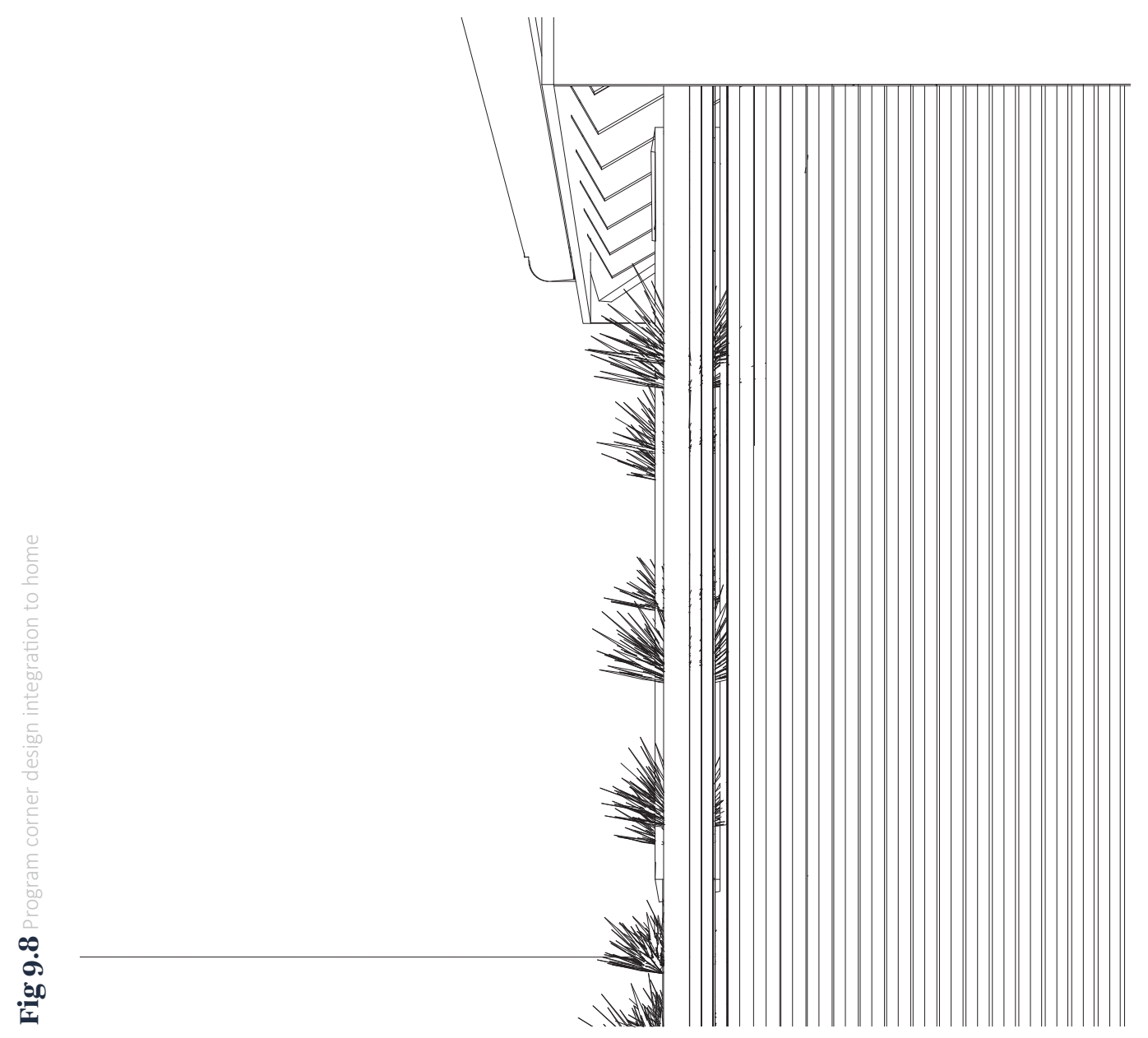




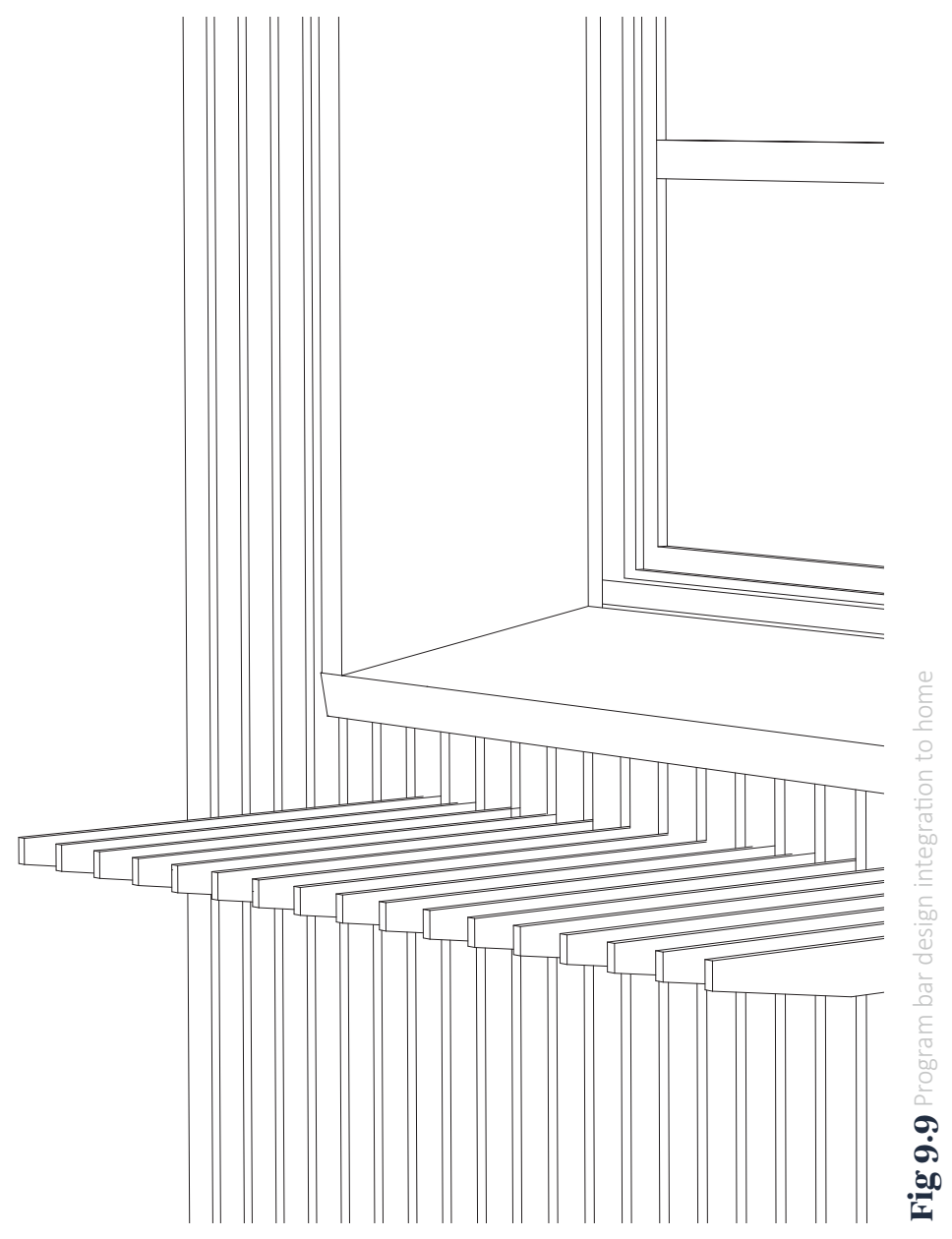




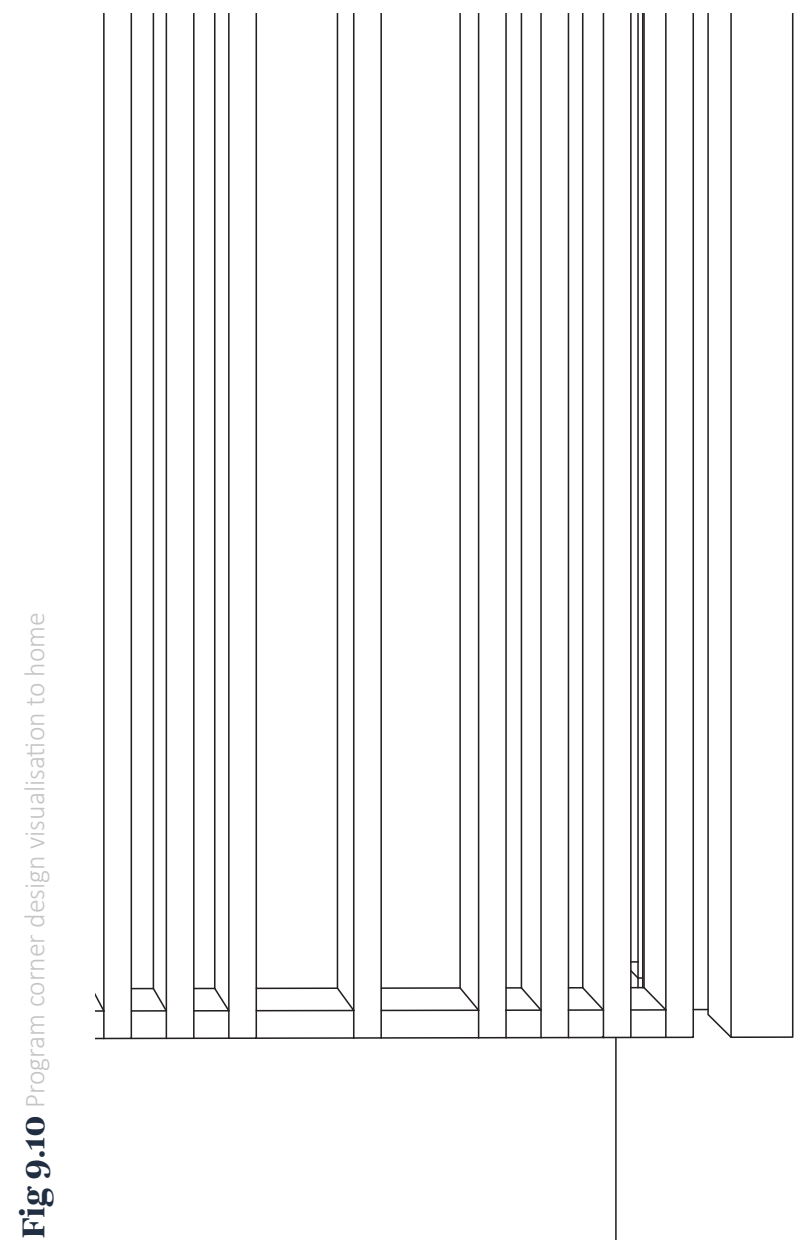




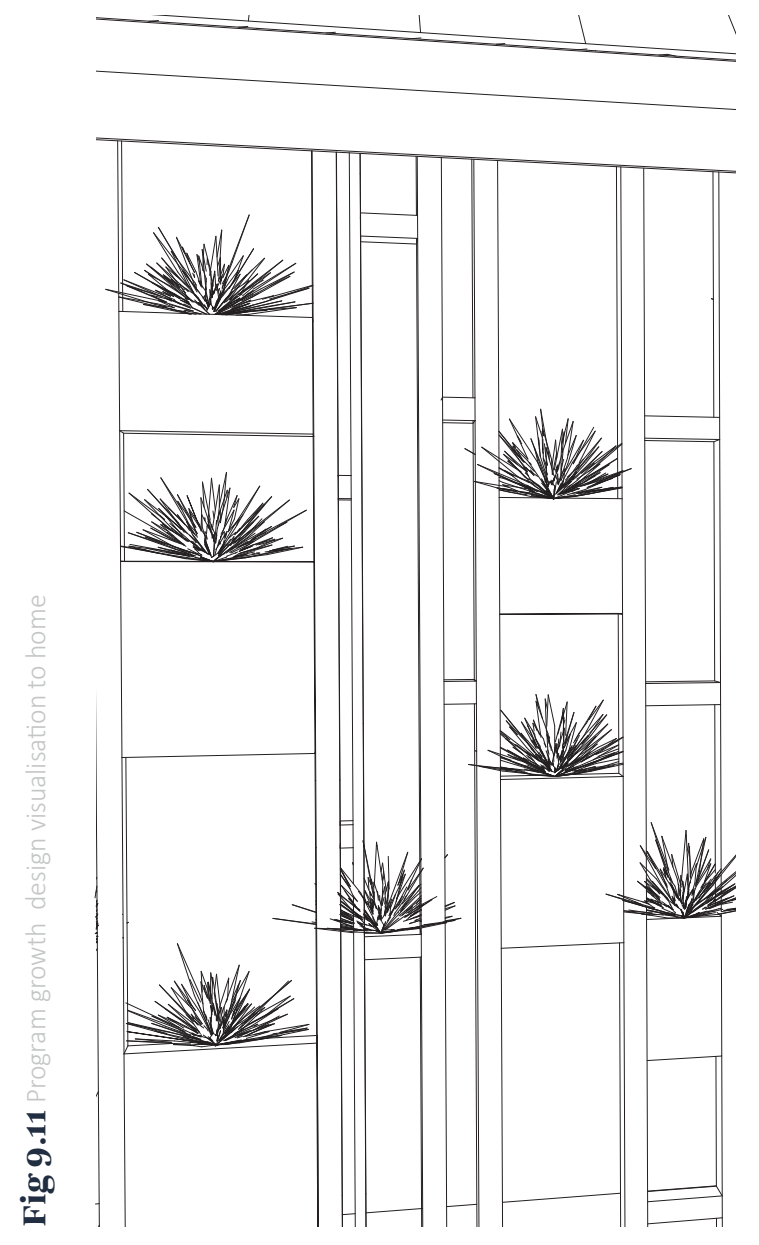




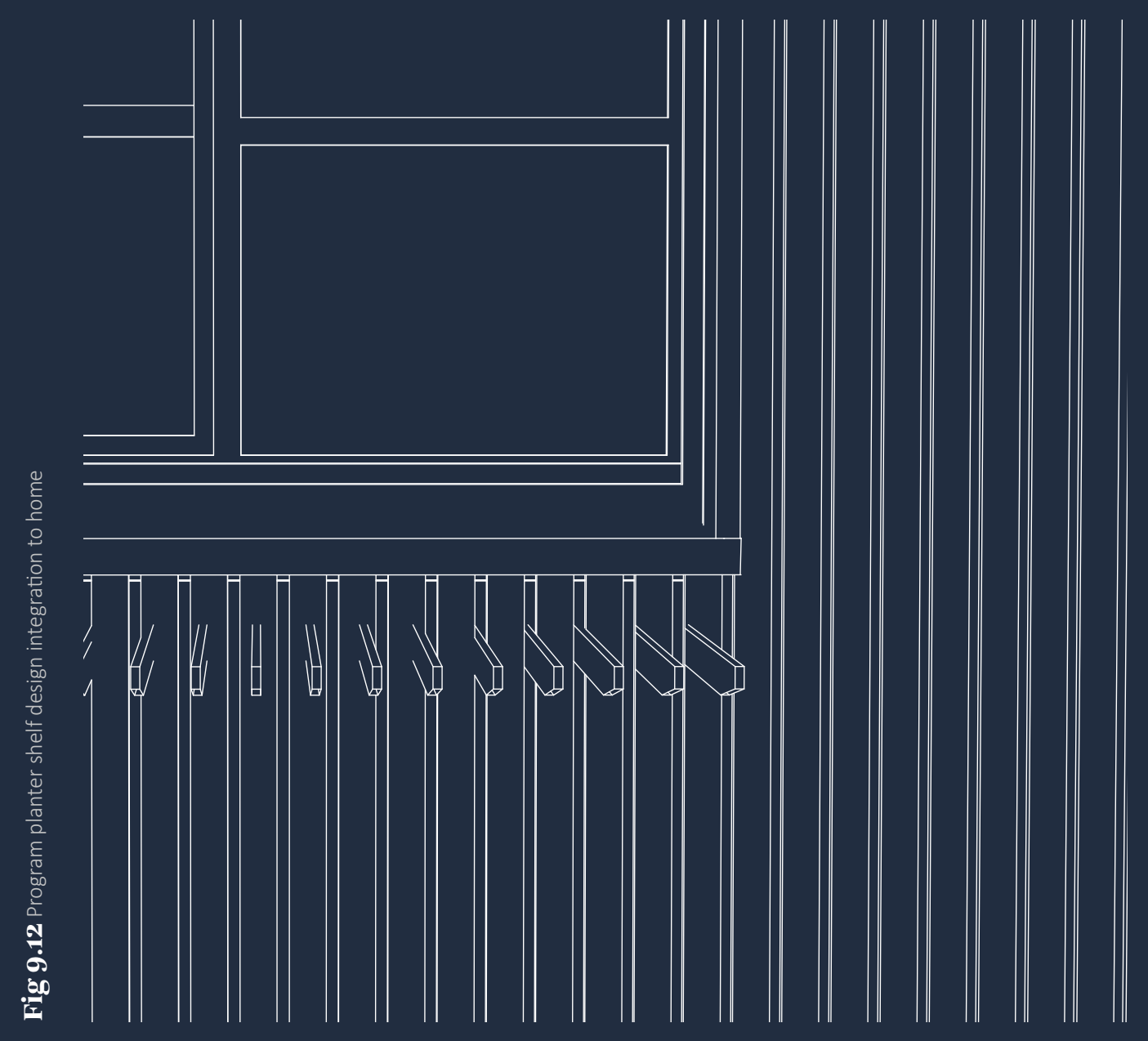




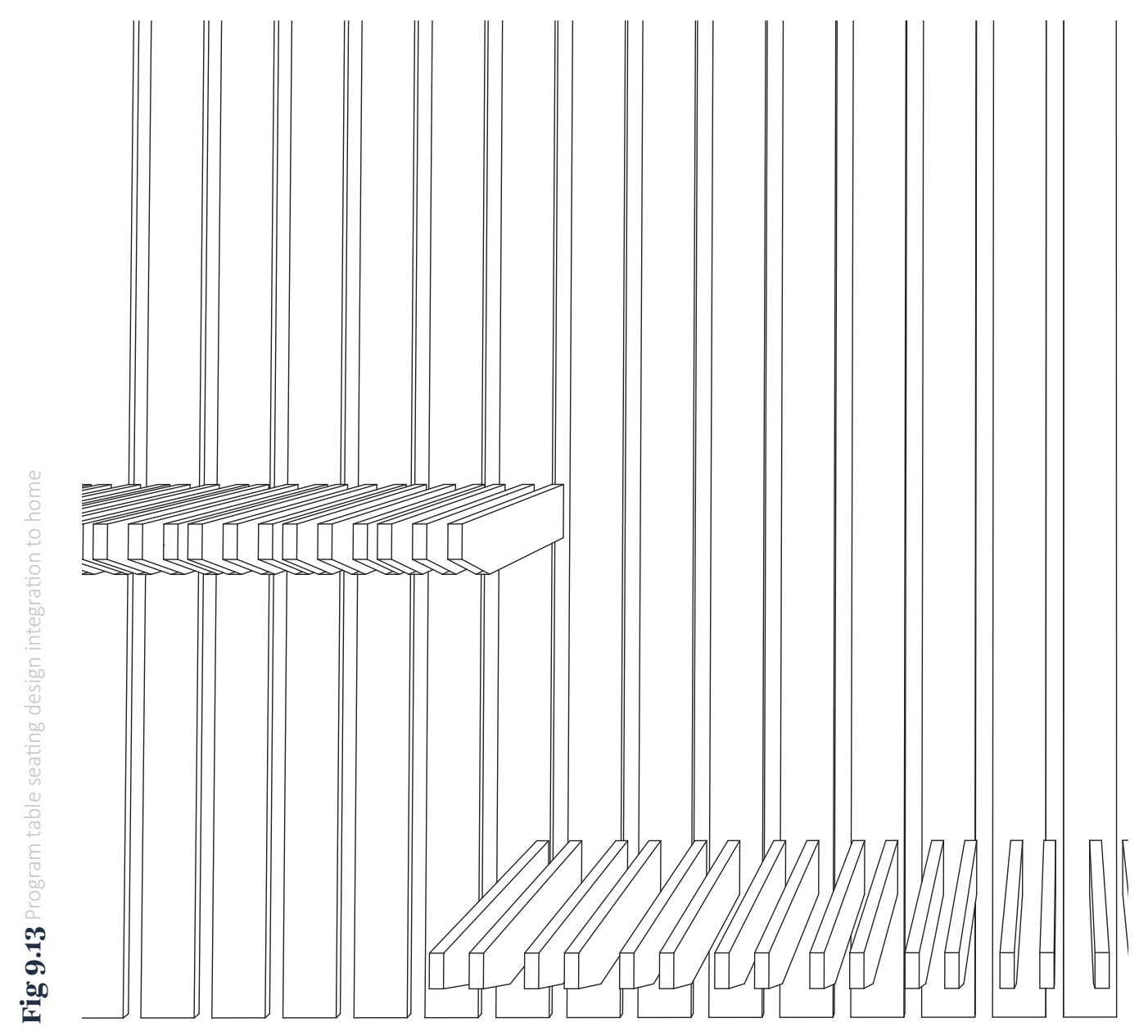




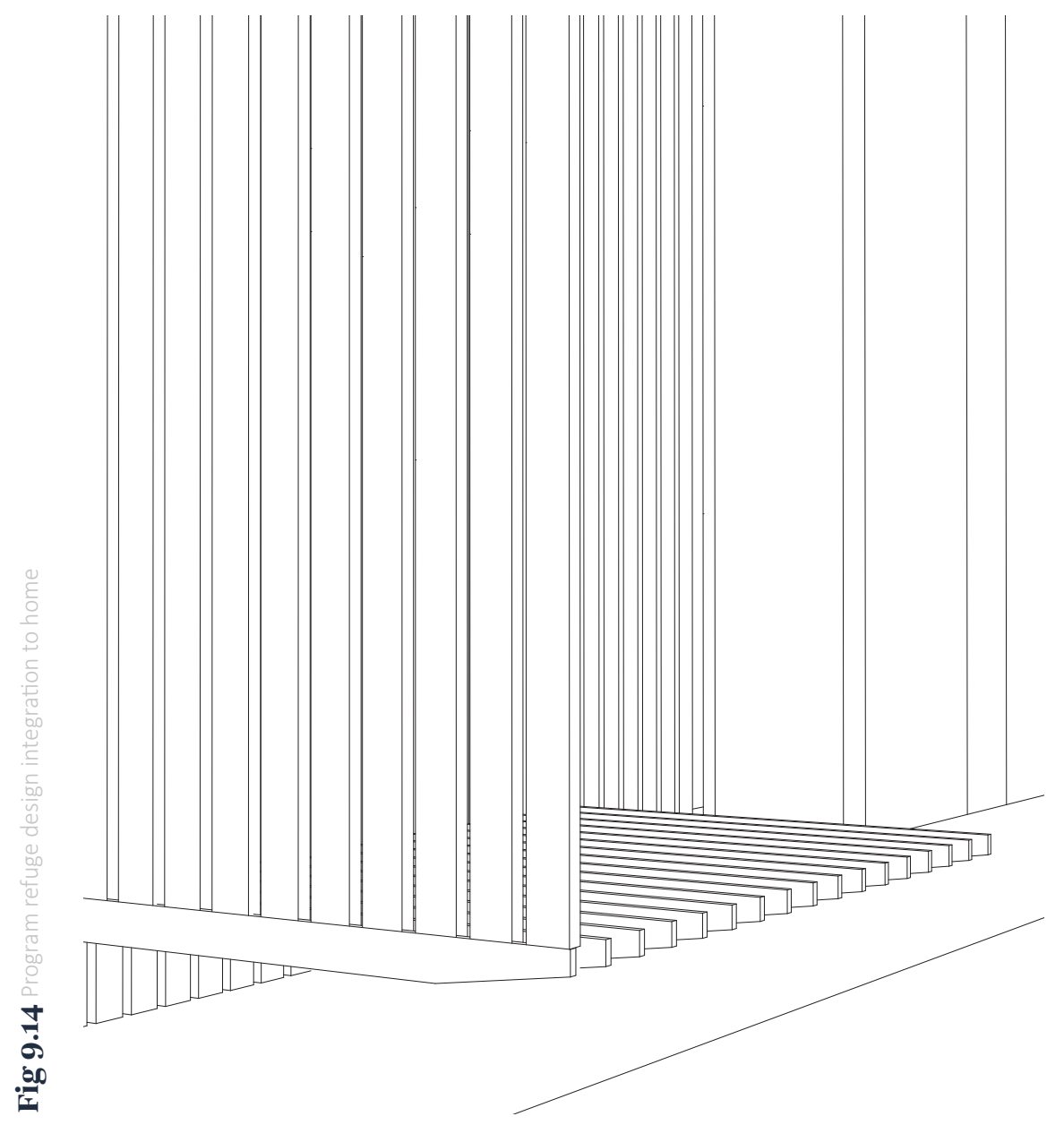




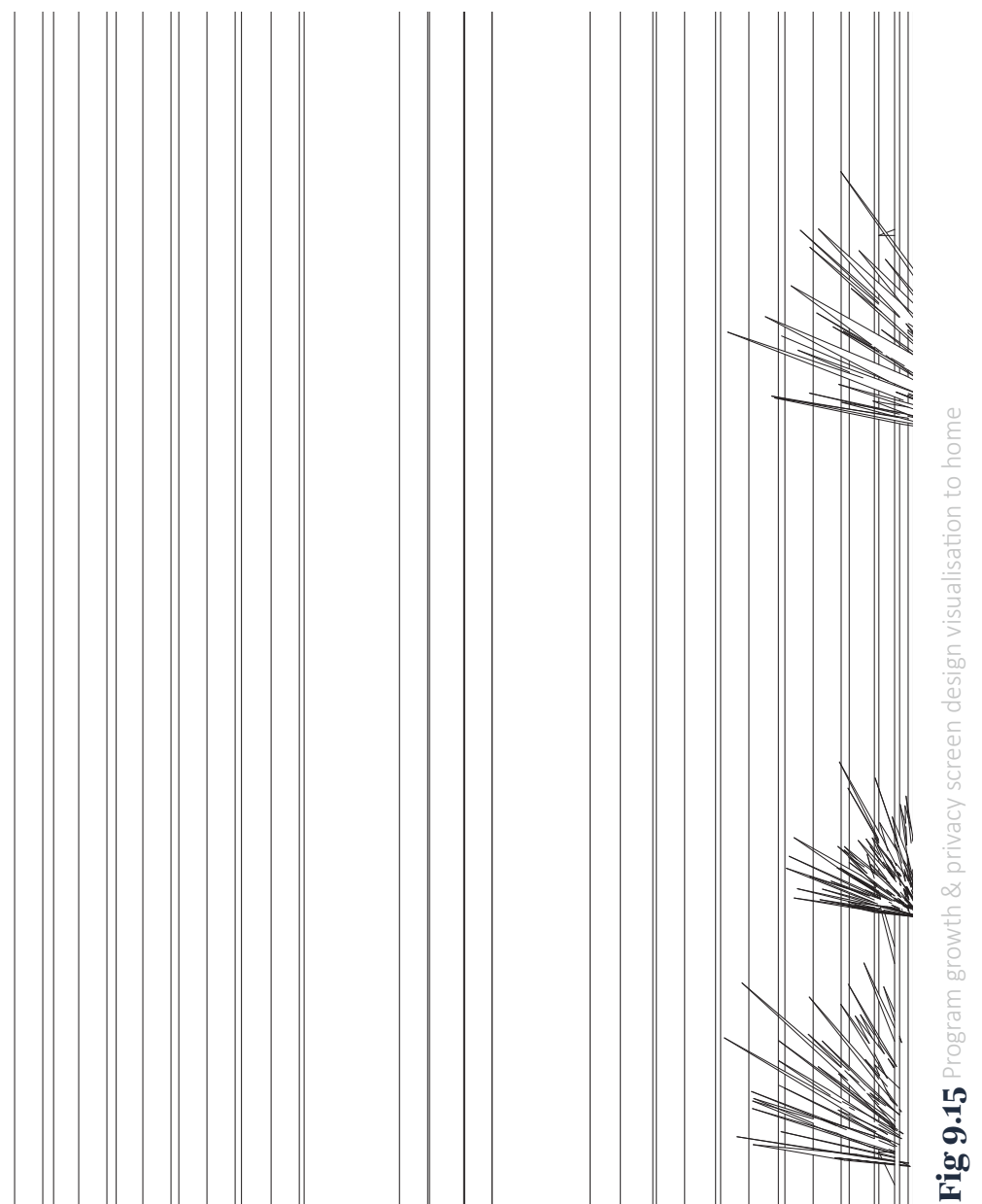




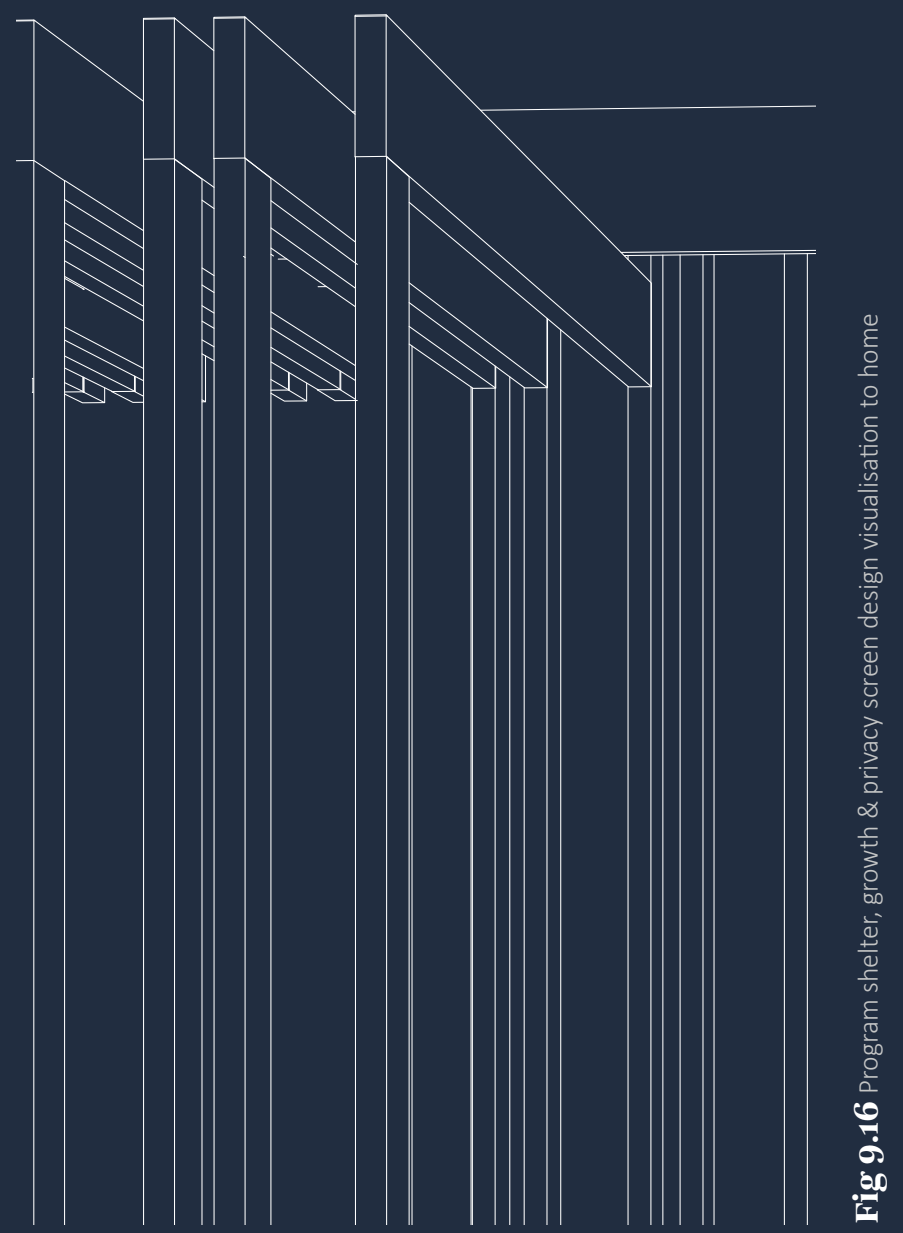



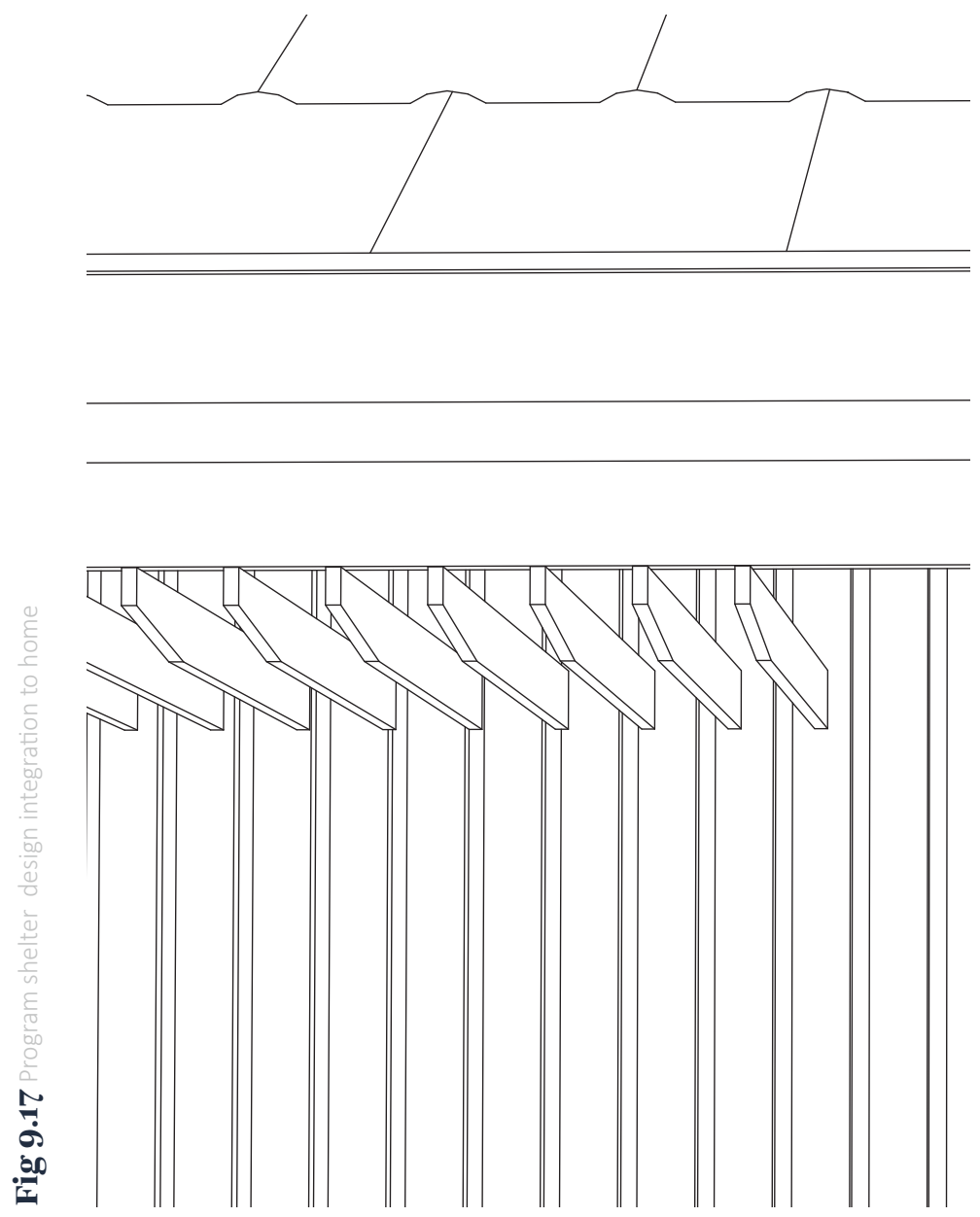


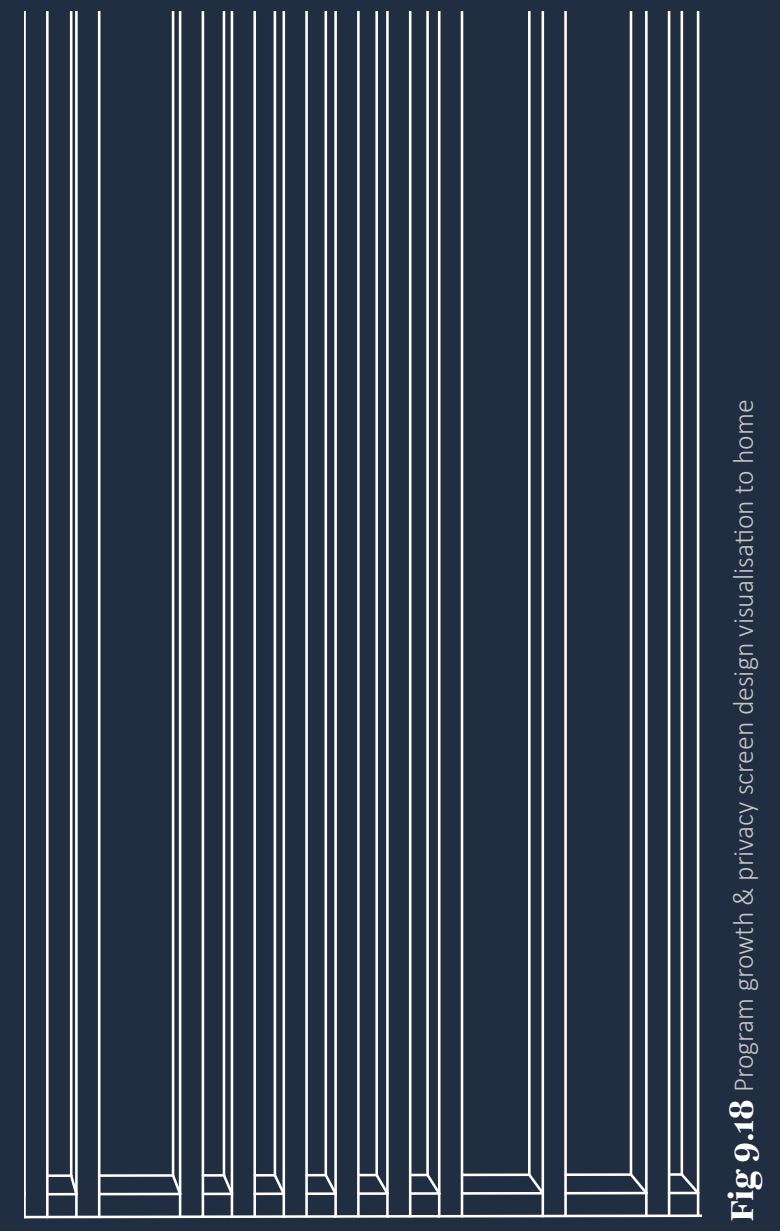




\section{Framework Integration}

\section{Performance}

1.0 Home Performance

1.1 High thermal performance

design principles

1.2 Continuous envelope

1.3 Limit thermal bridging

2.0 Environmental Performance

2.1 Use the existing housing resource

2.2 Passive design techniques

3.0 Adaptive Performance

3.1 Adaption relative to site and environment

3.2 Optimise and streamline design, construction and strategy proces

3.3 Optimise material use and fabrication methods

\section{Experience}

\section{(4.0 Occupant Experience}

4.1 No occupant displacement

4.2 Limit disruption on-site

4.3 Respond to client brief

5.0 Environmental Experience

5.1 Functional program

5.2 Encourage the human-nature relationship

\subsection{Adaptive Experience}

6.1 Aesthetic design diversity 6.2 Occupant program brief

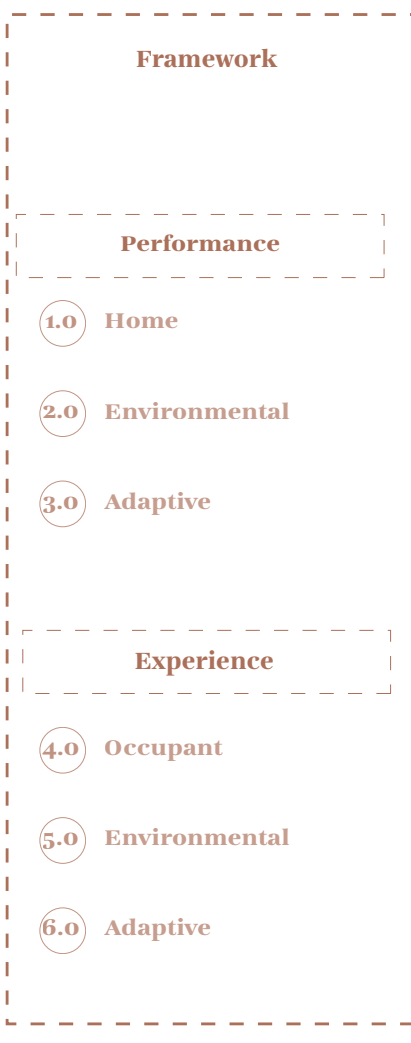

The Design Strategy

Base

Component

rogram

Component

Fig 10.1 Diagram highlighting areas of design framework informing the base, program and adaption components explored 


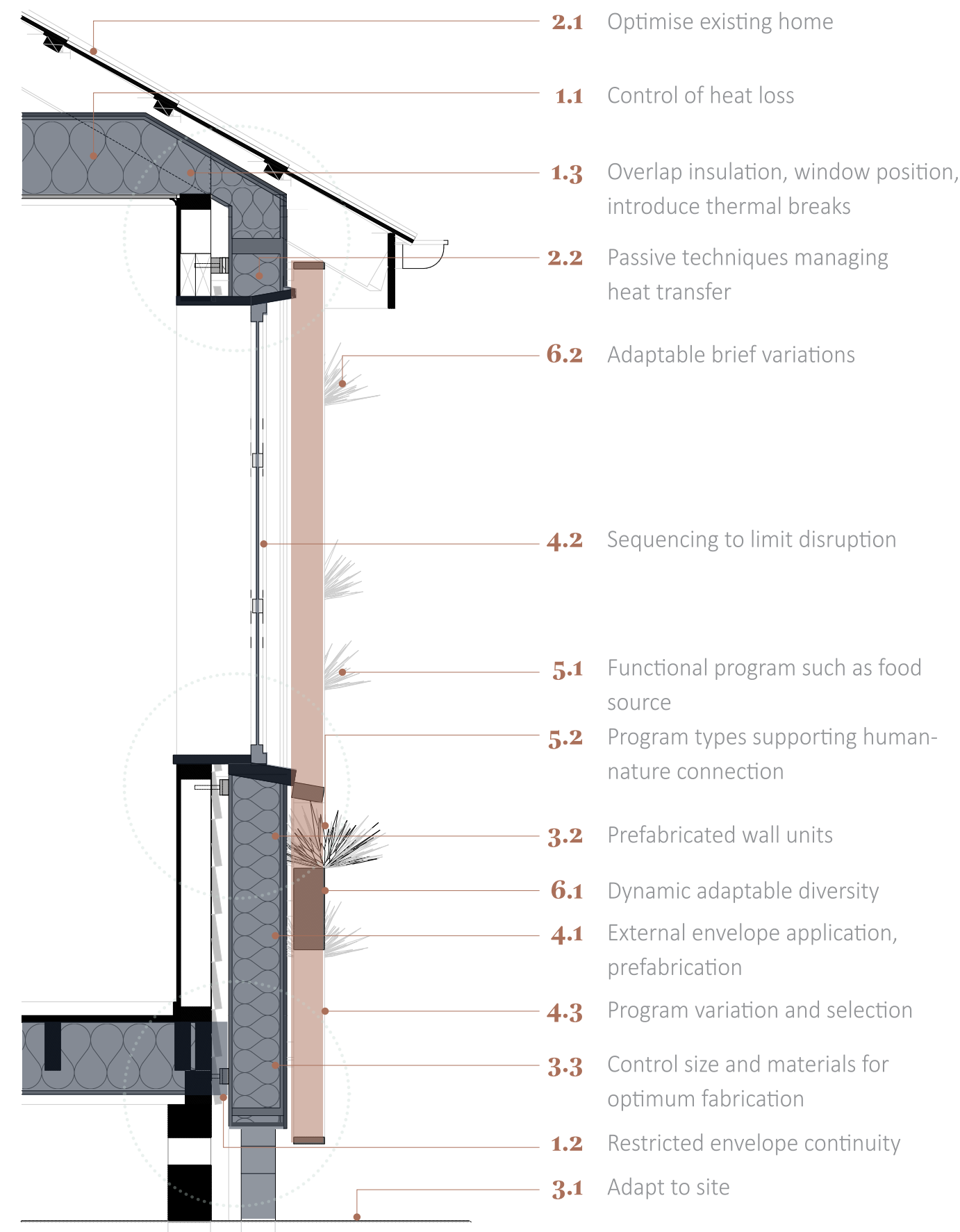

Fig 10.2 Diagram comparing areas of design framework for the 


\section{Base Component}

\section{Findings:}

The conceptual design of a continuous thermal envelope to the existing home explored a solution to not displace and limit occupant disruption as possible.

- Unfortunately, a compromise of some occupant disruption to provide high performing windows would occur. However, the unit prefabrication allows the occupants to still live in their homes while the work would occur.

- The research site was an original 1940s-1960s state house, but future research could address additional housing typologies.

- The base component's conceptual detailing would benefit from more structural, performance, weather and airtightness development and testing.

- The thermal performance would need testing and simulations to measure the home performance, particularly concerning thermal bridging and airtightness between the existing home, openings, and the strategy.

- The application to differing housing materials and typologies need to ensure compatibility between materials.

- The environmental focus was limited to the reuse of existing resources and improving home performance for energy efficiency. However, material selections, carbon impact and life cycle assessments are considered a fundamental component of the overall long-term strategy.

- Post-construction and post-occupancy testing and evaluations would additionally provide opportunities for testing and refining the design. 


\section{Program Component}

\section{Critical Reflections:}

- The breadth of initial design explorations was challenging to manage and establish a particular design direction. The difficulty identified the need for a program brief to identify program types and their collective functions to restrict the design exploration and reduce the overall outcome.

- The program brief only began to explore the breadth of envelope use opportunities, material selection, construction detailing and aesthetics. The possible combinations and variations are not limited to the brief and indicate plenty of scope for developing the strategy beyond the research.

- The visual aesthetic is not fully resolved and results in uncertainty of the overall aesthetic and material impact.

- The integration of the program and base components are conceptual and needs more significant development to resolve their cohesion.

- The site conditions, orientation and capacity for a specific program would impact program selections and uses. For example, vegetation would only be useful if sufficient shelter, exposure to sun and water are available. The seating and retreat programs would need appropriate shelter, especially in changing weather conditions.

- The initial design process used static sketching, physical and digital modelling tools. The static design method was useful to inform the initial designs. However, it was slow and labour intensive. It became clear that the strategy designed solely by static methods would prove ineffective for the strategy's overall function as any development to the designs was labour intensive.

\section{Findings:}

- The need to limit the program focus highlights the breadth of development opportunity beyond the thesis's scope for the strategy to evolve appropriately to individual occupant needs, site conditions, circumstances.

- The program is the crucial area the occupants interact with the envelope to expand the current home use and experience.

- The program brief of refuge, sustain and play were identified as a base for a diverse range of uses for the enriching the home experience with the human-nature relationship.

- The development and integration of the program units together have issues combining various program and materials and proposes an opportunity to express clean architectural details.

- The integration into the existing home is dependent on the desired aesthetic and material selection by the occupant. The outcome supports diversity among mass-scale application of the strategy and encourages individual identity and ownership over their home.

- The differing occupant and site circumstances highlight the need for the parametric strategy throughout the homes to change for the needs of the people, differing home locations and conditions.

- The static design process highlighted the need to integrate parametric design tools into the design of the strategy. The tools were crucial to proposing a dynamic strategy to quickly adapt housing variations, site topographies, conditions, program variations, design changes, aesthetics and occupant needs. 


\section{Adaption Component}

\section{Findings:}

- The digitalisation using parametric design provides a method for fast and dynamic realtime changes for theoretical adaption of the program's construction, aesthetics, and function to each individual home, occupant desires and needs. However, much greater development would be needed to streamline the system.

- The parametric script offers far more significant detailed design variation opportunities beyond the base design for future development and adaptable program use.

- The fluidity of the parametric component further highlighted potential program variations and home diversity.

- The parametric digitalisation allowed for greater and faster design exploration and output due to the digital tool's exponential variability.

- $\quad$ The development of the parametric script takes more time and requires complex anticipation of parameter variations and limitations of possible designs. However, once the base digital script is developed the output efficiency increases significantly.

- The fast and real-time changes provide a method to make changes to the design that result from physical testing, future design development, detail refinement, client desires, architectural intent, expression, site conditions, existing home, program use, needs and materiality. The outcome highlights future design development and the opportunity to evolve the strategy over time.

- The parametric design component would be integrated into prefabricated construction methods to streamline the strategy and increase efficiency.
- The issues found during the design process identified in Chapter 9.0, identify the need to refine the relationship between design elements and tectonics to produce a constructable output.

- The adaption to site becomes critical with the integration of program for appropriate heights to comfortably use the program or for designing in response to the site conditions to benefit from the natural environment or to protect the occupant from. 


\section{Scope $\mathcal{E}$ Limitations}

- The design and exploration of all of the design strategy components (Chapter 5.0) were too large for the thesis scope. Therefore, a series of explorations for three key components of the strategy began to test the overall scheme's possible design outcome. Further exploration such as the integration of site model data such as weather (sun, wind, solar) would strengthen the design. For example, sun data influencing and driving the design parameters of shading and orientation for planting and seating.

- The digital model developed to understand the 1940s-1960s house typology provided sufficient detail for the initial research. However, a 3D scanned into a point cloud digital model would provide complete accuracy for each specific house and input into the parametric design component to adapt to the exact house details.

- The transition from the parametric digital model into prefabrication would be fundamental to streamline the process between parametric adaptability to physical construction. Where the design could be developed and adapted as appropriate to site, occupant, needs and design development within the digital model. The changes are then directly also made into the construction of the unit. However, to also investigate the physical construction was too large for the research scope but the research would benefit from full-scale testing and prototyping of the base and program components for construction detailing. Additionally, full-scale testing of the design strategy process would test its feasibility against New Zealand housing. 
20.

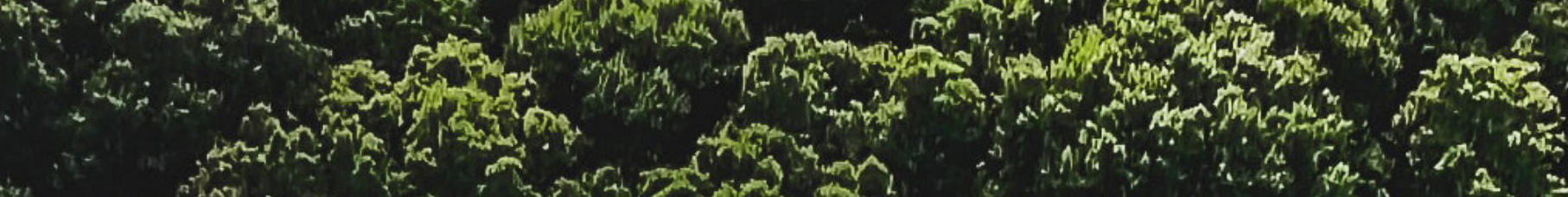

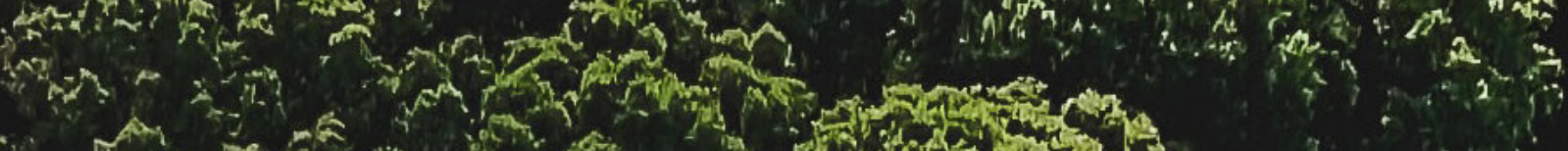

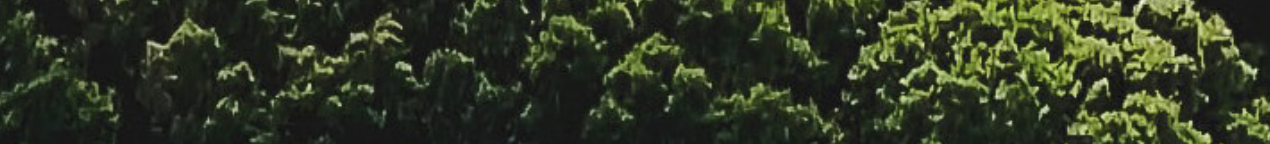

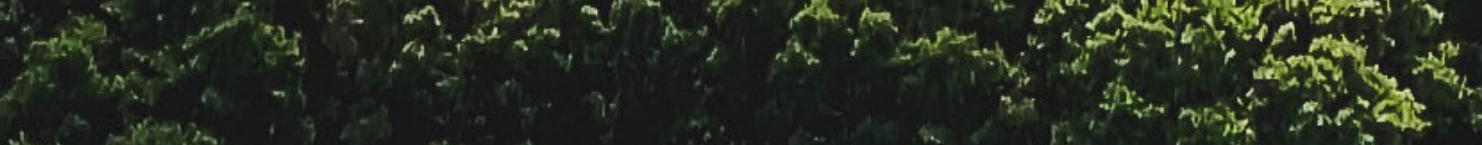

$$
\begin{aligned}
& \text { Whe } \quad x=?
\end{aligned}
$$$$
\sin \text { (t) }
$$

then

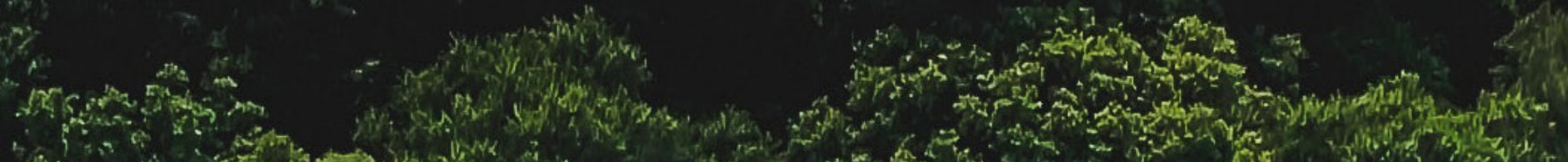

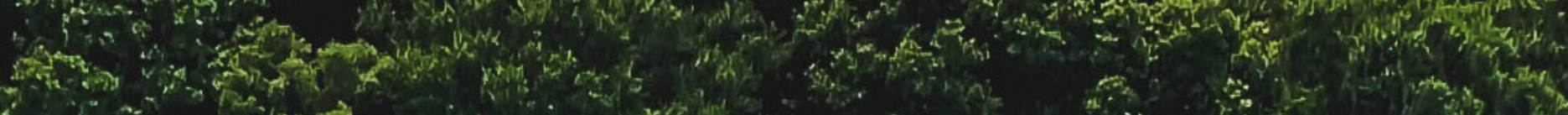

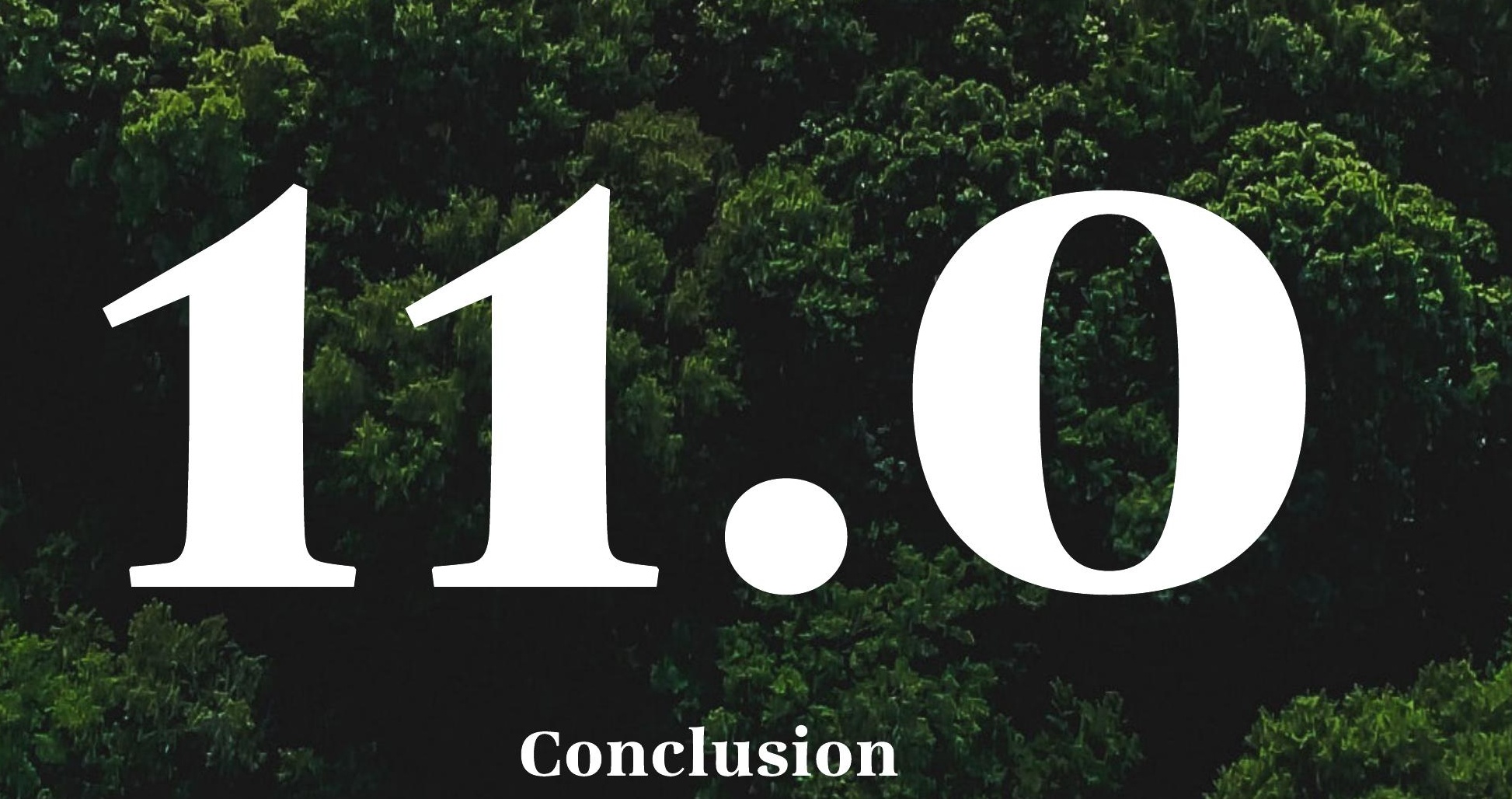

\section{Conclusion}
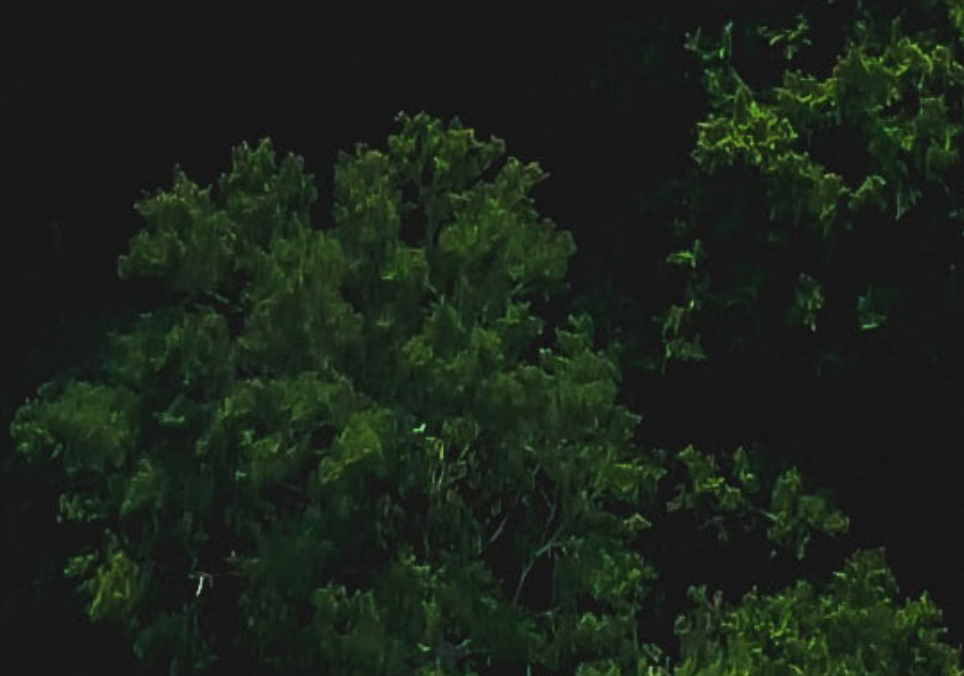


\section{Conclusion}

The research aimed to radically improve the thermal performance of existing New Zealand houses to enrich people's home experience. Enriching the Envelope Experience proposed an overall design strategy to address existing 1940s-1960s state housing for thermal performance and the home envelope experience to support occupant health and well-being. The design was informed by theoretical research findings and key case studies of external retrofit strategies. The key case studies identified the gap in New Zealand housing improvement approaches and the benefits to support occupant health and well-being. The design strategy proposed a process to enrich the envelope for thermal performance and experience as informed by the framework (Chapter 5.0). To investigate the design strategy process three key components were explored to understand their feasibility within the overall scheme.

First, the research outcome concluded an envelope retrofit of existing houses theoretically enhances the thermal performance of existing housing and provides a base for a wall program to enrich people's home experience. Through the design process, it was found the design of prefabricated wall units, ceiling and sub-floor insulation combined to form an almost continuous thermal envelope as a method improve the home's thermal performance and energy efficiency.

Secondly, the design research found integrating the program to the home envelope provided an opportunity to enrich the human-nature relationship and provide a functional addition to the home. The outcome highlighted the significant variance opportunity within the program component for a range of design outcomes.

Thirdly, the design research benefited from parametric digitalisation to support dynamic program variations for appropriate adaption. The parametric digitalised component proposes the design's possibility of adapting to a broader range of housing typologies. There are adaption abilities for program typologies to vary for home and occupant needs and adjust the program to be applied to the home and surrounding site and environmental context. Additionally, the adaption abilities highlight the program's capacity to grow and exponentially change due to requirements, available materials and future technology.

The design process was a continual exploration between the base thermal component, the program component and the adaptable component simultaneously as a result of their reciprocal relationship. The components' relationship resulted in a feedback loop design process where one component's development directly impacted another to resolve design issues. The development of each component of the design strategy with testing, materials and development aims toward reaching higher home performance and enriched occupant experience. A streamlined design strategy then applicable to various New Zealand existing housing for the benefit of people and the environment. 


\section{Key Contributions}

- Use of available resources. The strategy concept proposes an environmentally considerate approach to use the available resources of the existing housing stock. The research found a solution to improve the existing conditions supporting the health and wellbeing of occupants.

- External retrofit approach possible in New Zealand housing. The strategy to externally retrofit homes in New Zealand has conceptually been achieved to increase the thermal performance of homes.

- A design strategy process to improve the performance and experience of the home.

- Enrichment of home experience. The home envelope exploration highlighted the opportunity to maximise occupant humannature relationship and home experience with a variable architectural program application to the home.

- Parametric adaptability. The development of an adaptable base strategy and the architectural program for the adaption to varying housing typologies and the occupant brief. 


\section{Future Research}

The external retrofit design strategy to improve thermal performance and home experience address occupant health and wellbeing without needing to displace the occupants. The research explored three design components within the strategy as a starting point for the potential capacity of the strategy and to manage the research scope. However the strategy would need greater development to estabish the full design and construction implications and outcomes. Throughout the research, potential development areas were revealed but not explored to manage the research scope.

Opportunities for further development include but are not limited to:

- $\quad$ The adaption of the strategy to broader housing typologies.

- The construction methods, layers, and details development.

- Base component testing and simulation of airtightness, thermal bridging and windows.

- Program development for function, integration, combinations and use.

- Program wall adaption testing and simulation.

- Program selections for site, occupant needs, and circumstances.

- Material selection, aesthetic outcome, material availability and appropriateness to site and purpose further development.

- The use of sustainable materials, technology and processes.

- The strategy to explore a circular economy approach.

- The testing and simulations of the strategy for construction, deconstruction and reconstruction of materials.

- The further exploration of visual aesthetics, overall design appeal of the strategy, and architectural expression.

- A practical development and testing of models, materials and construction.

- The development of prefabrication, construction process and site installation.

- The generation of market demand for the strategy to be implemented throughout New Zealand.

- The integration of energy modules into the wall unit for overall house performance.

- The reuse of materials and net-zero waste construction techniques such as robotic 3D printing of recycled material.

- Net-zero carbon approaches.

- The environmental impact, carbon footprint and life cycle of material selections.

- $\quad$ Net-zero energy observation and method.

- $\quad$ The material selections \& construction detailing for combining various materials for appropriate compatibility within the automated system. 


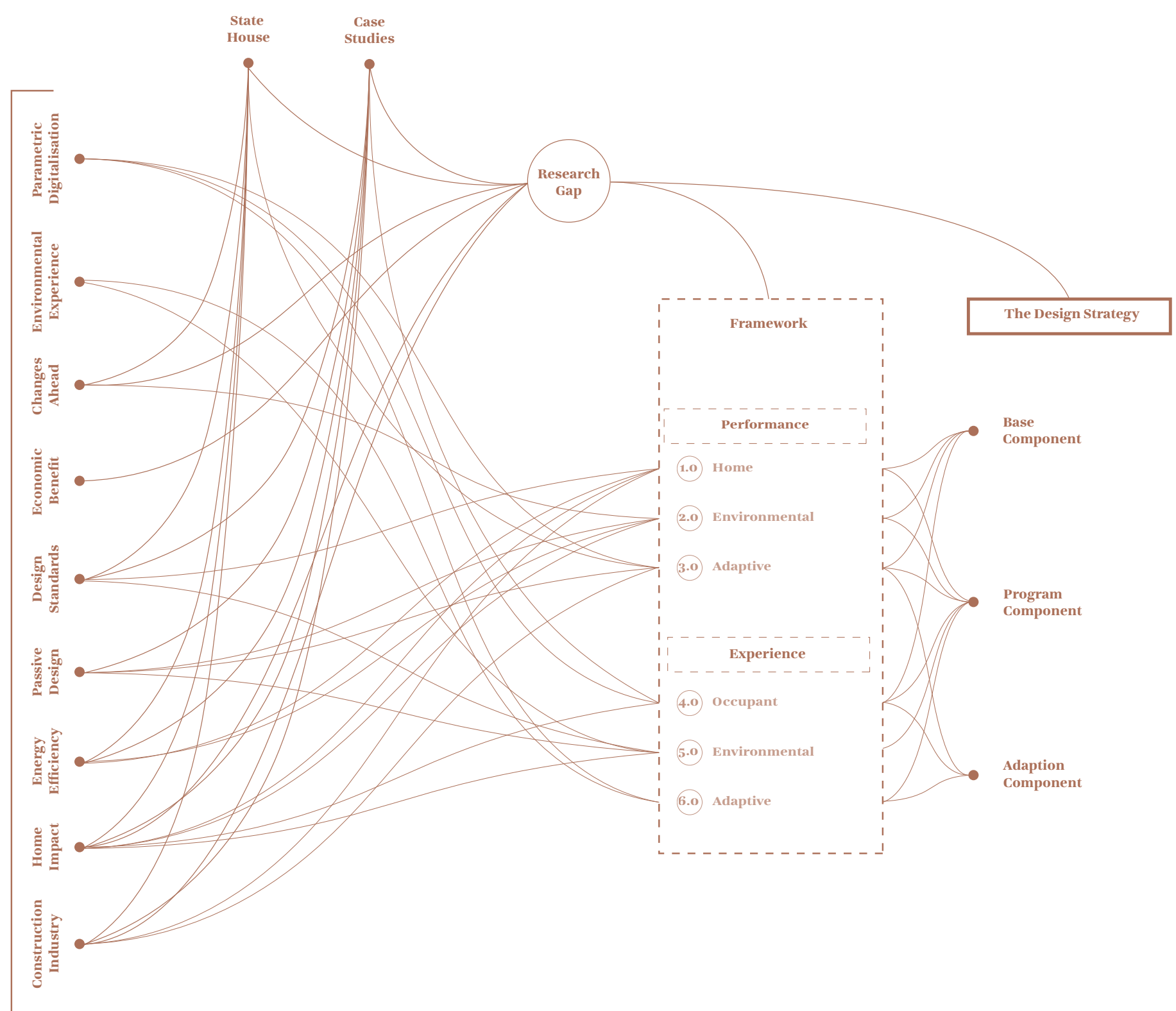

Fig 11.1 Overview of research process to establish a design strategy and the exploration of the three key components within the strategy to improve the thermal performance of existing New Zealand houses enriching peoples home experience 

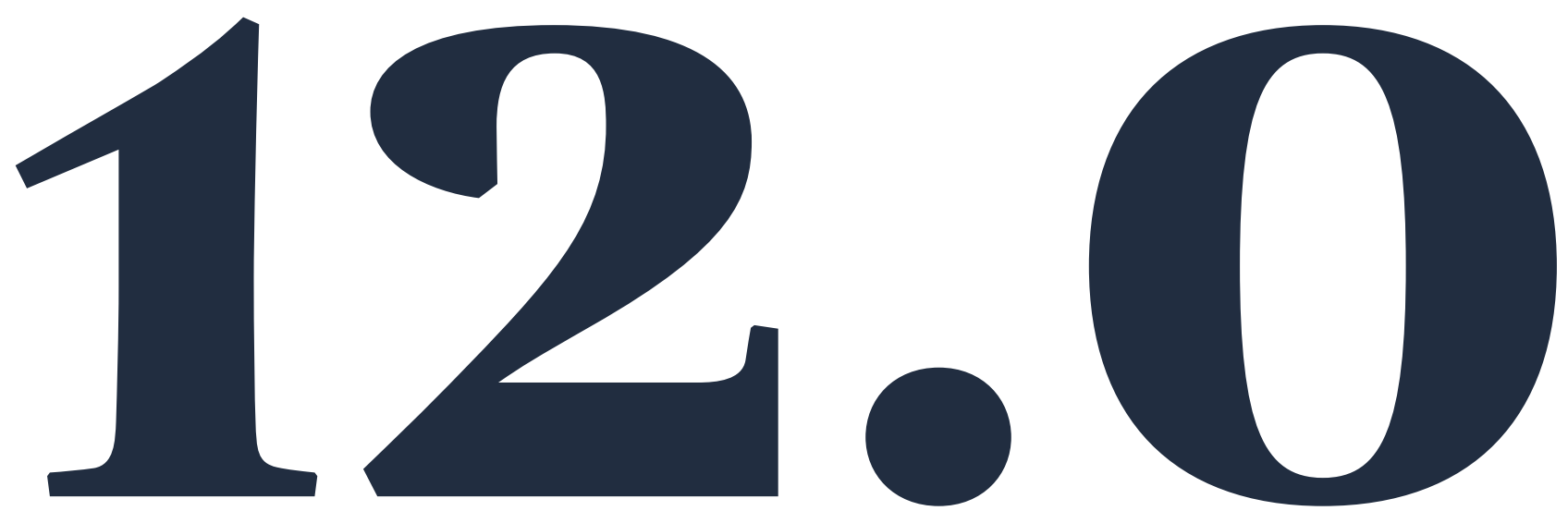

References 


\section{Reference List}

Appleton, J. (1996). The experience of landscape. (Rev ed.). England, UK: John Wiley \& Sons Ltd. (Accessed November 2020).

ASHRAE. (2001). International Weather for Energy Calculations (IWEC Weather Files) Users Manual and CD-ROM. Atlanta: ASHRAE. Wellington Weather Data. Retrieved from EnergyPlus https://energyplus. net/weather-location/southwest_pacific_wmo_ region_5/NZL//NZL_Wellington.Wellington.934360_ IWEC (Accessed August 2020).

Ayres, J. (2005). Sensory Integration and the Child: Understanding Hidden Sensory Challenges. Los Angeles, United States: Western Psychological Services. (Accessed November 2020).

Baker, M., Keall, M., Au, E. L., \& Howden-Chapman, P. (2007). Home is where the heart is--most of the time. The New Zealand Medical Journal (Online), 120(1264). Retrieved from https://search.proquest. com/docview/1034236732 ?accountid=14782 (Accessed November 2020).

BRANZ. (2020, December). House Condition. BRANZ Research Now: Pilot Housing Survey 2018/19 \#2. Retrieved from https://www.branz.co.nz/pubs/ research-now/warmer-drier-healthier/pilothousing-survey-3-insulation-ventilation-spaceheating-and-water-heating/ (Accessed February 2021).

BRANZ. (n.d.). 1940's-60's. Renovate: the technical resource for industry. Retrieved from https://www. renovate.org.nz/1940-60s/ (Accessed April 2020).

Browning, W., Ryan, C., \& Clancy, J. (2014). 14 Patterns of biophilic design: Improving health \& well-being in the built environment. Retrived from http://www.terrapinbrightgreen.com/wp-content/ uploads/2014/04/14-Patterns-of-Biophilic-DesignTerrapin-2014p.pdf (Accessed October 2020).
Chandrakumar, C., McLaren, S., Dowdell, D., \& Jaques, R. (2020, February). A science-based approach to setting climate targets for buildings: The case of a New Zealand detached house. Building and Environment. 169. DOI https://doi.org/10.1016/j. buildenv.2019.106560 (Accessed November 2020).

Cox-Smith, I. (2009, February). Thermal breaks and bridges. Build 110. 16-17. (Accessed February 2021).

Czerwinska, D. (2016). Green building: Improving the lives of billions by helping to achieve the UN Sustainable Development Goals. World Green Building Council. Retrieved from https://www. worldgbc.org/news-media/green-buildingimproving-lives-billions-helping-achieve-unsustainable-development-goals (Accessed 2020).

eHaus. (2019). eHaus: Redefining the way we live. Retrieved from https://ehaus.co.nz/my-ehaus/ ehaus-pacific/ (Accessed June 2020).

Engergiesprong. (n.d.). Energiesprong. Retrieved from https://energiesprong.org/ (Accessed March 2020).

Energiesprong. (2015, May). Transition Zero. Retrieved from https://energiesprong.org/wpcontent/uploads/2017/04/EnergieSprong_UKTransition_Zero_document.pdf (Accessed March 2020).

Energiesprong. (2019, April). Energiesprong works. Retrieved from https://energiesprong.org/wpcontent/uploads/2019/04/Energiesprong-works_ DEF.pdf (Accessed March 2020).

Ferguson, G. (1994). Building the New Zealand dream. Palmerston North, NZ: The Dunmore Press Limited (Accessed June 2020).

Firth, C. (1949). State Housing in New Zealand. Wellington, NZ: Ministry of Works. (Accessed April 2020). 
Grahn, P., \& Stigsdotter, U. (2003). Experiencing a Garden: A Healing Garden for People Suffering from Burnout Diseases. Journal of Therapeutic Horticulture. 14. 38-48. Retrieved from https:// www.researchgate.net/publication/234071989_ Experiencing_a_Garden_A_Healing_Garden_ for_People_Suffering_from_Burnout_Diseases (Accessed January 2021).

Grahn, P., \& Stigsdotter, U. (2010). The relation between perceived sensory dimensions of urban green space and stress restoration. Landscape and Urban Planning. 94. 264-275. DOI 10.1016/j. landurbplan.2009.10.012 (Accessed November 2020).

Grimes, A., Preval, N., Young, C., Arnold, R., Denne, T., Howden-Chapman, P., \& Telfar-Barnard, L. (2016). Does retrofitted insulation reduce household energy use? Theory and practice. The Energy Journal, 37(4) DOI: http://dx.doi.org/10.5547/01956574.37.4.agri (Accessed November 2020).

Howden-Chapman, P., Matheson, A., Crane, J., Viggers, H., Cunningham, M., Blakely, T., ... \& Davie, G. (2007). Effect of insulating existing houses on health inequality: cluster randomised study in the community. BMJ (Clinical research ed.), 334(7591), 460. DOI https://doi.org/10.1136/ bmj.39070.573032.80 (Accessed November 2020).

International Energy Agency (IEA). (2019). Global status report for buildings and construction 2019: Towards a zero-emission, efficient and resilient buildings and construction sector. Retrieved from http://globalabc.org/ (Accessed March 2020).

International Living Future Institute. (2019, June). Living Building Challenge 4.0: A Visionary Path to a Regenerative Future. Retrieved from http://livingfuture.org/wp-content/uploads/2019/08/LBC-4_0_ v13.pdf (Accessed July 2020).
Keatinge, W. R., Donaldson, G. C., Bucher, K., \& Jendritsky, G. (1997). Cold exposure and winter mortality from ischaemic heart disease, cerebrovascular disease, respiratory disease, and all causes in warm and cold regions of Europe. The Lancet, 349(9062), 1341-6. DOI: http://dx.doi. org/10.1016/S0140-6736(96)12338-2 (Accessed November 2020).

Kellert, S. (2012). Birthright: People and Nature in the Modern World. New Haven, London: Yale University Press. Retrieved from http://www.jstor.org/stable/j. ctt32bq08 (Accessed 9 November 2020).

Kibert, C. (2016). Sustainable construction: Green building design and delivery. New Jersey, US: John Wiley \& Sons. Retrieved from https://ebookcentralproquest-com.helicon.vuw.ac.nz/lib/vuw/detail. action?docID=4462528 (Accessed July 2020).

Kopec, D. (2009). Health, sustainability, and the built environment. New York, US: Fairchild Books. (Accessed March 2020).

Lstikburek, J. (2010, July). The Perfect Wall. (Rev ed.). Retrieved from https://www.buildingscience. com/documents/insights/bsi-001-the-perfect-wall (Accessed May 2020).

Mclsaac, S. (2020, April). Building with Science \#007: Building Enclosure Control Layers. Oculus. Retrieved from https://oculusltd.co.nz/ buildingwithscience007/ (Accessed May 2020).

New Zealand Government. (2018, June). Climate Change: The Paris Agreement. Ministry for the Environment. Retrieved from https://www.mfe.govt. nz/climate-change (Accessed July 2020). 
New Zealand Government. (2020, July, a). Boost to upgrade state housing to be warmer, drier, healthier homes. Beehive.govt.nz: The official website of the New Zealand Government. Retrieved from https://www.beehive.govt.nz/release/boostupgrade-state-housing-be-warmer-drier-healthierhomes\#: : text=Boost $\% 20$ to $\% 20$ upgrade $\% 20$ state\%20housing\%20to\%20be\%20warmer\%2C\%20 drier\%2C\%20healthier\%20homes,-Hon\%20Kris\%20 Faafoi\&text=More\%20warmer\%2C\%20drier\%20 homes\%20and,and\%20renewal\%20of\%20state\%20 homes (Accessed July 2020).

New Zealand Government. (2020, July, b). Building for Climate Change: Transforming the Building and Construction Sector to reduce emissions and improve climate resilience. Ministry of Business, Innovation and Employment. Retrieved from https:// www.mbie.govt.nz/dmsdocument/11522-buildingfor-climate-change (Accessed July 2020).

New Zealand Green Building Council. (2019, September). Net Zero Carbon Roadmap for Aotearoa's Buildings. New Zealand Green Building Council. Retrieved from https://www.nzgbc.org.nz/ zerocarbon/roadmap (Accessed July 2020).

New Zealand Green Building Council. (2020, May). Homestar v4: Technical Manual. Retrieved from https://www.nzgbc.org.nz/ Attachment? Action=Download\&Attachment $\mathrm{id}=3842$ (Accessed July 2020).

Nicol, S., Roys, M., Garrett, H., \& Building Research Establishment. (2011). The cost of poor housing to the NHS: Briefing Paper. Retrieved from https:// www.bre.co.uk/filelibrary/pdf/87741-Cost-of-PoorHousing-Briefing-Paper-v3.pdf (Accessed November 2020).

Overton, G. (2019, October). Household energy use. Build 174: Climate Change. 61-62. Retrieved from http://www.buildmagazine.org.nz/issues/show/ climate-change-2 (Accessed May 2020).
Passive House Institute. (2015a). About Passive House - What is a Passive House? Retrieved from https://passiv.de/en/02_informations/01_ whatisapassivehouse/01_whatisapassivehouse.htm (Accessed June 2020).

Passive House Institute. (2015b). EnerPHit - certified retrofits with Passive House components. Retrieved from https://passiv.de/en/03_certification/02_ certification_buildings/04_enerphit/04_enerphit. htm (Accessed June 2020).

Passivhaus. (2020). Passive House Database. Retrieved from https://passivehouse-database.org/ index.php (Accessed May 2020).

Quinn, J. (2018, August). Fundamental of Building Science-The Building Enclosure and the Four Control Layers. Sustainable Engineering Ltd. Retrieved from https://sustainableengineering.co.nz/fundamentalof-building-science-the-building-enclosure-and-thefour-control-layers/ (Accessed May 2020).

RC Panels. (2021). RC Panels. Retrieved from https:// rcpanels.nl/advies/ (Accessed April 2020).

Rogers, K. (2019, June). Biophilia hypothesis. Encyclopedia Britannica. Retrieved from https:// www.britannica.com/science/biophilia-hypothesis (Accessed January 2021).

Schrader, B. (2005). We call it home: A history of state housing in New Zealand. Auckland, NZ: Reed Publishing Ltd (Accessed March 2020).

Schumacher, P. (2009). Parametricism: A New Global Style for Architecture and Urban Design. Archit Design, 79. 14-23. DOI: https://doi.org/10.1002/ ad.912 (Accessed February 2021).

Schumacher, P. (2011). The autopoiesis of architecture, volume i: A new framework for architecture. ProQuest Ebook Central. Retrieved from https://ebookcentral-proquest-com.helicon. vuw.ac.nz (Accessed February 2021). 
Shorter, C., Crane, J., Wickens, K., Pierse, N., Stanley, T., Barnes, P., ... \& Howden-Chapman, P. (2014). PD47: Visible mould and dampness are associated with new onset wheezing in New Zealand children. Clin Transl Allergy 4(Suppl 1):P47. DOI https://doi. org/10.1186/2045-7022-4-S1-P47 (Accessed May 2020).

Shorter, C., Crane, J., Pierse, N., Barnes, P., Kang, J., Wickens, K., ... \& Howden-Chapman, P. (2017). Indoor visible mold and mold odor are associated with new-onset childhood wheeze in a dosedependent manner. Indoor Air. 2018(28). 6-15. DOI https://doi.org/10.1111/ina.12413 (Accessed May 2020).

Sustainable Engineering Ltd. (2019, November). Sustainable Engineering Case Study Series: "Better than new": refurbs an opportunity to lift standards. Sustainable Engineering Ltd. Retrieved from https:// sustainableengineering.co.nz/casestudy/betterthan-new-refurbs-an-opportunity-to-lift-standards/ (Accessed June 2020).

UCLA Energy Design Tools Group. (2019). Climate Consultant 6.0. Retrieved from http://www.energydesign-tools.aud.ucla.edu/climate-consultant/ request-climate-consultant.php (Accessed August 2020).

Ulrich, R. (2006). Evidence-based health-care architecture. Lancet. 368. S38-S39. doi:10.1016/ S0140-6736(06)69921-2 Retrieved from https:// www.thelancet.com/pdfs/journals/lancet/PIIS01406736(06)69921-2.pdf (Accessed January 2021).

United Nations. (2015, September). Transforming our world: the 2030 Agenda for Sustainable Development. United Nations: Department of Economic and Social Affairs, Sustainable Development. Retrieved from https://sdgs.un.org/2030agenda (Accessed July 2020).

White, V. (2017, August). Are we warm, dry and healthy? Build 161: Fire Safety. 87-89. Retrieved from https://www.buildmagazine.org.nz/index.php/ issues/show/fire-safety-3 (Accessed May 2020).

White, V. (2019, October). Energy poverty in New Zealand. Build 174: Climate Change. 55-56. Retrieved from http://www.buildmagazine.org.nz/issues/ show/climate-change-2 (Accessed May 2020).

World Green Building Council. (2017). Green Building \& the Sustainable Development Goals. World Green Building Council. Retrieved from https:// www.worldgbc.org/green-building-sustainabledevelopment-goals (Accessed July 2020).

World Health Organisation. (2018). WHO Housing and Health Guidelines. Geneva: World Health Organization. Retrieved from https://www.ncbi.nlm. nih.gov/books/NBK535294/ (Accessed November 2020). 


\section{Figure List}

External figure sources not Author's own

Fig o.1 Bastian, M. (2018). Roys Peak, New Zealand [Photograph]. Retrieved from https://unsplash. com/photos/ovFxNk2uxZQ

Fig 1.o Sanford, I. (2018). Te Arai, New Zealand: Textures of East Coast [Photograph]. Retrieved from https://unsplash.com/photos/ jUGgnKuj5k8

Fig 2.o Vysohlid, P. (2017). Port Waikato, Tuakau, Auckland, New Zealand: Cloudy sunset over the sand dunes [Photograph]. Retrieved from https://unsplash.com/photos/9fqwGqGLUxc

Fig 2.2 Gunaratnam, Y. (2020). Tāne Mahuta State Highway 12, Waipoua Kauri Forest, New Zealand [Photograph]. Retrieved from https://unsplash. com/photos/dFxHzcxQEwM/info

Fig 3.o Meena, N. (2015). Hidden Lake Lookout trailhead, United States [Photograph]. Retrieved from https://unsplash.com/photos/ RbbdzZBKRDY

Fig 4.o Myburgh, K. (2018). White's Beach, New Zealand [Photograph]. Retrieved from https:// unsplash.com/photos/zWWq8J6igOo

Fig 5.0 Jason, A. (2016). Mount Cook, New Zealand [Photograph]. Retrieved from https://unsplash. com/photos/a562ZEFKW8I

Fig 6.o Krum, A. (2020a). [Untitled photograph of orange rock pattern]. Retrieved from https:// unsplash.com/photos/WXPbzpe6Cpw

Fig 6.1 Sullivan, A. (2020). Antelope Canyon, Arizona, USA [Photograph]. Retrieved from https:// unsplash.com/photos/b732piJ3EEg

Fig 6.8 Krum, A. (2020b). [Untitled orange rock pattern]. Retrieved from https://unsplash.com/photos/ LHRzMsO1iz8
Fig 6.14 Basheer, A. (2019). Antelope Canyon, Arizona, USA [Photograph]. Retrieved from https:// unsplash.com/photos/Xrx3WWyrwes

Fig 7.0 Truettner, W. (2019). [Untitled photograph of beach]. Retrieved from https://unsplash.com/ photos/ZrY7I1eEbi8

Fig 8.0 Serhan, J. (2020). Vines growing on wall in diagonal pattern [Photograph]. Retrieved from https://unsplash.com/photos/kJu97Xq9dLY

Fig 9.o Harris, Z. (2019). [Untitled photograph of beach]. Retrieved from https://unsplash.com/ photos/x2-qYR7PoOg

Fig 10.0 Marshall, T. (2016). Muriwai Beach, Muriwai, New Zealand [Photograph]. Retrieved from https://unsplash.com/photos/RHeZJxXNr90

Fig 11.o Brock, T. (2019). [Untitled photograph of trees]. Retrieved from https://unsplash.com/photos/ UQiBY1yu8U0

Fig 12.o Clark, R. (2020). Waihi Falls Road, ManawatuWanganui, New Zealand [Photograph]. Retrieved from https://unsplash.com/ photos/8eoAqGyT1-4 